\title{
HADOC - A Computer Code for Calculation of External and Inhalation Doses From Acute Radionuclide Releases
}
D. L. Strenge
R. A. Peloquin

April 1981

Prepared for the U.S. Department of Energy under Contract DE-AC06-76RLO 1830

Pacific Northwest Laboratory Operated for the U.S. Department of Energy by Battelle Memorial Institute 


\title{
NOTICE
}

This report was prepared as an account of work sponsored by the United States Government. Neither the United States nor the Department of Energy, nor any of their employees, nor any of their contractors, subcontractors, or their employees, makes any warranty, express or implied, or assumes any legal liability or responsibility for the accuracy, completeness or usefulness of any information, apparatus, product or process disclosed, or represents that its use would not infringe privately owned rights.

The views, opinions and conclusions contained in this report are those of the contractor and do not necessarily represent those of the United States Government or the United States Department of Energy.

\author{
PACIFIC NORTHWEST LABORATORY \\ operated by \\ BATTELLE \\ for the \\ UNITED STATES DEPARTMENT OF ENERGY \\ Under Contract EY-76-C-06-1830
}

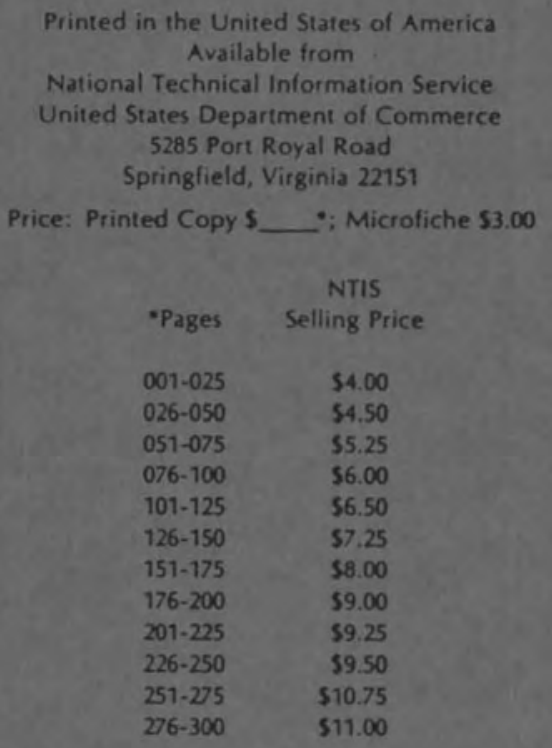


PNL -3503

UC-70

\section{9}

HADOC - A COMPUTER CODE FOR CALCULATION OF EXTERNAL AND INHALATION DOSES FROM ACUTE RADIONUCLIDE RELEASES

D. L. Strenge

R. A. Peloquin

Apri1 1991

Prepared for the U.S. Department of Energy under Contract DE-ACO6-76RLO 1830

Pac if ic Northwest Laboratory

Richland, Washington 99352 


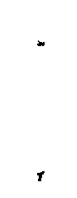




\section{$\underline{\text { ABSTRACT }}$}

The computer code HADOC (Hanford Acute Dose Calculations) is described and instructions for its use are presented. The code calculates external dose from air submersion and inhalation doses following acute radionuclide releases. Atmospheric dispersion is calculated using the Hanford model with options to determine maximum conditions. Building wake effects and terrain variation may also be considered. Doses are calculated using dose conversion factor supplied in a data library. Doses are reported for one and fifty year dose commitment periods for the maximum individual and the regional population (within 50 miles). The fractional contribution to dose by radionuclide and exposure mode are also printed if requested. 



\section{ACKNOWLEDGMENTS}

This work was performed for the Department of Energy, Waste Management Division, Richland Operations Office. The computer program HADOC was prepared to aid in performing environmental dose estimates in support of environmental impact statements for Department of Energy activities on the Hanford Reservation.

The authors would like to express appreciation for manuscript preparation by Ruth Laidler, Pattie Freed and Cindy Wise. 


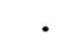

. 


\section{CONTENTS}

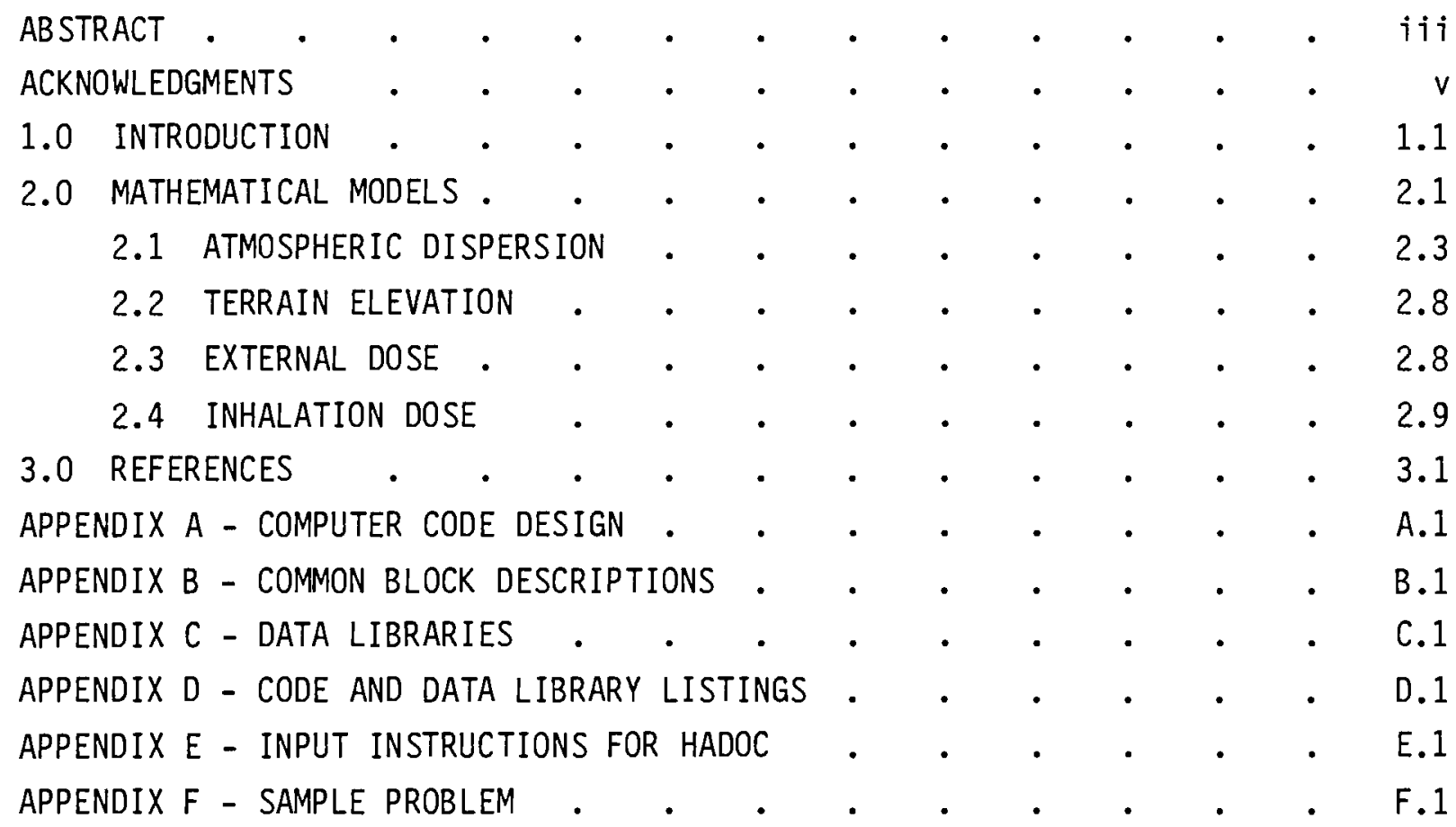


FIGURES

2.0-1 Population Dose Grid System Definition . . . . . . 2.2

A.1-1 Hierarchy Diagram of the MAIN Program . . . . . A.2

A.1-2 Hierarchy Diagram for Subroutine DISPRS (called by MAIN) - A.5

A.1-3 Hierarchy Diagram for Subroutine ACHAIN (called by TRNSIT) . A.6

A.3-1 Chapin Chart Logic Constructs . . . . . . . A.41

A.3-2 Logic Diagram for Module MAIN . . . . . . . . . A.42

A.3-3 Logic Diagram for Module ACHAIN . . . . . . . . A.43

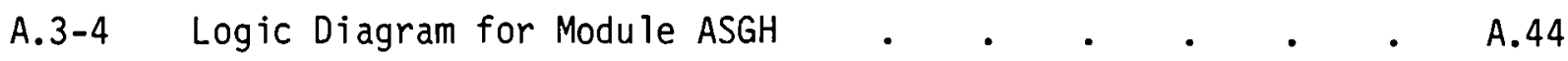

A.3-5 Logic Diagram for Module ASUM . . . . . . . . . . . . A.45

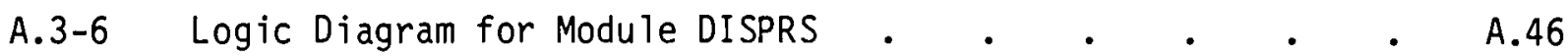

A.3-7 Logic Diagram for Module DSORPT . . . . . . . . . A.47

A.3-8 Logic Diagram for Module EXMO . . . . . . . . . A.48

A.3-9 Logic Diagram for Module FRDOSE . . . . . . . . A.49

A.3-10 Logic Diagram for Module FRDRPT . . . . . . . . A.50

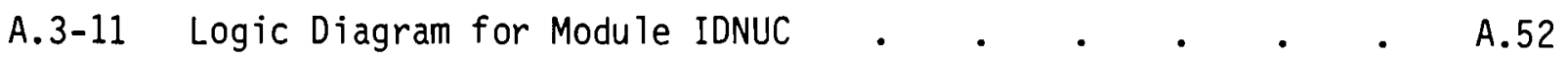

A.3-12 Logic Diagram for Module LIBRPT . . . . • . . . A.53

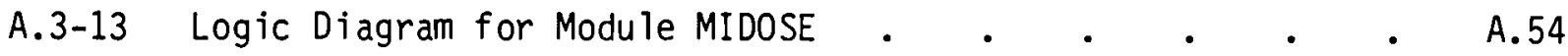

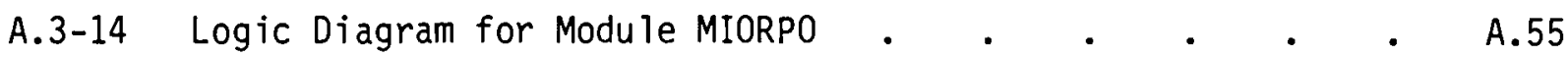

A.3-15 Logic Diagram for Module MMAXEQ . • . • • • • . A.56

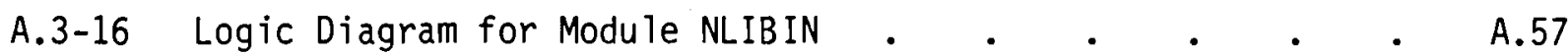

A.3-17 Logic Diagram for Module ORGCHK . . . . . . . . . A.58

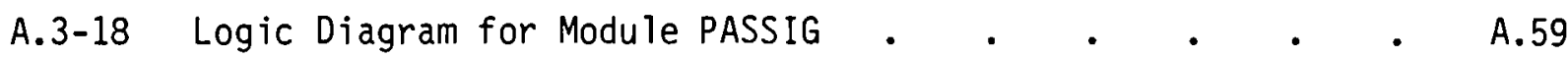

A.3-19 Logic Diagram for Module PMAXEQ . . . . . . . . A.60

A.3-20 Logic Diagram for Module POPDOS . . . . . . . . . A.61

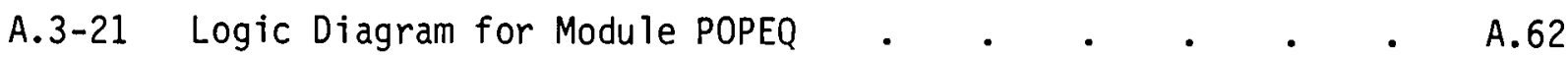

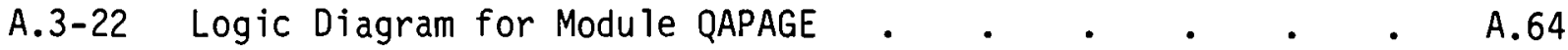

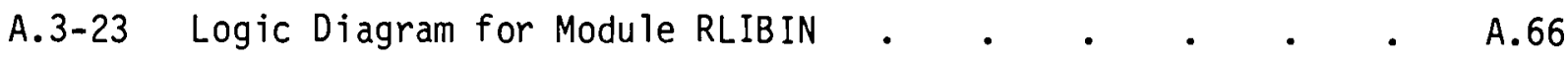

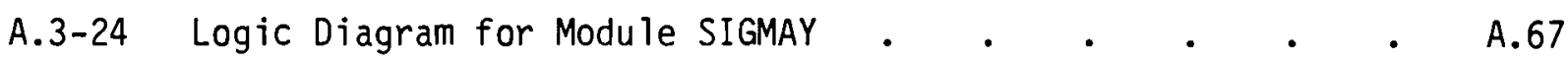

A.3-25 Logic Diagram for Module SIGMAZ . • • • • • . . A.68

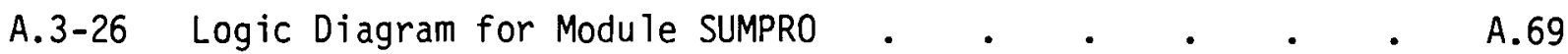

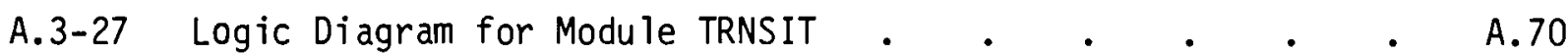

A.3-28 Logic Diagram for Module ZEROI . . . . . . . . . . A.71 


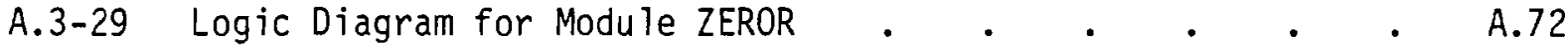

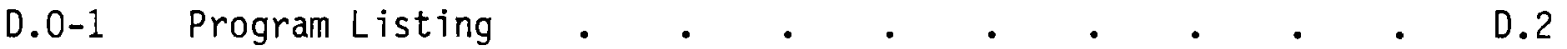
D.0-2 Radionuclide Master Data Library-RMDLIB . . . . . 0.47
D.0-3 Dose Conversion Factor Data Library-NUCDFL . • • • • D.51

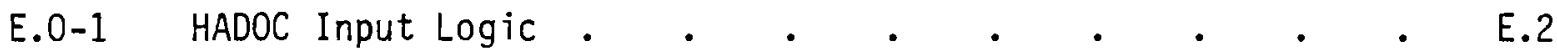
F.0-1 HADOC Sample Problem Input . . . . . . . . F.3

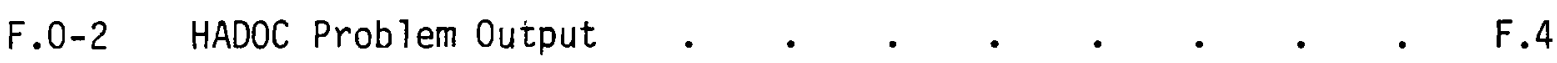




\section{TABLES}

2.1-1 Values of Meteorological Parameters for the Hanford Model . 2.6

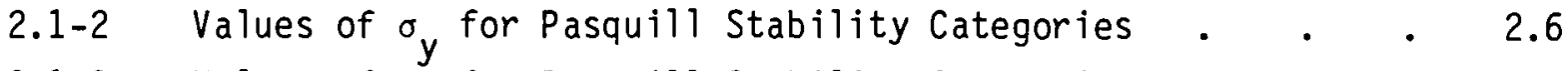

2.1-3 Values of $\sigma_{2}$ for Pasquill Stability Categories $\quad . \quad$ • $\quad$ • 2.7

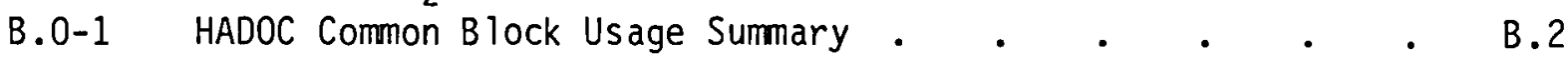

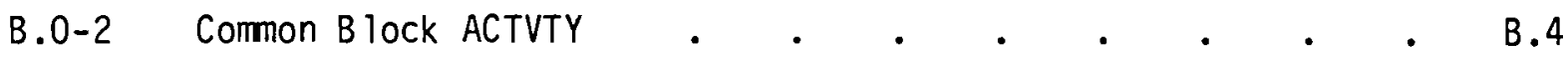

B.0-3 Common B lock AIRCON

B.0-4 Common Block DAY .

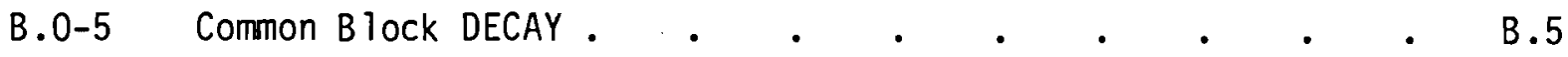

B.0-6 Common B lock DISPSN

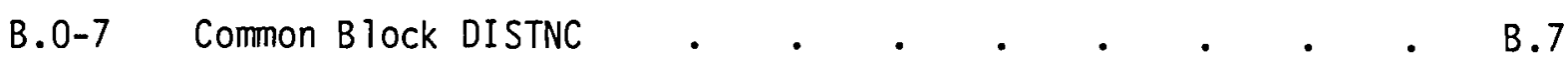

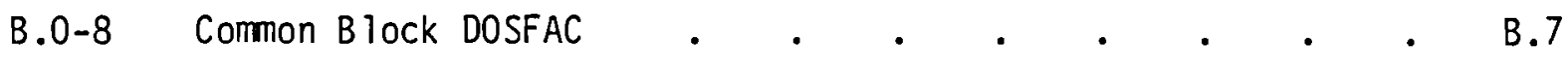

B. 0-9 Common B lock DOSMI .

B. 0-10 Common B lock DOSPOP $\quad$.

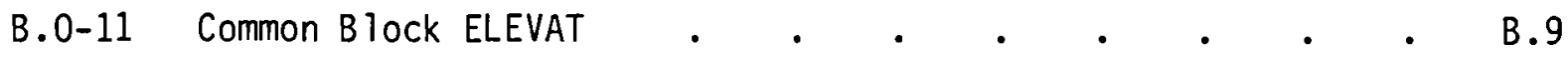

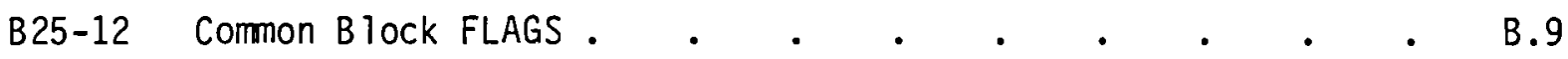

B. 0-13 Common B lock NAMES . . . . . . . . . . . . B. 10

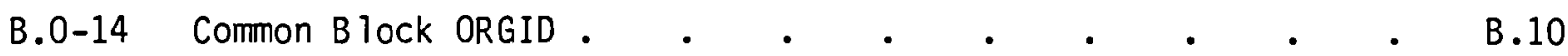

B. 0-15 Common B lock POPU . . . . . . . . . . . . . . B.11

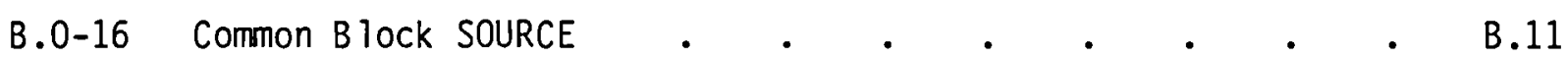

C.2-1 Organs Available in NUCDFL . . . . . . . . . . . C.3.

E.6-1 NAMELIST Parameter Default Values . . . . . . . E.6.

F.0-1 Sample Problem Case 1 Input Parameters . . . . . . F.2

F.0-2 Sample Problem Radionuclide Inventory . . . . . . F.2 


\section{HADOC - A COMPUTER CODE FOR CALCULATION OF EXTERNAL AND INHALATION DOSES FROM ACUTE RADIONUCLIDE RELEASES}

\subsection{INTRODUCTION}

The computer code HADOC (Hanford Acute Dose Calculations) was prepared for calculation of external and inhalation doses resulting from postulated accidental radionuclide releases on the Hanford site. The code generates doses to an individual at a specified location (referred to as the maximum individual) and to the population in the region near the Hanford site.

Atmospheric dispersion is calculated using the Hanford dispersion model (Fuquay et al. 1964) with building wake effects and terrain elevation considered as options. For elevated releases, the code will also determine (as an option) the worst case dispersion conditions by considering Pasquill dispersion categories A-F. The maximally exposed individual dispersion factor is calculated using the bivariate Gaussian dispersion equation (defined in Section 2.0). The population dispersion factors are based on a cross-wind sector averaged dispersion equation. The population dose is calcuated for the sector having the highest population exposure factor as determined by the dispersion factors and the specified population distribution.

The decay of the released radionuclide activities is considered during transit from the release point to the location of the maximally exposed individual, MI, and to the center of each population ring. Decay times are based on user supplied average wind speeds. A chain decay processor with multiple branching is used to calculate decayed activities.

The doses from external and inhalation exposure are calculated at each location for specified organs. Doses reported include the MI dose (by organ and exposure mode) and the total population dose (by organ and exposure mode) in the sector having the highest population exposure factor. The first year and fifty-year dose commitments are reported.

Optional reports may be printed giving the fractional contribution to total dose by radionuclide for each organ and dose commitment period for the MI and the population. 


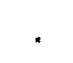

. 


\subsection{MATHEMATICAL MODELS}

The mathematical models employed by HADOC in estimation of potential radiation doses to individuals and the population are described in this section. The models were selected to be consistent with the current methodology used for accident consequence analysis for releases on the Hanford Site. This code implements models for dose calculations that are currently performed using hand calculations and other codes not designed for this type of calculation.

The doses to the maximally exposed individual are calculated at the location of nearest public access to the release site as specified by the user. The population doses are calculated for the maximum exposed sector as determined by the maximum value generated for the population-exposure factor. The population dose calculations are performed for the spatial grid system shown in Figure 2.0-1. The population-exposure factor is calculated for each sector by:

$$
P M_{j}=\sum_{i=1}^{d_{j}}(E / Q)_{i j} P_{i j}
$$

where

$$
\begin{aligned}
& P M_{j} \text { - population-exposure factor for sector } j \text {, person-sec } / m^{3} \text {, } \\
& (E / Q)_{i j} \text { - time-integrated air concentration, at center of spatial interval } \\
& P_{i j} \text { - number of people living in the spatial interval in direction } j \\
& \text { and at distance } i \text {, persons. }
\end{aligned}
$$

Values are generated for $\mathrm{PM}_{\mathrm{j}}$ for each sector and the maximum sector value is used for the population dose calculations.

Models are described in the following sections for atmospheric dispersion, terrain elevation, external exposure from submersion in the plume and inhalation exposure from inhalation during plume passage. 


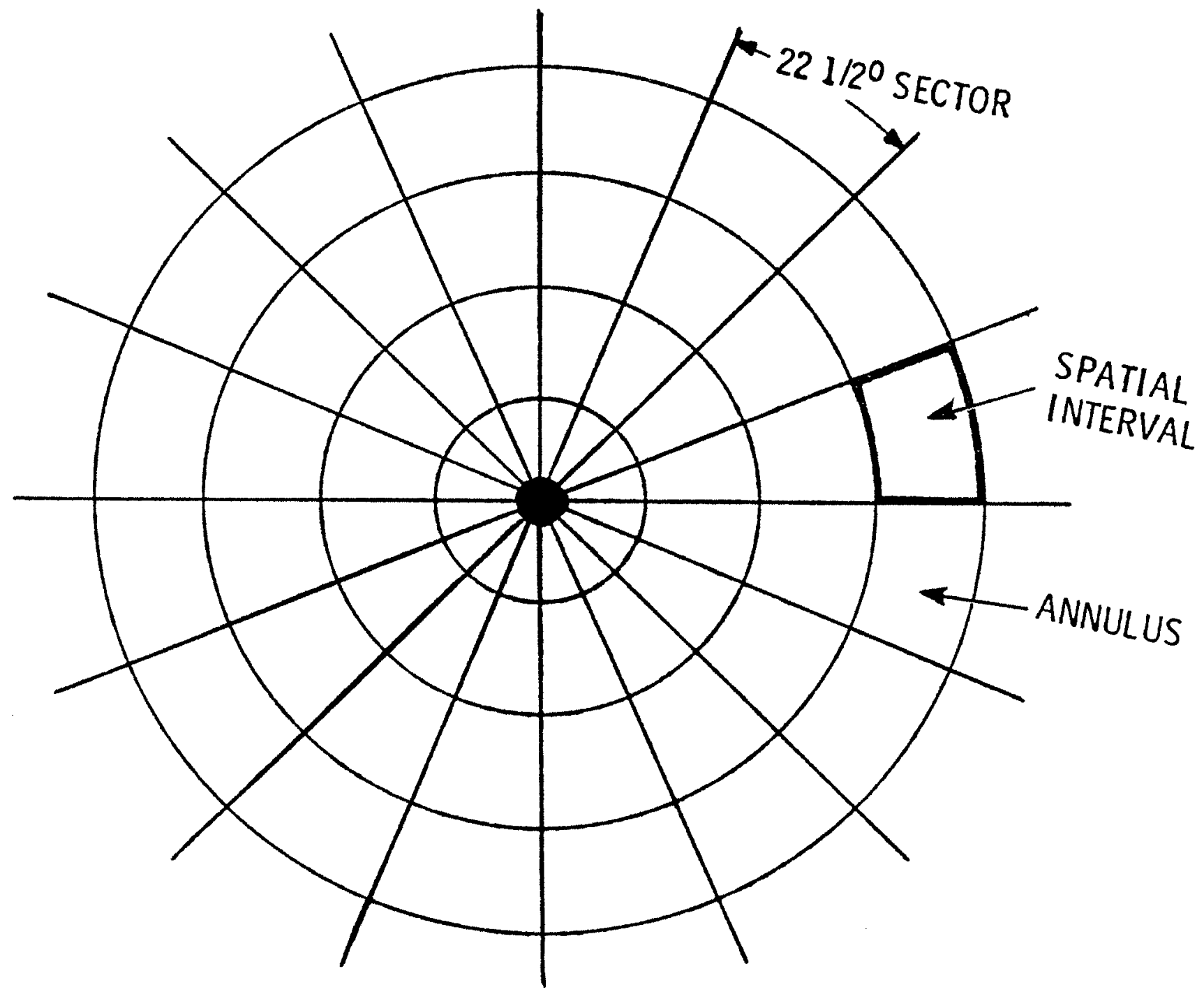

(FACILITY AT CENTER OF GRID)
EIGURE 2.0-1 POPulation Dose Grid System Definition 


\subsection{ATMOSPHERIC DISPERSION}

The dispersion of released activity is estimated at the location of the MI and at the midpoint of each population distance interval. The atmospheric dispersion of activity is expressed as the time-integral of air concentration at each location of interest. For the MI's location, the atmospheric dispersion calculation is based on the following assumptions:

- the individual is located at the closest point of public access,

- the wind blows toward the individual at a continuous speed of one $\mathrm{m} / \mathrm{sec}$,

- the air concentration is described by a bivariate Gaussion plume model,

- atmospheric stability conditions are stable (Hanford model or Pasquill

$E-F$ ) or unstable (Pasquill A-D) whichever is limiting,

- plume rise is not considered,

- building wake effects are considered for ground level releases, and

- terrain variation is considered.

With these assumptions the time-integrated normalized air concentration at the location of the MI is given by:

$$
(E / Q)_{m}=\frac{\exp \left[-n_{e}^{2} /\left(2 \Sigma_{z}\right)\right]}{\pi u \Sigma_{y} \Sigma_{z}}
$$

where:

$(E / Q)_{m}$ - time-integrated air concentration at the location of the maximally exposed individual, $\mathrm{sec} / \mathrm{m}^{3}$,

$h_{e}$ - effective release height at the location of interest, $m$,

$\mathrm{u}$ - average wind speed at the release elevation, $\mathrm{m} / \mathrm{sec}$,

$\Sigma_{y}$ - effective crosswind horizontal standard deviation of plume concentration at the location of interest, $m$, and

$\Sigma_{z}$ - effective crosswind vertical standard deviation of plume concentration at the location of interest, $m$.

The dispersion parameters $\left(\Sigma_{y}\right.$ and $\left.\Sigma_{z}\right)$ include building wake effects and are defined as: 


$$
\begin{aligned}
& \Sigma_{y}=\left(\sigma_{y}^{2}+A / 2\right)^{1 / 2} \\
& \Sigma_{z}=\left(\sigma_{y}^{2}+A / 2\right)^{1 / 2}
\end{aligned}
$$

where

$$
\begin{aligned}
& A \text { - minimum cross sectional area of the facility, } \mathrm{m}^{2}, \\
& \sigma_{y} \text { - crosswind horizontal standard deviation of plume concentration at } \\
& \text { the location of interest, } m \text {, and } \\
& \sigma_{z} \text { - crosswind vertical standard deviation of plume concentration at } \\
& \text { the location of interest, } m \text {. }
\end{aligned}
$$

This model for the effective dispersion parameters includes enhanced dispersion in the wake of the building through the cross sectional area parameter $A$ (Slade 1968). For stack releases significantly above the height of the building, wake effects would not be important and $A$ would be set to zero. The Nuclear Regulatory Commission (USNRC 1979) suggests that building wake effects be considered only when the release point is lower than two and one-half times the height of adjacent solid structures. Building wake effects are limited by the relation:

$$
\Sigma_{y} \Sigma_{z} \leq 3 \sigma_{y} \sigma_{z}
$$

When $\Sigma_{y} \Sigma_{z}>3 \sigma_{y} \sigma_{z}$ the value used for $\Sigma_{z}$ in the exponential of Equation 2.1-1 is calculated as:

$$
\Sigma_{z}=\sigma_{z} \sqrt{3}
$$

The effective release height is given by:

$$
h_{e}=h_{s}-h_{t} \geq 0
$$

where

$h_{S}$ stack height, $m$, and

$\mathrm{h}_{\mathrm{t}}$ - maximum terrain elevation above the base of the stack between the stack and the location of interest, m. (See Section 2.2). 
The dispersion parameters $\left(\sigma_{y}, \sigma_{z}\right)$ are calculated using the Hanford dispersion model for moderately stable conditions when ground-level releases are considered. For elevated releases, however, unstable conditions (Pasquill A-D) may result in higher values for $(E / Q)_{m}$ at locations near the release point. Values for $(E / Q)_{m}$ are calculated for each stability (Pasquill A-F and Hanford) and the maximum value is used in the dose calculations.

The crosswind standard deviations, $\sigma_{y}$ and $\sigma$, for stable atmospheric conditions are calculated by the Hanford model as follows:

$$
\begin{aligned}
& \sigma_{y}^{2}=A\left[T-\alpha\left(1-e^{-T / \alpha}\right)\right] \\
& \sigma_{z}^{2}=a\left(1-e^{-K^{2} T^{2}}\right)+b T
\end{aligned}
$$

where:

T transport time from point of release to point of interest, sec

and: $\quad A=c+d\left(\sigma_{\theta} u\right)$

$$
\alpha=A / 2\left(\sigma_{\theta} u\right)^{2}
$$

$a, b, c, d, k$ and $\left(\sigma_{\theta} u\right)$ are parameters describing the atmospheric condition. Table 2.1-1 summarizes suggested parameter values to be used with Hanford moderately stable and Hanford very stable conditions.

Graphical representations of $\sigma_{y}$ and $\sigma_{z}$ for the six pasquill stability categories (Slade, 1968) have been tabluated and incorporated in a subroutine for the computer code SUBDOSA (Strenge et al. 1975). This subroutine has been modified for use by $H A D O C$ in estimating dispersion parameters for the six pasquill stability categories $(A-F)$. Tabulated values for $\sigma_{y}$ and $\sigma_{z}$ are presented in Tables 2.1-2 and 2.1-3 respectively.

Atmospheric dispersion for the population dose calculations is calculated with the following assumptions: 
TABLE 2.1-1 Values of Meteorological Parameters for the Hanford Model

\begin{tabular}{lll} 
Parameter & $\begin{array}{l}\text { Moderately Stable } \\
\text { Conditions }\end{array}$ & $\begin{array}{l}\text { Very Stable } \\
\text { Conditions }\end{array}$ \\
\cline { 2 - 2 } $\mathrm{a}, \mathrm{m}^{2}$ & 97 & 34 \\
$\mathrm{~b}, \mathrm{~m}^{2} / \mathrm{sec}$ & 0.33 & 0.025 \\
$\mathrm{c}, \mathrm{m}^{2} / \mathrm{sec}$ & 13 & 13 \\
$\mathrm{~d}, \mathrm{~m}$ & 230 & 230 \\
$\mathrm{k}^{2}, \mathrm{sec}-2$ & $2.5 \times 10^{-4}$ & $8.8 \times 10^{-4}$ \\
\multicolumn{3}{l}{ MINIMUM VALUES OF $\left(\sigma_{\theta} \bar{u}\right), \mathrm{radian} \cdot \mathrm{m} / \mathrm{sec}$}
\end{tabular}

Assumed Duration of Release, Min.

\begin{tabular}{|c|c|c|c|c|}
\hline ease, Min. & 1 & $2.5)$ & 5 & 10 \\
\hline $\begin{array}{r}10 \\
60 \\
120 \\
240 \\
480\end{array}$ & $\begin{array}{l}0.024 \\
0.04 \\
0.08 \\
0.10 \\
0.18\end{array}$ & $\begin{array}{l}0.10 \\
0.15 \\
0.25 \\
0.40 \\
0.60\end{array}$ & $\begin{array}{l}0.20 \\
0.25 \\
0.35 \\
0.50 \\
0.70\end{array}$ & $\begin{array}{l}0.30 \\
0.35 \\
0.45 \\
0.60 \\
0.90\end{array}$ \\
\hline
\end{tabular}

TABLE 2.1-2 Values of $\sigma_{y}$ for Pasquill Stability Categories

Distance

Meters

100

150

250

350

500

700

1,000

1,500

2,500

3,500

5,000

7,000

10,000

15,000

25,000

35,000

50,000

70,000

100,000 $\sigma_{y}(m)$ for Pasquill Type

\begin{tabular}{|c|c|c|c|c|c|}
\hline A & B & $C$ & $D$ & $E$ & $F$ \\
\hline 21 & 16 & 12 & 8.0 & 6.0 & 3.9 \\
\hline 34 & 24 & 18 & 12 & 9.0 & 6.0 \\
\hline 54 & 40 & 28 & 20 & 14 & 9.8 \\
\hline 75 & 55 & 40 & 26 & 20 & 14 \\
\hline 100 & 76 & 55 & 37 & 28 & 18 \\
\hline 140 & 110 & 76 & 51 & 37 & 26 \\
\hline 200 & 150 & 110 & 72 & 52 & 36 \\
\hline 290 & 220 & 160 & 100 & 75 & 52 \\
\hline 450 & 340 & 240 & 160 & 120 & 81 \\
\hline 610 & 460 & 330 & 220 & 160 & 110 \\
\hline 830 & 630 & 450 & 310 & 220 & 150 \\
\hline 1,100 & 840 & 610 & 420 & 300 & 210 \\
\hline 1,600 & 1,200 & 850 & 570 & 410 & 280 \\
\hline 2,200 & 1,700 & 1,200 & 810 & 570 & 400 \\
\hline 3,400 & 2,600 & 1,800 & 1,200 & 880 & 610 \\
\hline 4,500 & 3,500 & 2,500 & 1,700 & 1,200 & 820 \\
\hline 6,200 & 4,700 & 3,400 & 2,300 & 1,600 & 1,100 \\
\hline 8,200 & 6,400 & 4,700 & 3,000 & 2,100 & 1,500 \\
\hline 11,000 & 8,500 & 6,300 & 4,100 & 2,800 & 2,000 \\
\hline
\end{tabular}


TABLE 2.1-3 Values of $\sigma_{z}$ for Pasquill Stability Categories

Distance $\sigma_{z}(m)$ for Pasquill Type

\begin{tabular}{|c|c|c|c|c|c|c|}
\hline Meters & A & B & C & D & $E$ & $F$ \\
\hline 100 & 15 & 10 & 7.8 & 4.7 & 3.0 & 1.4 \\
\hline 150 & 22 & 15 & 11 & 6.8 & 4.3 & 2.2 \\
\hline 250 & 43 & 26 & 18 & 10 & 7.1 & 4.0 \\
\hline 350 & 70 & 37 & 24 & 14 & 9.4 & 5.3 \\
\hline 500 & 140 & 57 & 34 & 19 & 13 & 7.6 \\
\hline 700 & 270 & 86 & 46 & 25 & 17 & 10 \\
\hline 1,000 & 670 & 140 & 64 & 33 & 22 & 14 \\
\hline 1,500 & 2,000 & 240 & 90 & 43 & 29 & 18 \\
\hline 2,500 & 2,000 & 580 & 140 & 62 & 41 & 25 \\
\hline 3,500 & 2,000 & 1,200 & 190 & 76 & 50 & 30 \\
\hline 5,000 & 2,000 & 2,000 & 260 & 95 & 61 & 35 \\
\hline 7,000 & 2,000 & 2,000 & 340 & 120 & 72 & 41 \\
\hline 10,000 & 2,000 & 2,000 & 440 & 140 & 84 & 47 \\
\hline 15,000 & 2,000 & 2,000 & 600 & 170 & 99 & 55 \\
\hline 25,000 & 2,000 & 2,000 & 880 & 220 & 120 & 64 \\
\hline 35,000 & 2,000 & 2,000 & 1,100 & 260 & 130 & 72 \\
\hline 50,000 & 2,000 & 2,000 & 1,400 & 320 & 140 & 79 \\
\hline 70,000 & 2,000 & 2,000 & 1,800 & 370 & 160 & 86 \\
\hline & & 2,000 & 2,000 & 450 & 170 & 94 \\
\hline
\end{tabular}

- the plume spreads uniformly over a $22.5^{\circ}$ sector,

- the wind blows in one direction continuously at one $\mathrm{m} / \mathrm{sec}$,

- the population is uniform within each sector and distance ring,

- the atmospheric conditions are stable,

- terrain variation is considered,

- plume rise is not considered,

- building wake effects are considered, and

- the release is transported through the sector with the highest value of $P M_{j}$ as defined by Equation 2.0-1.

The time-integrated air concentration at the center of each spatial interval is calculated as:

$$
(E / Q)_{i j}=\left(\frac{2}{\pi}\right)^{1 / 2} \frac{\exp \left[-h_{e}^{2} /\left(2 \Sigma_{z}^{2}\right)\right]}{\Sigma z \bar{u} W_{i}}
$$


where

$(E / Q)_{i j}$ - time-integrated air concentration for the spatial interval at distance $i$ in sector $j, \sec / \mathrm{m}^{3}$,

$W_{i}$ - sector width at distance $i, m$,

$w_{i} \cdot \pi x_{j} / 8$,

$x_{j}$ - distance from release point to center of spatial interval $i, m$. Other terms are as previously defined.

When building wake effects are to be considered, plumeexpansion in the wake is limited by:

$$
\Sigma_{z} \leq \sigma_{z} \sqrt{3}
$$

\subsection{TERRAIN ELEVATION}

The effects of terrain elevation variation are considered by defining an effective elevation $h_{t}$ at the location of the maximum individual and at the midpoint of each spatial interval. The effective terrain elevation is used to determine the effective plume height in Equation 2.1-6. The recommended method for defining values of $h_{t}$ is the horizontal plume model for terrain correction as described in Regulatory Guide 1.111 (USNRC, 1977). Using this method the value of $h_{t}$ is defined as the maximum terrain height between the release point and the exposure point. The values of $h_{t}$ are specified for each spatial interval.

\subsection{EXTERNAL DOSE}

Persons exposed to the plume will receive a radiation dose from gamma emitting radionuclides during plume passage. This external gamma dose is calculated assuming the plume to be semi-infinite in size (bounded by the ground) and of uniform concentration equal to the ground-level centerline air concentration. The dose to the maximally exposed individual is then given by:

$$
D_{m e}=\sum_{k=1}^{K} Q_{k}(E / Q)_{m} D_{k}^{e}
$$


where

$D_{\text {me }}$ - external total body dose to an individual from submersion in the plume, rem,

$Q_{k}$ - activity of radionuclide k passing the location of interest, curies, $D_{k}^{e}$ - external dose conversion factor for radionuclide $k$, rem per ( $i$

$K$ - total number of radionuclides considered.

The external dose conversion factors supplied in the data library NUCDFL (see Appendix C) are calculated for penetration to a tissue depth of $5 \mathrm{~cm}$.

The dose to the population from external exposure is given by:

$$
D_{p e}=\sum_{j=1}^{d_{j}} \sum_{i=1}^{K} Q_{k}(E / Q)_{i j} D_{k}^{e} P_{i j}
$$

where

$D_{p e}$ - population total body dose (in maximum sector $j$ ) from submersion in the plume, person-rem

and other terms are as previously defined.

The activity, $Q_{k}$, includes correction for radioactive decay in transit to the location of interest. Chain decay is considered with branching to and from isomeric states.

\subsection{INHALATION DOSE}

Persons in the passing plume will receive radiation dose via inhalation to the lungs and other internal organs. The dose to the maximally exposed individual is calculated as:

$$
D_{m o}=\sum_{k=1}^{K} Q_{k}(E / Q)_{m} D_{k o}^{i}
$$


where

$D_{\text {mo }}$ - inhalation dose to organ o of the maximally exposed individual at the location of interest, rem,

$D_{k 0}^{i}$ - inhalation dose conversion factor for radionuclide $k$ and organ o, rem per $\left(\mathrm{Ci} \mathrm{sec} / \mathrm{m}^{3}\right)$,

and other terms are as previously defined.

The population dose is calculated as:

$$
D_{p o}=\sum_{i=1}^{d_{j}} \sum_{k=1}^{k} Q_{k}(E / Q)_{i j} D_{k o}^{i} P_{i j}
$$

where

$$
\begin{aligned}
& D_{\text {po }} \text { - inhalation population dose (in maximum sector } j \text { ) to organ } 0 \text {, } \\
& \text { person rem, } \\
& D_{k o}^{i} \text { - inhalation dose conversion factor for radionuclide and organ } \\
& \quad \text {, rem per }\left(\mathrm{Ci} \mathrm{sec} / \mathrm{m}^{3}\right) \text {. }
\end{aligned}
$$

and other terms are as previously defined.

The inhalation dose conversion factors supplied in the data library NUCDFL (see Appendix C) were calculated using the computer program DACRIN (Houston, Strenge and Watson 1976; Strenge 1975). The program DACRIN employs the respiratory tract model adopted by the ICRP Task Group on Lung Dynamics (ICRP 1966; ICRP 1972). Dose factors are provided for acute inhalation followed by dose commitment periods of 1 year and 50 years. The computer program HADOC presents reports for both of these dose commitment periods. 


\subsection{REFERENCES}

Fuquay, JJ., CL Simpson and WT Hinds. 1964. Estimates of Ground Level Air Exposures Resulting from Protracted Emissions from 70-Meter Stacks at Hanford. HW80204. General Electric Company, Richland, WA.

Houston, JR, DL Strenge and EC Watson. 1976. DACRIN - A Computer Program for Calculating Organ Dose from Acute or Chronic Radionuclide Inhalation, BNWL-B-389, Pacific Northwest Laboratories, Richland, WA.

International Commission on Radiological Protection (ICRP). 1972. Recommendations of the International Commission on Radiological Protection. ICRP Publications 19, Pergamon Press, New York, NY.

International Commission on Radiological Protection (ICRP). 1966. Deposition and retention models for internal dosimetry of the human respiratory tract. Health Phys. 12:173-207.

Slade, DH. 1968. Meteorology and Atomic Energy, U.S. Atomic Energy Commission, Washington, DC.

Strenge, DL, EC Watson and JR Houston. 1975. SUBDOSA-A Computer Program for Calculating External Doses from Accidental Atmospheric Releases of Radionuclides, BNWL-B-351, Pacific Northwest Laboratories, Richland, WA 99352.

Strenge, DL. 1975. DACRIN - A Computer Program for Calculating Organ Dose from Acute or Chronic Radionuclide Inhalation: Modification for Gastrointestinal Tract Dose. BNWL-B-389 Supp. Pacif ic Northwest Laboratories, Richland, WA.

USNRC. 1977. Methods for Estimating Atmospheric Transport and Dispersion of Gaseous Effluents in Routine Releases from Light-Water-Cooled Reactors. Regulatory Guide 1.111, Rev. 1, U.S. Nuclear Regulatory Commission, Washington, DC. 20555.

USNRC. 1979. Atmospheric Dispersion Models for Potential Accident Consequence Assessments at Nuclear Power Plants. Regulatory Guide 1.145, U.S. Nuclear Regulatory Commission, Washington, D.C. 20555. 


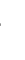


APPENDIX A

COMPUTER CODE DESIGN 


\section{COMPUTER CODE DESIGN}

This appendix provides information on the computer code design useful to programmers desiring to make modifications to the program. The average user of the code will not need the information provided here. The following sections provide:

- code hierarchy diagrams

- module summary information

- module logic diagrams.

The computer program was developed for execution on the UNIVAC 1100/44 system operated by Boeing Computer Services for the Department of Energy at Richland, washington. The programming language is ASCII FORTRAN as implemented by the UNIVAC FTN compiler. A listing of the FORTRAN source code is given in Appendix $D$.

\section{A.1 CODE HIERARCHY}

The computer code HADOC is composed of 29 modules including the main program. The calling sequence for the program is indicated in the hierarchy diagrams of Figures A.1-1 through A.1-3. These diagrams only indicate module calling sequences; module logic diagrams are given in Section A.3. A brief description of the function of each model is also indicated on the hierarchy diagrams. 


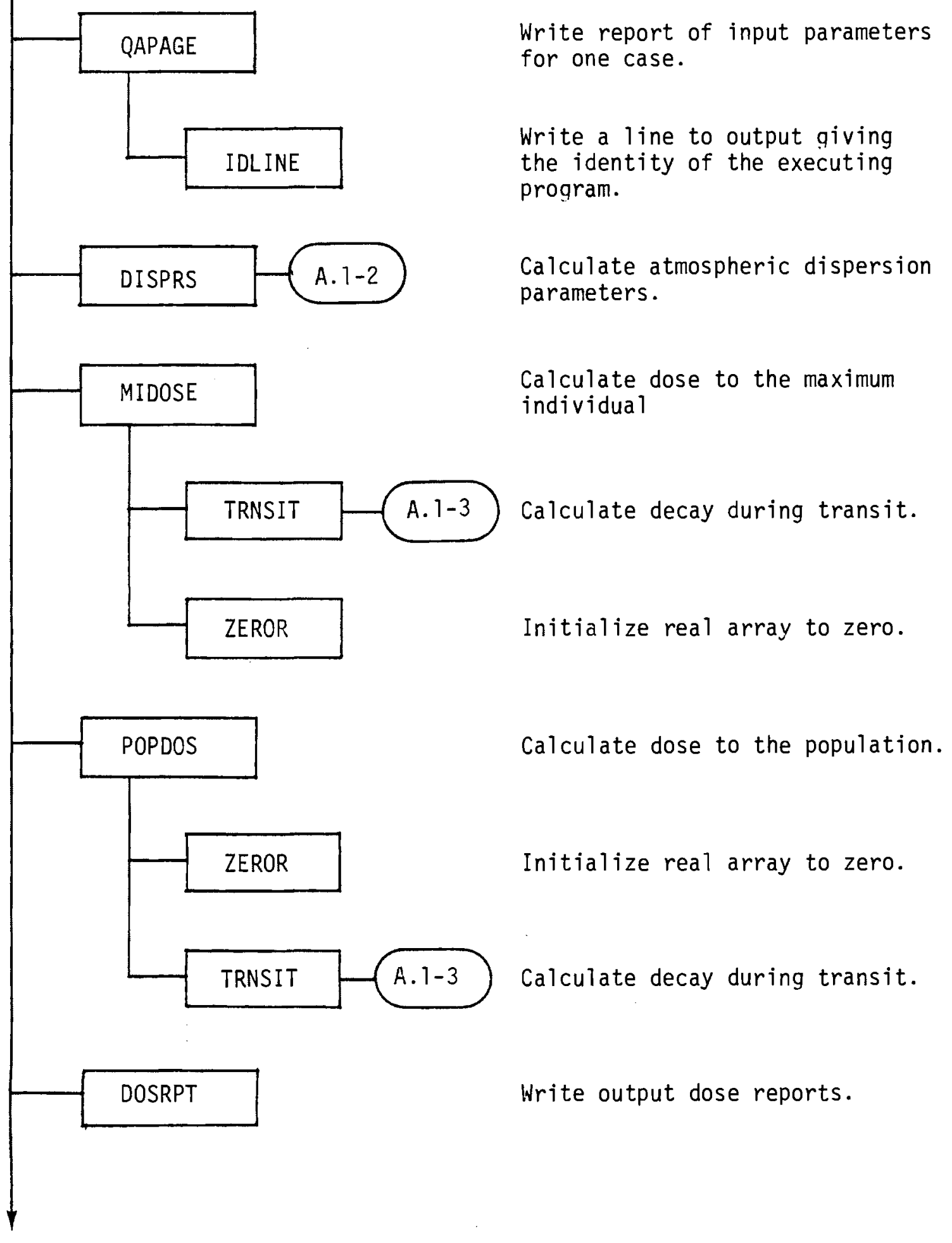

FIGURE A.1-1. (Cont'd) 


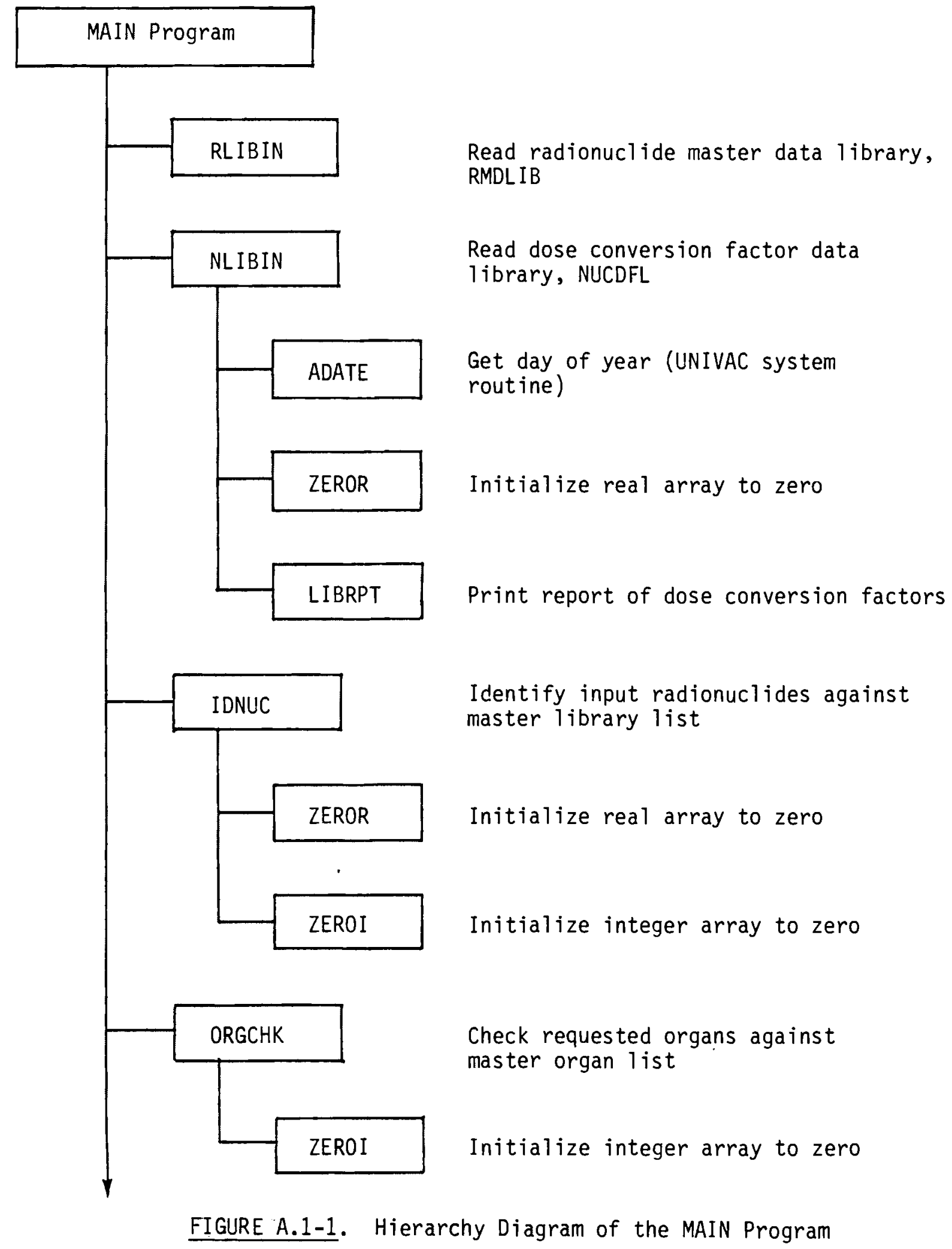




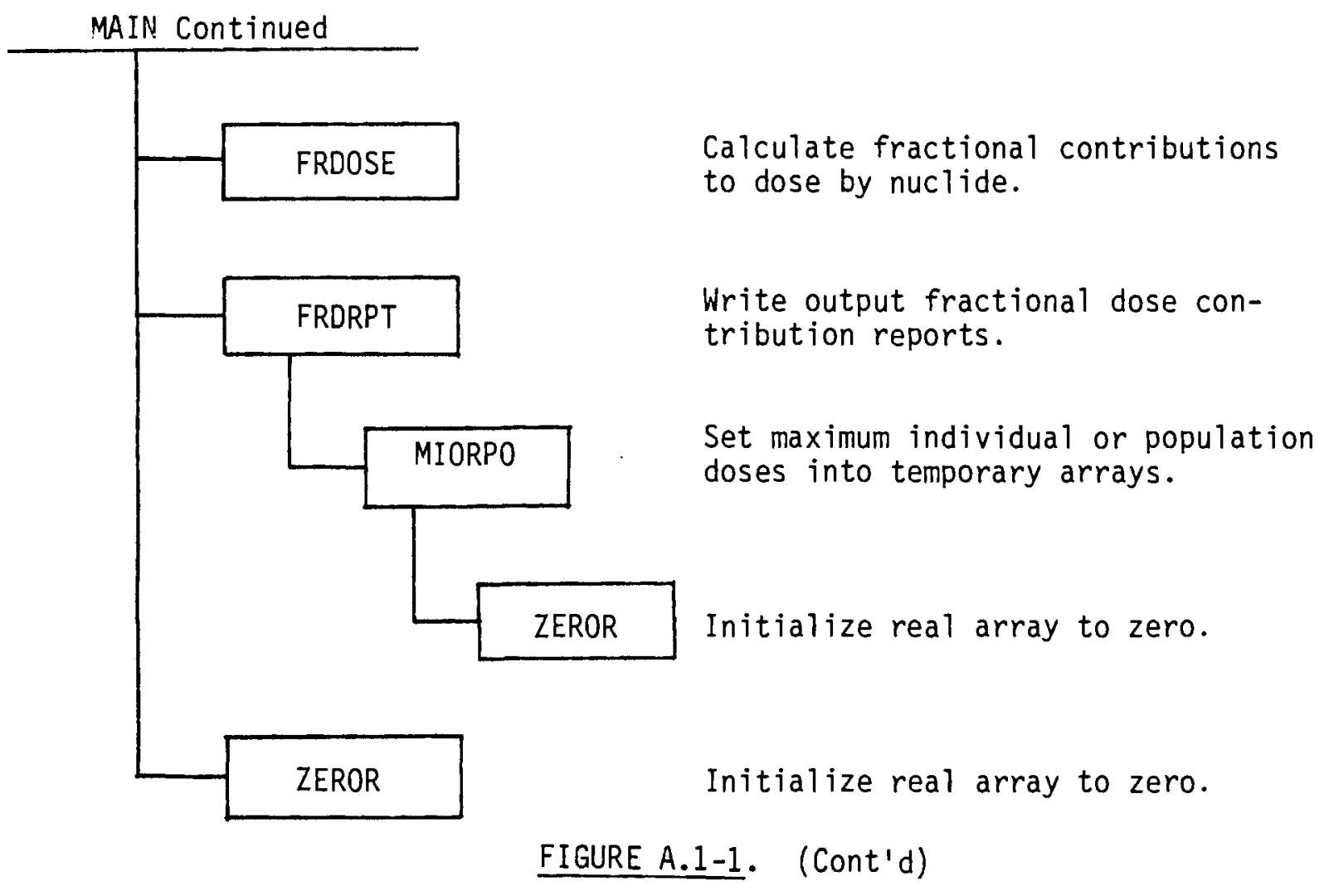

A. 4 


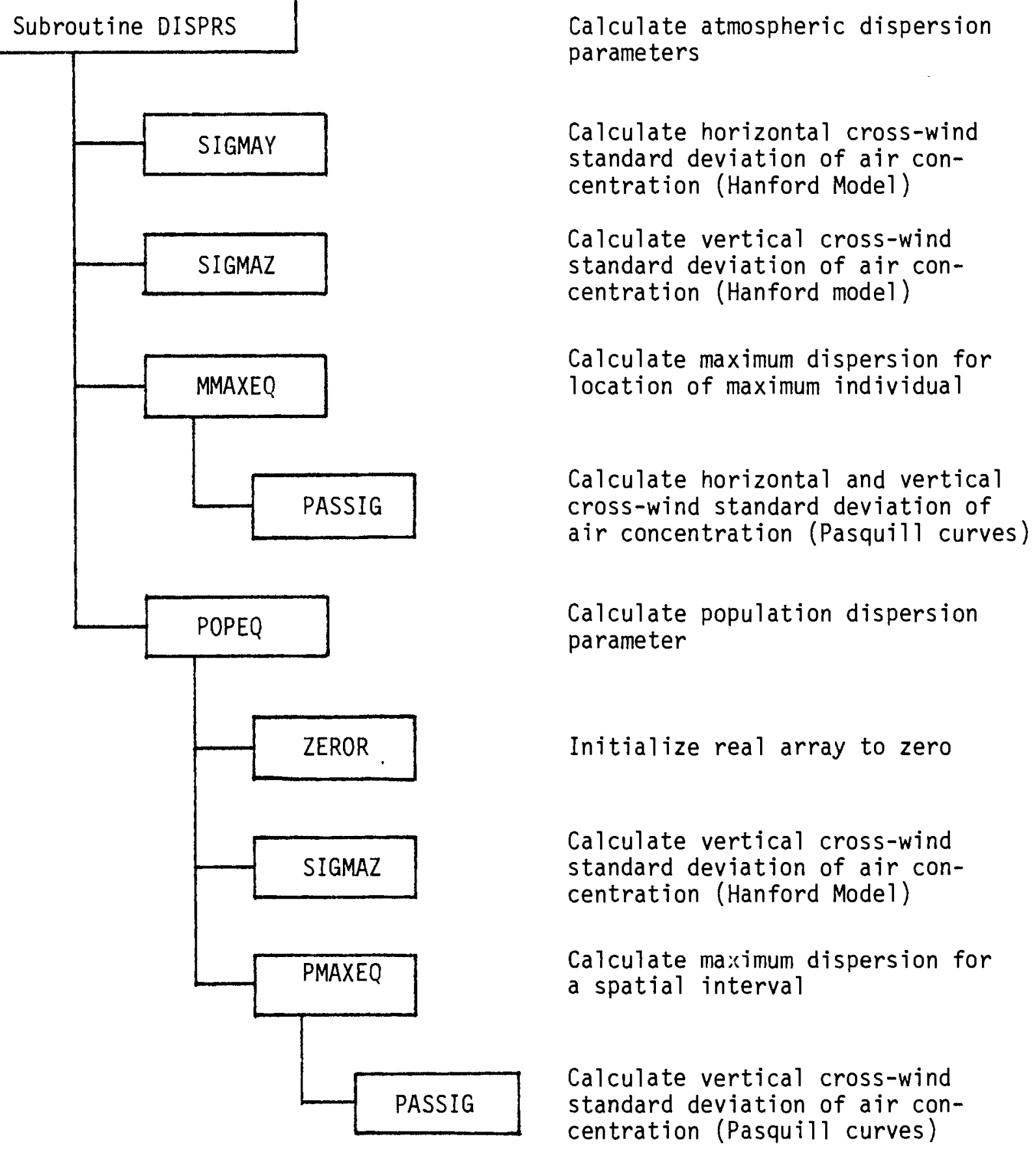

FIGURE A.1-2. Hierarchy Diagram for Subroutine DISPRS (called by MAIN) 


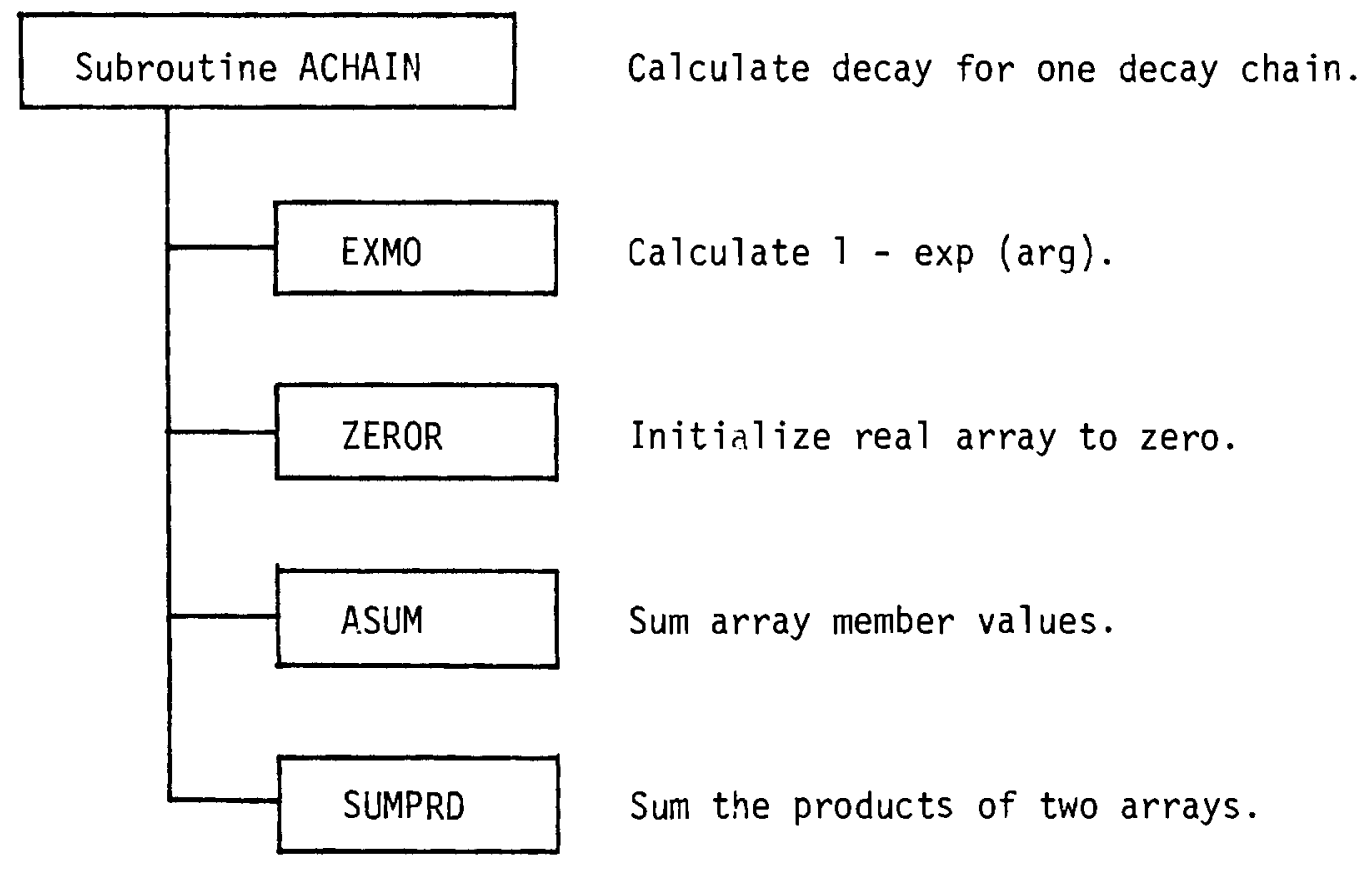

FIGURE A.1-3. Hierarchy Diagram for Subroutine ACHAIN (called by TRNSIT) 


\section{A.2 MODULE SPECIFICATIONS}

The computer program HADOC has been designed as a structured program consisting of 29 well defined modules. Summary information on each module is provided in the following subsections. The main proaram (module MAIN) is described first followed by each subroutine (or function) in alphabetical order. The descriptions contain the following information:

- module name

- calling module(s)

- primary function

- common block usage

- argument list

- subordinate modules

- detailed specifications 


\section{A.2.1. Specifications for MAIN Program}

Primary Function: This code calculates radiation doses from external and inhalation uptake from accidental releases on the Hanford site.

Common Blocks Used: ACTVTY, AIRCON, DAY, DECAY, DISPSN, DISTNC, DOSFAC, DOSMI, DOSPOP, ELEVAT, FLAGS, NAMES, ORGID, SOURCE, POPU

Argument List: None

Subordinate Routines: ASGH, RLIBIN, NLIBIN, IDNUC, ORGCHK, QAPAGE, DISPRS, MIDOSE, POPDOS, DOSRPT, FRDOSE, FRDRPT, ZEROR

This module controls data input, calculations and result output through calls to subroutines. Default parameter values are also specified. The subroutine ASGH is called to request that necessary data files be made avilable for the run. Conversion of the code to other computers would require rewriting of the subroutine ASGH or replacing it with appropriate control cards prior to program execution. 


\section{A.2.2. Specifications for Subroutine ACHAIN, Called by TRNSIT}

Primary Function:

Calculate radioactive decay for a chain of radionuclides for a given time period.

Common Blocks Used:

None

Argument List:

NUC, T, DK, IFRM, AL, AM, AO, INTGRL

Subordinate Routines:

ZEROR, EXMO, ASUM, SUMPRD

This subroutine calculates radioactive decay for a time period $(T$ ) for a chain of NUC radionuclides. The argument list parameters have the following uses:

Parameter

Description

NUC

Number of radionuclides in the decay chain. $1 \leq N U C \leq 9$.

$\mathrm{T}$

Time over which decay is to be considered. Units of $T$ must

be compatible with the units of the decay constants, AL.

DK $(2,9) \quad$ Branching ratios:

$\operatorname{DK}(1, i)$, fraction of first parent decays resulting in production of chain member $i$.

$D K(2, i)$, fraction of second parent (if any) decays resulting in production of chain member $i$.

$\operatorname{IFRM}(2,9) \quad$ Position in chain of parents for each chain member.

$\operatorname{IfRM}(1, i)$, index of first parent for chain member $i$.

$\operatorname{IFRM}(2, i)$, index of second parent for chain member $i$.

AL(9) Radiological decay constants for each chain member in units compatible with $T$.

AM(9) Initial quantity of each radionuclide in mass units (or Curieseconds). 

mass units (or Curie-seconds).

INTGRL Control integer to select decay or the time integral of activity.

INTGRL $\leq 0$; decayed activity

INTGRL $>0$, calculate $\int_{0}^{t} A(T) d t$ where $A(t)$ is mass of a radionuclide.

The data arrays IFRM and DK provide branching data and allow for complex decay schemes of up to 9 chain members. Additional chain members could be considered by increasing array dimensions for $A$ and EXPO. The dimension for $A$ is determined by $\sum_{n=1} n$ and the dimension for EXPO is the number of chain members (NUC).

Three subroutines are called by ACHAIN:

- EXMO - to calculate $\left(1-e^{-\lambda t}\right) / \lambda$ when INTGRL $>0$

- ASUM - to generate the sum of terms for a chain member

- SUMPRD - to generate the sum of the product of members of two arrays. 
A.2.3. Specifications for Subroutine ASGH, called by MAIN

Primary Function:

This subroutine makes necessary data files available to the run.

Common Blocks Used:

None

Argument List:

IEND

Subordinate Routines:

None

This subroutine accesses necessary data files for the run through calls to the system routine FACSF. The function of this subroutine could be replaced by appropriate system control cards. When the input argument IEND $=1$ (first cal1), the necessary data files are assigned to the run. When IEND $\neq 0$ (second cal1), the files are released for use elsewhere. 
A.2.4. Specifications for Function ASUM, called by ACHAIN

Primary Function:

This function sums terms of an array.

Common Blocks Used:

None

Argument List:

$\mathrm{J}, \mathrm{A}$

Subordinate Routines:

None

This function calculates the sum of $J$ terms of array $A$.

$$
\operatorname{ASUM}=\sum_{i=1}^{J} A(i)
$$




\section{A.2.5. Specifications for Subroutine DISPRS, called by MAIN}

Primary Function:

Calculate atmospheric dispersion parameters for maximum individual and population locations.

Common Blocks Used:

DISTNC, DISPSN, ELEVAT, A.IRCON

Argument List:

IQP, KKRPT

Subordinate Routines:

SIGMAY, SIGMAZ, POPEQ, MMAXEQ

This subroutine calculates the air concentration at the location of the maximum individual and then calls subroutine POPEQ which calculates the population dispersion parameters. The maximum individual air concentration is calculated using Equation 2.1-1 of the text.

The argument list parameters have the following use:

Parameter

Use

IQP

Control integer to cause printing of air concentration values (printed if IQP > 0 ).

KKRPT

Control air concentration calculation:

KKRPT $\leq 0$ for population and maximum individual dispersion parameters,

KKRPT = 1 for maximum individual only,

KKRPT $\geq 2$ for population on $1 y$. 
A.2.6. Specifications for Subroutine DOSRPT, called by MAIN

Primary Function:

Write dose result reports.

Common Blocks Used:

DOSMI, DOSPOP, DAY, ORGID

Argument List:

KKRPT, TITLE1

Subordinate Routines:

None

This subroutine writes dose result reports as requested by the control parameter KKRPT. When KKRPT $\leq 0$, total doses to each organ are printed (maximum individual and population). When KKRPT $=1$, only doses to the maximum individuai are printed and when KKRPT $=2$, only population doses are printed. The title array TITLE $]$ is printed in each page heading. 


\section{A.2.7. Specifications for Function EXMO, called by ACHAIN}

\section{Primary Function:}

The function calculates a value for the expression $\left(1-e^{-\lambda t}\right) / \lambda$.

Common Blocks Used:

None

Argument List:

ARG, AL

Subordinate Routines:

None

This function calculates a value for the expression:

$$
\frac{1-e^{-\lambda t}}{\lambda}
$$

The argument list is:

- $A R G=\lambda t$

- $\mathrm{AL}=\lambda$

The method used to evaluate the expression is determined by the value of ARG. When $A R G$ is positive, an error message is printed and execution is stopped. When $-A R G>0.001$, then the expression is evaluated as

$$
\operatorname{EXMO}=(1 .-\operatorname{EXP}(A R G)) / A L
$$

When $-A R G \leq 0.001$, the expression is evaluated as

$$
\text { EXMO }=\sum_{n=1}^{I} \frac{(\lambda t)^{n}(-1)^{n-1}}{n^{1} \lambda}
$$

where $I=$ integer value of $8-\log _{10}(-A R G)$ and $I \geq 2$. 


\section{A.2.8 Specifications for Subroutine FRDOSE, called by MAIN}

Primary Function:

Calculate fractional contributions to doses.

Common Blocks Used:

DOSMI, DOSPOP, NAMES, ORGID, NFLAGS

Argument List:

KKRPT

Subordinate Routines:

None

This subroutine converts dose result tables to fractional dose contribution tables by dividing by total dose. 


\section{A.2.9 Specifications for Subroutine FRDRPT, called by MAIN}

\section{Primary Function:}

Write reports of fractional contributions to dose.

Common Blocks Used:

DAY, FLAGS, NAMES, ORGID

Argument List:

FRAC, KKRPT, TITLEI

Subordinate Routines:

MIORPO

This subroutine prepares output reports of fractional dose contributions by radionuclide. The argument list parameters have the following use.

Parameter

Use

FRAC

KKRPT

Fractional contribution cutoff value. Any radionuclide contributing more than FRAC to the dose to an organ will be included in the fractional dose contribution table.

Control parameter for selection of population and maximum individual reports.

KKRPT $\leq 0$, print al1 reports

KKRPT $=1$, print only maximum individual reports

KKRPT $\geq 1$, print only population reports

TITLEl Descriptive title array (20 words) for the current run

A maximum of eight output reports may be prepared depending on the value of KKRPT (as described above). The fractional contribution reports are:

- maximum individual one-year dose commitment contribution by intake mode (external and inhalation)

- maximum individual fifty-year dose commitment contribution by intake mode 
- maximum individual total one-year dose commitment contribution

- maximum individuar total fifty-year dose commitment contribution

- population one-year dose commitment contribution by intake mode

- population fifty-year dose commitment contribution by intake mode

- population total one-year dose commitment contribution

- population total fifty-year dose commitment contribution.

The subroutine MIOPRO is called to establish the fractional contribution values for maximum individual and population reports. 
A.2.10 Specifications for Subroutine IDLINE, called by MAIN

Primary Function:

This subroutine writes a line to output giving identification information on the program being executed.

Common Blocks Used:

None

Argument List:

None

Subordinate Routines:

None

IDLINE is a nonessential subroutine called to print the name of the program being executed. The subroutine is written in assembly language. To eliminate the subroutine simply remove the call statement from subroutine QAPAGE. 


\section{A.2.11 Specifications for Subroutine IDNUC, called by MAIN}

Primary Function:

This module attempts to identify input inventory radionuclides against the master library list.

Common Blocks Used:

ACTVTY, DECAY, FLAGS, NAMES, SOURCE

Argument List:

QI, FINV

Subordinate Routines:

ZEROI, ZEROR

This subroutine tests the input radionuclide names against the master list names. The input activity, QI, is converted to curie-sec (mass units for decay calculation) and stored in array $Q$. The names of any unidentified radionuclides are printed. (Execution stops if there are unidentified radionuclides). The arguments are:

QI(300) array of released activities.

FINV factor by which each release activity is multiplied. 


\section{A.2.12 Specifications for Subroutine LIBRPT, called by NLIBIN}

Primary Function:

This subroutine prepares a report of data contained in the library NUCDFL.

Common Blocks Used:

DAY, NAMES

Argument List:

TITLN, NUC, LORG, INFLG, EXDF, ODF, ONAME

Subordinate Routines:

None

This subroutine writes a report of dose conversion factors supplied in the data library NUCDFL. The argument list parameters have the following uses:

Parameter Use

TITLN(20) Title array from the library NUCDFL

NUC Number of radionuclides in master list from data library RMDLIB

LORG Number of organs for which data is available in data library NUCDFL

INFLG(300) Flag array to identify which nuclides have dose factors given in data library NUCDFL

$\operatorname{EXDF}(300) \quad$ External dose factor array

$\operatorname{ODF}(2,10$, Inhalation dose factor array for 2 dose commitment periods, 300) 10 organs and 300 radionuclides

ONAME (10) Organ name tities (10 character words)

The subroutine prints dose factors for each radionuclide for which data is given in library NUCDFL. 


\section{A.2.13 Specifications for Subroutine MIDOSE, called by MAIN}

Primary Function:

This subroutine calculates the maximum individual doses.

Common Blocks Used:

ACTVTY, AIRCON, DISPSN, DISTNC, DECAY, DOSFAC, DOSMI, FLAGS, ORGID

Argument List:

None

Subordinate Routines:

TRNSIT, ZEROR

This subroutine calculates the external and inhalation dose contributions using equations 2.3-1 and 2.4-1 of the text. A call to subroutine TRNSIT is made to generate the radionuclide inventory with decay to the location of the maximum individual. The travel time to the maximum individual location is calculated as:

$$
T=D M I / U M I
$$

Doses are calculated for the first year and fifty year comitment periods. 


\section{A.2.14 Specifications for Subroutine MIORPO, called by FRDRPT}

Primary Function:

This subroutine fills temporary dose contribution arrays.

Common Blocks Used:

DOSMI, DOSPOP, NAMES, ORGID

Argument List:

DVET, DVE, DVOT, DVO, IRPRT

Subordinate Routines:

ZEROR

This subroutine fills temporary fractional dose contribution arrays with either maximum individual values or population values. The argument list parameters have the following use:

Parameter

Use

DVET

Total external total body dose

DVE(300) Fractional contribution to external dose for each radionuclide

DVOT $(2,5) \quad$ Total inhalation doses for two time periods and five organs

DVO $(2,5,300)$ Fractional contribution to inhalation dose for each radionuclide for two time periods and five organs

IRPRT Control integer to select maximum individual data or population data

$$
\begin{aligned}
& \text { IRPRT }=1 \text { for maximum individual data, } \\
& \text { IRPRT }=2 \text { for population data. }
\end{aligned}
$$

When maximum individual data is requested (IRPRT $=1$ ) the data arrays DVET, DVE, DVOT and DVO are set equal to the maximum individual data arrays DMET, DME, DMOT and DMO respectively. When population data is requested (IRPRT = 2) the data arrays DVET, DVE, DVOT and DVO are set equal to the population data arrays DPET, DPE, DPOT and DPO respectively. 


\section{A.2.15 Specifications for Subroutine MMAXEQ, called by DISPRS}

Primary Function:

This subroutine determines which atmospheric stability gives the highest value for the maximum individual air concentration.

Common Blocks Used:

None

Argument List:

EQMI, HE, UMI, IMP, AREA, IWAKE, DMI

Subordinate Routines:

PASSIG

This subroutine calculates the time-integrated air concentration at the location of the maximum individual for the six Pasquill dispersion categories $(A-F)$ and returns the highest value EQMI and the condition index IMP.

\begin{tabular}{|c|c|}
\hline IMP & Condition \\
\hline 1 & Pasquill A \\
\hline 2 & Pasquill B \\
\hline 3 & Pasquill C \\
\hline 4 & Pasquill D \\
\hline 5 & Pasquill E \\
\hline 6 & Pasquill F \\
\hline 7 & Hanford \\
\hline
\end{tabular}

The other argument list parameters have the following use:

Parameter Use

HE

Effective plume height at the location of the maximum individual, m

UMI

Average wind speed $(\mathrm{m} / \mathrm{sec})$ for the maximum individual dose calculation

IWAKE Control parameter to indicate that building wake effects are to be considered (if IWAKE > 0) 
Parameter

AREA Minimum building cross-sectional area for use with the building wake effects model, $\mathrm{m}^{2}$

DMI
Use

Distance from the release point to the maximum individual location, $m$.

The subroutine PASSIG is called to determine dispersion parameter values $\left(\sigma_{y}\right.$ and $\left.\sigma_{z}\right)$ for the Pasquill stability categories. 


\section{A.2.16 Specifications for Subroutine NLIBIN, called by MAIN}

Primary Function:

This subroutine reads inhalation and external dose conversion factor data.

Common Blocks Used:

DECAY, FLAGS, DOSFAC, DAY, NAMES, ORGID

Argument List:

TITLN

Subordinate Routines:

LIBRPT, ZEROI, ZEROR

This subroutine reads inhalation and external dose conversion factors from the data library NUCDFL on input unit 12. The library title (TITLN) is returned as an argument for printing in subroutine QAPAGE. The first four cards of the data library give descriptive information on the data that follows. Each nuclide has data for external exposure and some have data for inhalation exposure also. The flag array (INFLG(i) is set to 1 if data for external exposure only is supplied for readionclide $i$. If inhalation dose factors are also supplied then INFLG(i) is set to 2. Each radionuclide read from NUCDFL is compared to those in the master radionuclide 1 ist. If a radionuclide cannot be identified then an error message is printed and execution is stopped.

Subroutine LIBRPT is called to prepare a report of dose conversion factors read from data library NUCDFL. 


\section{A.2.17 Specifications for Subroutine ORGCHK, called by MAIN}

\section{Primary Function:}

This subroutine checks input organ index values against allowed values provided in data library NUCDFL.

Common Blocks Used:

ORGID

\section{Argument List:}

None

\section{Subordinate Routines:}

ZEROI

This subroutine checks the input organ index values (array KORG) against allowed values provide in data library NUCDFL (array IORG). The number of organs requested is also calculated. 


\section{A.2.18 Specifications for Subroutine PASSIG, called by MMAXEQ and PMAXEQ}

Primary Function:

Calculate dispersion parameters for a given distance and Pasquill stability category.

Common Blocks Used:

None

Argument List:

$X X, I P, S Y, S Z$

\section{Subordinate Routines:}

None

This slibroutine interpolates stored data to determine dispersion parameters $\sigma_{y}$ and $\sigma_{z}$ for a Pasquill atmospheric stability category and a given distance.

The argument list parameters have the following uses:

Parameter

Use

$x \times$

IP

Index to indicate which Pasquill stability category is to be used: $I P=1$ for $A, I P=2$ for $B, I P=3$ for $C$, IP $=4$ for $D$, $I P=5$ for $E$ and $I P=6$ for $F$.

SY

Crosswind horizontal standard deviation of plume concentration at the location of interest, $m$

SZ

Crosswind vertical standard deviation of plume concentration at the location of interest, $m$

Tabulated values are interpolated for the distance $x X$ between 1 and $10^{5}$ meters. In practical applications the distance $X X$ should not be less than 100 meters or greater than $10^{5}$ meters. The vertical dispersion parameter $\sigma_{z}$ is 1 imited to 2000 meters.

Tabulated values are provided for distances given in array DIST(20). Horizontal dispersion parameters are given for 6 stabilities and 20 distances in the array $\operatorname{SIGY}(6,20)$ and vertical dispersion parameters are given in the array $\operatorname{SIGZ}(6,20)$. 


\section{A.2.19 Specifications for Subroutine PMAXEQ, called by POPEQ}

Primary Function:

This subroutine determines which atmospheric stability condition gives the highest value for sector averaged air concentration.

Common Blocks Used:

None

Argument List:

$E, H 2$, UP, $X, A R E A$, IWAKE, IPL

Subordinate Routines:

PASSIG

This subroutine calculates sector averaged air concentrations at a given distance using six Pasquill stability categories A-F. The highest value is compared with the Hanford model air concentration, E. If the Pasquill value is higher then $E$ is replaced by the Pasquill value and the stability index IPL is reset.

The argument list parameters have the following use:

\section{Parameter}

E

$\mathrm{H} 2$

UP

$X$

AREA

IWAKE

IPL

\section{Use}

maximum air concentration, $\mathrm{sec} / \mathrm{m}^{3}$

effective height term $=h_{e}^{2}, m^{2}$

windspeed for population dose calculation, $\mathrm{m} / \mathrm{sec}$

distance to location of interest, $x$

building cross sectional area, $\mathrm{m}^{2}$, for building wake effects calculation

control parameter to indicate that building wake effects are to be considered (if IWAKE > 0)

index of the stability giving the highest value for air concentration

IPL $=1$ through 6 for Pasquil1 A through $F$ respectively and IPL $=7$ for Hanford. 


\section{A.2.20 Specifications for Subroutine POPDOS, called by MAIN}

Primary Function:

This subroutine calculates the population doses for selected organs.

Common Blocks Used:

ACTVTY, AIRCON, DECAY, DISPSN, DISTNC, DOSFAC, DOSPOP, FLAGS, ORGID, POPU

Argument List:

None

Subordinate Routines:

TRNSIT, ZEROR

This subroutine calculates population doses for the maximum exposed sector for selected organs. Doses are calculated for one year and fifty year dose commitment periods by radionuclide. The contribution for each spatial interval is summed with decay in transit from the release point to the spatial interval midpoint calculated by a call to TRANSIT. 


\section{A.2.21 Specifications for Subroutine POPEQ, called by DISPRS}

Primary Function:

This subroutine calculates the population dispersion factor for the maximum sector.

Common Blocks Used:

DISPSN, DISTNC, POPU, ELEVÁT

\section{Argument List:}

EQP, PM, MS, IP

\section{Subordinate Routines:}

SIGMAZ, PMAXEQ, ZEROR

This routine calculates the maximum sector population dispersion factor, PM. The ground level air concentration is calculated as a function of distance for a ground level release. If terrain effects are included, the directional dependence of air concentration is also calculated (when an elevated release is requested: HSTACK > 0).

The argument list parameters have the following uses:

Parameter Use

EQP(10) air concentration at each spatial interval of the maximum sector, $\mathrm{sec} / \mathrm{m}^{3}$

PM population dispersion factor for the maximum sector, person$\mathrm{sec} / \mathrm{m}^{3}$

MS index of the maximum sector, $1 \leq M S \leq 16$

IP(10) index value for the maximum atmospheric stability condition at each distance in the maximum sector.

When LIMTST > 0 the maximum atmospheric conditions are determined with calls to subroutine PMAXEQ. 


\section{A.2.22 Specifications for Subroutine QAPAGE, called by MAIN}

Primary Function:

This subroutine writes a report giving all input information.

Common Blocks Used:

DAY, DISPSN, DISTNC, ELEVAT, ORGID, POPU, SOURCE

Argument List:

TITLE1, TITLR, TITLN, QI, FINV, IFRAC, KKRPT, FRAC

Subordinate Routines:

IDLINE

This subroutine prints a quality assurance report describing all input parameters and requested options. The argument list parameters have the following uses:

Parameter

Use

TITLEI(20) descriptive title for the current case,

TITLR(20) descriptive title for the master radionuclide data library

TITLN(20) descriptive title for the dose conversion factor data library

QI(300) input radionuclide activity inventory

FINV inventory modification factor

IFRAC control integer, positive when fractional contributions to dose by radionuclide are to be determined

KKRPT

control integer to select types of doses to calculate

$$
\begin{aligned}
& \text { KKRPT } \leq 0 \text { for population and maximum individual } \\
& \text { KKRPT }=1 \text { for maximum individual only } \\
& \text { KKRPT }>1 \text { for population only }
\end{aligned}
$$

FRAC fractional contribution dose cutoff value. 


\section{A.2.23 Specifications for Subroutine RLIBIN, called by MAIN}

Primary Function:

This subroutine reads data from the master radionuclide data library.

Common Blocks Used:

DECAY, NAMES

Argument List:

TITLR

Subordinate Routines:

ZEROR

This subroutine reads from the radionuclide master data library, RMDLIB. Data read include radionuclide identification parameter arrays ELT and AW and radiological half-life and chain decay data. The argument list parameter is a descriptive title read from RMDLIB and printed on the input summary report in QAPAGE.

In reading the data library this subroutine does several functions:

- the number of nuclides are counted, NUC

- decay constants are calculated, AL

- chain branching parameters are set, IFR, DKF

- chain lengths are set, NOFNUC 
A.2.24 Specifications for Function SIGMAY, called by DISPRS

Primary Function:

This function calculates $\sigma_{y}$ at a given location using the Hanford model.

Common Blocks Used:

None

Argument List:

TT, STUB

Subordinate Routines:

None

The value of $\sigma_{y}$ is evaluated at a location TT seconds travel distance away from the release point.

The equations for $\sigma_{y}$ are:

$$
\begin{aligned}
& \sigma_{y}^{2}=A\left[T T-\alpha\left(1-e^{-T T / \alpha}\right)\right] \\
& A=13+230\left(\sigma_{\theta} \bar{u}\right) \\
& \alpha=A /\left[2\left(\sigma_{\theta} \bar{u}\right)^{2}\right]
\end{aligned}
$$

where $\sigma_{\theta} \vec{u}=$ STUB. 


\section{A.2.25 Specifications for Function SIGMAZ, called by DISPRS, POPEQ}

Primary Function:

This function calculates $\sigma_{z}$ at a given location using the Hanford model.

Common Blocks Used:

None

Argument List:

KS, TT

Subordinate Routines:

None

The value of $\sigma_{z}(m)$ is evaluated at the travel time distance, TT (seconds). When $\mathrm{KS} \leq 0$, moderately stable conditions are used and when $\mathrm{KS}>0$ very stable conditions are used. The equation is

$$
\sigma_{z}^{2}=a\left[1-\exp \left(-k^{2} T^{2}\right)\right]+b T
$$

where $T=T T$, travel time, sec and values for $a, b$ and $k^{2}$ are as follows:

\begin{tabular}{llll} 
Parameter & & $\begin{array}{c}\text { ModerateTy } \\
\text { Stable }\end{array}$ & $\begin{array}{c}\text { Very } \\
\text { Stable }\end{array}$ \\
\cline { 1 - 1 } a $\left.^{2} \mathrm{~m}^{2}\right)$ & 97 & 34 \\
$\mathrm{~b}\left(\mathrm{~m}^{2} / \mathrm{sec}\right)$ & .33 & .025 \\
$\mathrm{~K}^{2}\left(\mathrm{sec}^{2}\right)$ & $2.5 \times 10^{-4}$ & $8.8 \times 10^{-4}$
\end{tabular}


A.2.26 Specifications for Function SUMPRD, called by ACHAIN

Primary Function:

This function sums the term by term products of two arrays.

Common Blocks Used:

None

Argument List:

$\mathrm{J}, \mathrm{A}, \mathrm{B}$

Subordinate Routines:

None

The function evaluates the expression:

$$
\text { SUMPRD }=\sum_{i=1}^{J} A(i) * B(i)
$$




\section{A.2.27 Specifications for Subroutine TRNSIT, called by MIDOSE and POPDOS}

Primary Function:

This subroutine controls the radiological decay calculations.

Common Blocks Used:

ACTVTY, DECAY, FLAGS

Argument List:

T

Subordinate Routines:

ACHAIN

This subroutine controls the calculation of inventory radiological decay in transit during a period of $T$, seconds. The chain decay calculation is performed in subroutine ACHAIN for one chain at a time. The flag array NFLAGC is used to determine which chains to consider. NFLAGC $(i)>0$ indicates the chain contains radionuclides with nonzero activities. 


\section{A.2.28 Specifications for Subroutine ZEROI, called by IDNUC and ORGCHK}

Primary Function:

This subroutine initializes an integer array to zero.

Common Blocks Used:

None

Argument List:

$\mathrm{N}, \mathrm{K}$

Subordinate Routines:

None

This subroutine sets the first $\mathrm{N}$ members of integer array $\mathrm{K}$ to zero. 


\section{A.2.29 Specifications for Subroutine ZEROR}

Primary Function:

This subroutine initializes a real valued array to zero.

Common Blocks Used:

None

Argument List:

$N, A$

Subordinate Routines:

None

This subroutine sets the first $N$ values of real array $A$ to zero.

ZEROR is called by ACHAIN, IDNUC, MAIN, MIDOSE, MIORPO, NLIBIN, POPDOS AND POPEQ. 


\section{A. 3 MODULE LOGIC DIAGRAMS}

This section provides logic diagrams for each module. The logic diagrams use flow charting techniques described by Chapin (1974)* and are referred to as chapin charts. The basic logic constructs used in the diagrams are indicated in Figure A.3-1.

Logic diagrams are provided for each module (except IDLINE) in Figures A.3-2 through A.3-29 as follows.

$\begin{array}{llllll}\text { Figure } & \text { Module } & \text { Figure } & \text { Module } & \text { Figure } & \text { Module } \\ \text { A.3-2 } & \text { MAIN } & \text { A.3-12 } & \text { LIBRPT } & \text { A.3-22 } & \text { QAPAGE } \\ \text { A.3-3 } & \text { ACHAIN } & \text { A.3-13 } & \text { MIDOSE } & \text { A.3-23 } & \text { RLIBIN } \\ \text { A.3-4 } & \text { ASGH } & \text { A.3-14 } & \text { MIORPO } & \text { A.3-24 } & \text { SIGMAY } \\ \text { A.3-5 } & \text { ASUM } & \text { A.3-15 } & \text { MMAXEQ } & \text { A.3-25 } & \text { SIGMAZ } \\ \text { A.3-6 } & \text { DISPRS } & \text { A.3-16 } & \text { NLIBIN } & \text { A.3-26 } & \text { SUMPRD } \\ \text { A.3-7 } & \text { DOSRPT } & \text { A.3-17 } & \text { ORGCHK } & \text { A.3-27 } & \text { TRNSIT } \\ \text { A.3-8 } & \text { EXMO } & \text { A.3-18 } & \text { PASSIG } & \text { A.3-28 } & \text { ZEROI } \\ \text { A.3-9 } & \text { FRDOSE } & \text { A.3-19 } & \text { PMAXEQ } & \text { A.3-29 } & \text { ZEROR } \\ \text { A.3-10 } & \text { FRDRPT } & \text { A.3-20 } & \text { POPDOS } & & \\ \text { A.3-11 } & \text { IDNUC } & \text { A.3-21 } & \text { POPEQ } & & \end{array}$

*Chapin, N. 1974. "New Format for Flowcharts," Software-Practice and Experience, Vol. 4, pp. 341-357, John Wiley and Sons Ltd, London. 

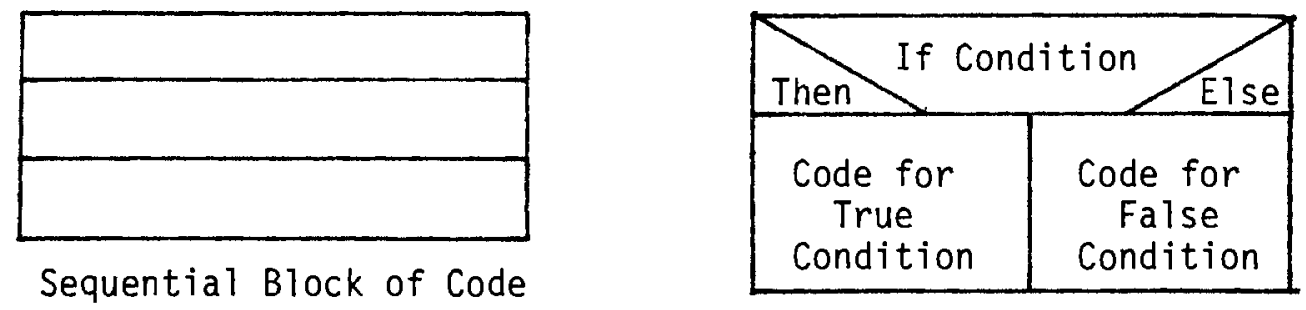

Conditional

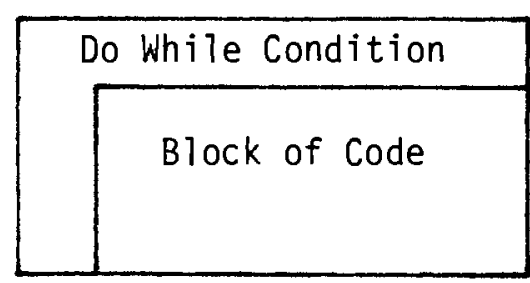

Do While Loop

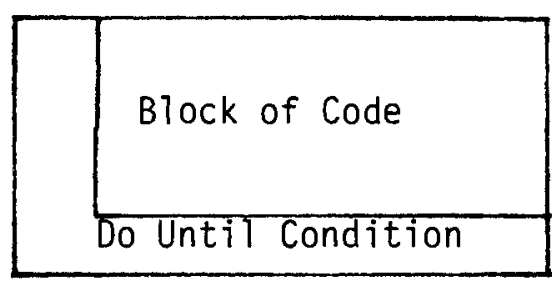

Do Until Loop

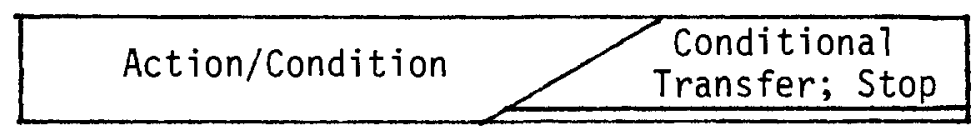

Abnormal Transfer

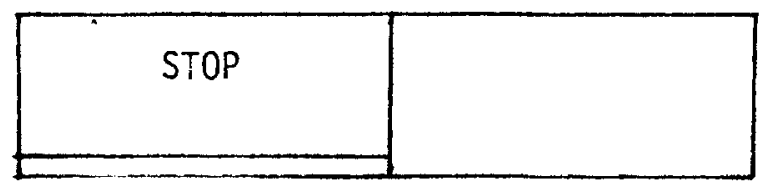

Abnormal Termination

FIGURE A.3-1. Chapin Chart Logic Constructs 
Set default values and call ASGH to request data files

Cal1 RLIBIN to read radionuclide master data library

Call NLIBIN to read dose conversion factor data library.

Call ASGH to release data files

Read title card and NAMELIST data for a case

\begin{tabular}{|l|l|}
\hline If NEXT $=3$ \\
\hline If KKRPT $\neq 1$ and KKPOP $\geq 1$ \\
\hline Read new release inventory \\
\hline Read terrain data
\end{tabular}

Call ORGCHK to count and check organs requested.

Call QAPAGE to write input data $Q A$ report.

Call DISPRS to calculate atmospheric dispersion parameters

If KKRPT $\leq 1$

Call MIDOSE to calculate maximum individual doses

If KKRPT $\neq 1$

Then

Call POPDOS to calculate population doses

Call DOSRPT to write dose reports

If IFRAC $>0$
Call FRDOSE to calculate fractional dose contributions
Call FRDRPT to write fractional dose reports


$N 2 N=N U C *(N U C-1) / 2+N U C:$ number of spaces in array $A$ used

Call ZEROR (N2N,A); Initialize coefficient array $A$ to zero

Do while $\mathrm{J}=1$, NUC; loop on chain members

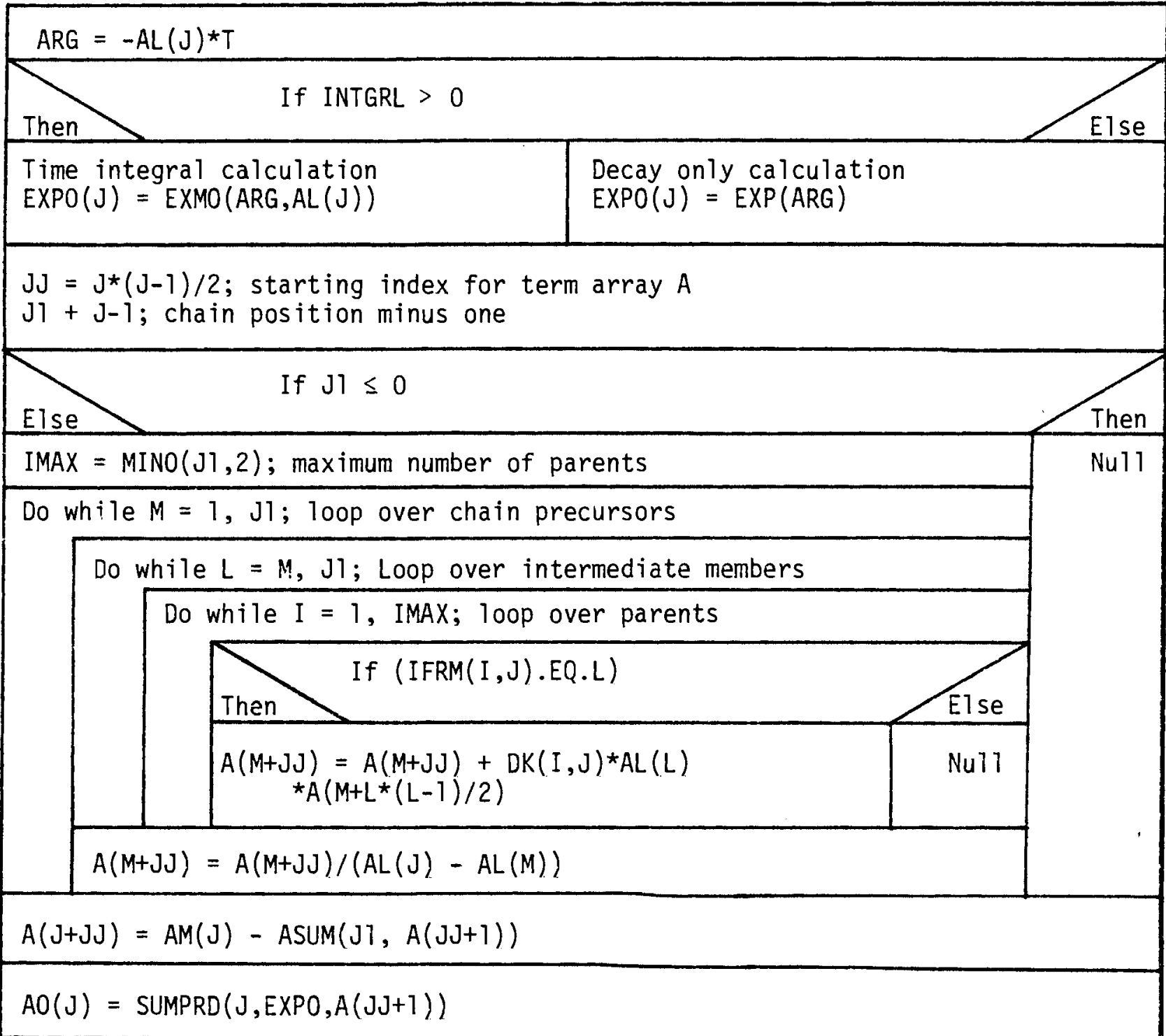

Return

FIGURE A.3-3. Logic Diagram for Module ACHAIN 


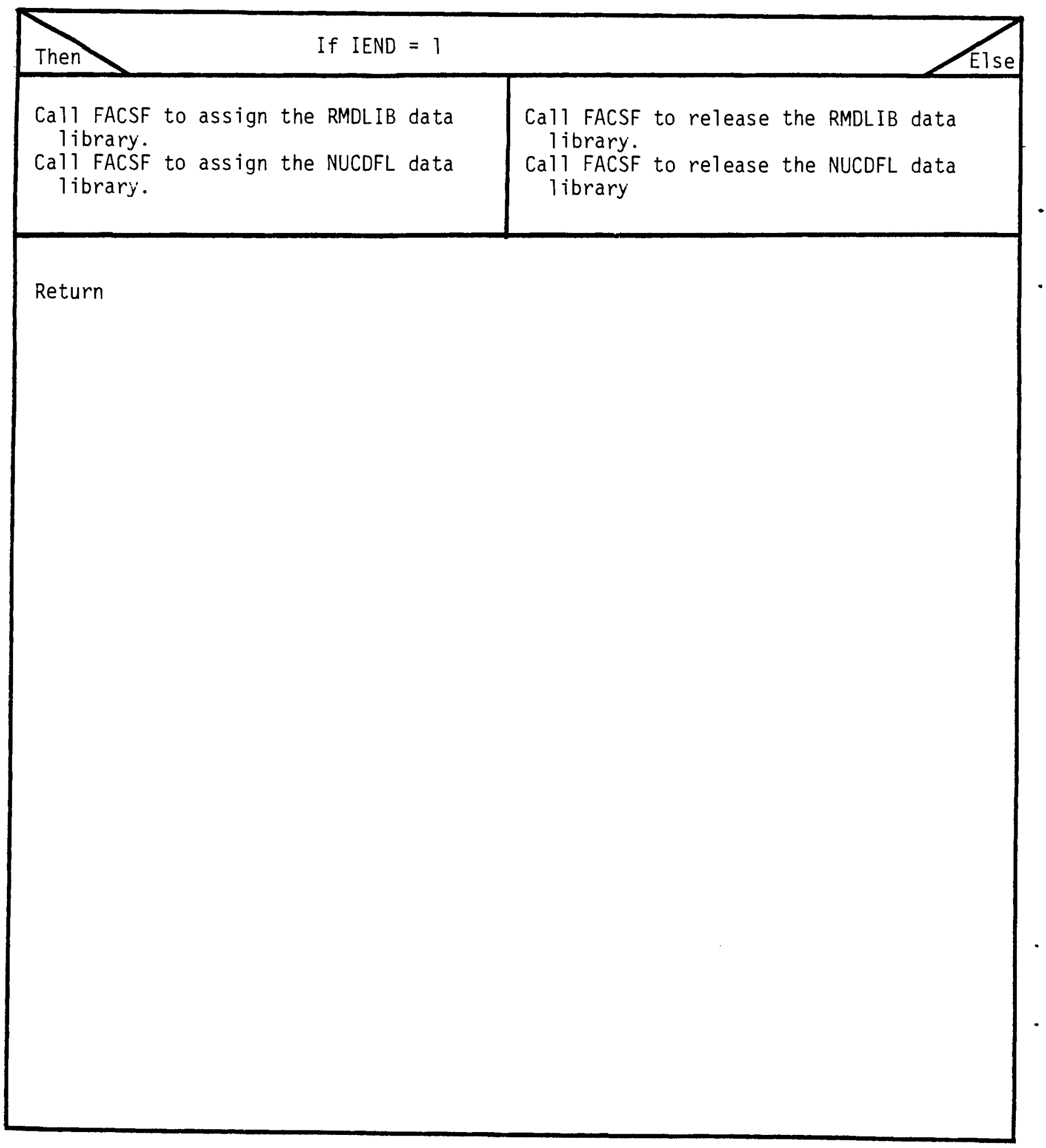

FIGURE A.3-4. Logic Diagram for Module ASGH 


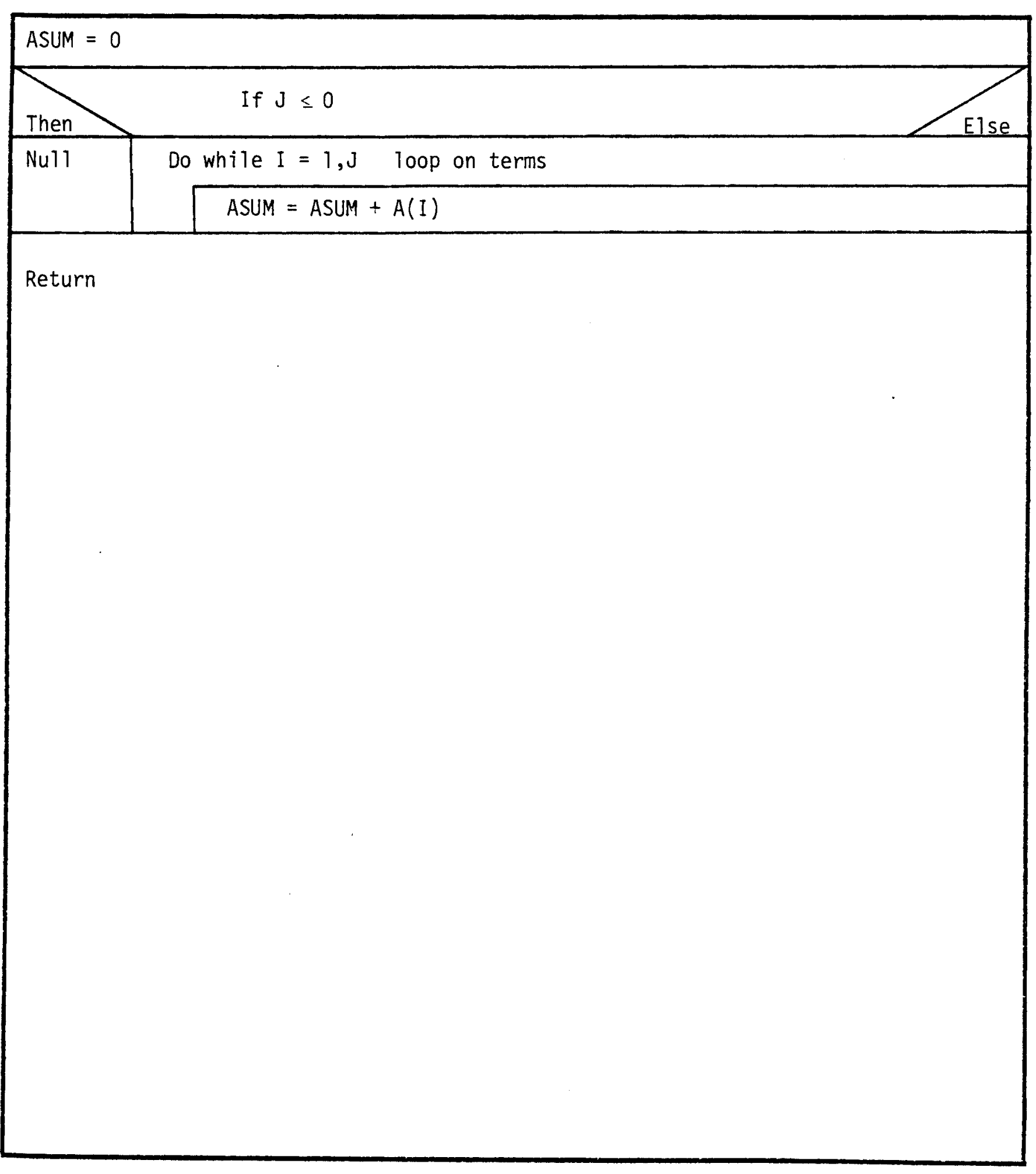

FIGURE A.3-5. Logic Diagram for Module ASUM 


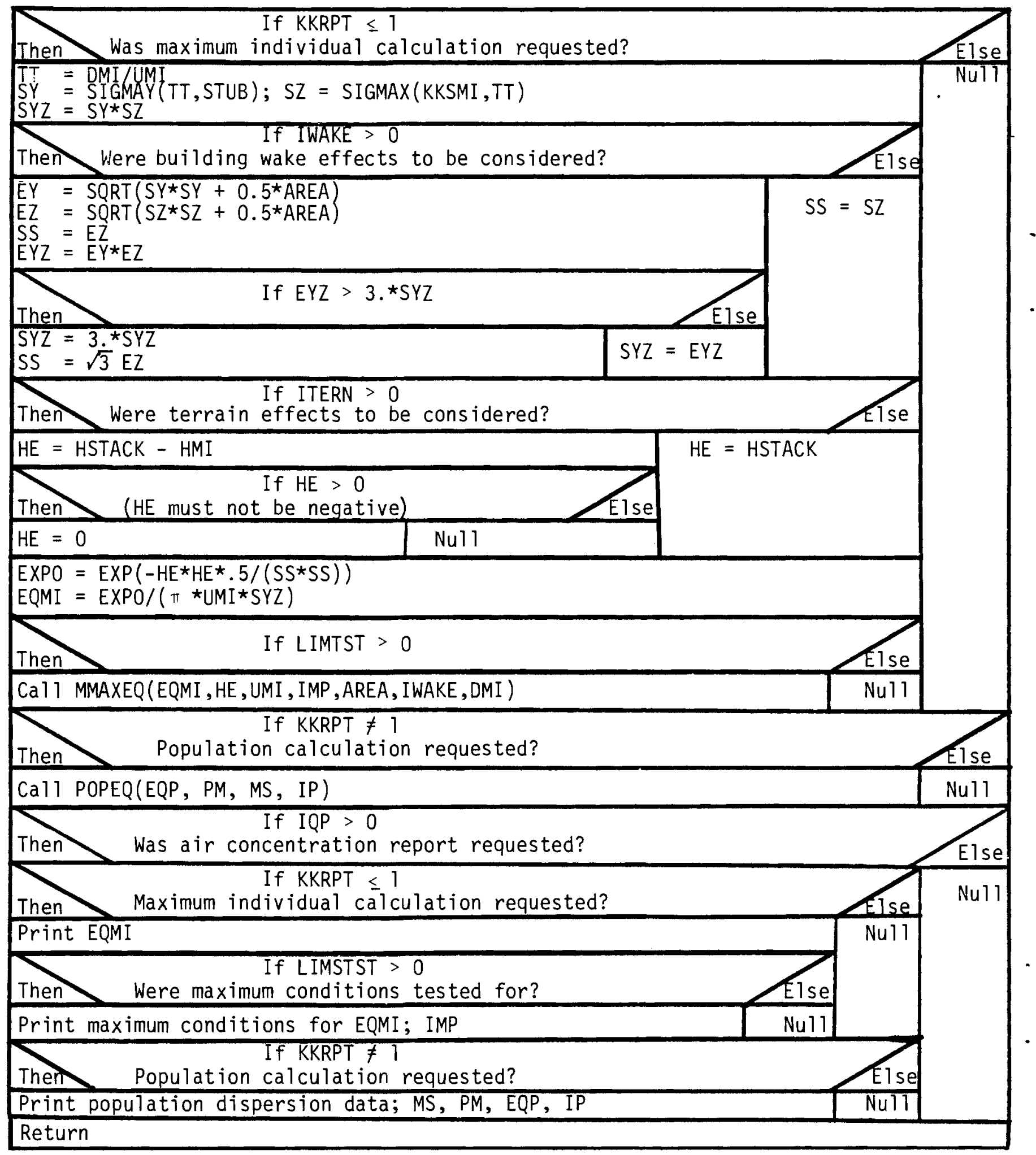

FIGURE A.3-6. Logic Diagram for Module DISPRS 


\begin{tabular}{|c|c|}
\hline If $K K R P T \leq 1$ & \\
\hline Print TITLEI and DAIT on new page & \multirow[t]{10}{*}{ Nu11 } \\
\hline Print "Maximum Individual Dose Commitments (REM)" & \\
\hline Print column headings & \\
\hline Print "air submersion" heading and dose DMET, DMET & \\
\hline Print "inhalation" heading and dose: $\operatorname{DMOT}(1, i), \operatorname{DMOT}(2, i), i=1$, NORG & \\
\hline \multirow{3}{*}{$\begin{array}{l}\text { Do for I0 }=1 \text {, NORG (organs) } \\
\qquad \begin{array}{l}\text { TOT }(1, I 0)=\text { DMOT }(1, \text { IO })+\text { DMET } \\
\text { TOT }(2, I 0)=\operatorname{DMOT}(2, I 0)+D M E T\end{array} \\
\text { Print total dose heading }\end{array}$} & \\
\hline & \\
\hline & \\
\hline \multirow{2}{*}{$\begin{array}{l}\text { Do for } \mathrm{IO}=1 \text {, NORG (organs) } \\
\qquad \text { Print ORGT(I0), TOT }(1, \mathrm{IO}), \operatorname{TOT}(2, \mathrm{IO})\end{array}$} & \\
\hline & \\
\hline \multicolumn{2}{|l|}{ If $\quad$ KKRPT $\neq 1$} \\
\hline Print TITLEI and DAIT on new page & \multirow[t]{10}{*}{ Nul1 } \\
\hline Print "Population Dose Conmitments (MAN-REM)" & \\
\hline Print column headings & \\
\hline Print "air submersion" heading and DPET, DPET & \\
\hline Print "Inhalation" heading and dose $\operatorname{DPOT}(1, i), \operatorname{DPOT}(2, i), i=1, \operatorname{NORG}$ & \\
\hline Do for IO $=1$, NORG (organs) & \\
\hline $\begin{array}{l}\operatorname{TOT}(1, \mathrm{IO})=\operatorname{DPOT}(1, \mathrm{IO})+\mathrm{DPET} \\
\mathrm{TOT}(2, \mathrm{IO})=\operatorname{DPOT}(2, \mathrm{IO})+\mathrm{DPET}\end{array}$ & \\
\hline Print total dose heading & \\
\hline Do for IO $=1$, NORG (organs) & \\
\hline Print ORGT(I0), TOT $(1,10), \operatorname{TOT}(2,10)$ & \\
\hline \multirow{2}{*}{\multicolumn{2}{|c|}{ Return }} \\
\hline & \\
\hline & \\
\hline
\end{tabular}

FIGURE A.3-7. Logic Diagram for Module DOSRPT 


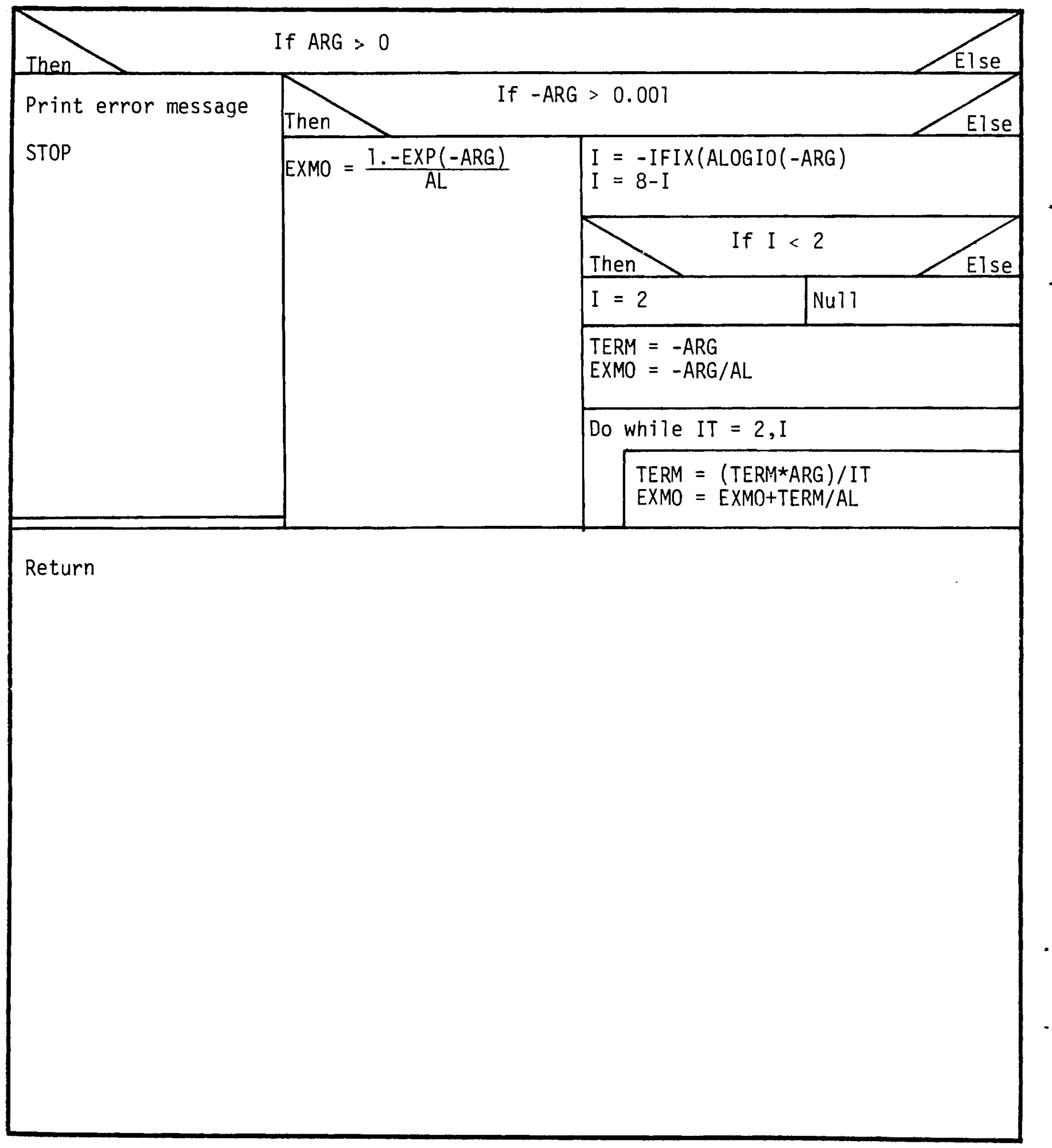

FIGURE A.3-8. Logic Diagram for Module EXMO 


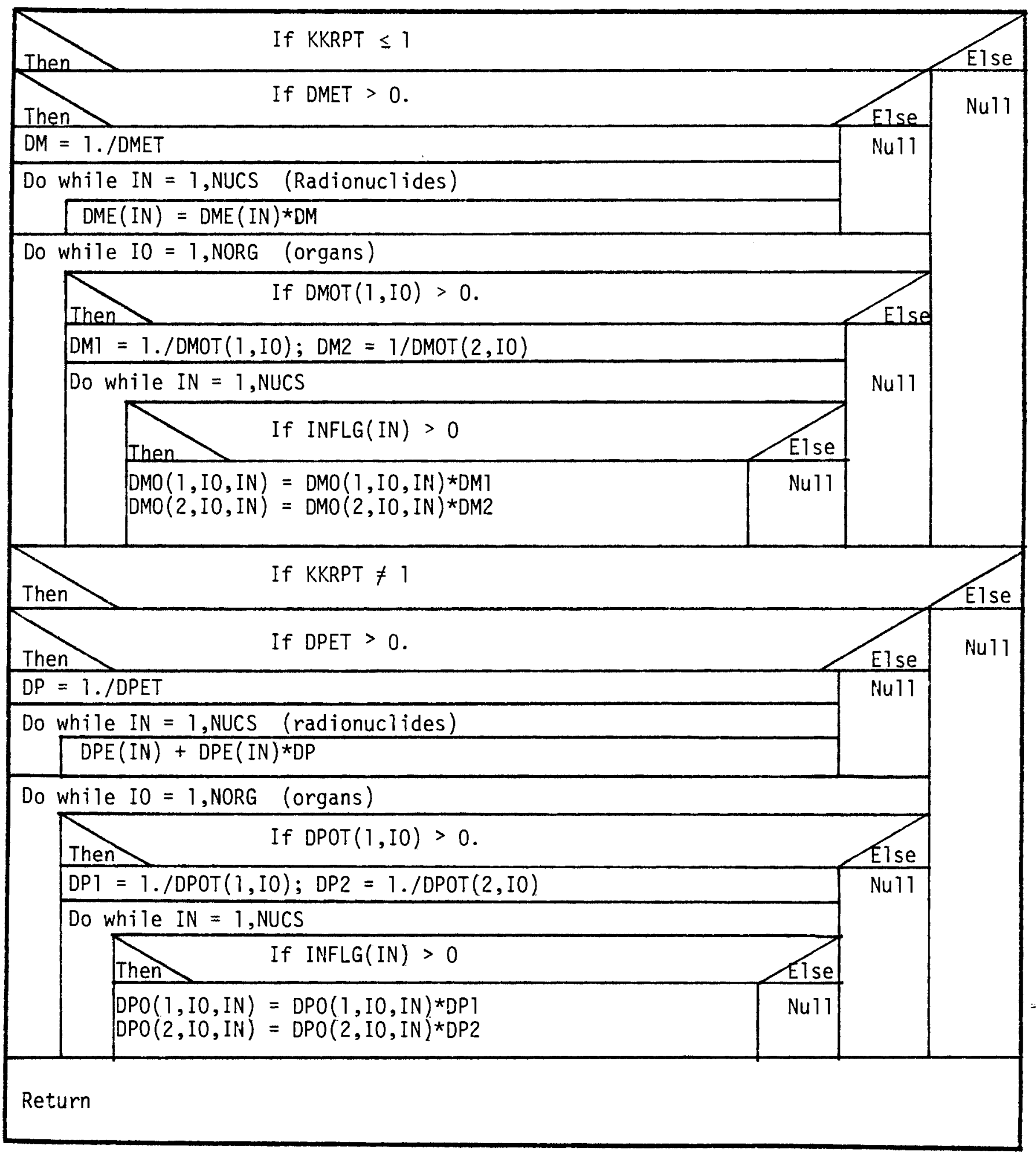

FIGURE A.3-9. Logic Diagram for Module FRDOSE 


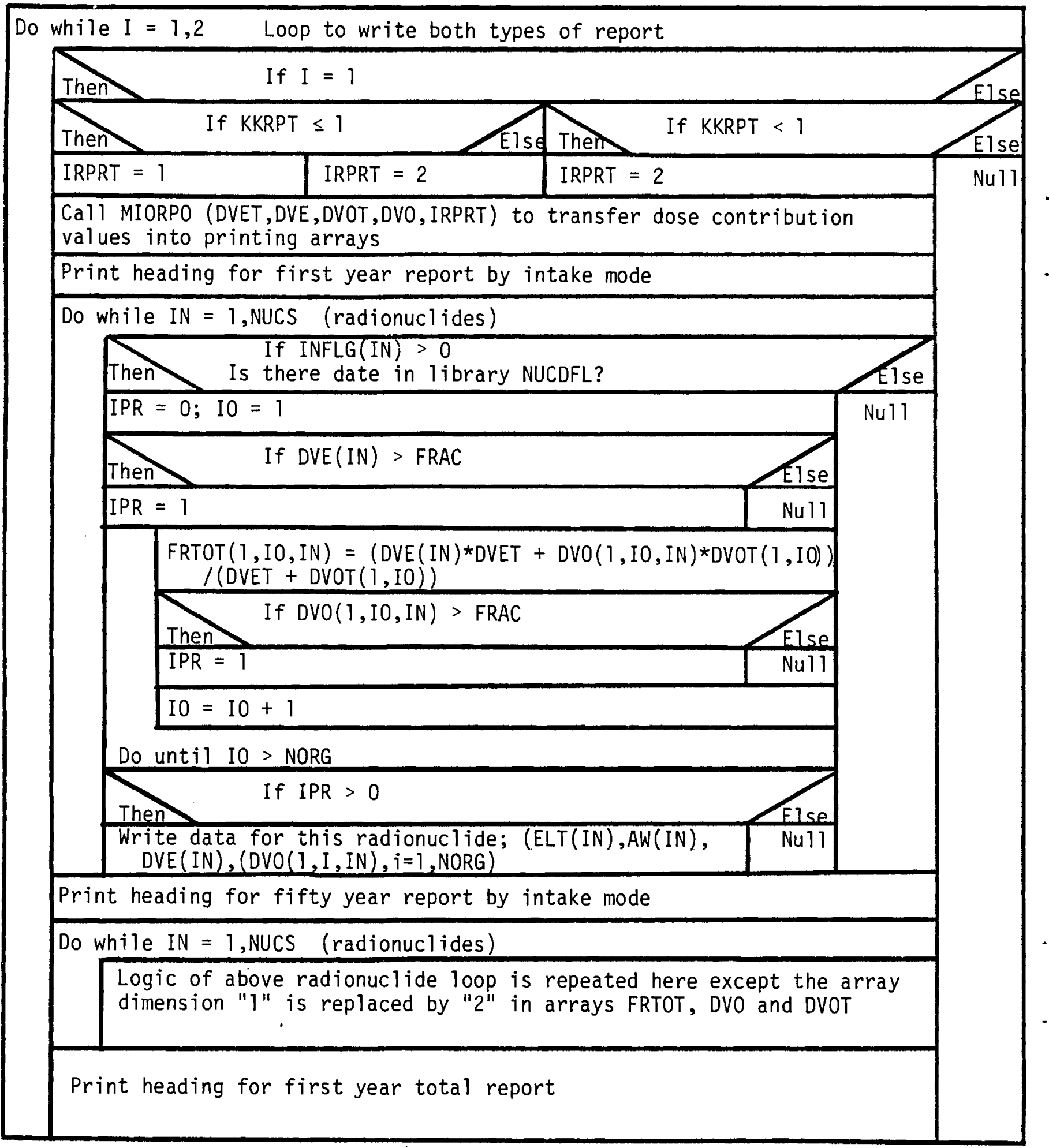

FIGURE A.3-10. Logic Diagram for Module FRDRPT 


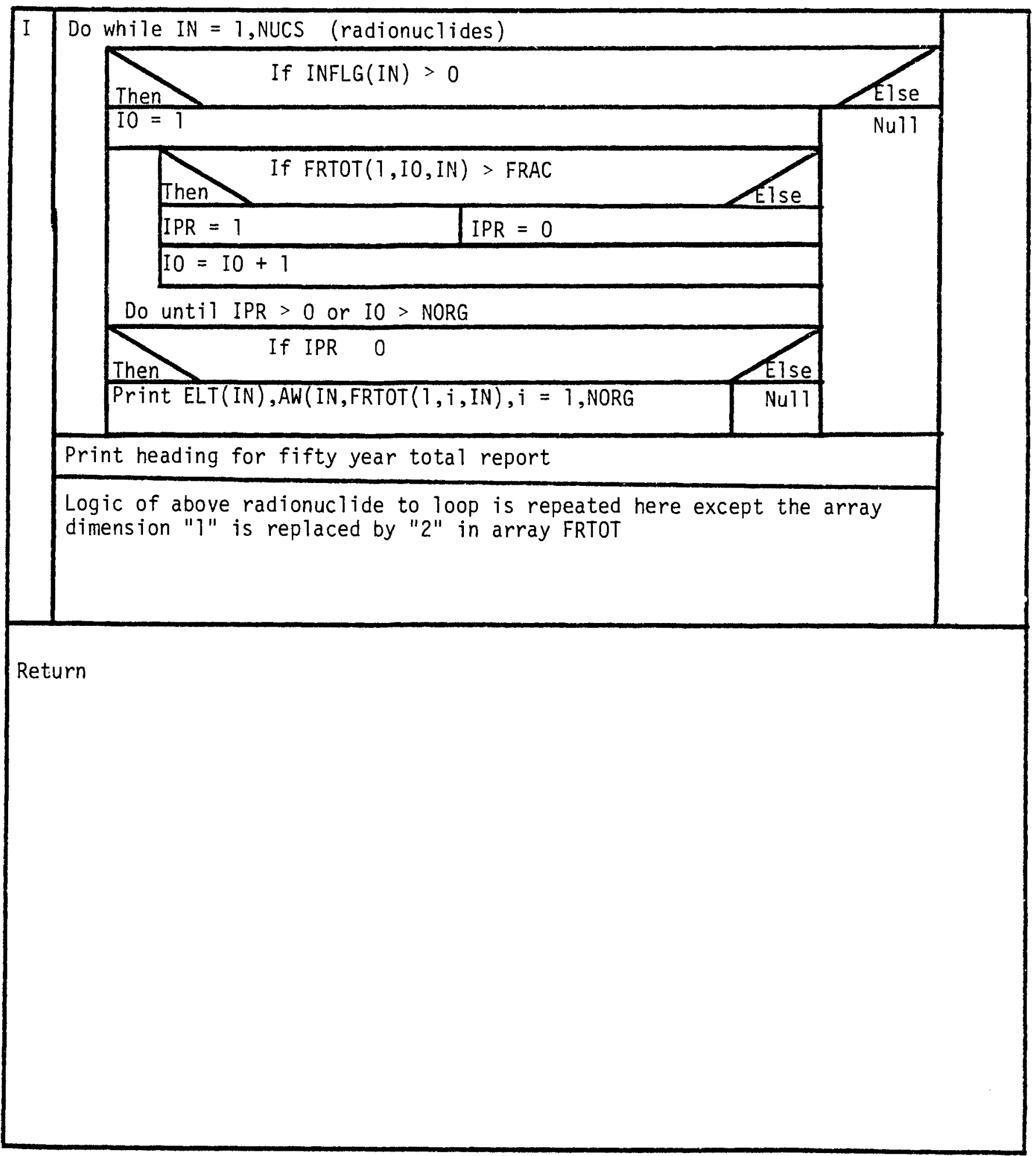

FIGURE A.3-10. (Cont'd) 


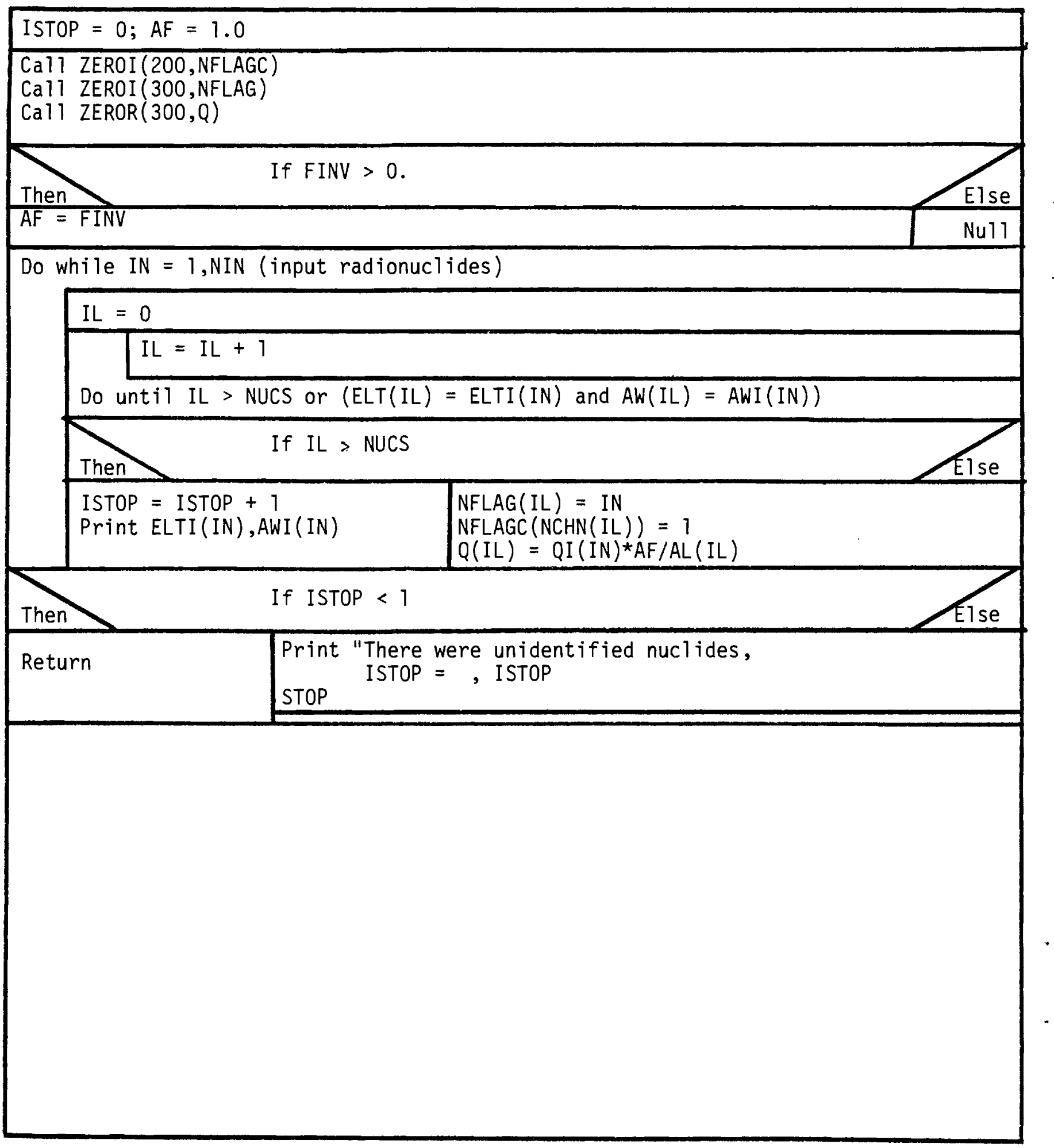

FIGURE A.3-11. Logic Diagram for Module IDNUC 


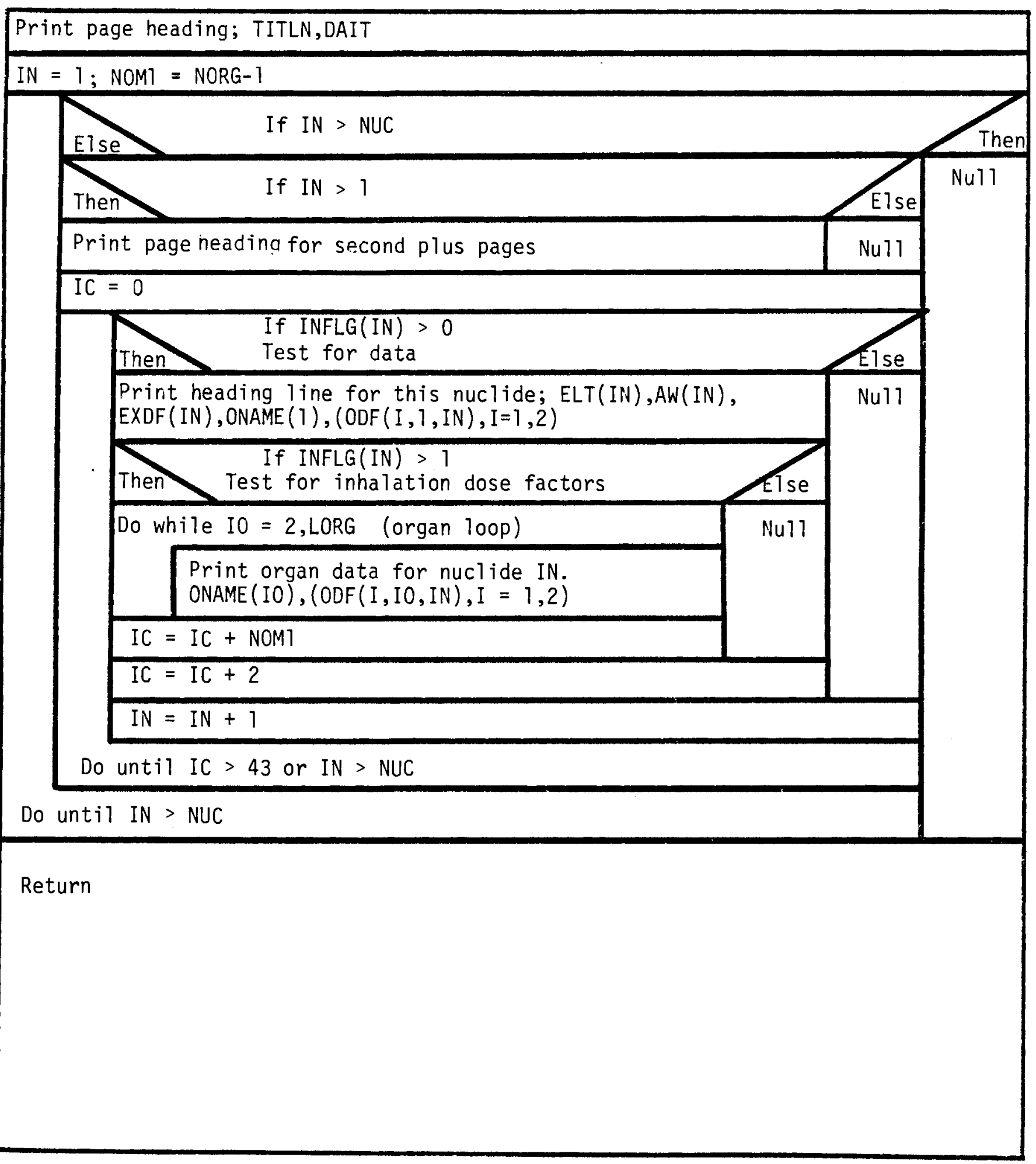

FIGURE A.3-12. Logic Diagram for Module LIBRPT 
Ca11 ZEROR (300,DME); DMET $=0$.

Cal1 ZEROR (3000,DMO)

Cal1 ZEROR(10,DMOT)

$T=$ DMITUMI

Cal1 TRNSIT(T)

INUC $=0$

Do while IC $=1, \mathrm{NCH}$ (decay chains)

$\mathrm{J}=\operatorname{NOFNUC}(\mathrm{IC})$

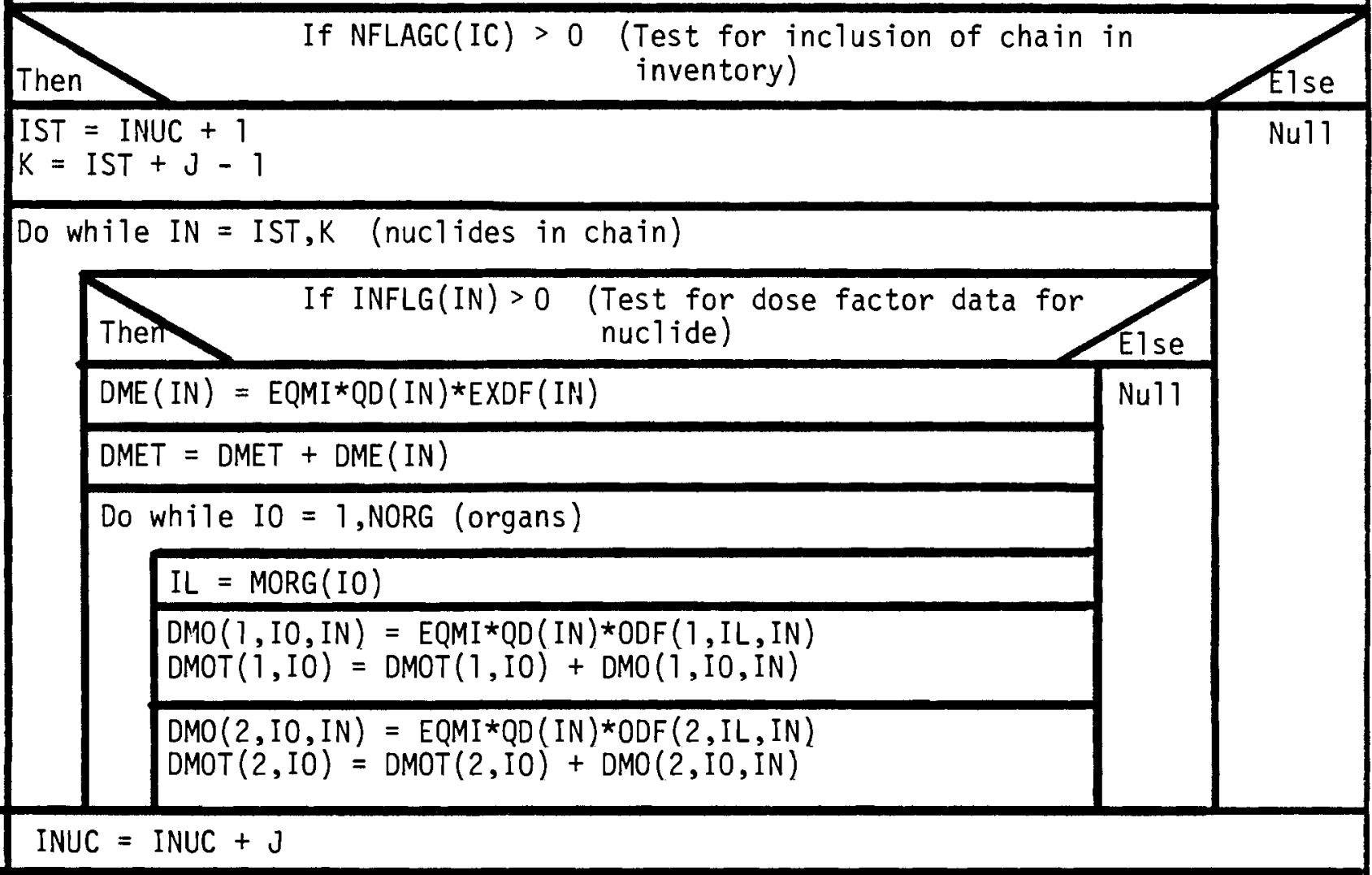

Return

FIGURE A.3-13. Logic Diagram for Module MIDOSE 


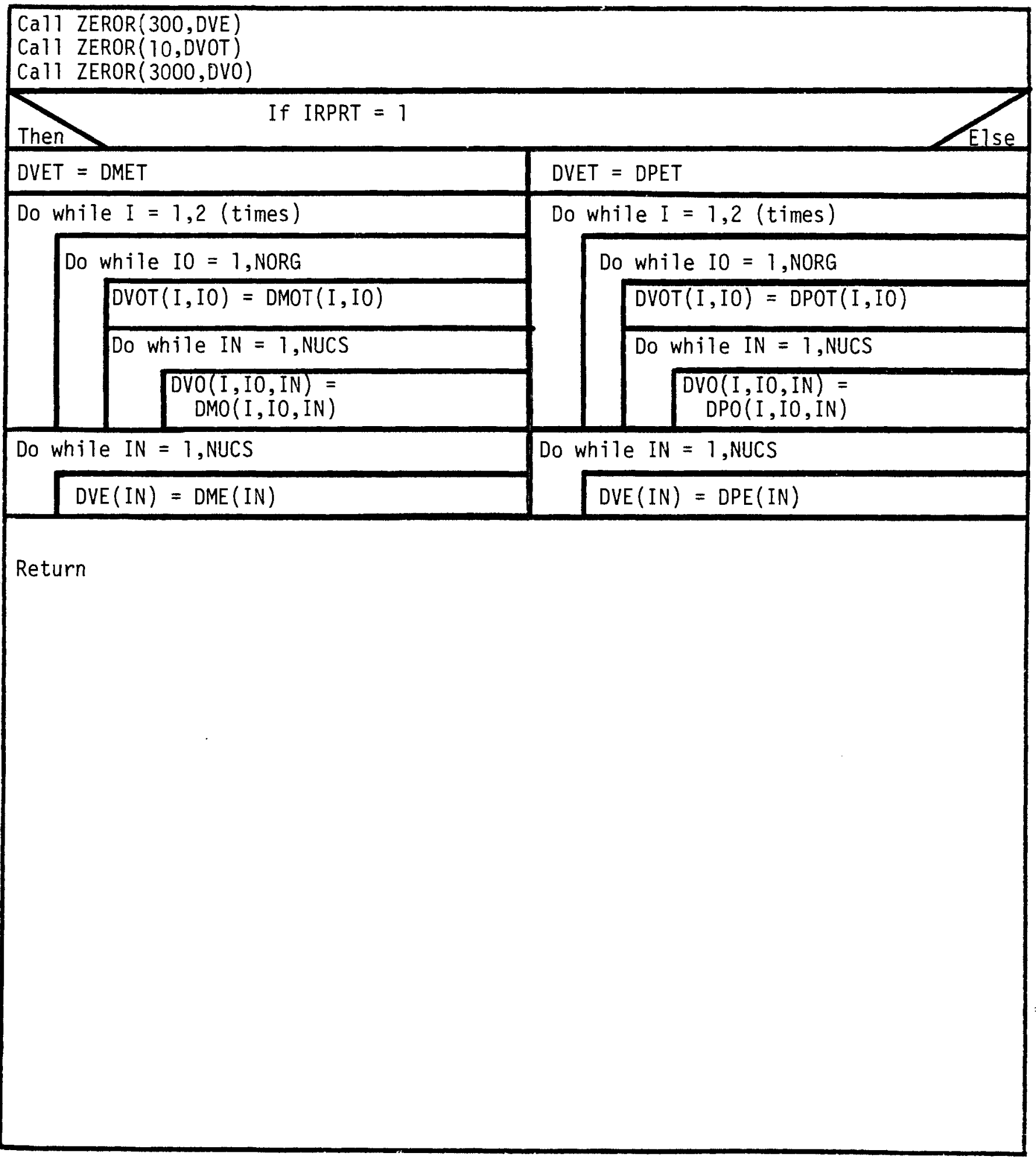

FIGURE A.3-14. Logic Diagram for Modu Te MIORPO 


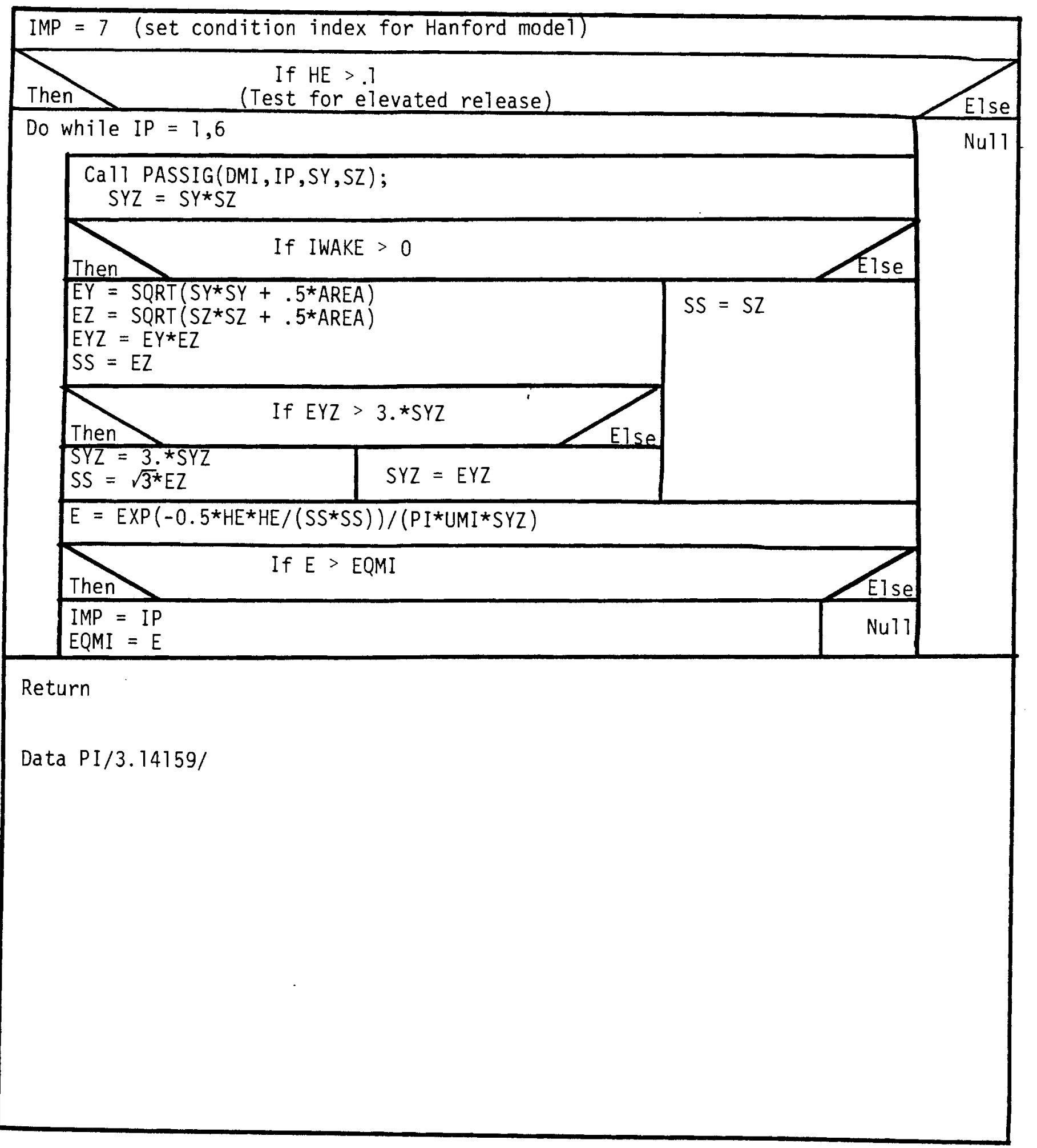

FIGURE A.3-15. Logic Diagram for Module MMAXEQ 
Ca11 ADATE(DAIT, XX) Get current date

Read first cards of data library, NU

CaIT ZEROR(6000,00F)

Ca 11 ZEROR $(300$, EXDF)

Ca 11 ZEROI (300, INFLG)

Do while $I=1, N U$ (number of radionuclides in data library NUCDFL)

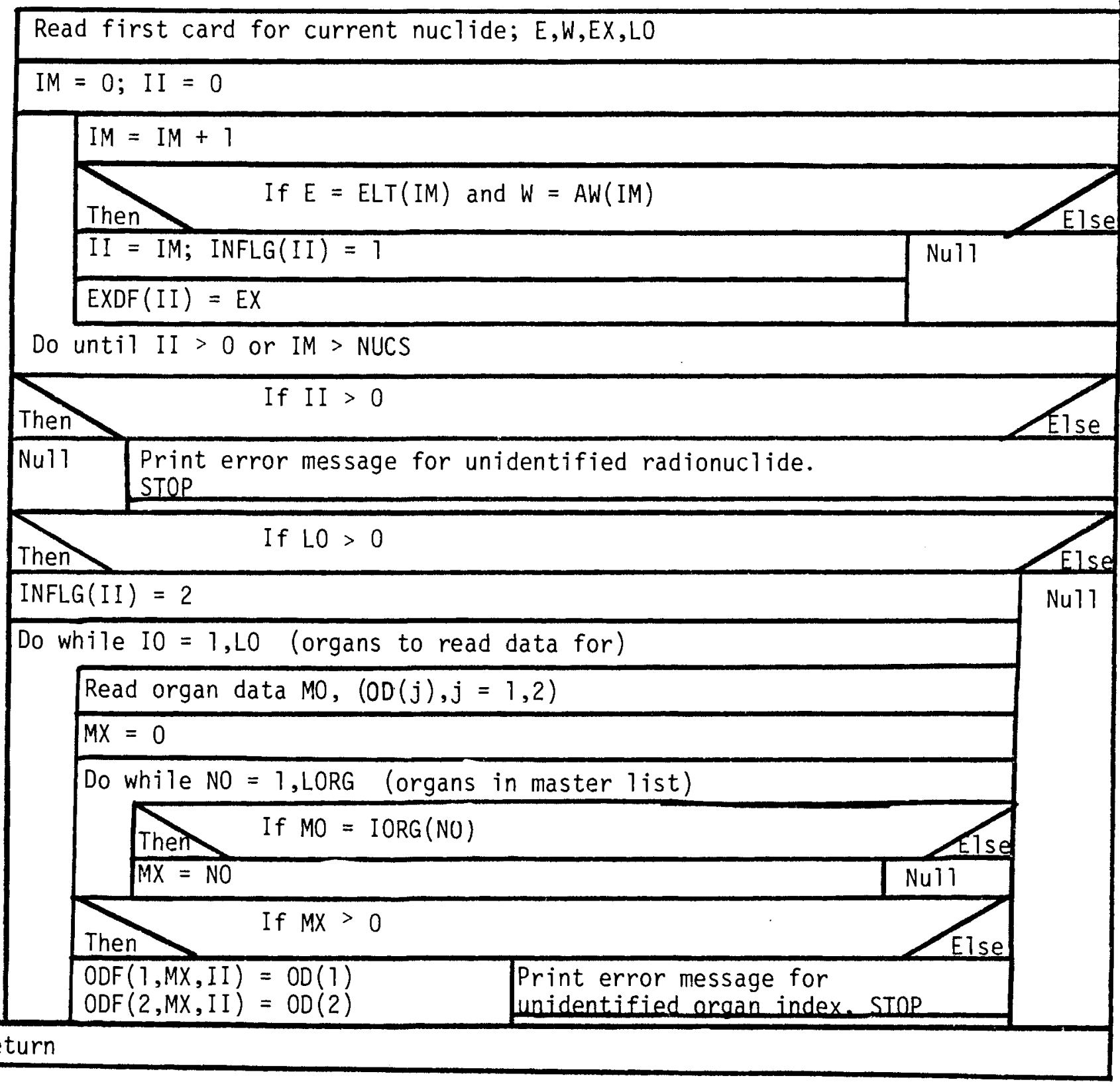

FIGURE A.3-16. Logic Diagram for Module NLIBIN 


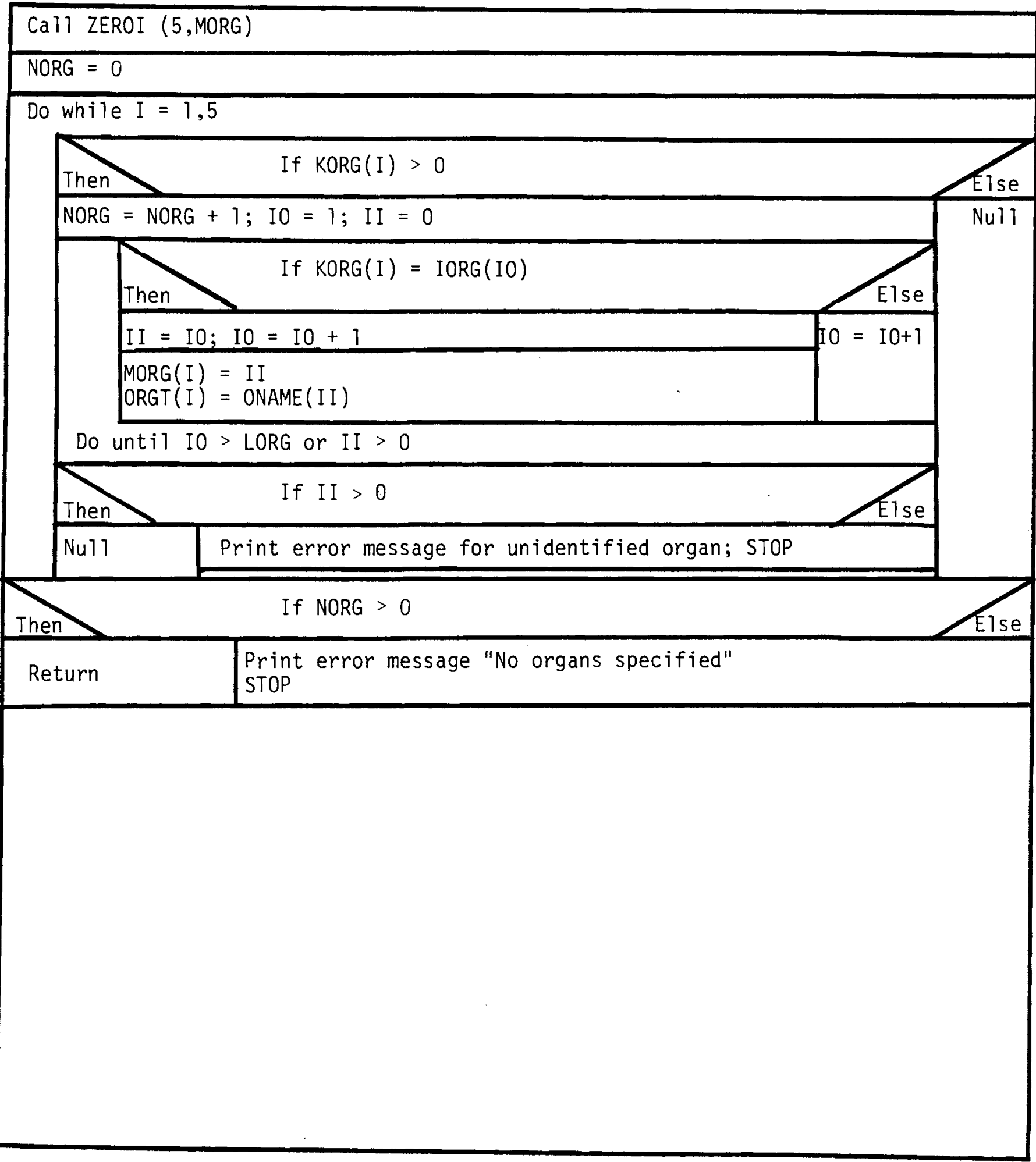

FIGURE A.3-17. Logic Diagram for Module ORGCHK 


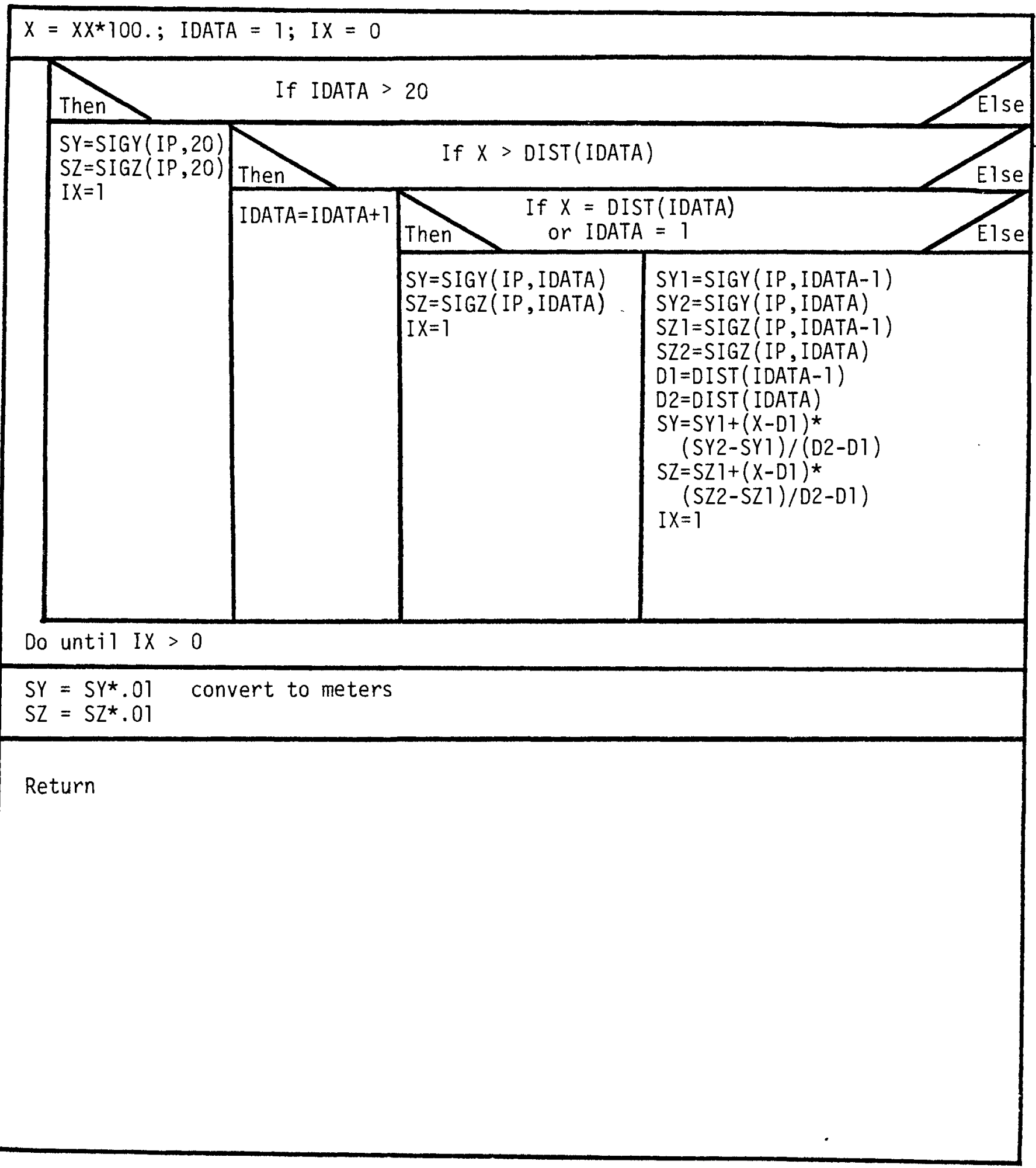

FIGURE A.3-18. Logic Diagram for Module PASSIG 


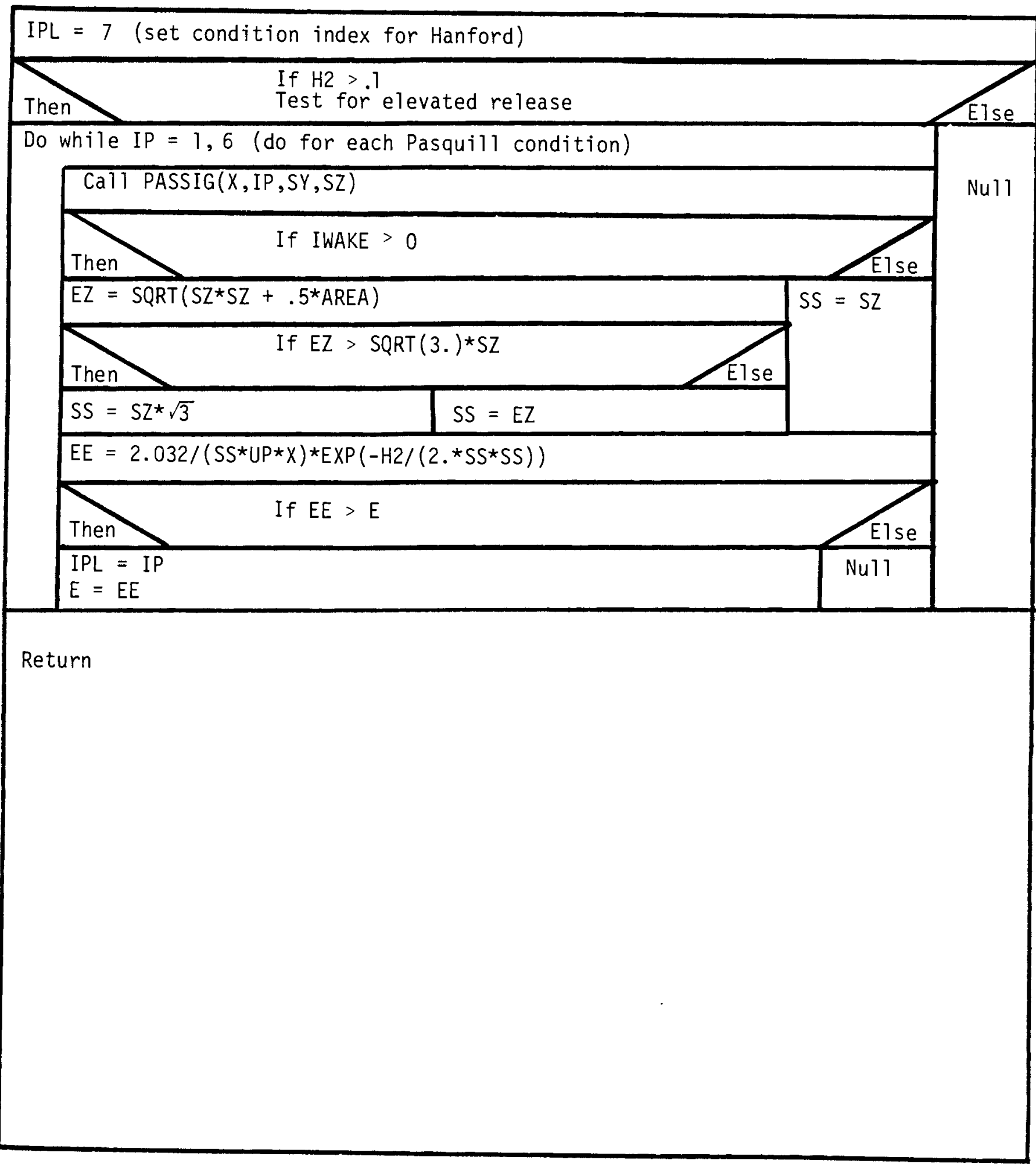

FIGURE A.3-19. Logic Diagram for Module PMAXEQ 


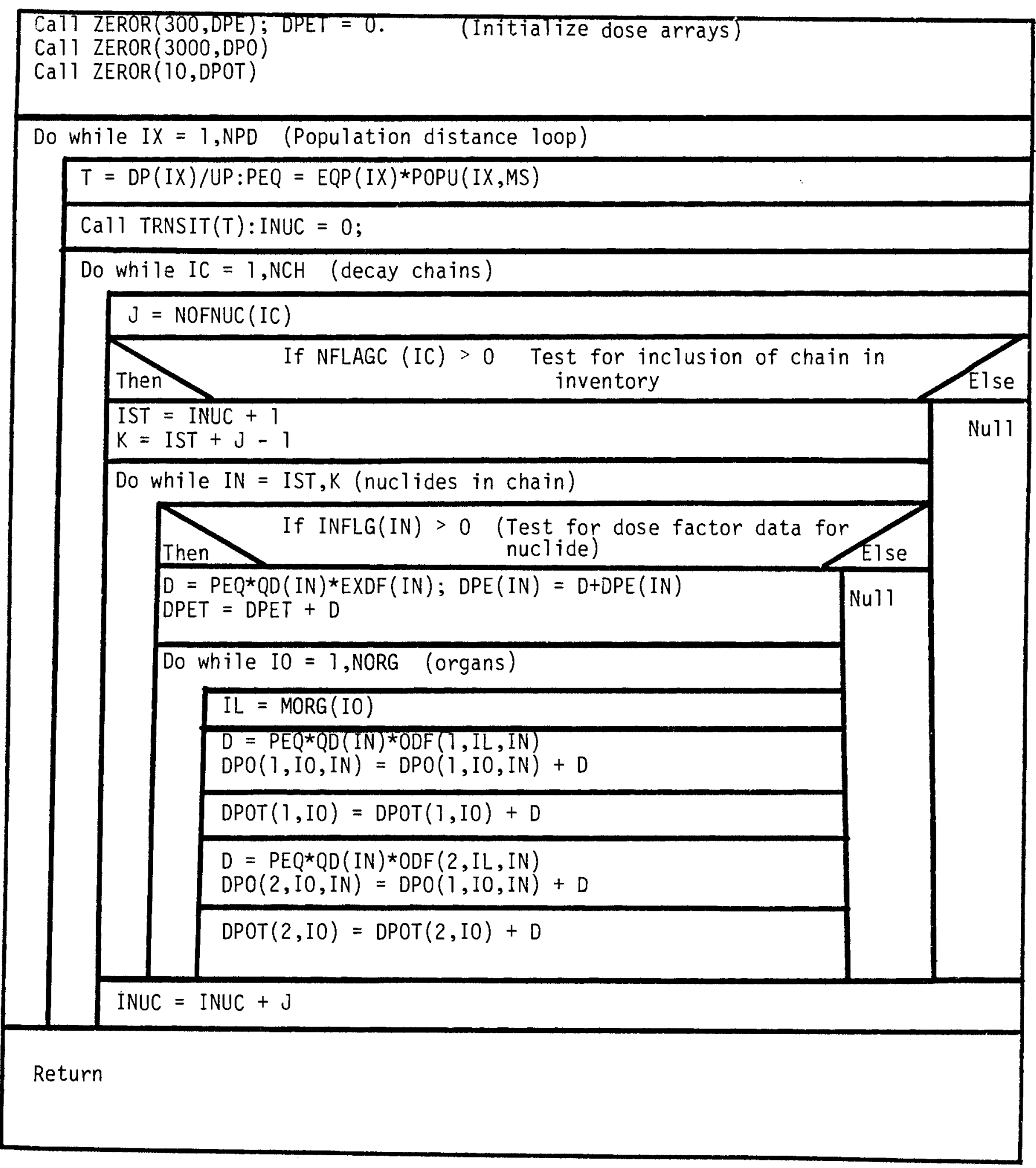

FIGURE A.3-20. Logic Diagram for Module POPDOS 


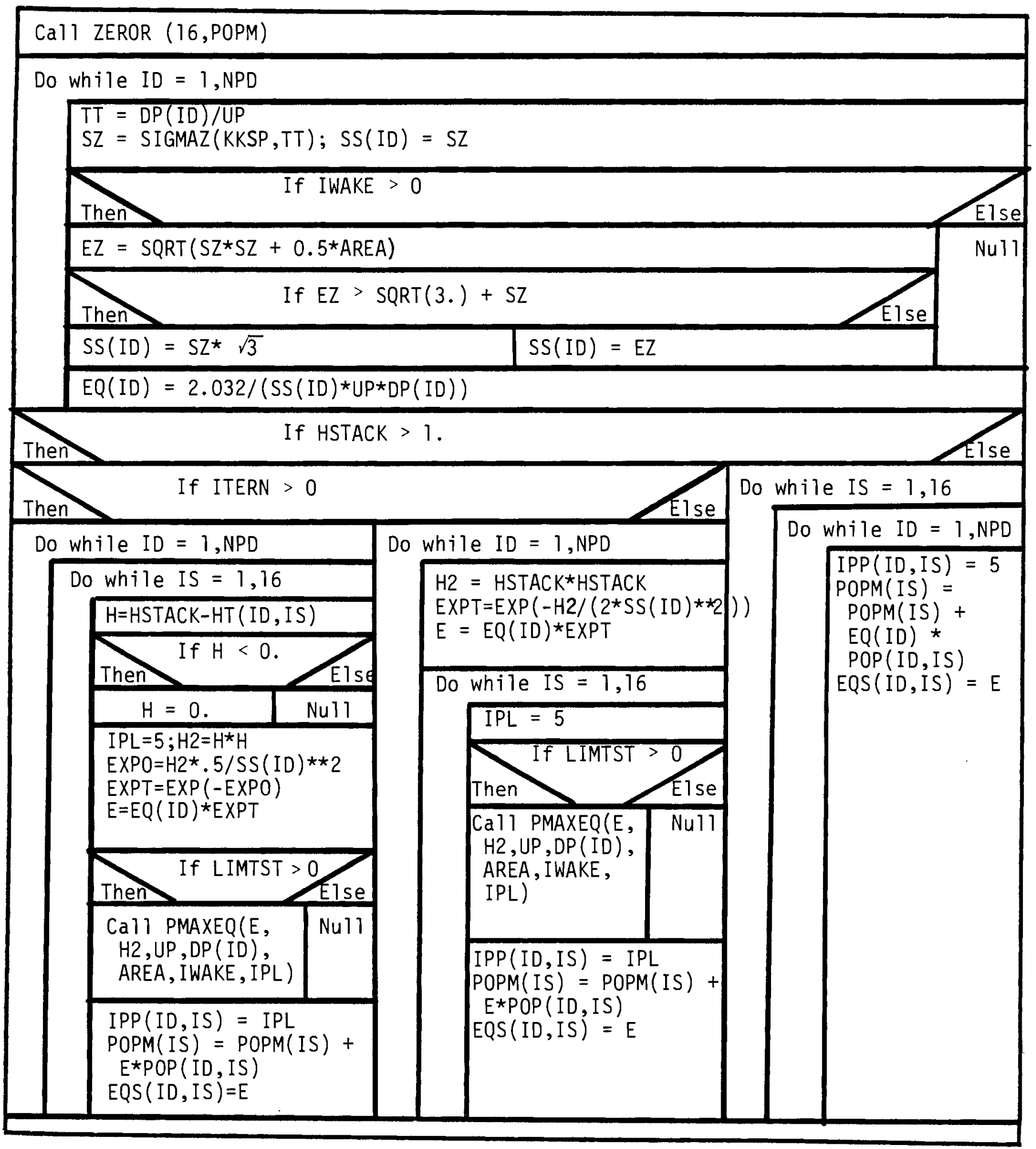

FIGURE A.3-21. Logic Diagram for Module POPEQ 


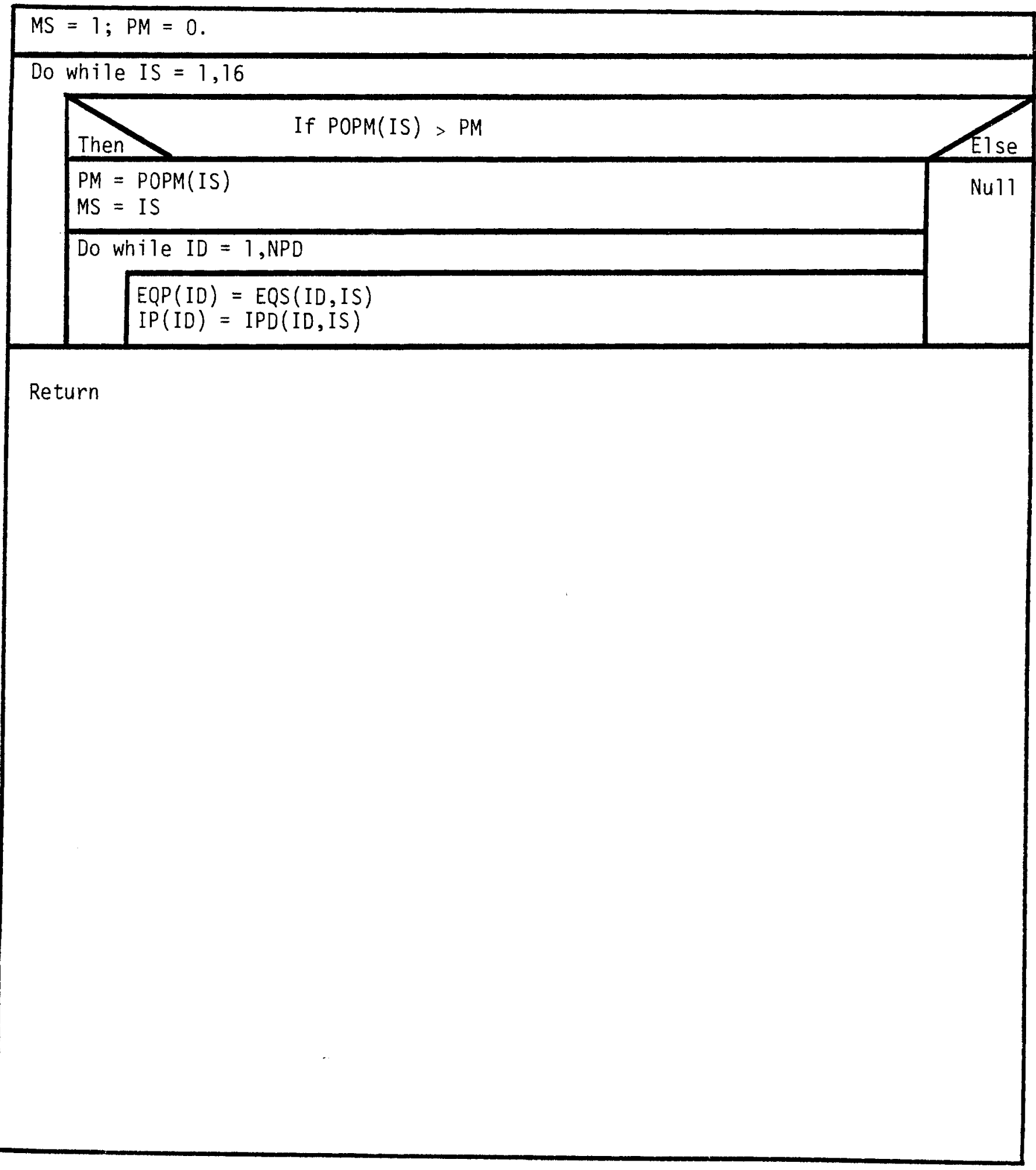

FIGURE A.3-21. (Cont'd) 


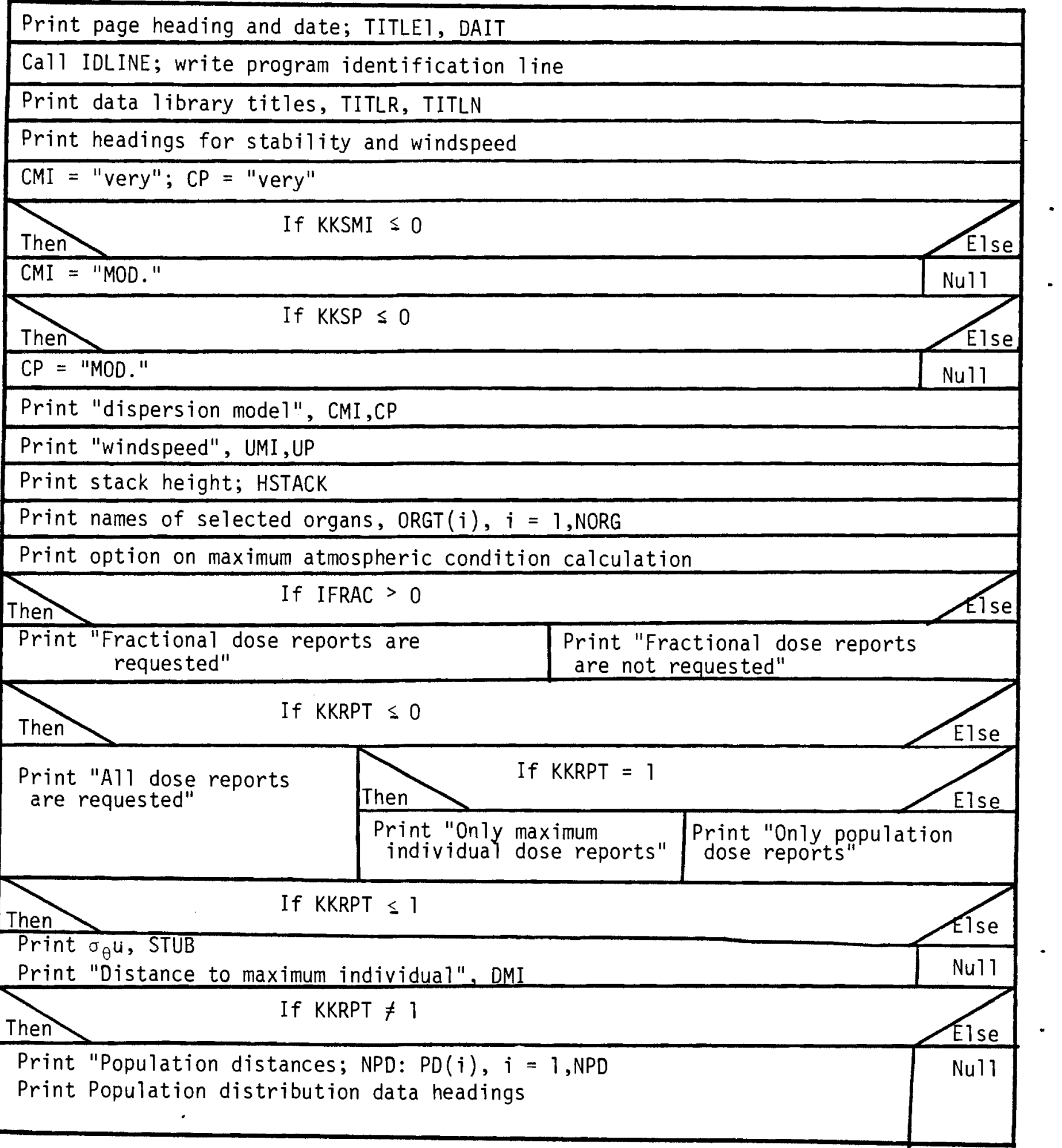

FIGURE A.3-22. Logic Diagram for Module QAPAGE 


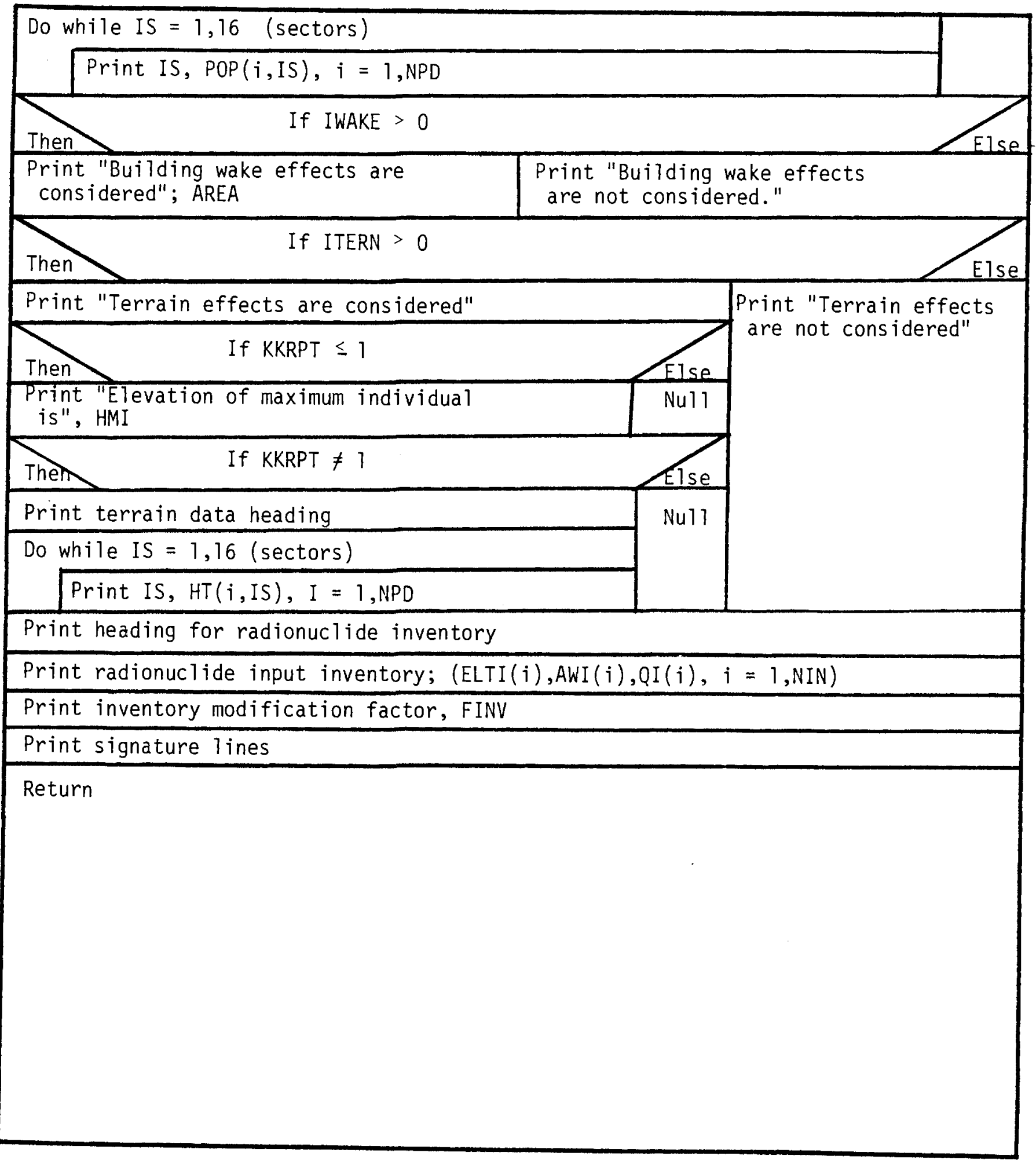

FIGURE A.3-22. (Cont'd) 


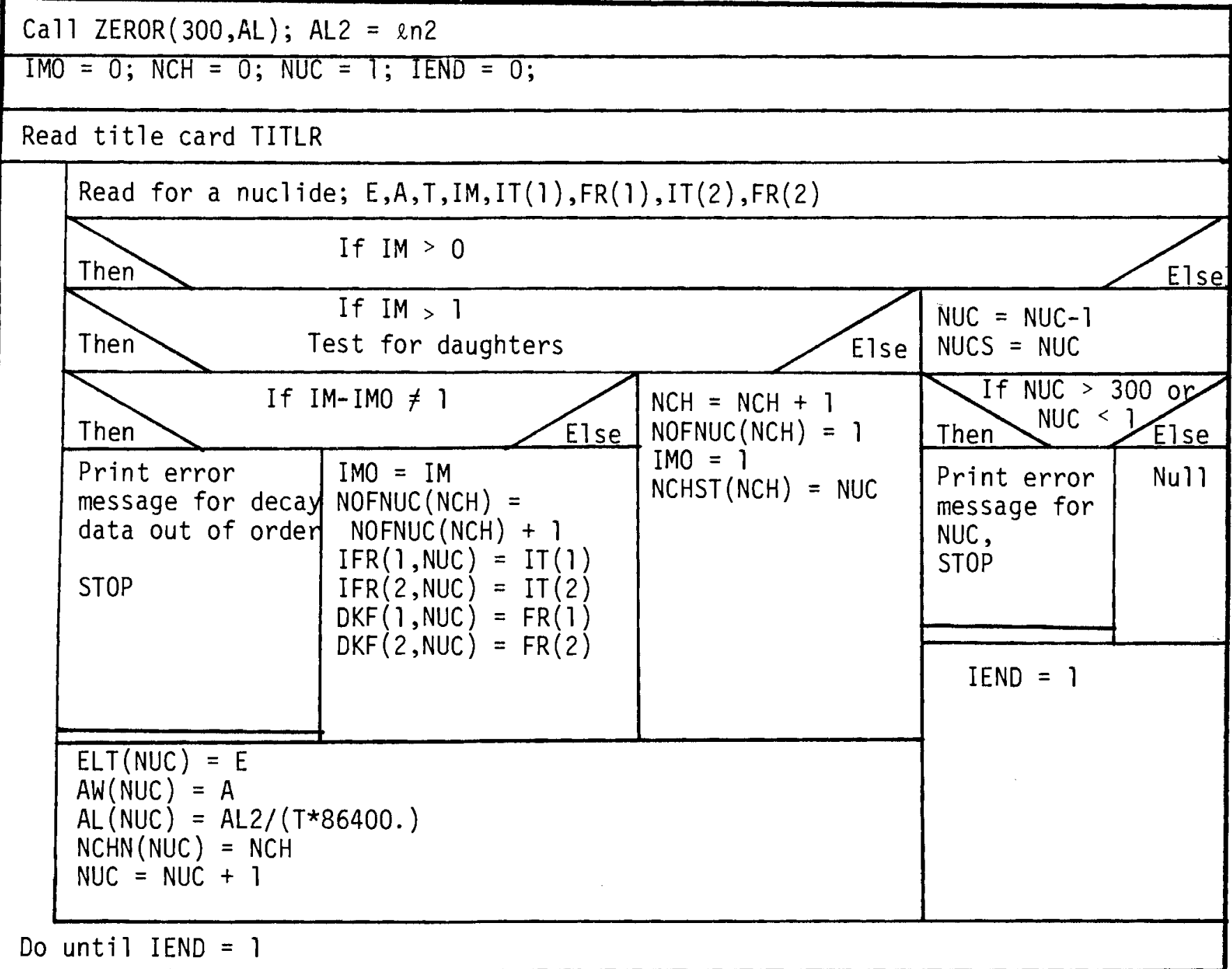

Return

FIGURE A.3-23. Logic Diagram for Module RLIBIN 


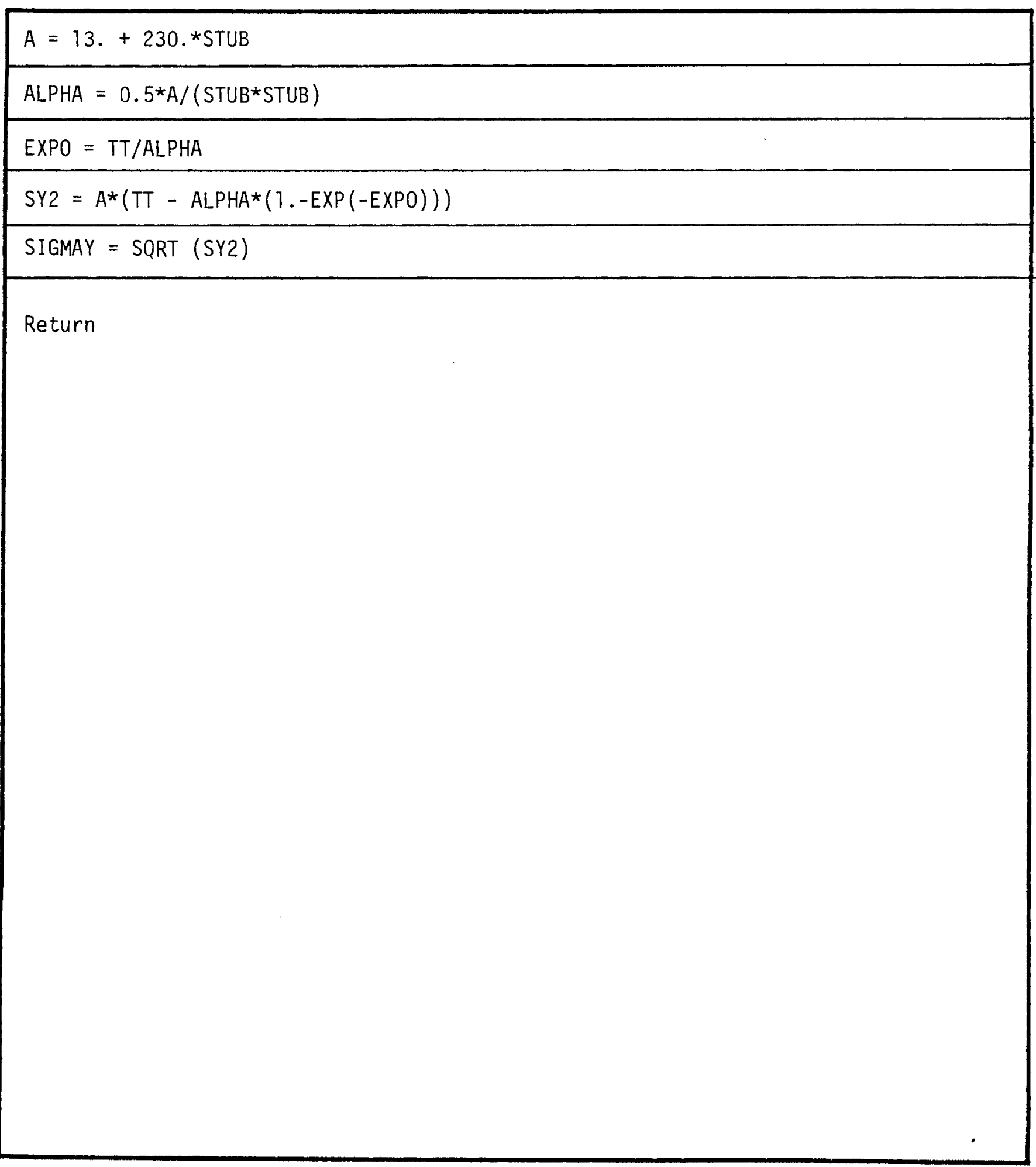

FIGURE A.3-24. Logic Diagram for Module SIGMAY 


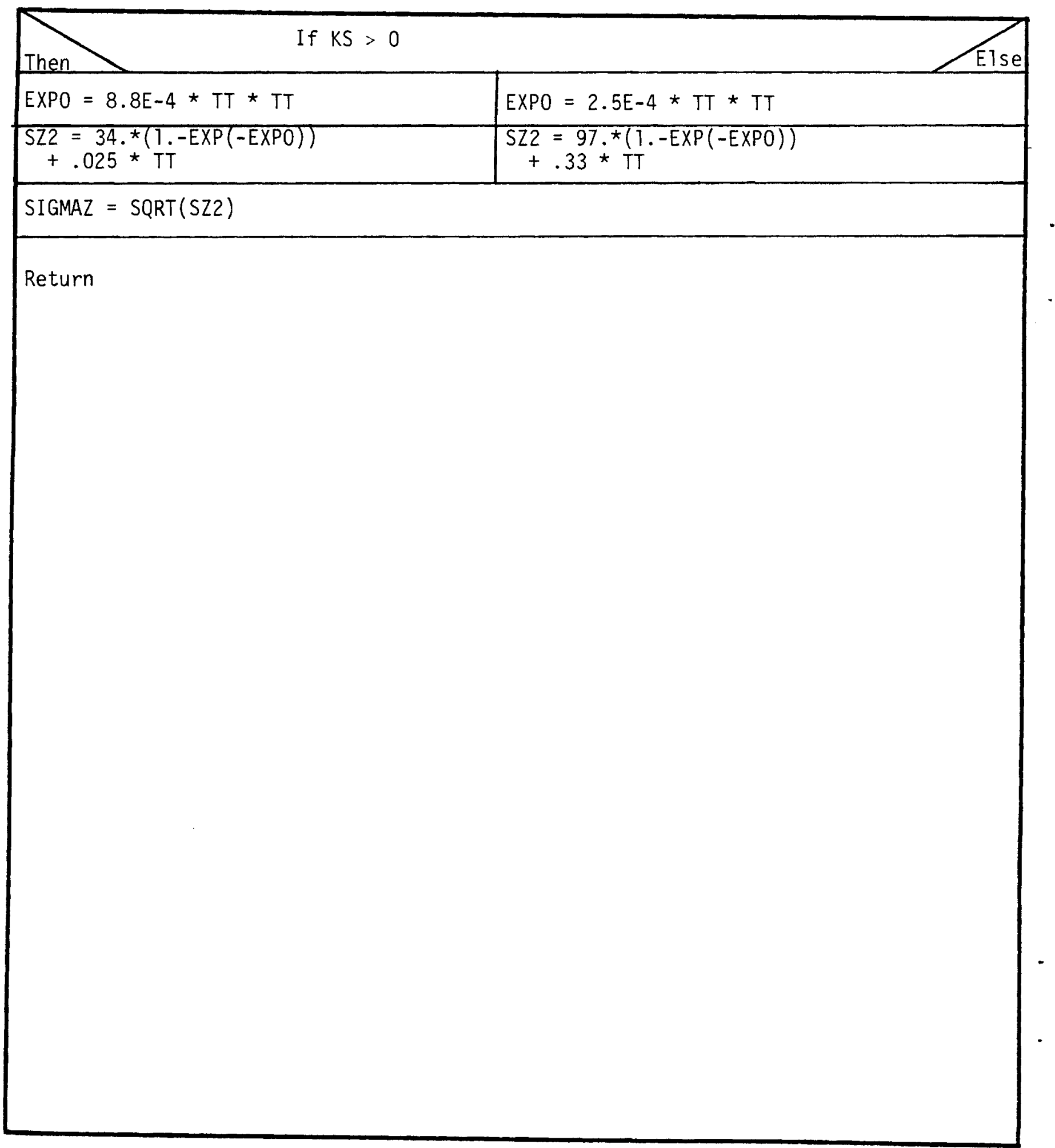

FIGURE A.3-25. Logic Diagram for Modu le SIGMAZ 
SUMPRD $=0$

Do while $I=1, \mathrm{~J}$ loop on terms

SUMPRD $=$ SUMPRD $+A(I) * B(I)$

Return

FIGURE A.3-26. Logic Diagram for Modu Te SUMPRD 


$$
\text { INUC }=0
$$

Do while IC $=1, \mathrm{NCH}$ (number of chains)

\begin{tabular}{|l|} 
Ifen \\
IST NOFNUC(IC) \\
IST INUC +1 \\
$K=$ IST $+J-1$
\end{tabular}

Return

EIGURE A.3-27. Logic Diagram for Module TRNSIT 


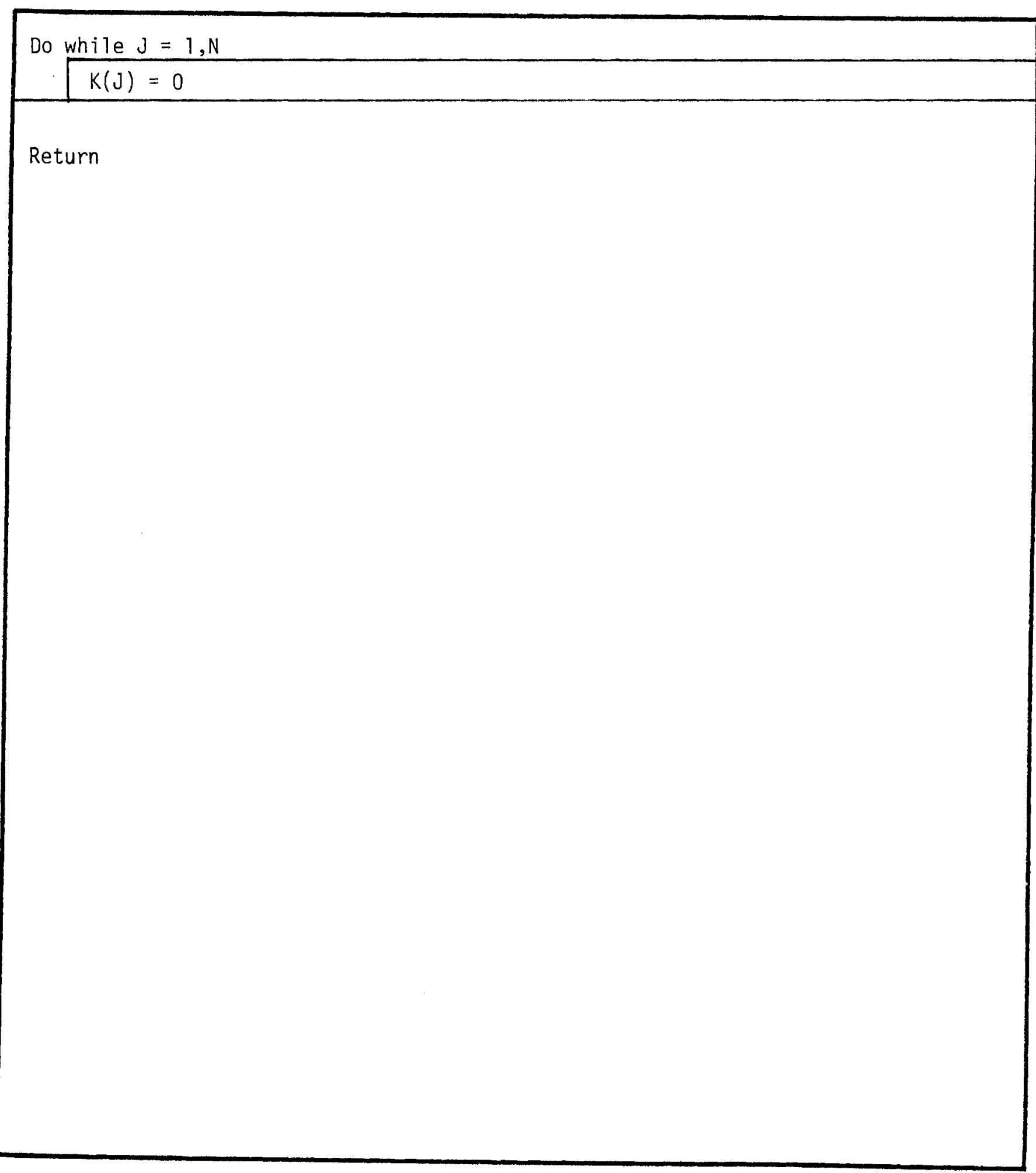

FIGURE A.3-28. Logic Diagram for Module ZEROI

$$
\text { A.71 }
$$




$$
\begin{gathered}
\text { Do while } N=1, N \\
A(J)=0 .
\end{gathered}
$$

Return

FIGURE A.3-29. Logic Diagram for Module ZEROR 
APPENDIX B

COMMON BLOCK DESCRIPTIONS 


\section{APPENDIX B}

\section{COMMON BLOCK DESCRIPTIONS}

The computer code HADOC uses labeled common blocks for the majority of data transfers between modules. Table B.0-1 gives a summary of each common block and indicates the modules that use each block. A detailed description of the parameters in each common block is given in Tables B.0-2 through B. 0-16.

All common blocks are included in the main program module MAIN even though some are not referenced. This was done to facilitate variable checking during code conversion and testing. 
TABLE B.0-1. HADOC Conmon B lock Usage Surmmary

ACTVTY

Description: Released radionuclide activities

Used by: IDNUC, MAIN, MIDOSE, POPDOS, TRNSIT

AIRCON

Description: Time-integrated air concentration

Used by: DISPRS, MAIN, MIDOSE, POPDOS

DAY

Description: Day-of-year symbol

Used by: DOSRPT, FRDRPT, LIBRPT, MAIN, NLIBIN, QAPAGE

DECAY

Description: Decay parameters

Used by: IDNUC, MAIN, MIDOSE, NLIBIN, POPDOS, RLIBIN, TRNSIT

DISPSN

Description: Atmospheric dispersion model parameters

Used by: DISPRS, MAIN, MIDOSE, POPDOS, POPEQ, QAPAGE

DISTNC

Description: Exposure point locations

Used by: DISPRS, MAIN, MIDOSE, POPDOS, POPEQ, QAPAGE

DOSFAC

Description: Dose conversion factors

Used by: MAIN, MIDOSE, NLIBIN, POPDOS

DOSMI

Description: Maximum individual doses

Used by: DOSRPT, FRDOSE, MAIN, MIDOSE, MIORPO

DOSPOP

Description: Population doses

Used by DOSRPT, FRDOSE, MAIN, MIORPO, POPDOS

ELEVAT

Description: Terrain elevations

Used by: DISPRS, MAIN, POPEQ, QAPAGE 


\section{TABLE B.0-1. (Cont'd)}

FLAGS

Description Radionuclide usage flags

Used by FRDOSE, FRDRPT, IDNUC, MAIN, MIDOSE, NLIBIN, POPDOS

NAMES

Description: Master list radionuclide identification

Used by: $\quad$ FRDOSE, FRDRPT, IDNUC, LIBRPT, MAIN, MIORPO, NLIBIN, RLIBIN

ORGID

Description: Organ identification parameters

Used by: DOSRPT, FRDOSE, FRDRPT, MAIN, MIDOSE, MIORPO, NLIBIN, ORGCHK, POPDOS, QAPAGE

POPU

Description: Population distribution data

Used by: MAIN, POPDOS, POPEQ, QAPAGE

SOURCE

Description: Input radionuclide identification symbols

Used by: IDNUC, MAIN, QAPAGE 
TABLE B.0-2. Common B lock ACTVTY

\begin{tabular}{l|l|l}
$\begin{array}{l}\text { Symbol \& } \\
\text { Dimension }\end{array}$ & Type & \multicolumn{1}{|c}{ Problem Symbol/Definition/Values/Units } \\
\hline$Q(300)$ & Real & $\begin{array}{l}\text { Activity in release inventory for each radionuclide in } \\
\text { the master radionuclide list, curies. }\end{array}$ \\
$Q D(300)$ & Real & $\begin{array}{l}\text { Release activities corrected for decay in transit, } Q_{k}, \\
\text { curies. }\end{array}$
\end{tabular}

TABLE B.0-3. Common B Tock AIRCON

\begin{tabular}{|c|c|c|}
\hline $\begin{array}{l}\text { Symbol \& } \\
\text { Dimension }\end{array}$ & Type & Problem Symbol/Definition/Values/Units \\
\hline EQMI & Real & $\begin{array}{l}\text { Time integrated air concentration for the maximum } \\
\text { individual location }(E / Q) \mathrm{m}, \mathrm{sec} / \mathrm{m}^{3} \text {. }\end{array}$ \\
\hline PM & Real & $\begin{array}{l}\text { Time integrated air concentration times population, } \mathrm{PM}_{j} \text {, } \\
\operatorname{man}-\mathrm{sec} / \mathrm{m}^{3} \text {. }\end{array}$ \\
\hline $\operatorname{EQP}(10)$ & Real & $\begin{array}{l}\text { Time integrated air concentration at each population } \\
\text { distance in the direction of the maximum exposure sector } \\
(E / Q)_{s i}, \mathrm{sec} / \mathrm{m}^{3} \text {. }\end{array}$ \\
\hline MS & Int. & Index of the maximum population dose sector. \\
\hline
\end{tabular}

TABLE B.0-4. Common B lock DAY

\begin{tabular}{l|l|l}
\begin{tabular}{l|l} 
Symbol \& \\
Dimension
\end{tabular} & Type & Problem Symbol/Definition/Values/Units \\
\hline DAIT & Char. & $\begin{array}{l}\text { Eight character name for day of year, MMDDYY: } \\
\text { MM - month } \\
\text { DD - day } \\
\text { YY - year }\end{array}$
\end{tabular}


TABLE B.0-5. Common B lock DECAY

\begin{tabular}{|c|c|c|}
\hline $\begin{array}{l}\text { Symbol \& } \\
\text { Dimension }\end{array}$ & Type & Problem Symbol/Definition/Values/Units \\
\hline NUC & Int. & $\begin{array}{l}\text { Number of radionuclides in the master library, RMDLIB. } \\
1 \leq N U C \leq 300 \text {. }\end{array}$ \\
\hline $\mathrm{NCH}$ & Int. & $\begin{array}{l}\text { Number of decay chains in the master library, RMDLIB. } \\
1 \leq N C H \leq 200 \text {. }\end{array}$ \\
\hline NOFNUC (200) & Int. & $\begin{array}{l}\text { Number of radionuclides in each decay chain. } \\
1 \leq \operatorname{NOFNUC}(i) \leq 9 \text {. When } \operatorname{NOFNUC}(i)=1 \text {, the radionuclide } \\
\text { has no daughters. }\end{array}$ \\
\hline NCHST (200) & Int. & $\begin{array}{l}\text { Location in the master radionuclide list of the first } \\
\text { member of a radionuclide chain. } 1 \leq \mathrm{NCHST}(i) \leq 300 \text {. }\end{array}$ \\
\hline $\operatorname{IFR}(2,300)$ & Int. & $\begin{array}{l}\operatorname{IFR}(1, i) \text { gives the chain member that is the first precursor } \\
\text { to radionuclide } i . \operatorname{IFR}(2, i) \text { gives the } 1 \text { ocation of the } \\
\text { second precursor. } \operatorname{IFR}(1, i)<\operatorname{IFR}(2, i)<\operatorname{IMEM}(i) \text {. }\end{array}$ \\
\hline $\operatorname{DKF}(2,300)$ & Int. & $\begin{array}{l}\text { Fraction of first and second precursor that decay to } \\
\text { this radionuclide. }\end{array}$ \\
\hline$A L(300)$ & Int. & $\begin{array}{l}\text { Radiological decay constant for each radionuclide, } \\
\sec ^{-1} \text {. }\end{array}$ \\
\hline $\operatorname{NCHN}(300)$ & Int. & Chain number that each radionuclide is a member of. \\
\hline
\end{tabular}


TABLE B.0-6. Common B lock DISPSN

\begin{tabular}{|c|c|c|}
\hline $\begin{array}{l}\text { Symbol \& } \\
\text { Dimension }\end{array}$ & Type & Problem Symbol/Definition/Values/Units \\
\hline UMI & Rea 1 & $\begin{array}{l}\text { Wind speed to be used for the maximum individual dose } \\
\text { calculation, } \bar{u}, \mathrm{~m} / \mathrm{sec} \text {. }\end{array}$ \\
\hline UP & Rea 1 & $\begin{array}{l}\text { Wind speed to be used for the population dose calculation, } \\
\bar{u}, \mathrm{~m} / \mathrm{sec} \text {. }\end{array}$ \\
\hline AREA & Real & $\begin{array}{l}\text { Minimum building cross sectional area for the building } \\
\text { wake model }, \mathrm{A}, \mathrm{m}^{2} \text {. }\end{array}$ \\
\hline KKSMI & Int. & $\begin{array}{l}\text { Indicator for the dispersion model to be used for the } \\
\text { maximum individual air concentration calculation. } \\
\text { KKSMI } \leq 0 \text { for Hanford moderately stable } \\
\text { KKSMI } \geq 1 \text { for Hanford very stable }\end{array}$ \\
\hline KKSP & Int. & $\begin{array}{l}\text { Indicator for the dispersion model to be used for the } \\
\text { population air concentration calculation } \\
\text { KKSP } \leq 0 \text { for Hanford moderately stable } \\
\text { KKSP } \geq 1 \text { for Hanford very stable }\end{array}$ \\
\hline STUB & Rea 1 & $\begin{array}{l}\text { Value for } \sigma_{\theta} \bar{u} \text { to be used for the maximum individual } \\
\text { dispersion calculation. }\end{array}$ \\
\hline ITERN & Int. & $\begin{array}{l}\text { Control integer to indicate if terrain effects are to } \\
\text { be considered. ITERN }>0 \text { to include terrain effects. }\end{array}$ \\
\hline IWAKE & Int. & $\begin{array}{l}\text { Control integer to indicate if building wake is to be } \\
\text { considered. IWAKE }>0 \text { to include wake effects. }\end{array}$ \\
\hline
\end{tabular}


TABLE B.0-7. Common B lock DISTNC

\begin{tabular}{|c|c|c|}
\hline $\begin{array}{l}\text { Symbol \& } \\
\text { Dimension }\end{array}$ & Type & Problem Symbol/Definition/Values/Units \\
\hline NPD & Int. & $\begin{array}{l}\text { Number of distances considered for the population dose } \\
\text { calculation. } \quad 1 \leq N P D \leq 10 \text {. }\end{array}$ \\
\hline $\mathrm{DP}(10)$ & Real & $\begin{array}{l}\text { Distances from the release point to the center of each } \\
\text { population ring, } x_{i}, m \text {. NPD values must be given in } \\
\text { increasing order. }\end{array}$ \\
\hline DMI & Real & $\begin{array}{l}\text { Distance from the release point to the location of the } \\
\text { maximum individual, } \mathrm{m} \text {. }\end{array}$ \\
\hline
\end{tabular}

TABLE B.0-8. Common B lock DOSFAC

\begin{tabular}{l|l|l}
$\begin{array}{l}\text { Symbol \& } \\
\text { Dimension }\end{array}$ & Type & \multicolumn{1}{|c}{ Problem Symbol/Definition/Values/Units } \\
\hline $\operatorname{EXDF}(300)$ & Real & $\begin{array}{l}\text { External dose conversion factors for air submersion for } \\
\text { each radionuclide, } \mathrm{D}_{\mathrm{k}}^{\mathrm{e}}, \mathrm{rem} \mathrm{per} \mathrm{Ci} \cdot \mathrm{sec} / \mathrm{m}^{3} .\end{array}$ \\
$\operatorname{ODF}(2,10,300)$ & Real & $\begin{array}{l}\text { Inhalation dose conversion factors for two time periods } \\
\text { ten organs and } 300 \text { radionuclides, } \mathrm{D}_{\mathrm{k} 0}^{i}, \mathrm{rem} \operatorname{per} \mathrm{Ci} \cdot \mathrm{sec} / \mathrm{m}^{3} .\end{array}$
\end{tabular}


TABLE B.0-9. Common B lock DOSMI

\begin{tabular}{|c|c|c|}
\hline $\begin{array}{l}\text { Symbol \& } \\
\text { Dimension }\end{array}$ & Type & Problem Symbol/Definition/Values/Units \\
\hline $\operatorname{DME}(300)$ & Real & $\begin{array}{l}\text { External dose to maximum individual for each radionuclide. } \\
\text { Also used for fractional dose storage, rem. }\end{array}$ \\
\hline DMET & Real & $\begin{array}{l}\text { Total dose from external radiation for the maximum } \\
\text { individual, } D_{\text {me }} \text {, rem. }\end{array}$ \\
\hline $\operatorname{DMO}(2,5,300)$ & Rea 1 & $\begin{array}{l}\text { Inhalation dose for two times, } 5 \text { organs and } 300 \text { radio- } \\
\text { nuclides for the maximum individual, rem. Also used for } \\
\text { fractional dose storage. }\end{array}$ \\
\hline $\operatorname{DMOT}(2,5)$ & Real & $\begin{array}{l}\text { Total dose to each organ ( } 2 \text { times) for maximum individual, } \\
D_{m o} \text {, rem }\end{array}$ \\
\hline
\end{tabular}

TABLE B.0-10. Common B lock DOSPOP

\begin{tabular}{|c|c|c|}
\hline $\begin{array}{l}\text { Symbol \& } \\
\text { Dimension }\end{array}$ & Type & Problem Symbol/Definition/Values/Units \\
\hline $\mathrm{DPE}(300)$ & Real & $\begin{array}{l}\text { External dose to the population for each radionuclide, } \\
\text { person-rem. Also used for fractional dose contribution } \\
\text { storage. }\end{array}$ \\
\hline DPET & Real & $\begin{array}{l}\text { Total dose to the population from external exposure, } D_{p e} \text {, } \\
\text { person-rem. }\end{array}$ \\
\hline $\mathrm{DPO}(2,5,300)$ & Rea 1 & $\begin{array}{l}\text { Population dose from inhalation for two time periods, } 5 \\
\text { organs and } 300 \text { radionuclides, person-rem. Also used } \\
\text { for fractional dose contribution storage. }\end{array}$ \\
\hline $\operatorname{DPOT}(2,5)$ & Real & $\begin{array}{l}\text { Total population dose from inhalation for two time periods } \\
\text { and } 5 \text { organs, } D_{p o} \text {, person-rem. }\end{array}$ \\
\hline
\end{tabular}


TABLE B.0-11. Common B lock ELEVAT

\begin{tabular}{|c|c|c|}
\hline $\begin{array}{l}\text { Symbol \& } \\
\text { Dimension }\end{array}$ & Type & Problem Symbol/Definition/Values/Units \\
\hline HMI & Real & $\begin{array}{l}\text { Terrain elevation (above the base of the stack) at the } \\
\text { location of the maximum individual, } h_{t}, m \text {. }\end{array}$ \\
\hline $\mathrm{HT}(10,16)$ & Rea 1 & $\begin{array}{l}\text { Terrain elevation at each location ( } 10 \text { distances and } \\
16 \text { directions) above the base of the stack, } h_{+}, m \text {. }\end{array}$ \\
\hline HSTACK & Real & $\begin{array}{l}\text { Elevation of the release point (above the base of the stack), } \\
h_{S}, m \text {. }\end{array}$ \\
\hline
\end{tabular}

TABLE B. 0-12. Common B lock FLAGS

\begin{tabular}{|c|c|c|}
\hline $\begin{array}{l}\text { Symbol \& } \\
\text { Dimension }\end{array}$ & Type & Problem Symbol/Definition/Values/Units \\
\hline $\operatorname{NFLAGC}(200)$ & Int. & $\begin{array}{l}\text { Control integer to indicate if any radionuclides in each } \\
\text { chain are supplied on input. } \\
\operatorname{NFLAGC~}(i) \leq 0 \text { radionuclide not given } \\
\operatorname{NFLAGC}(i)>0 \text { radionuclide given }\end{array}$ \\
\hline $\operatorname{NFLAG}(300)$ & Int. & $\begin{array}{l}\text { Control integer to indicate if data is given in input } \\
\text { inventory for each radionuclide. } \\
\text { IFLAG }(i) \leq 0 \text { data not given } \\
\text { IFLAG }(i)>0 \text { data given }\end{array}$ \\
\hline $\operatorname{INFLG(300)}$ & Int. & $\begin{array}{l}\text { Control integer to indicate which master list radionuclides } \\
\text { have dose factors supplied in library NUCDFL. } \\
\text { INFLG }(i) \leq 0 \text { no NUCDFL data } \\
\text { INFLG }(i)>0 \text { NUCDFL data given }\end{array}$ \\
\hline NPRT & Int. & $\begin{array}{l}\text { Control integer to cause printing of data in library } \\
\text { NUCDFL. Data is printed if NPRT }>0 \text {. }\end{array}$ \\
\hline
\end{tabular}


TABLE B.0-13. Common B lock NAMES

\begin{tabular}{l|l|l}
$\begin{array}{l}\text { Symbol \& } \\
\text { Dimension }\end{array}$ & Type & \multicolumn{1}{|c}{ Problem Symbol/Definition/Values/Units } \\
\hline AW(300) & Char. & $\begin{array}{l}\text { Two character element name for each radionuclide in the } \\
\text { master radionuclide data library. }\end{array}$ \\
NUCS & $\begin{array}{l}\text { Six character atomic weight symbol for each radionuclide } \\
\text { in the master radionuclide data library. Isomeric states } \\
\text { are indicated by the letter M after the atomic weight. } \\
\text { Daughter contributions are indicated by "+D" after the } \\
\text { atomic weight and "M" if present. } \\
\text { Number of radionuclides in the master 1ibrary. (Same as } \\
\text { NuC of common block DECAY.) }\end{array}$ \\
\hline
\end{tabular}

TABLE B.0-14. Common B lock ORGID

\begin{tabular}{|c|c|c|}
\hline $\begin{array}{l}\text { Symbol \& } \\
\text { Dimension }\end{array}$ & Type & Problem Symbol/Definition/Values/Units \\
\hline LORG & Int. & $\begin{array}{l}\text { Number of organs for which data is supplied in the dose } \\
\text { conversion factor library NUCDFL. } 1 \leq L O R G \leq 10 \text {. }\end{array}$ \\
\hline $\operatorname{IORG}(10)$ & Int. & $\begin{array}{l}\text { Organ index values for which data is supplied in the dose } \\
\text { conversion factor library, NUCDFL. } 1 \leq \operatorname{IORG}(i) \leq 23 \text {. }\end{array}$ \\
\hline NORG & Int. & $\begin{array}{l}\text { Number of organs for which doses are to be calculated. } \\
1 \leq \text { NORG } \leq 5 \text {. }\end{array}$ \\
\hline KORG $(5)$ & Int. & $\begin{array}{l}\text { Organ index values for which doses are to be calculated. } \\
\text { The index values must be taken from values in index array } \\
\text { IORG from the dose conversion factor library, NUCDFL. }\end{array}$ \\
\hline $\operatorname{MORG}(5)$ & Int. & $\begin{array}{l}\text { Position in IORG corresponding to selected organs. This } \\
\text { array is set in subroutine ORGCHK. }\end{array}$ \\
\hline ORGT (5) & Char. & Ten character organ names for output. \\
\hline $\operatorname{ONAME}(10)$ & Char. & Ten character organ names for data in library NUCDFL. \\
\hline
\end{tabular}


TABLE B.0-15. Common B lock POPU

\begin{tabular}{l|l|l}
$\begin{array}{c}\text { Symbol \& } \\
\text { Dimension }\end{array}$ & Type & \multicolumn{1}{|c}{ Problem Symbol/Definition/Values/Units } \\
\hline $\operatorname{POP}(10,16)$ & Real & $\begin{array}{l}\text { Population within each spatial interval for 10 distances } \\
\text { and 16 direction sectors, } P_{i j}, \text { persons. }\end{array}$
\end{tabular}

TABLE B.0-16. Common B lock SOURCE

\begin{tabular}{l|l|l}
\begin{tabular}{l|l} 
Symbol \& \\
Dimension
\end{tabular} & Type & \multicolumn{1}{|c}{ Problem Symbol/Definition/Values/Units } \\
\hline NIN & Int. & $\begin{array}{l}\text { Number of radionuclides in the input inventory, } \\
1 \leq N I N \leq N U C .\end{array}$ \\
AWI(300) & Char. & $\begin{array}{l}\text { Character names for input radionuclides. The names must } \\
\text { be spelled identically to the spelling in the master } \\
\text { radionuclide list. } \\
\text { Six character atomic weight symbol for each input radio- } \\
\text { nuclide. The spelling must correspond to the master list } \\
\text { spelling (see variable AW in common block NAMES). }\end{array}$
\end{tabular}




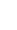


APPENDIX C

DATA LIBRARIES 
APPENDIX C

DATA LIBRARIES

Two data libraries are required to run HADOC: a radionuclide master data library and a dose conversion factor data library. The libraries have been designed such that additional data or changes to existing data may be entered with little difficulty. Listings of the libraries are given in Appendix $D$.

\section{C.1 RADIONUCLIDE MASTER DATA LIBRARY - RMDLIB}

The radionuclide master data library (RMDLIB) contains all radiological decay data used by HADOC. The library is organized into two sections. The first section contains radionuclides which are not members of decay chains, and also radionuclides singled out from chains with the "D" (plus daughters) designation. Radionuclides in the first section are arranged by increasing atomic number. The second section of the library contains radionuclides organized into decay chains ordered under the radionuclides highest in the chain. RMDLIB contains about 280 entries.

The first card of the library contains 80 characters of descriptive information used as identification in the input data report printed by subroutine QAPAGE. The remainder of the data cards have the following information:

Column 1 Alphabetic element symbol

Column 2 Atomic weight, also metastable and/or "+D" designation

Column 3 Radiological half-life, days

Column 4 Relative position in decay chain

Column 5 Precursor in decay chain

Column 6 Branching ratio from primary percursor

Column 7 Alternate precursor in decay chain

Column 8 Branching ratio from alternate precursor

The RMOLIB FORTRAN format is (A2, A6, E10.2, 2I2, F7.4, I2, F7.4). The parameter in Column 4 is used to signal the end of the data library $(\leq 0)$.

C.2 DOSE CONVERSION FACTCR DATA LIBRARY - NUCDFL

The radionuclide dose conversion factor data library provides master organ identification parameters and dose conversion factor data for external exposure and inhalation uptake. The first card contains the following data: 


\begin{tabular}{|c|c|c|c|}
\hline Parameter & Columns & Format & Description \\
\hline NU & $1-5$ & I5 & $\begin{array}{l}\text { Number of radionuclides for which } \\
\text { data will be supplied, } 1 \leq N U \leq 300 \text {. }\end{array}$ \\
\hline LORG & $6-10$ & 15 & $\begin{array}{l}\text { Number of organs for which data is } \\
\text { supplied in this library, } 1 \leq \text { LORG } \\
\leq 10 .\end{array}$ \\
\hline-- & $11-20$ & -- & Not used (read as NT, NR, 2I5) \\
\hline $\operatorname{IORG}(10)$ & $\begin{array}{l}21-23 \\
24-26 \\
- \\
48-50\end{array}$ & 1013 & $\begin{array}{l}\text { Organ index values for each organ that } \\
\text { data will be provided for, } 1 \leq \text { IORG(i) } \\
\leq 23 \text {. (See organ title information } \\
\text { on the third card). }\end{array}$ \\
\hline
\end{tabular}

The second card contains an 80 character descriptive title to be printed in the input data report prepared by subroutine QAPAGE.

The third (and fourth card if necessary) contain descriptive titles (ONAME) for organs data is supplied for in this library. The format is $8 A 10$ with 10 characters allowed for each organ name. If more than eight organs are specified (LORG) then an additional card is read. The card following the last organ name card gives the dose commitment periods data is supplied for (2I5). For the current library the times are 1 and 50 years. The remainder of the library contains dose conversion factor data for the NU radionuclides. The first card for each radionuclide contains the following data:

\begin{tabular}{|c|c|c|c|}
\hline Parameter & Columns & Format & Description \\
\hline $\operatorname{ELT}(i)$ & $1-2$ & $A 2$ & Element symbol for radionuclide $i$. \\
\hline$A W(i)$ & $3-8$ & A6 & $\begin{array}{l}\text { Atomic weight symbol for radionucide } i \\
\text { including metastable " } M \text { " and/or "+D" } \\
\text { designation. }\end{array}$ \\
\hline $\operatorname{EXDF}(i)$ & $\begin{array}{r}9-14 \\
15-22\end{array}$ & $\begin{array}{l}6 \times \\
E 8.1\end{array}$ & $\begin{array}{l}\text { External total body dose conversion } \\
\text { factor in rem per }\left(\mathrm{C} i \text { sec per } \mathrm{m}^{3}\right) \text {. }\end{array}$ \\
\hline LO & $\begin{array}{l}23-38 \\
39-40\end{array}$ & $\begin{array}{l}16 x \\
12\end{array}$ & $\begin{array}{l}\text { The number of organs for which } \\
\text { inhalation dose conversion factor data } \\
\text { will be given. } 1 \leq L 0 \leq \text { LORG. }\end{array}$ \\
\hline
\end{tabular}

When no inhalation data is provided for a radionuclide, $L O$ is zero and no additional cards are read for the radionuclide. Inhalation data is supplied for each organ as needed with data for one organ on one card as follows: 


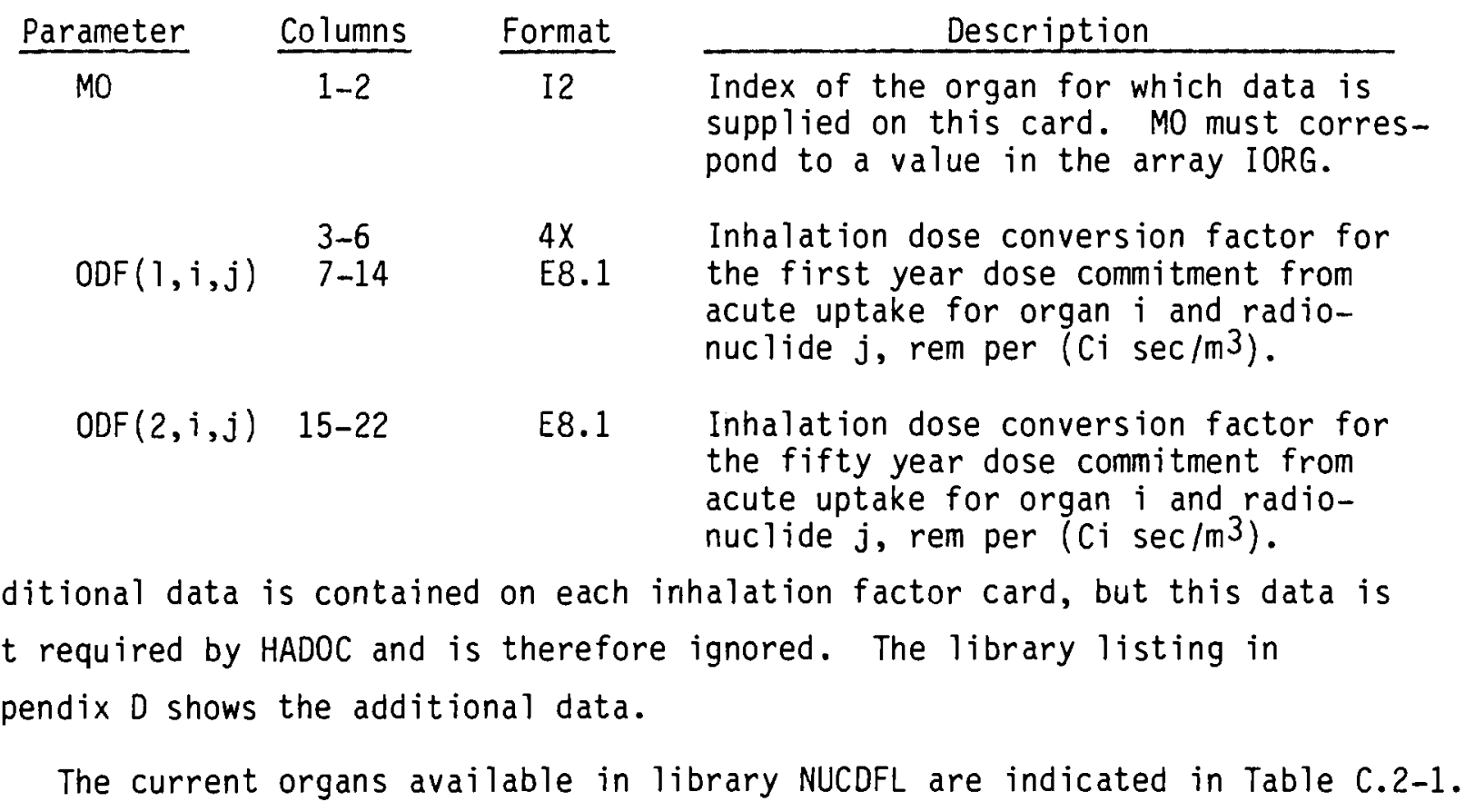

TABLE C.2-1 Organs Available in NUCDFL

\begin{tabular}{ccl} 
Organ Number & Organ Index & Organ Name \\
\cline { 2 - 3 }$i$ & IORG $(i)$ & ONAME $(i)$ \\
1 & 1 & Total Body \\
2 & 3 & Kidney \\
3 & 4 & Liver \\
4 & 6 & Bone \\
5 & 8 & Lungs \\
6 & 16 & Thyroid \\
7 & 23 & LLI
\end{tabular}




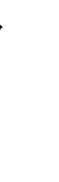


APPENDIX D

CODE AND DATA LIBRARY LISTINGS 
APPENDIX D

\section{CODE AND DATA LIBRARY LISTINGS}

This appendix contains listings of each module for the computer code HADOC plus listings of the two data libraries RMDLIB and NUCDFL. The code listing (Figure $0.0-1$ ) starts with the main program (MAIN) followed by the remaining modules in alphabetical order and common blocks in alphabetical order. The listing of RMDLIB is next (Figure D.0-2) with the NUCDFL listing last (Figure $0.0-3$ ). 


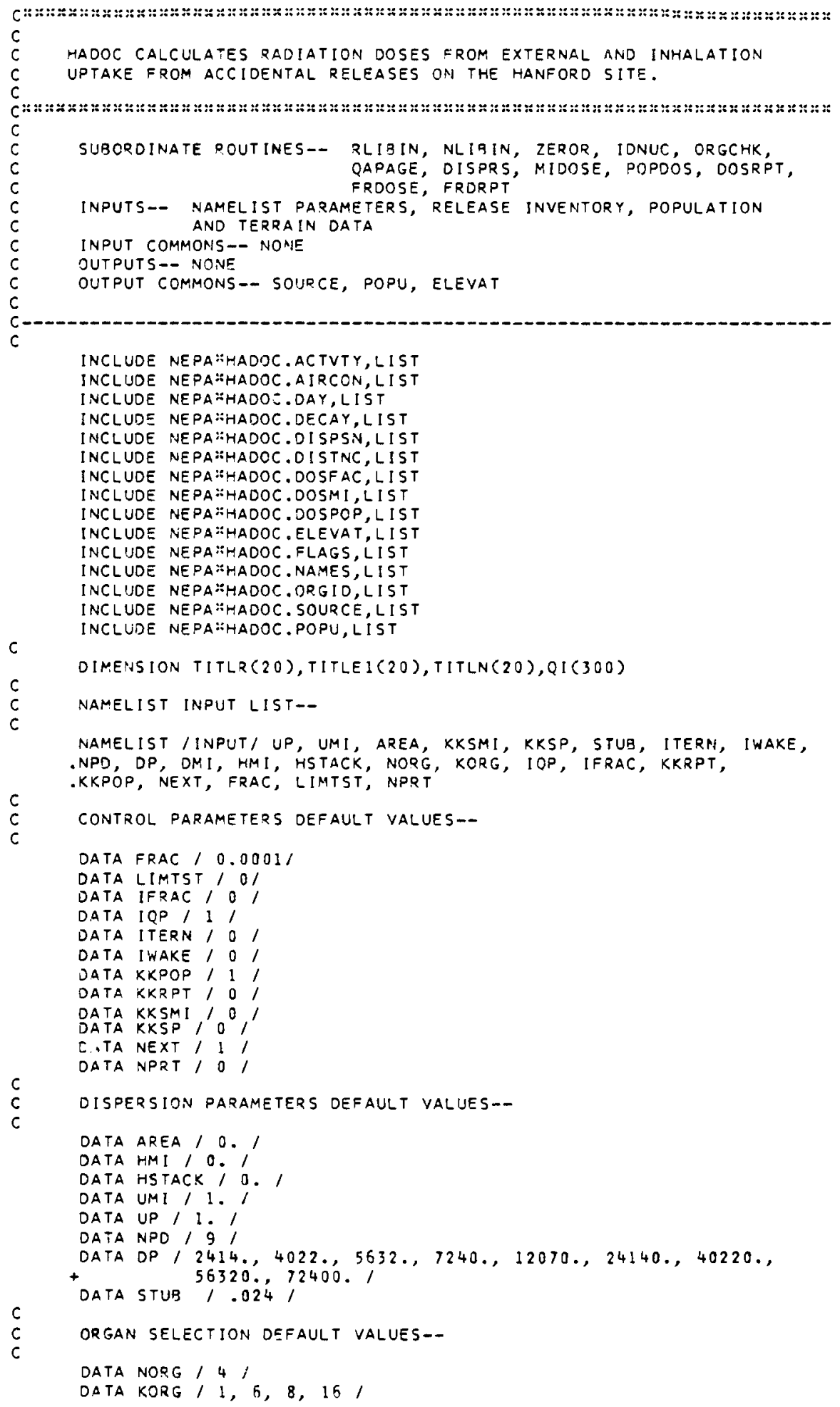

FIGURE D.0-1. Program Listing 


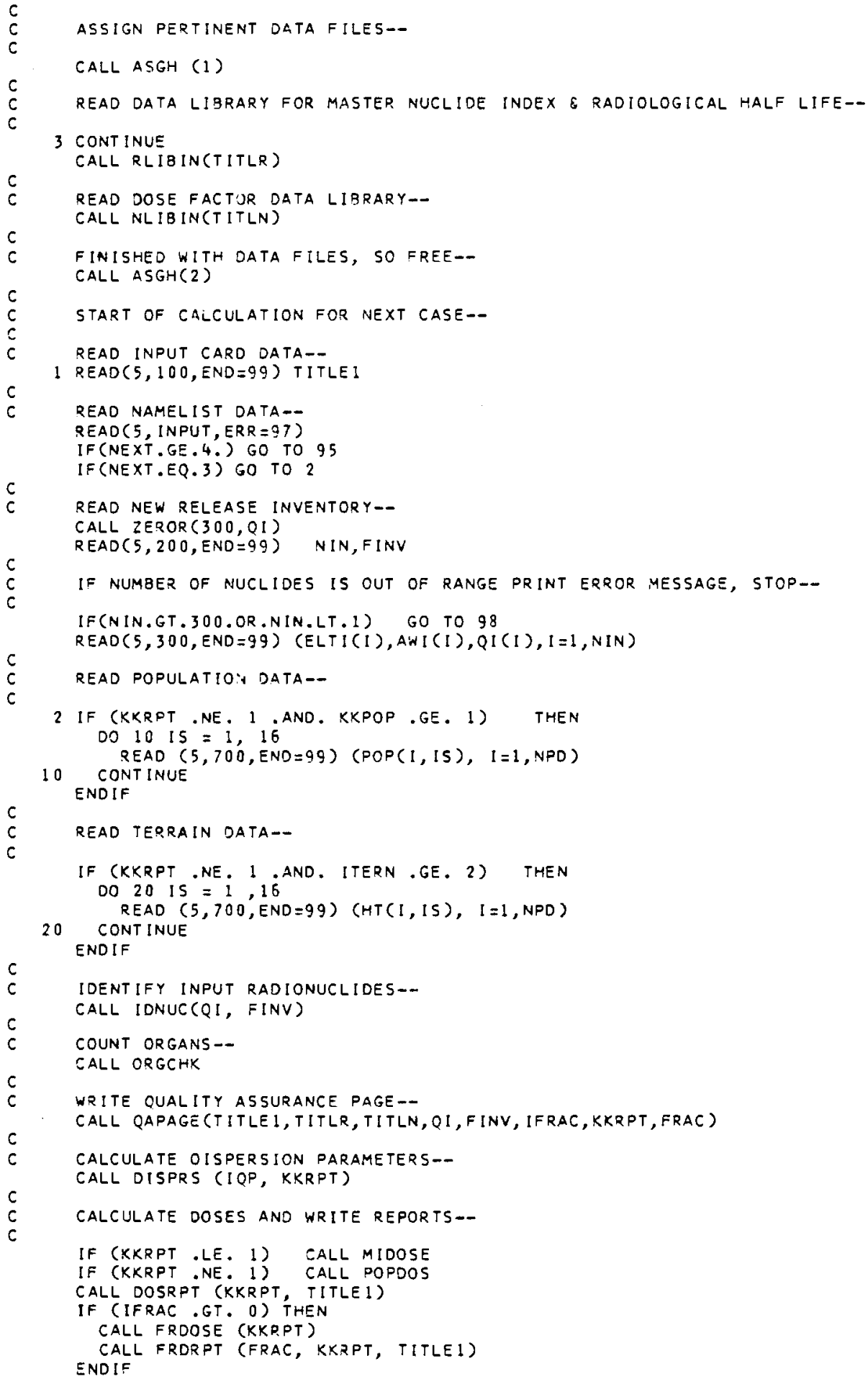

\section{FIGURE $0.0-1$. Program Listing}

D.3 


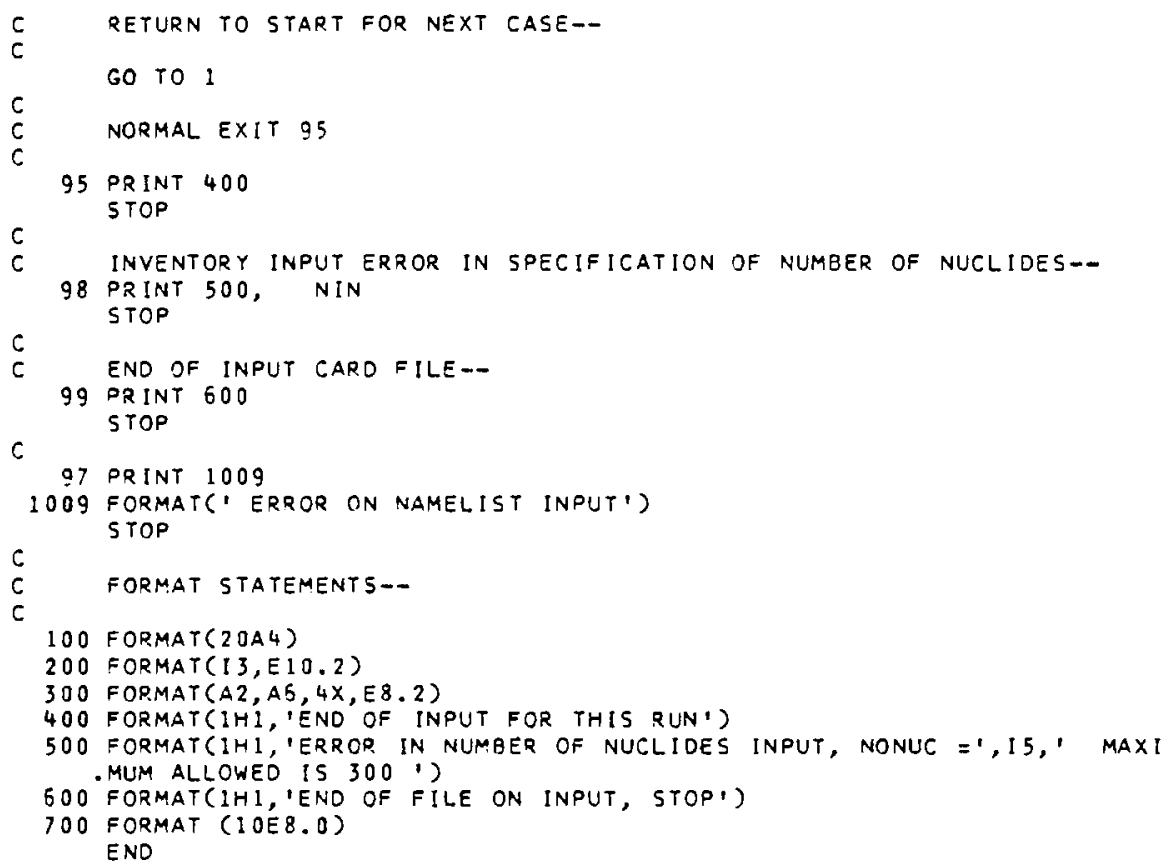

FIGURE D.0-1. Program Listing 
SUBROUTINE ACHAIN (NUC, T, OK, IFRM, AL, AM, AO, INTGRL)

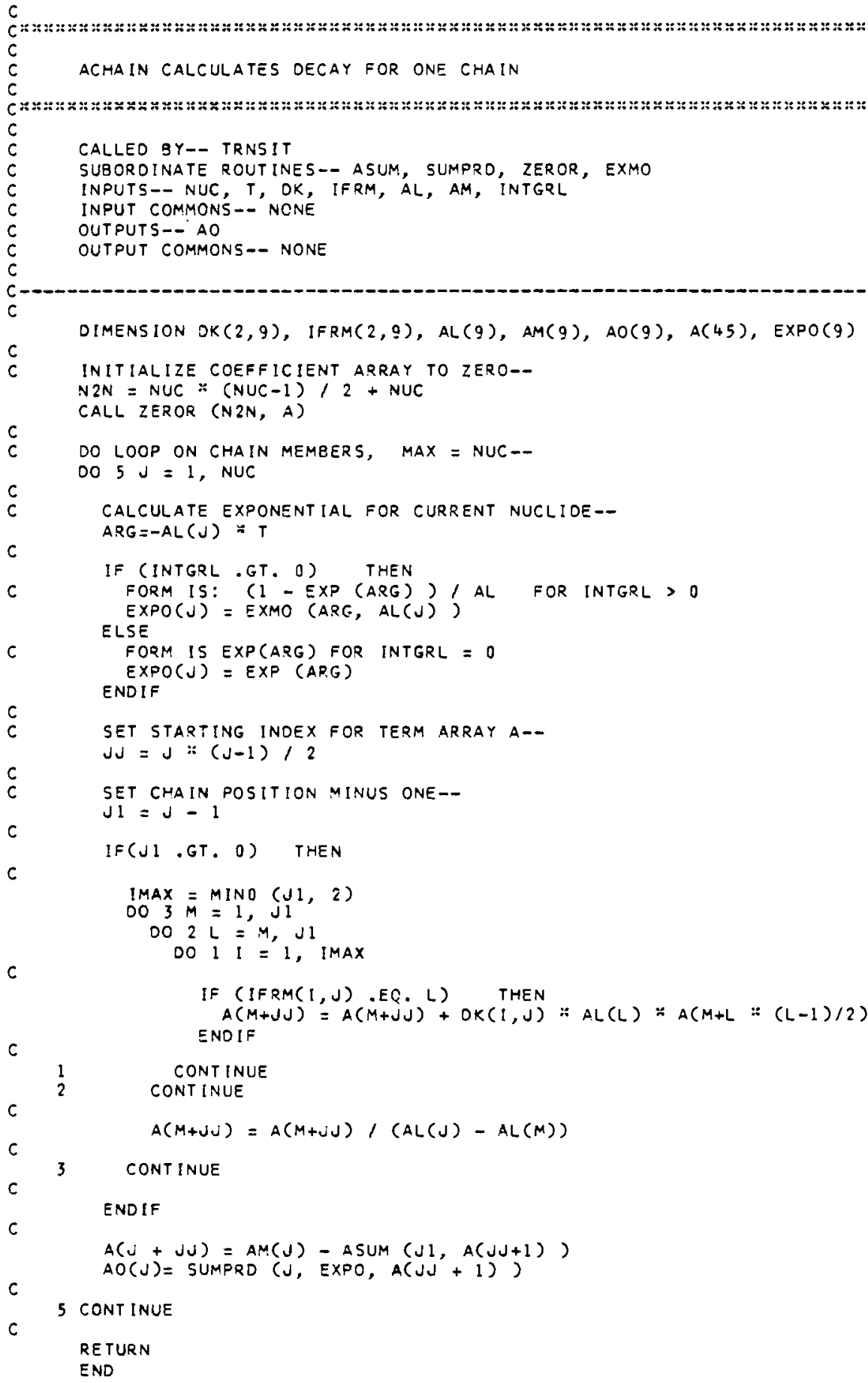

FIGURE D.0-1. liodule ACHAIN 


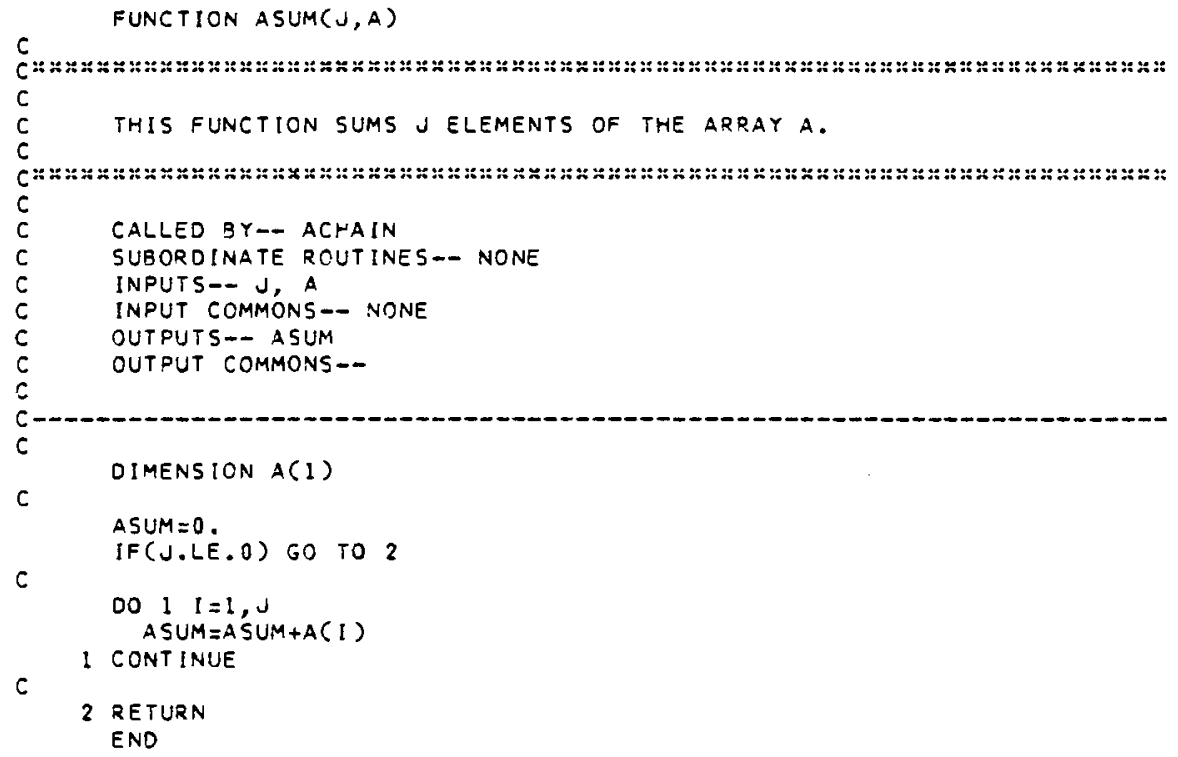

FIGURE D.0-1. Module ASUM 
MODULE DISPRS

SUEROUTINE JISPRS (IQP, KKRPT)

\$\$START

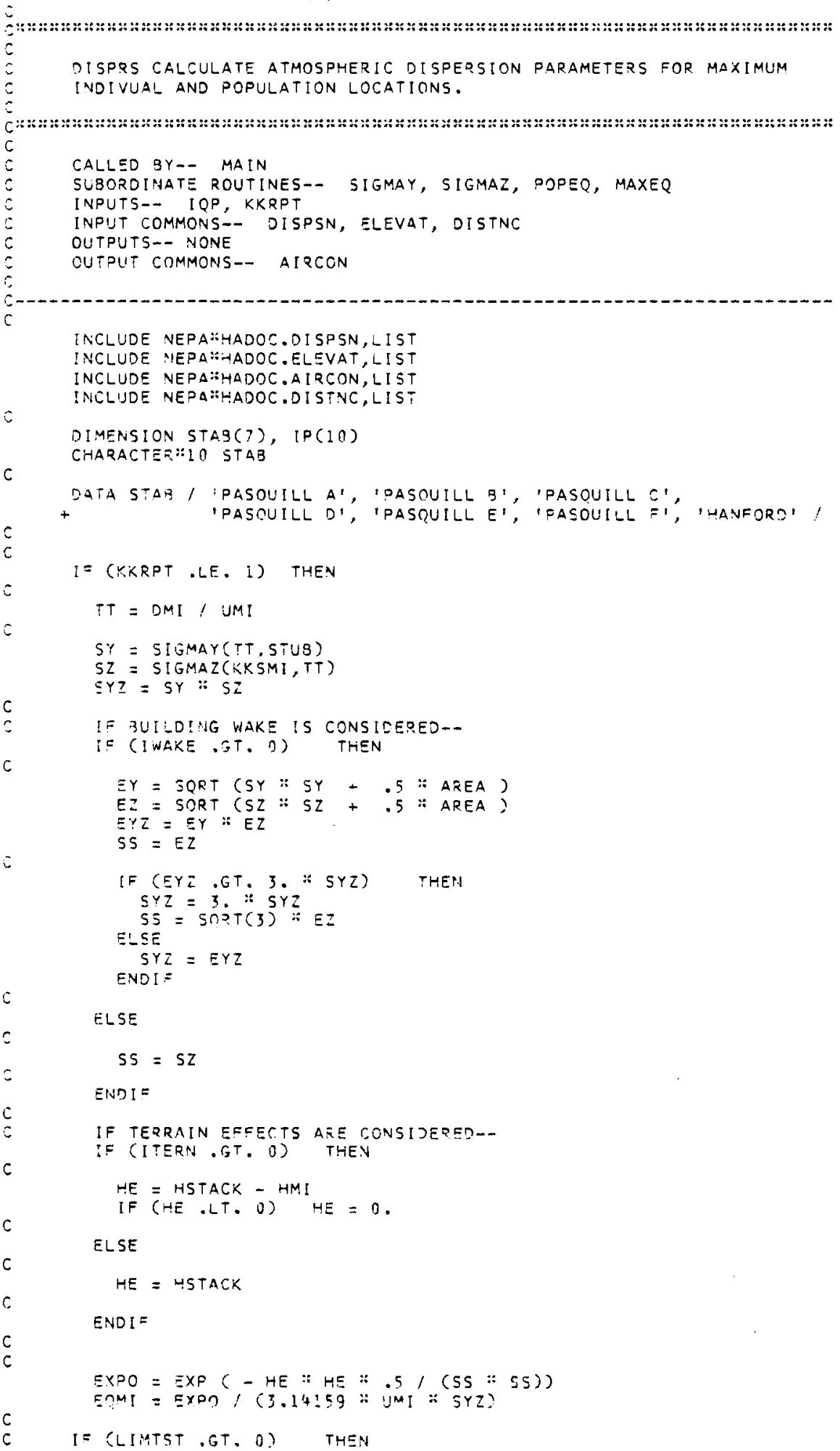

FIGURE $0.0-1$. Module DISPRS 


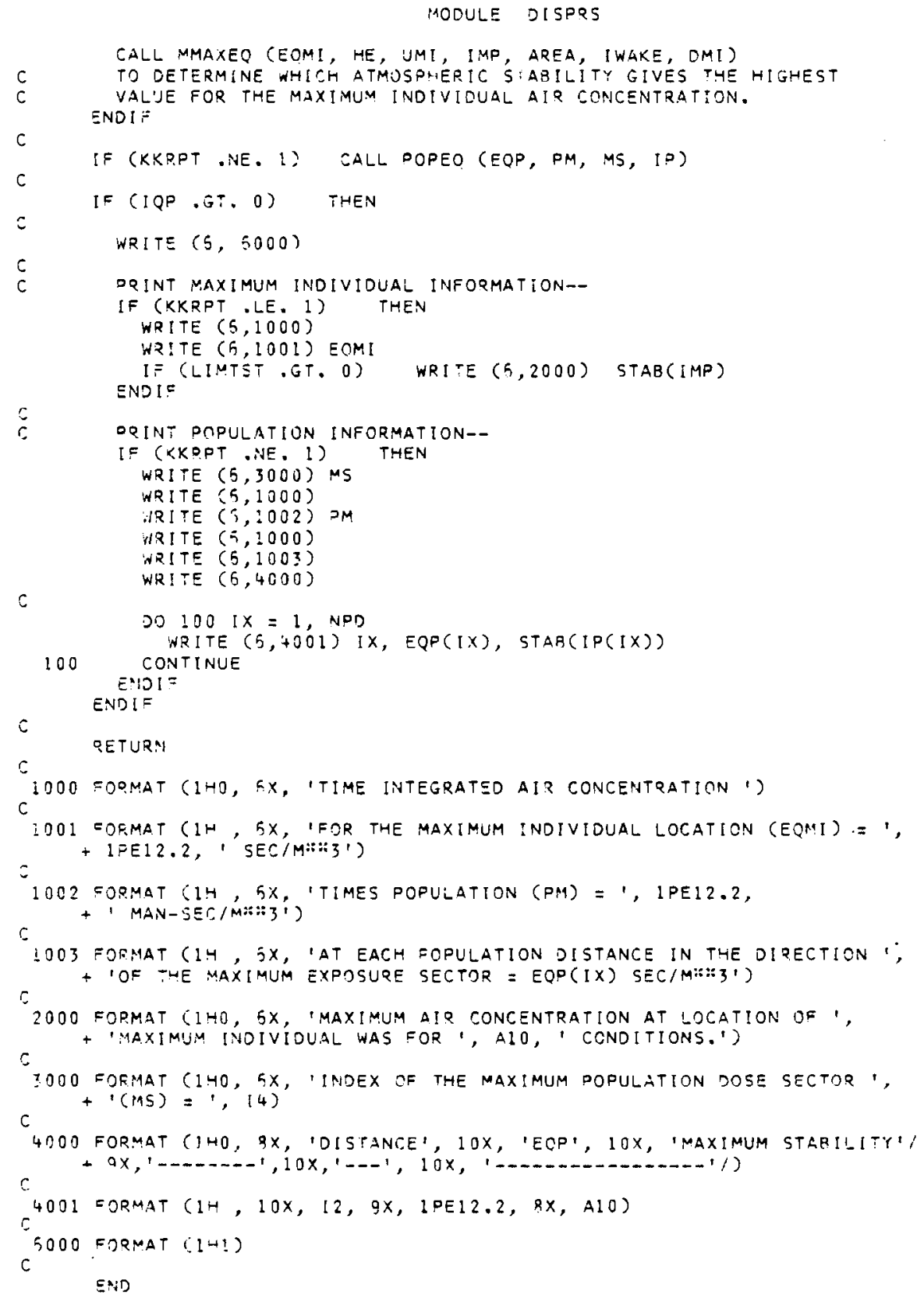

FIGURE D.0-1. ModuTe DISPRS 


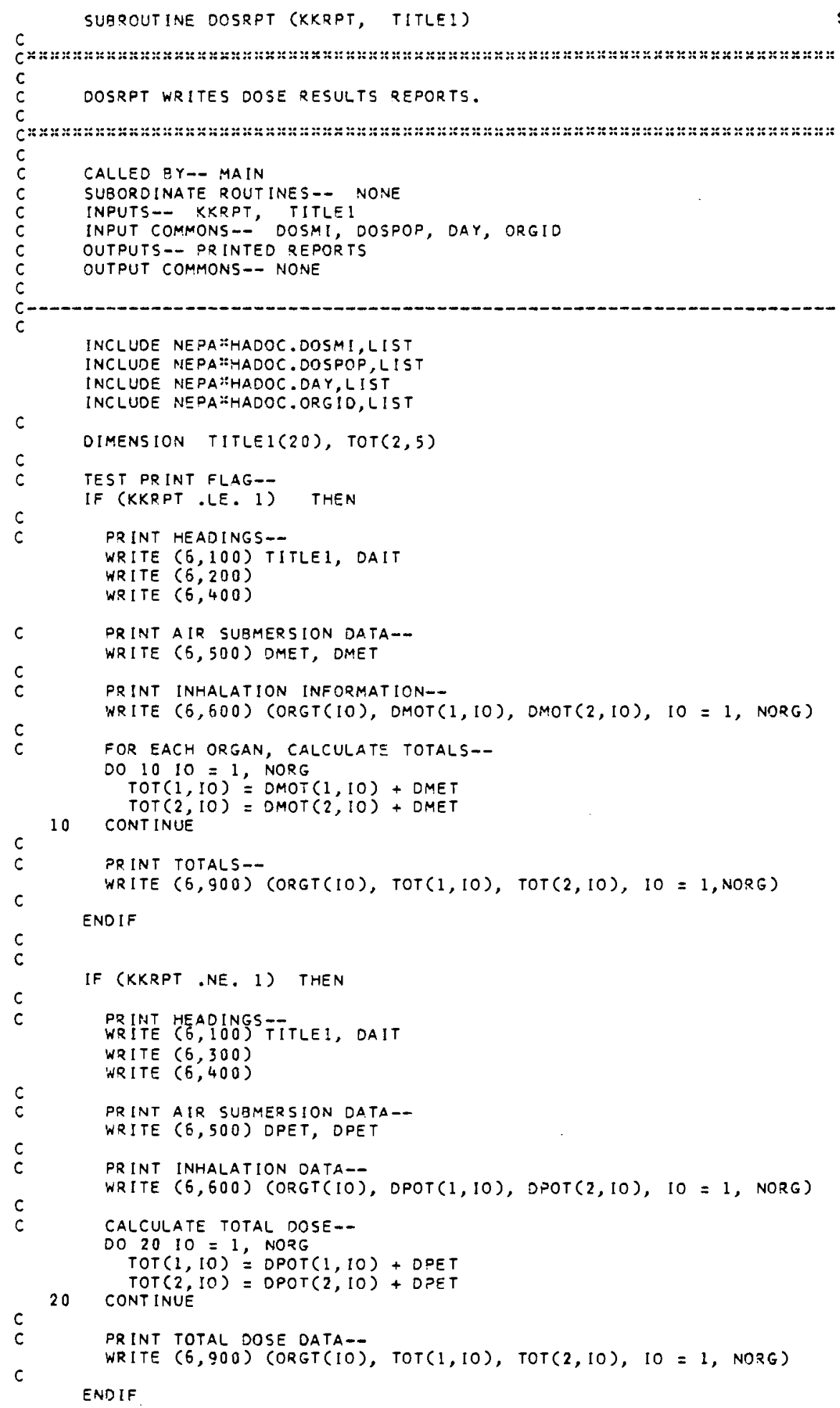

FIGURE $0.0-1$. Module DOSRPT 


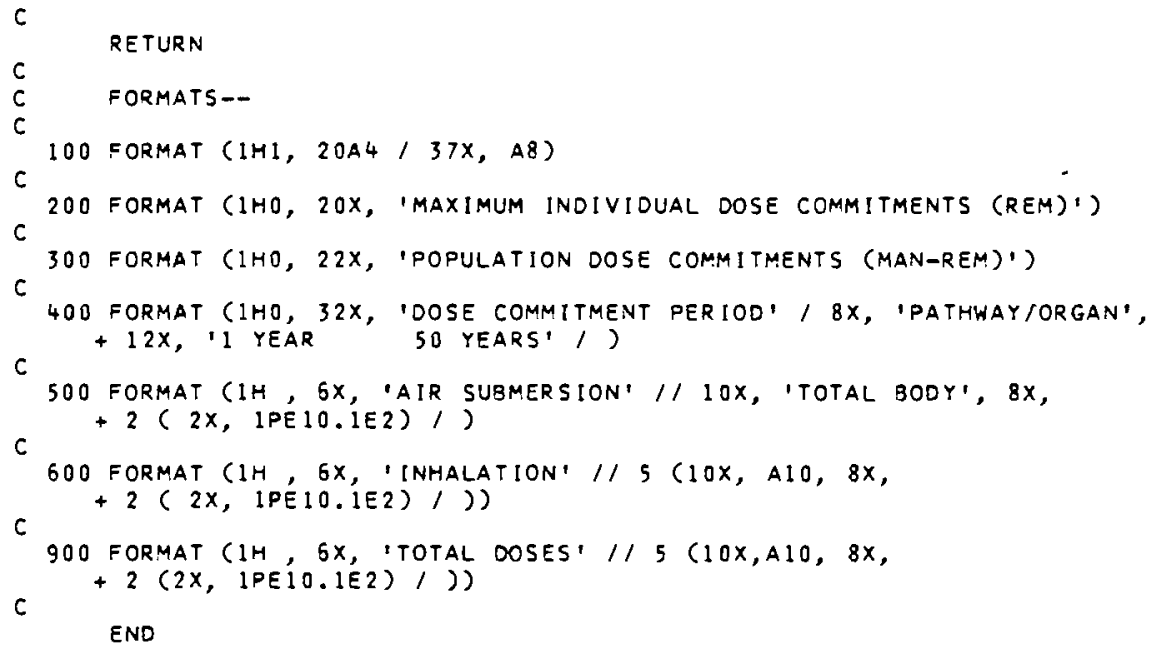

FIGURE D.0-1. ModuTe DOSRPT 


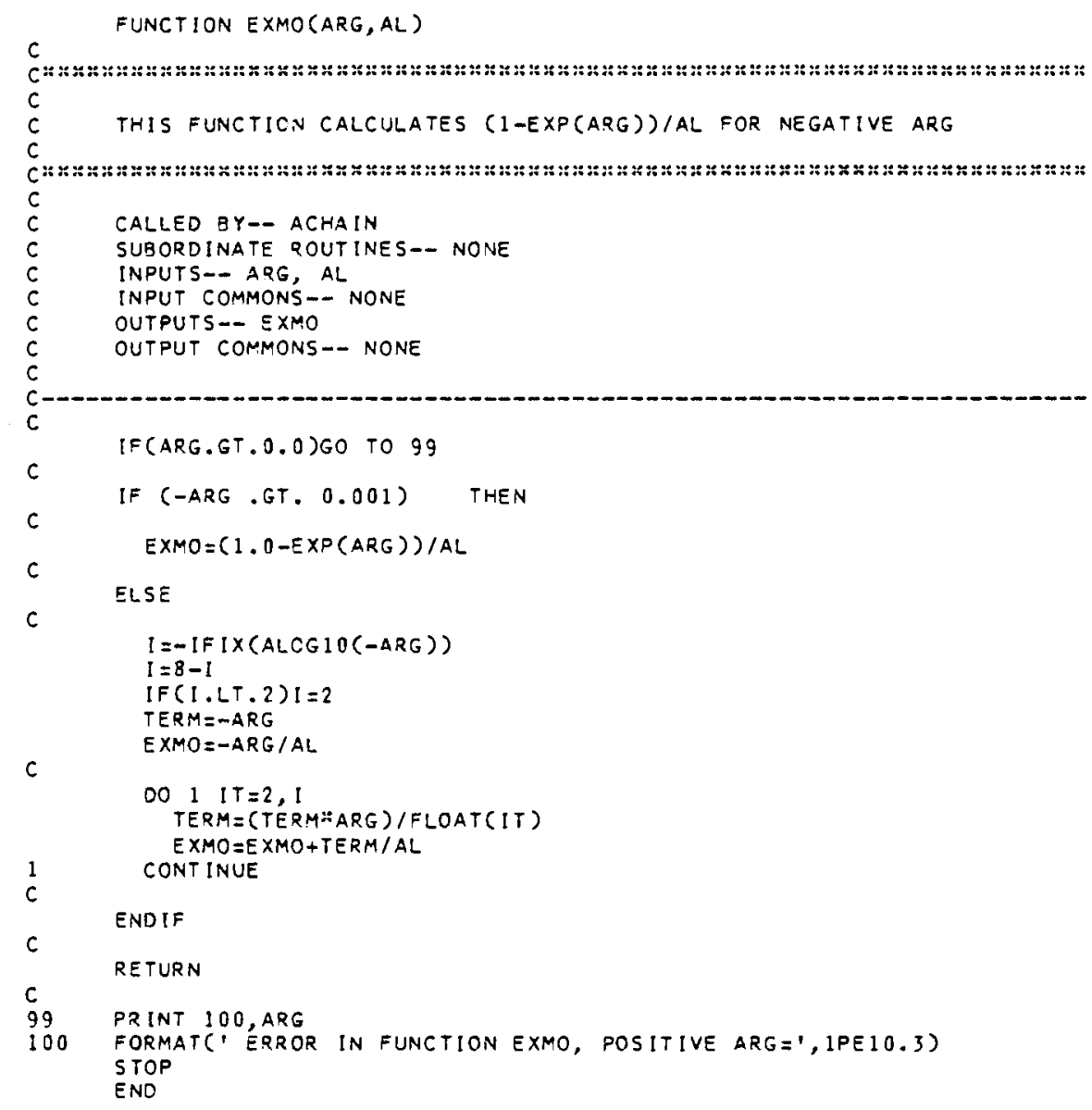

\section{FIGURE D.0-1. ModuTe EXMO}




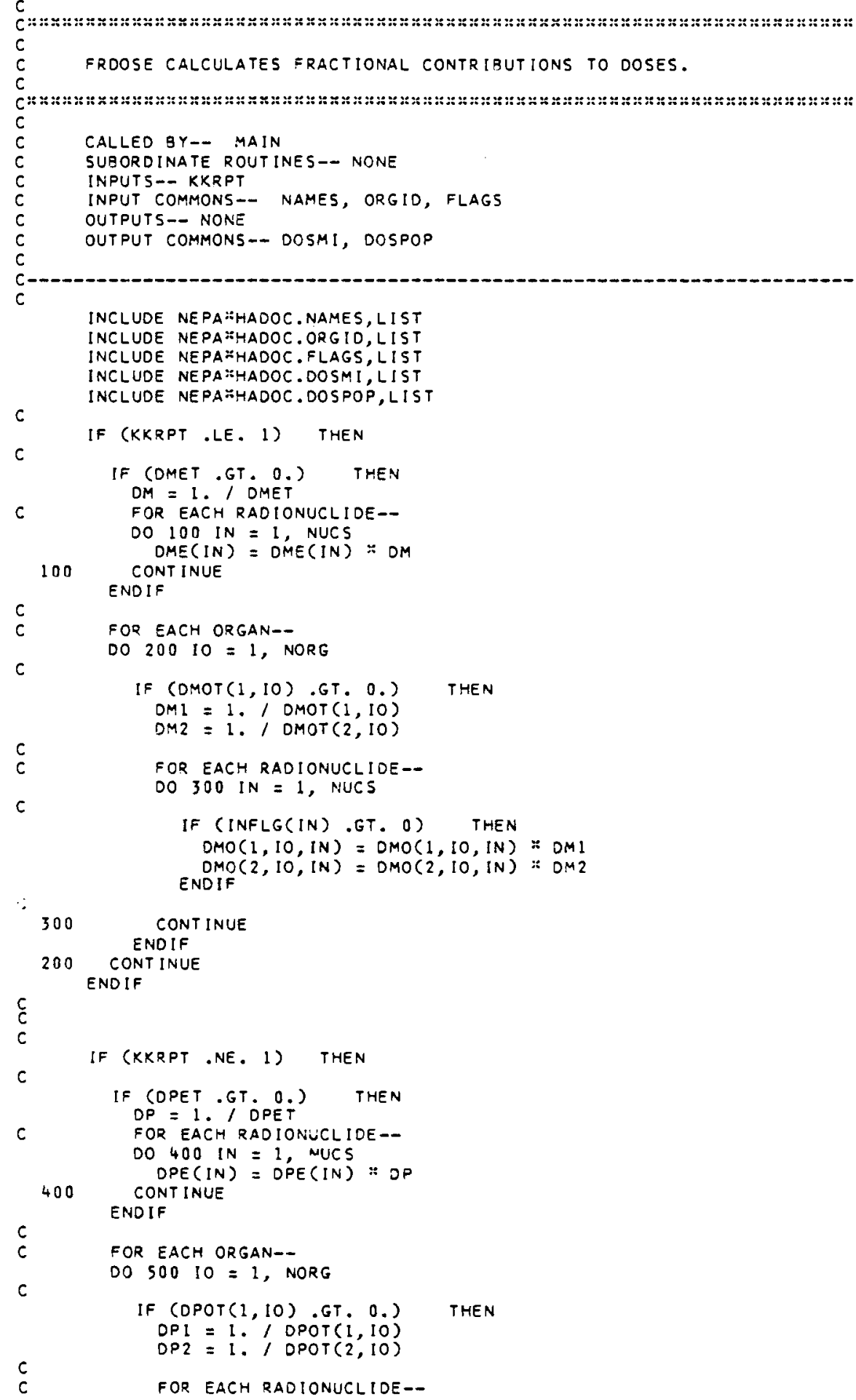

FIGURE $0.0-1$. Module FRDOSE 


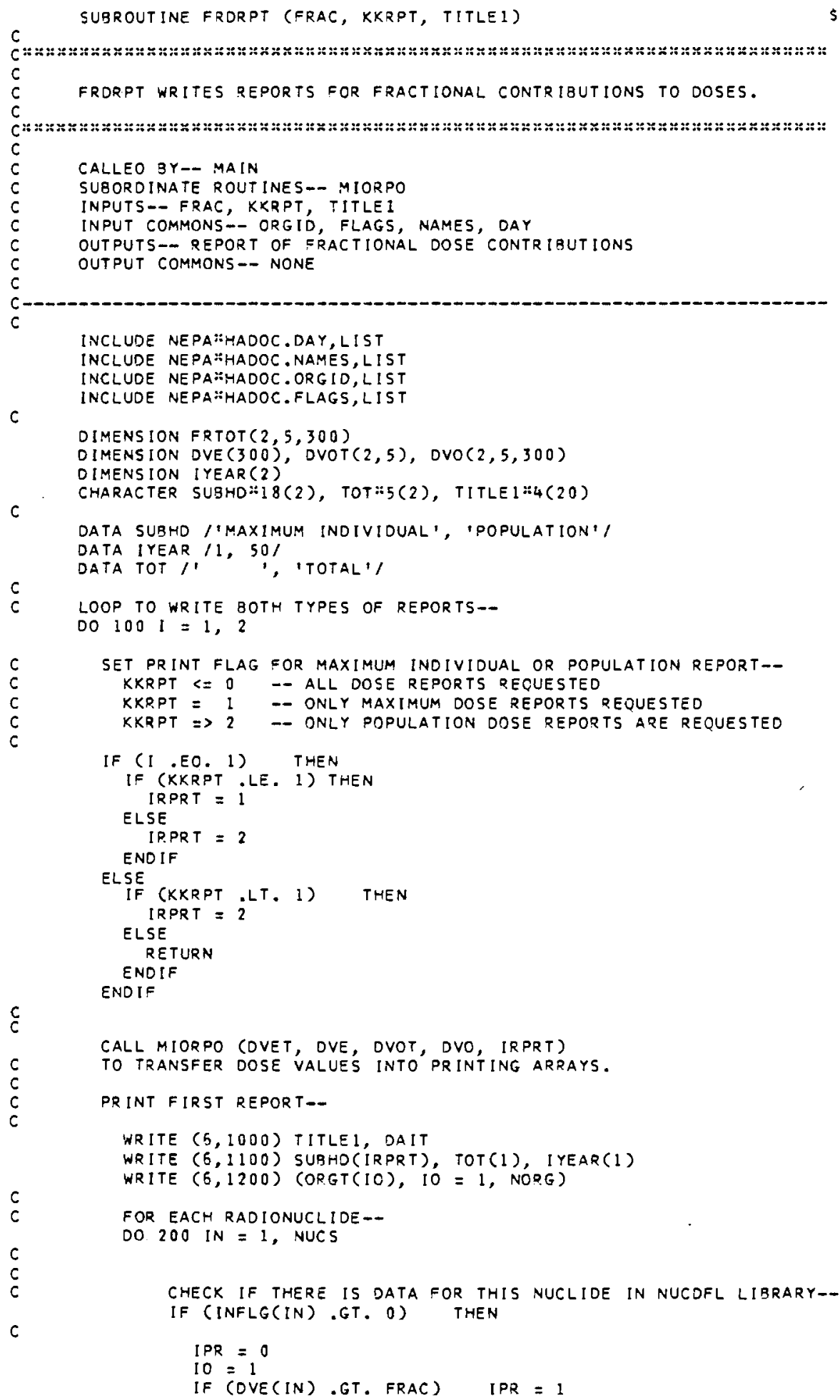

\section{FIGURE $0.0-1$. Module FRDRPT}




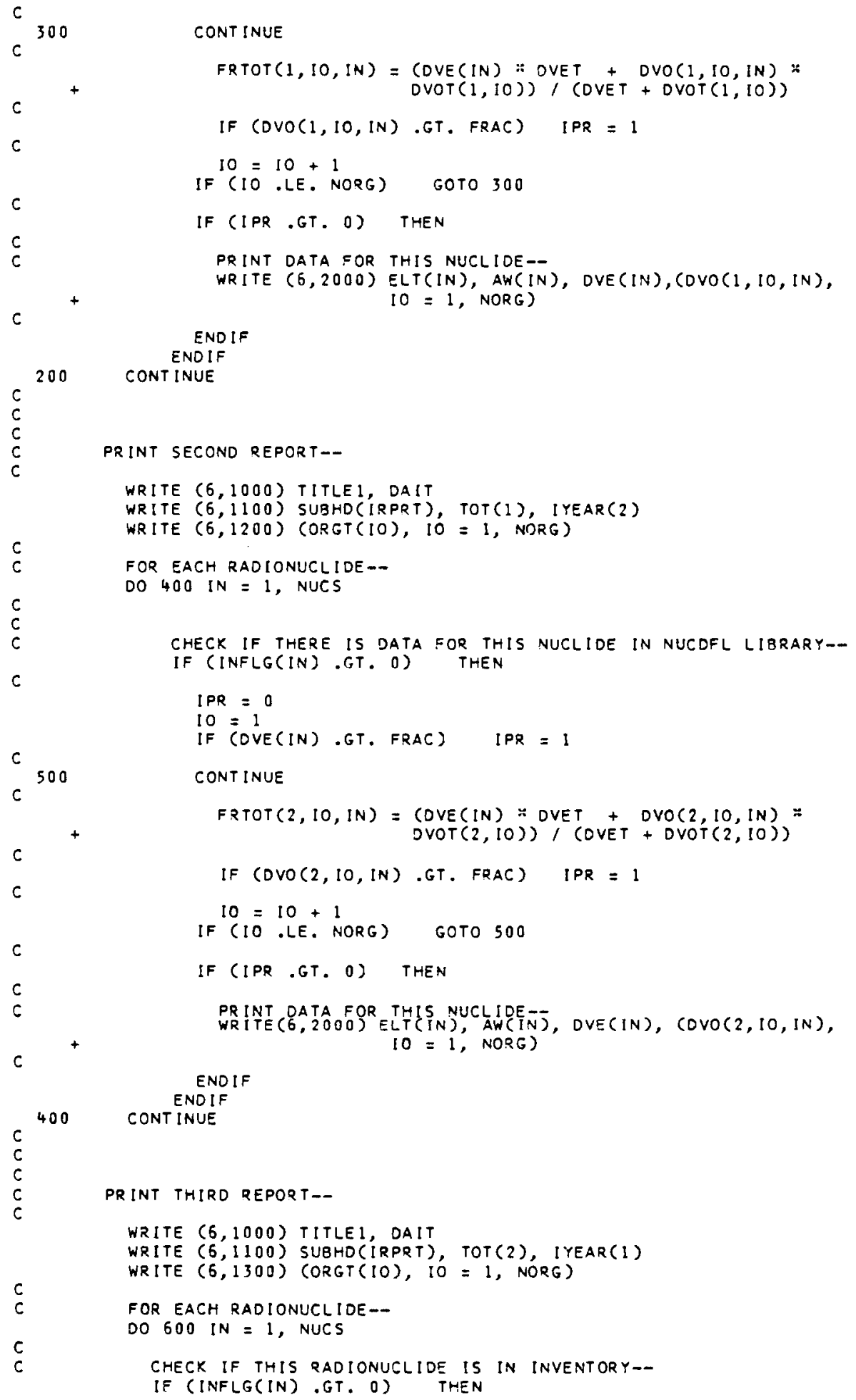

FIGURE $0.0-1$. Module FRDRPT 


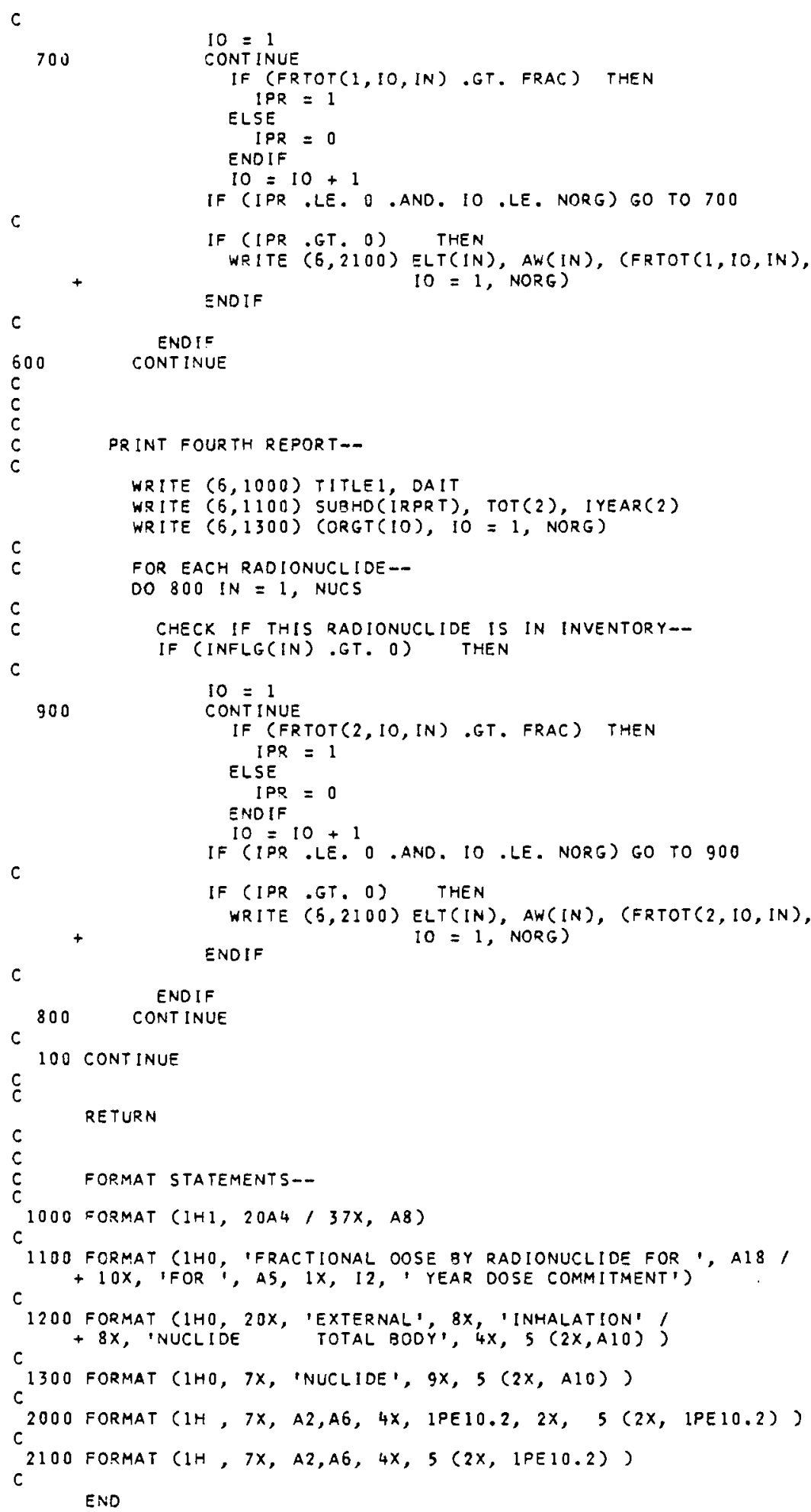

FIGURE $0.0-1$. Module FRDRPT 


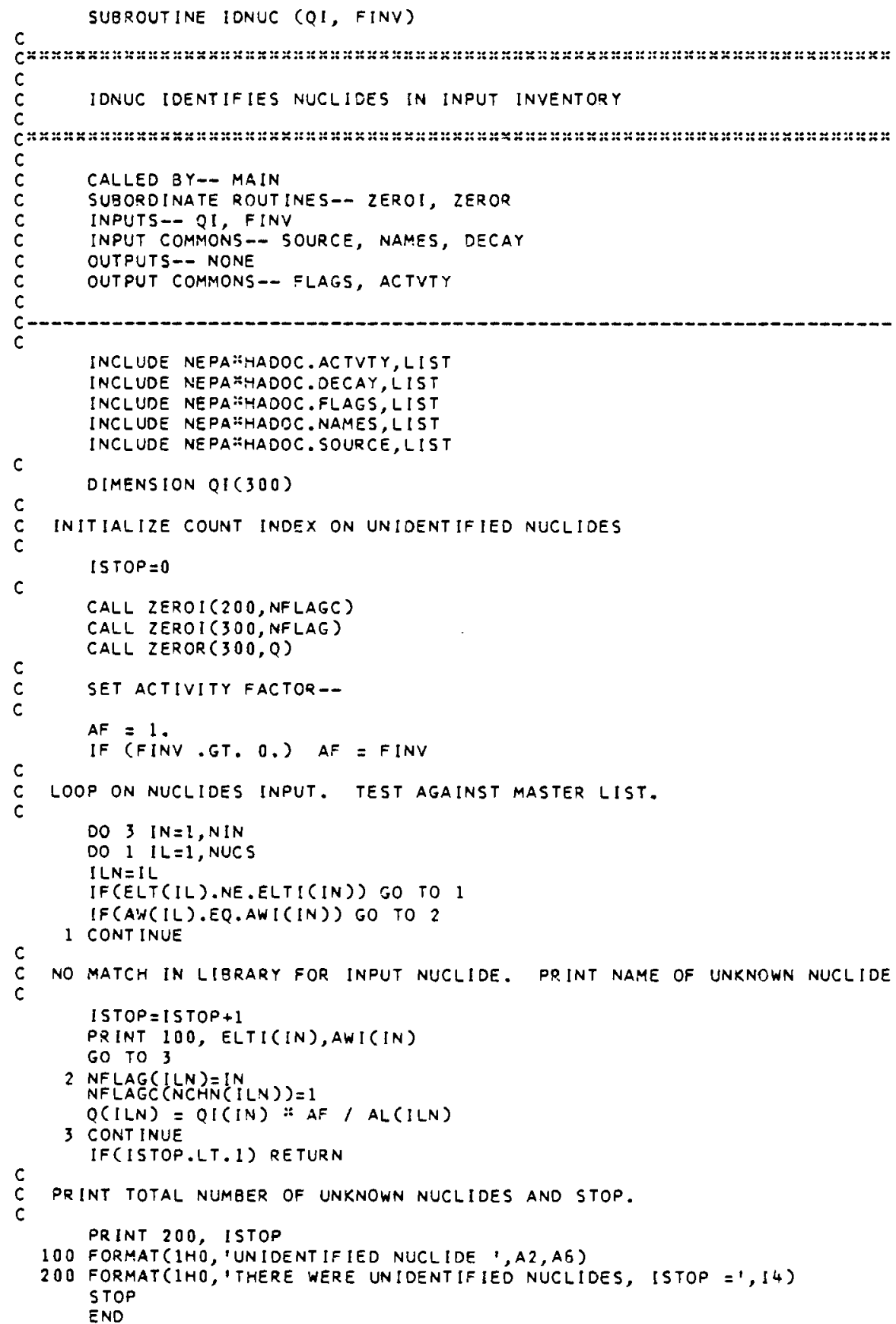

FIGURE D.0-1. Module IDNUC 


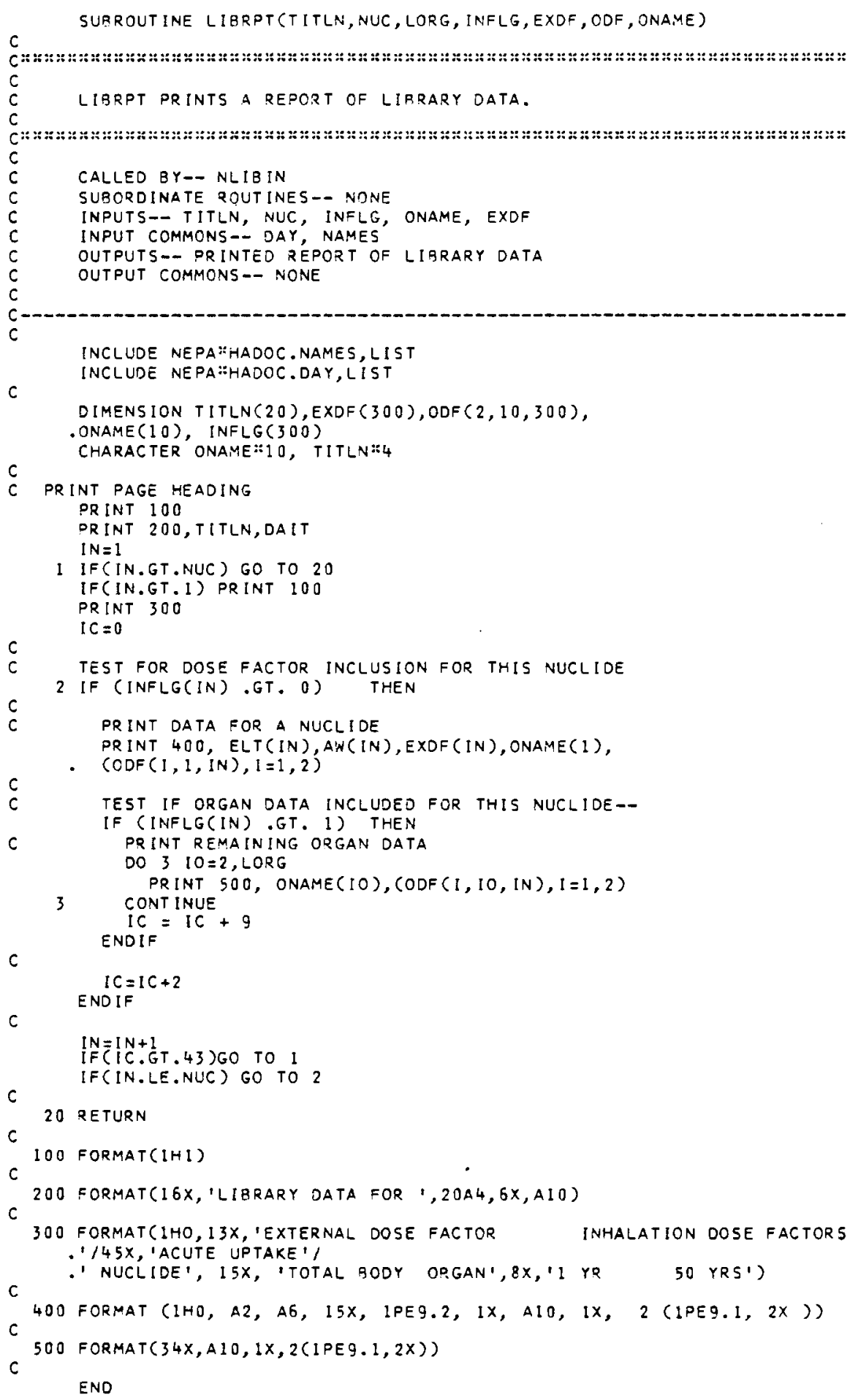

FIGURE D.0-1. Module LIBRPT 


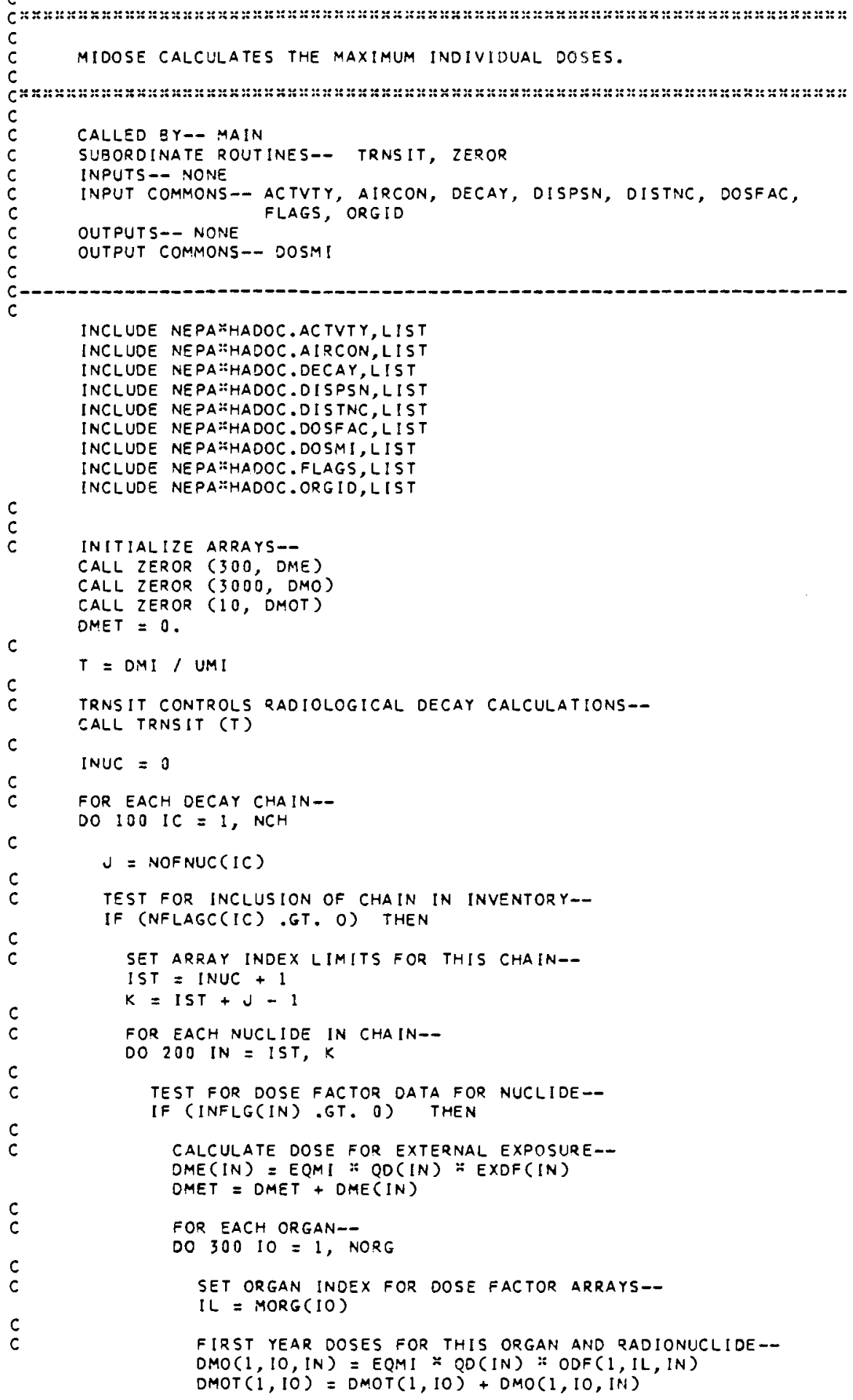

FIGURE D.0-1. Modu Te MIDOSE 


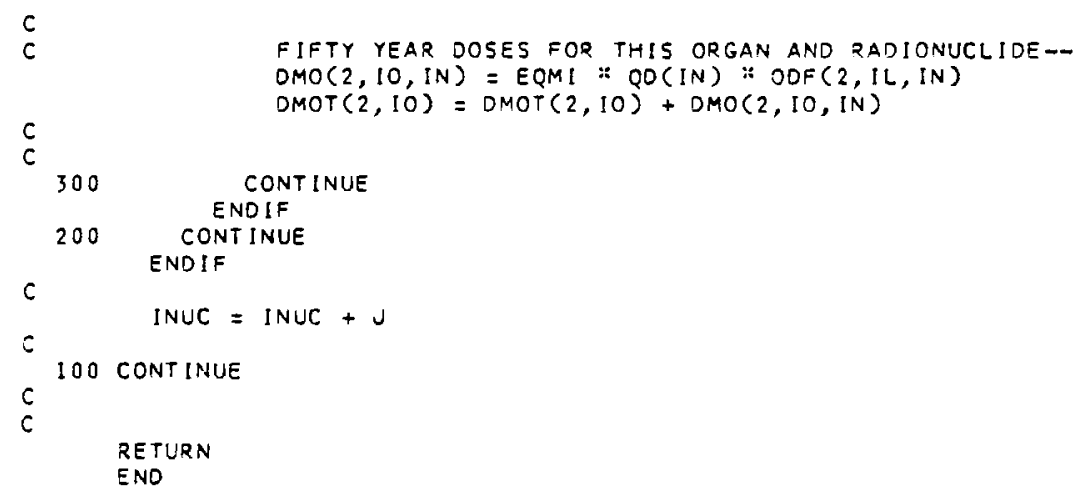

FIGURE D.0-1. ModuTe MIDOSE 
MODULE MMAXEQ

SUBRoUtine mMAXEQ (EOMI, he, UMI, IMP, AREA, [WAKE, DMI)

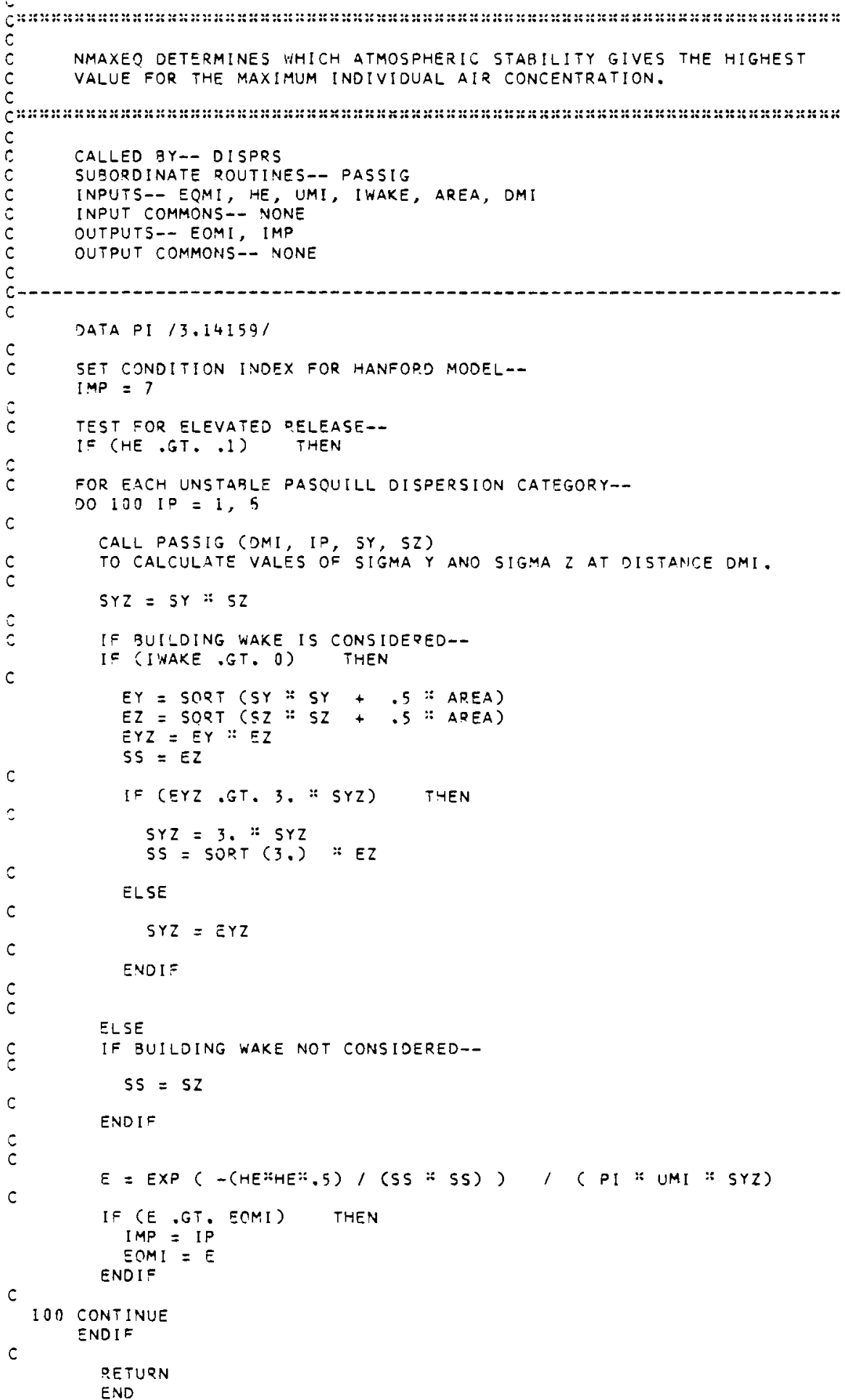

FIGURE D.0-1. Module MMAXEQ 
SUBROUTINE MIORPO (DVET, DVE, DVOT, DVO, IRPRT)

"

C

c

C

MIORPOP TRANSFERS EITHER MAXIMUM INDIVIDUAL OR POPULATION DOSE

VALUES INTO PRINTING ARRAYS.

C

SUBORDINATE ROUT INES

SUBORDINATE ROUTINES-- ZEROR

INPUTS-- IRPRT

INPUT COMMONS-- DOSMI, DOSPOP, NAMES, ORGID

OUTPUTS-- DVET, DVE, DVOT, DVO

OUTPUT COMMONS-- NONE

$c$

INCLUDE NEPÄ̈HADOC.DOSMI, LIST

INCLUDE NEPA:HADOC.DOSPOP,LIST

INCLUDE NEPA:HADOC.NAMES, LIST

INCLUDE NEPA:HADOC.ORGID,LIST

C

DIMENSION DVE $(300), \operatorname{DVOT}(2,5), \operatorname{OVO}(2,5,300)$

C INITIALIZE ARRAYS--

CALL ZEROR ( 300 , DVE)

CALL ZEROR ( 10 , DVOT)

CALL ZEROR ( 3000 , OVO)

IF (IRPRT EEQ. 1) THEN

$c$
$c$

TRANSFER MAXIMUM INDIVIDUAL DOSE ARRAYS--

OVET $=$ OMET

$001001=1,2$

DO $20010=1$, NORG

$\operatorname{DVOT}(1,10)=\operatorname{DMOT}(1,10)$

DO $300 I N=I$, NUCS

DVO $(I, 10, I N)=\operatorname{DMO}(1,10$, IN $)$ CONT INUE

CONT INUE

CONT INUE

DO 400 IN $=1$, NUCS

400 CONT INUE

DVE (IN) $=$ DME (IN)

ELSE

$c$
$c$

TRANSFER POPULATION DOSE ARRAYS--

DVET = DPET

DO $5001=1,2$

DO $60010=1$, NORG

$D \operatorname{DVT}(1,10)=$ DPOT $(1,10)$

DO 700 IN $=1$, NUCS

$D V O(I, I 0, I N)=D P O(1,10, I N)$

CONT INUE

CONT INUE

CONT INUE

DO 800 IN $=1$, NUCS

800 CONT INUE

DVE (IN) = DPE (IN)

ENDIF

RE TURN

ENO

FIGURE D.0-1. ModuTe MIORPO 


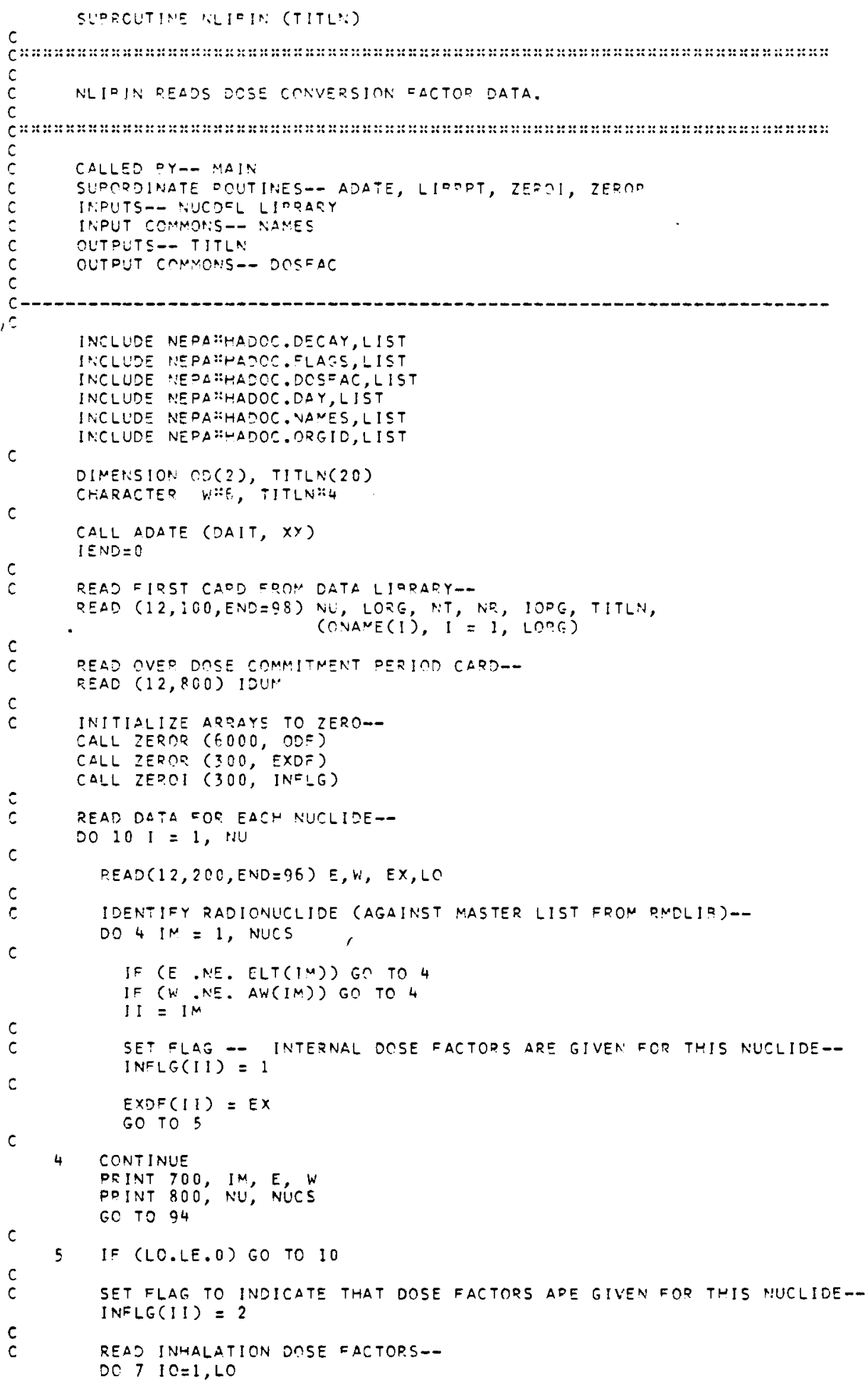

FIGURE D.0-1. Module NLIBIN 


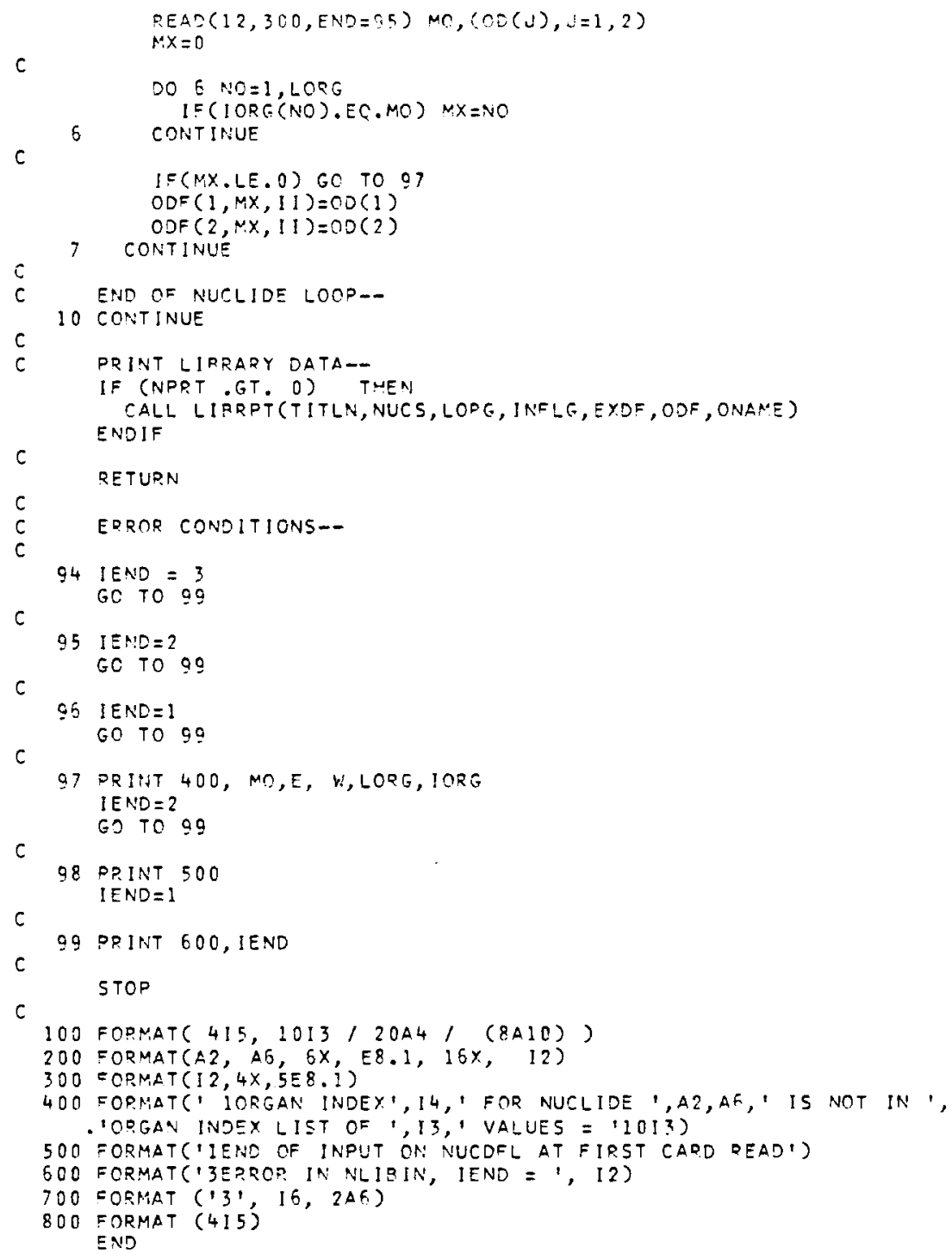

FIGURE D.0-1. Module NLIBIN 


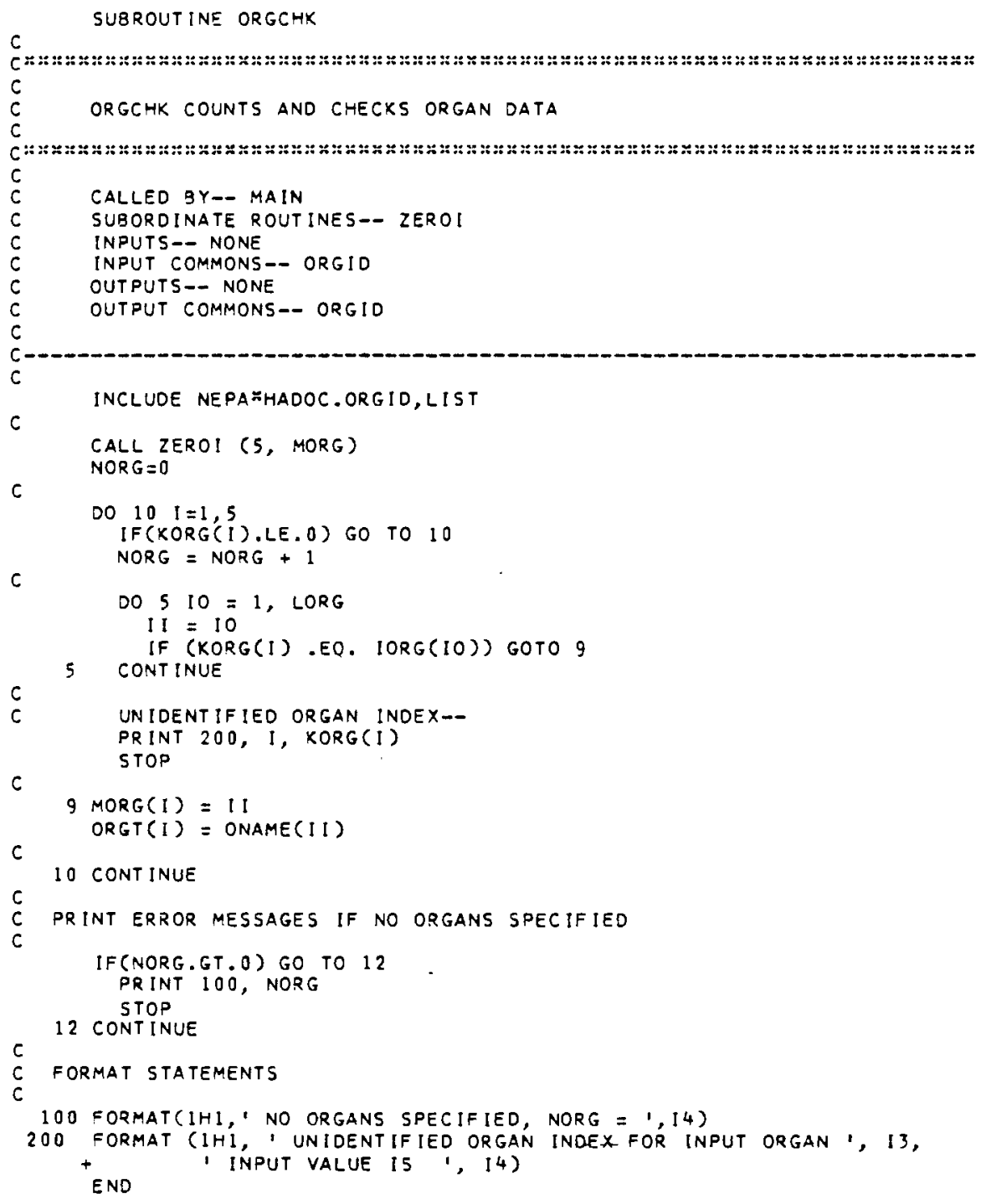

\section{FIGURE D.0-1. Module ORGCHK}




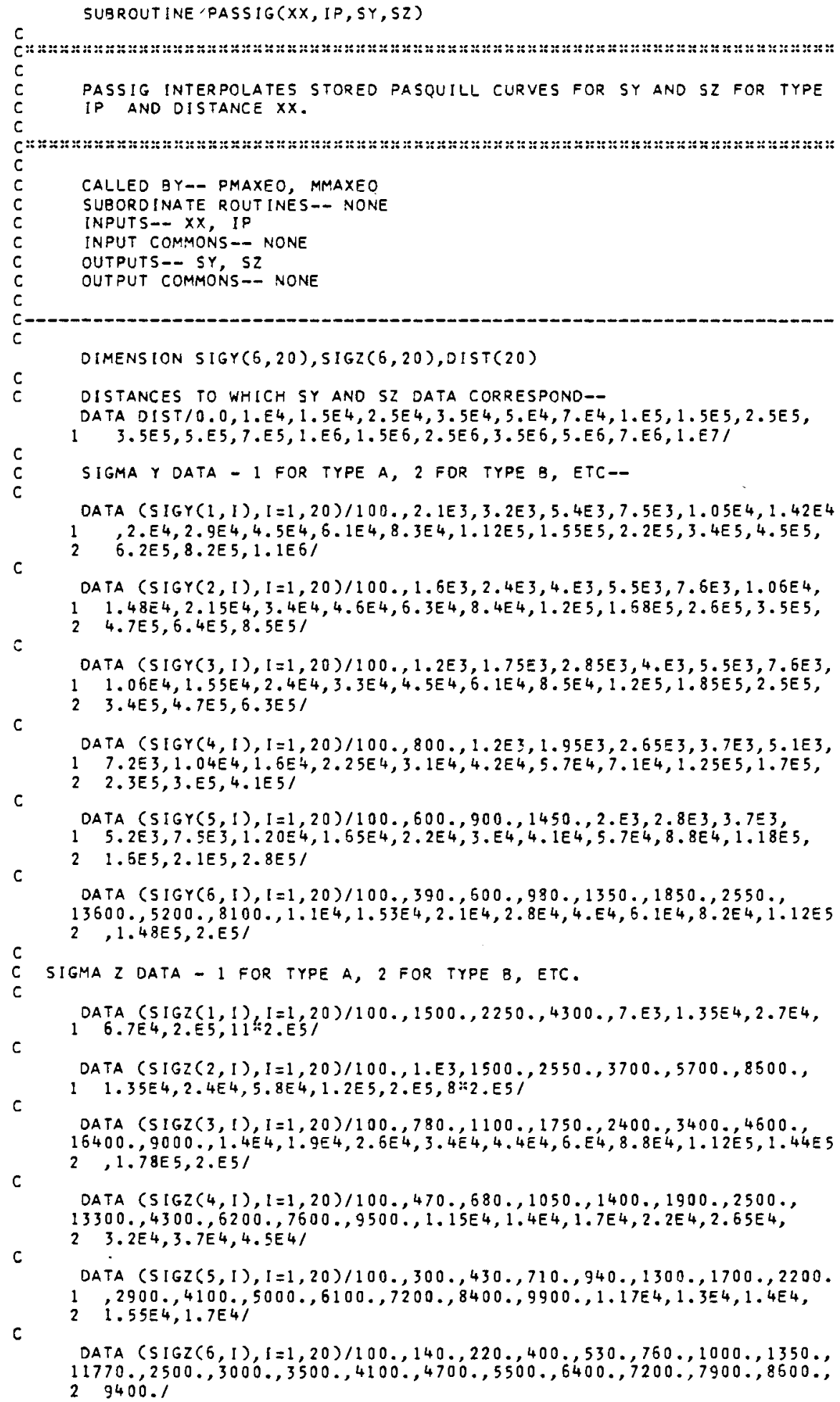

DATA (SIGY $(4,1), I=1,20) / 100 ., 800,1.2 E 3,1.95 E 3,2.65 E 3,3.7 E 3,5.1 E 3$, $17.2 E 3,1.04 E 4,1.6 E 4,2.25 E 4,3.1 E 4,4.2 E 4,5.7 E 4,7.1 E 4,1.25 E 5,1.7 E 5$,

DATA (SIGZ(6,I), I=1,20)/100,,140,220, 400,,530,,760,,1000,,1350, $11770 ., 2500 ., 3000 ., 3500,4100 ., 4700 ., 5500,6400 ., 7200 ., 7900 ., 8500 \%$ 29400.1

\section{FIGURE D.0-i. Module PASSIG}




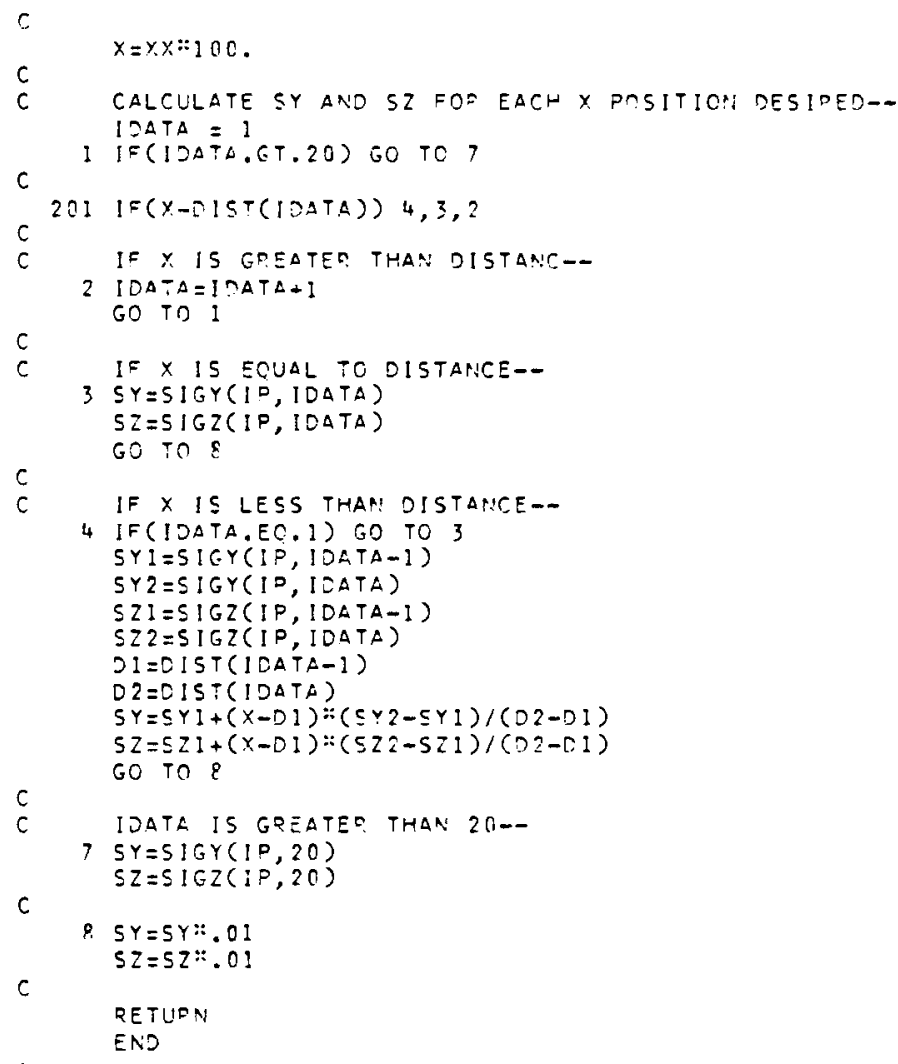

FIGURE $0.0-1$. ModuTe PASSIG 


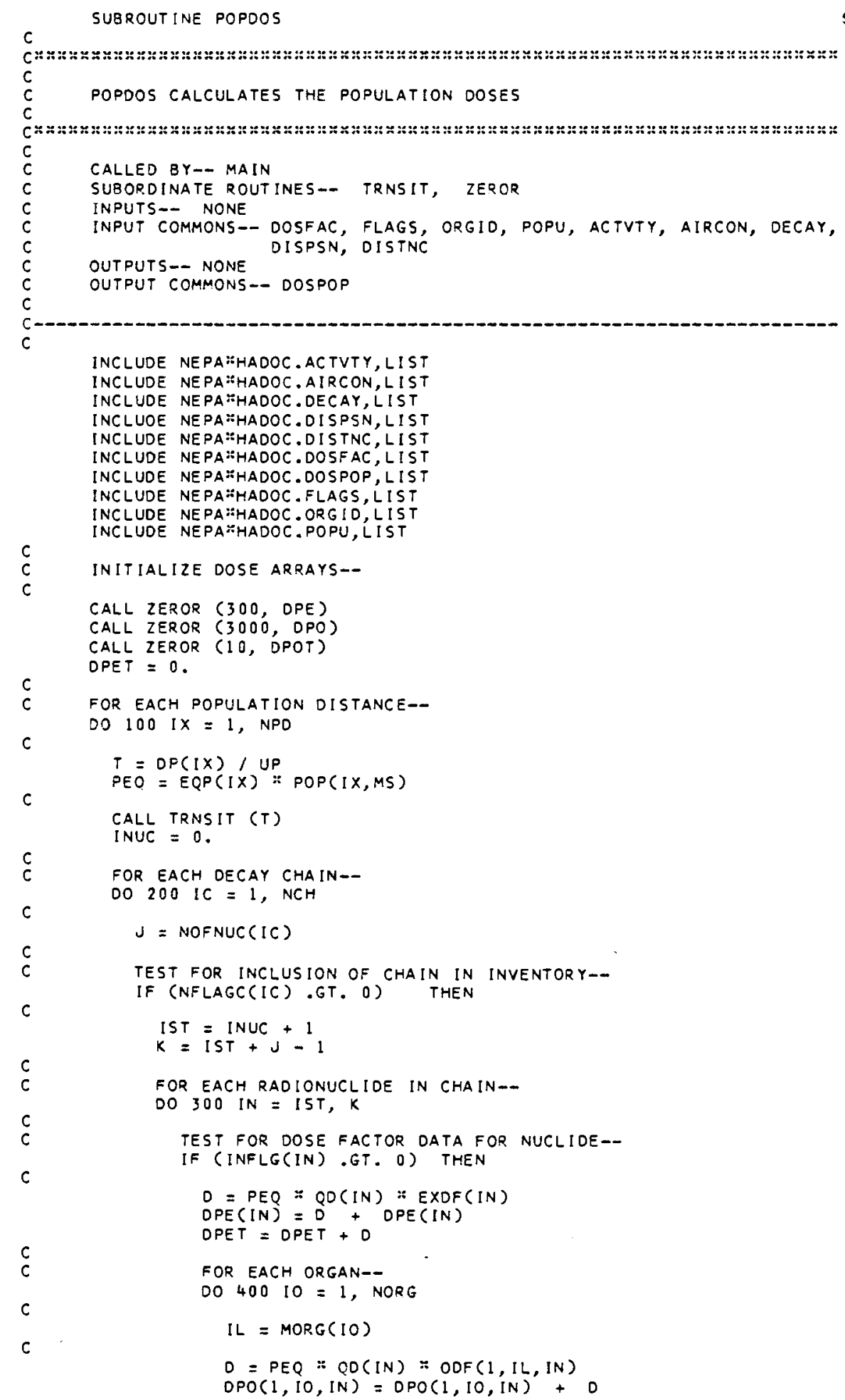

FIGURE D.0-1. Module POPDOS 


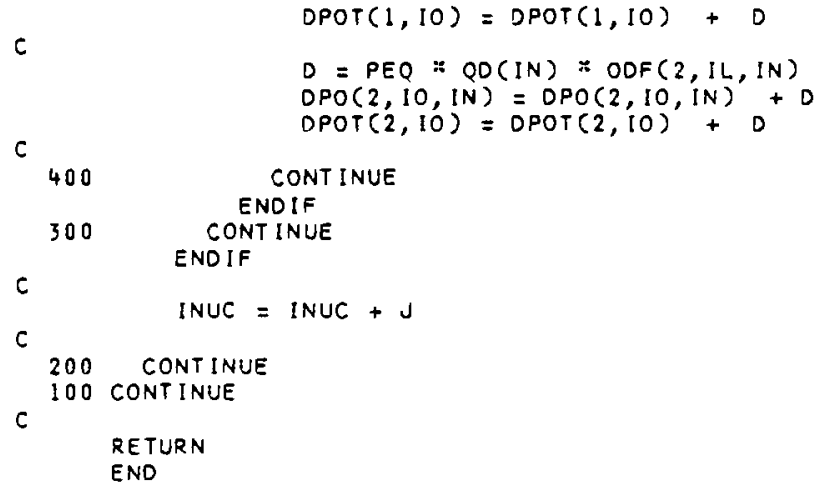

FIGURE D.0-1. Module POPDOS 


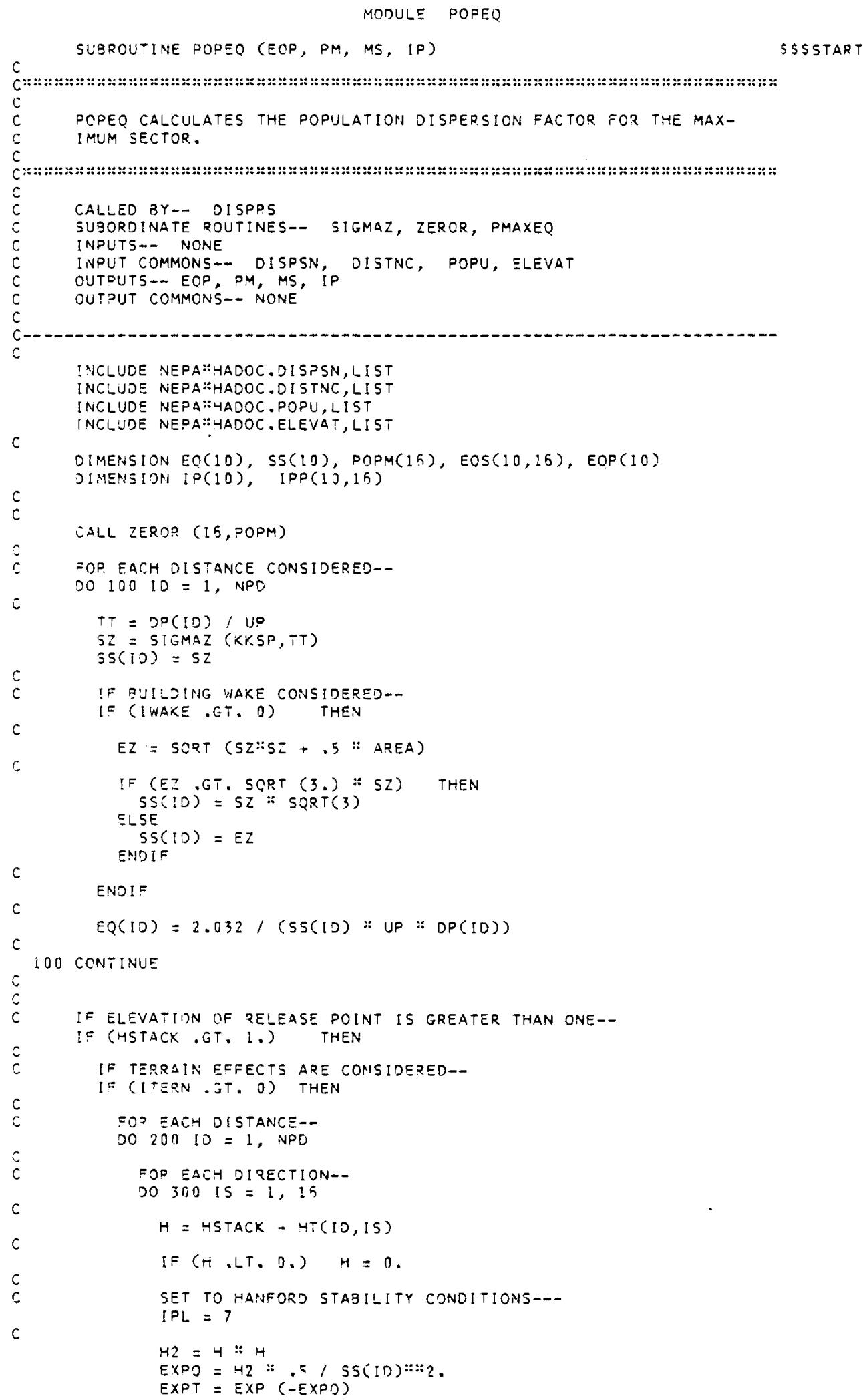

FIGURE $0.0-1$. Module POPEQ 


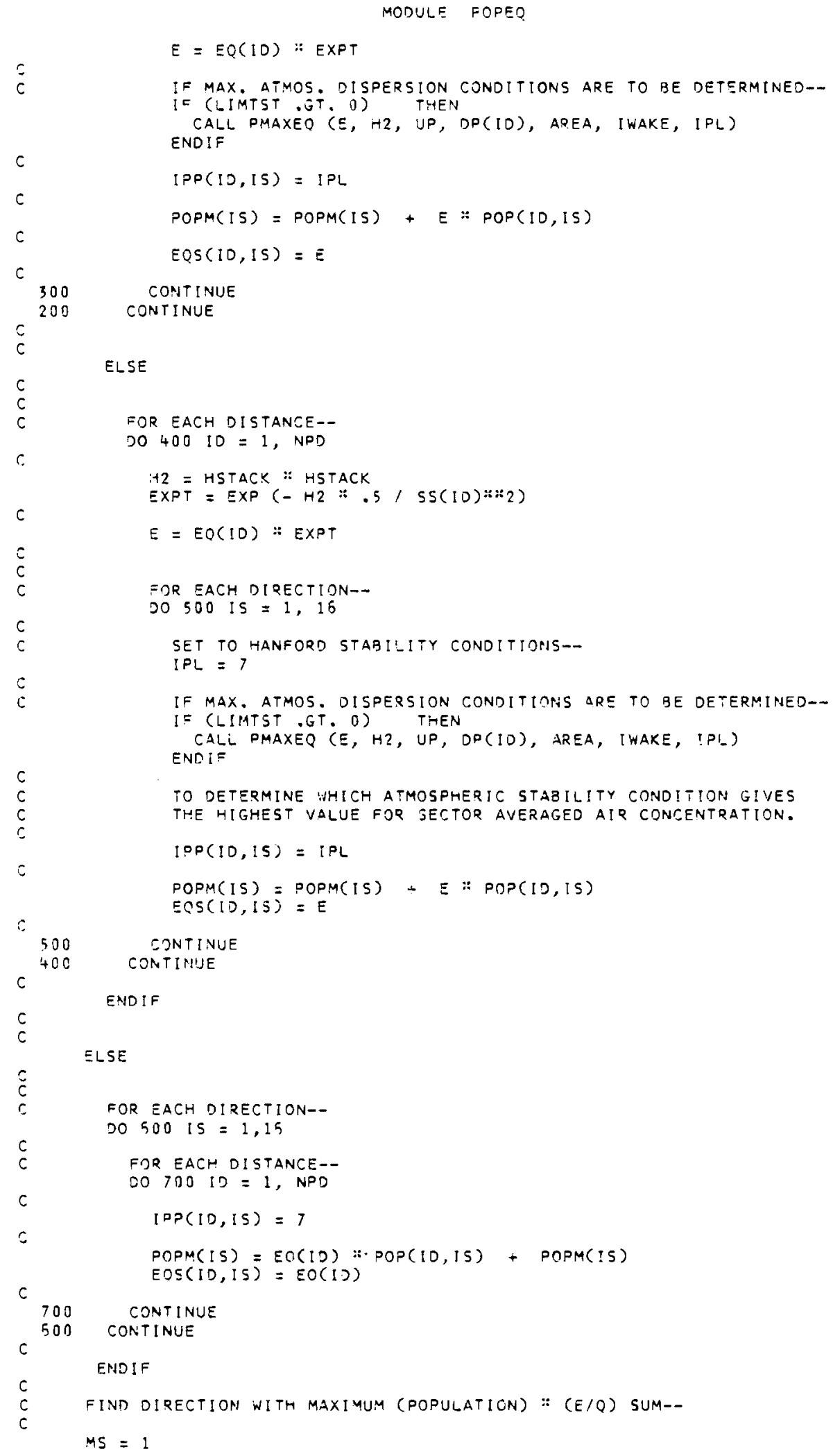

\section{FIGURE D.0-1. Module POPEQ}




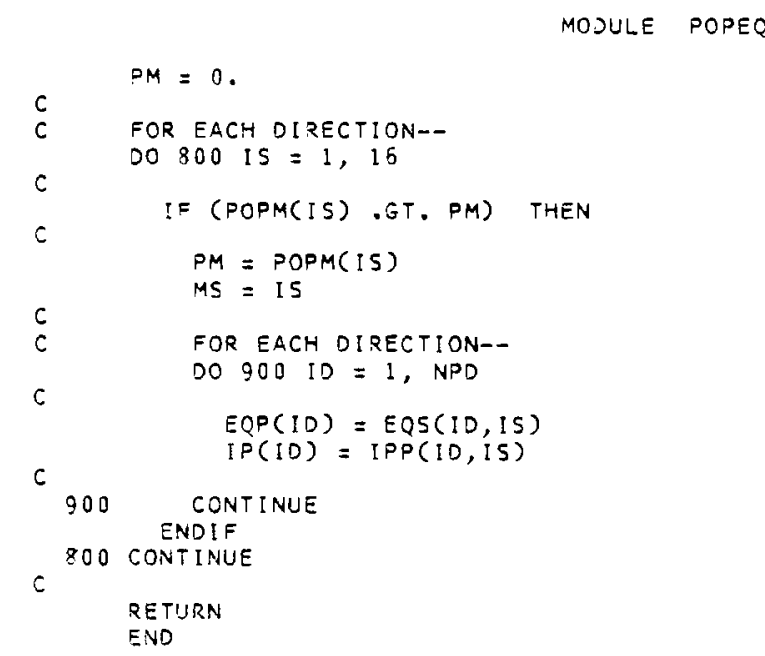

FIGURE D.0-1. ModuTe POPEQ

D. 31 
MODULE PMAXEQ

SUBROUTINE PMAXEQ ( $E$, H2, UP, $X$, AREA, IWAKE, IPL) \$S5START

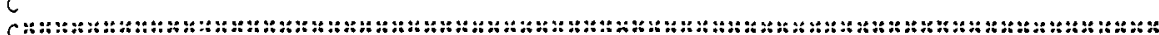

c PMAXEQ DETERMINES WHICH ATMOSPHERIC STAGILITY CONDITION GIVES

THE HIGHEST VALUE COR SECTOR AVERAGED AIR CONCENTRATION.

A:4:

c

CALIED BY-- POPEO

SUAOROINATE ROUTINES-- PASSIO

INPUTS-- H2, IJP, $x$, AREA, IWAKE

INPLIT COMMONS-- NONE

OUTPHTS-- E, IPL

OUTPUT COMMONS-- NONE

SET CONDITION INDEX FOR HANFUPO--

$I P L_{-}=7$

C TEST FJR ELEVATED RELEASE--

FOR EACH PASOUILL CONOITION--

20100 IP $=1,5$

CALL PASSIG (X, IP, SY, SZ)

TO CALCULATE SIGMA Y AND SIGIMA Z FOR PASOUILL DISPERSION

¿ATEGORIES.

IF EUIDING WAKE CENSIDERED--

IF (IHAKE .GT. D) THEN

$E Z=S O R T(5 Z: 5 Z+.5:$ AQEA)

IF (EZ.LT. SOQT (3.) * SZ) THEN

$5 S=5 Z: \because$ SORT $(3$.

ELSE

$S S=E Z$

ENDIF

ELSE

$\therefore 55=52$

C

$c$

$c$

GE $=2.032 /(\subseteq 5:$ UP $: x): \operatorname{ExP}(-H 2: .5 ;(55: 35))$

I (ES .GT.E) THEN

$I^{\circ} L=I P$

$E=E E$

END! :

100 CONTINUE
ENOIF

P.ETISRN

END

FIGURE $0.0-1$. Module PMAXEQ

D. 32 
SUBROUTINE QAPAGE (TITLEI, TITLR, TITLN, QI, FINV, IFRAC, KKRPT, FRAC) SSSSTART

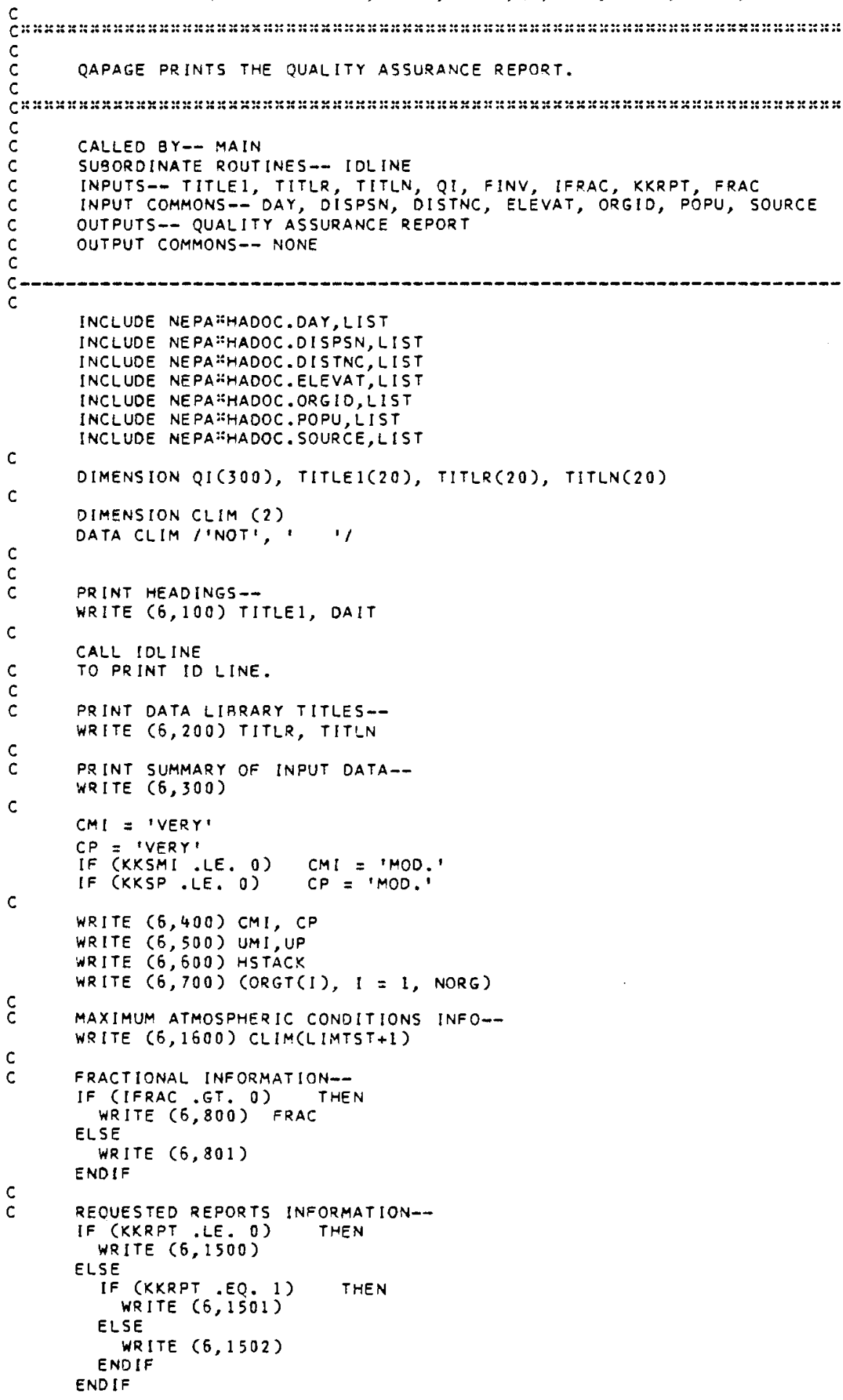

FIGURE D.0-1. ModuTe QAPAGE 


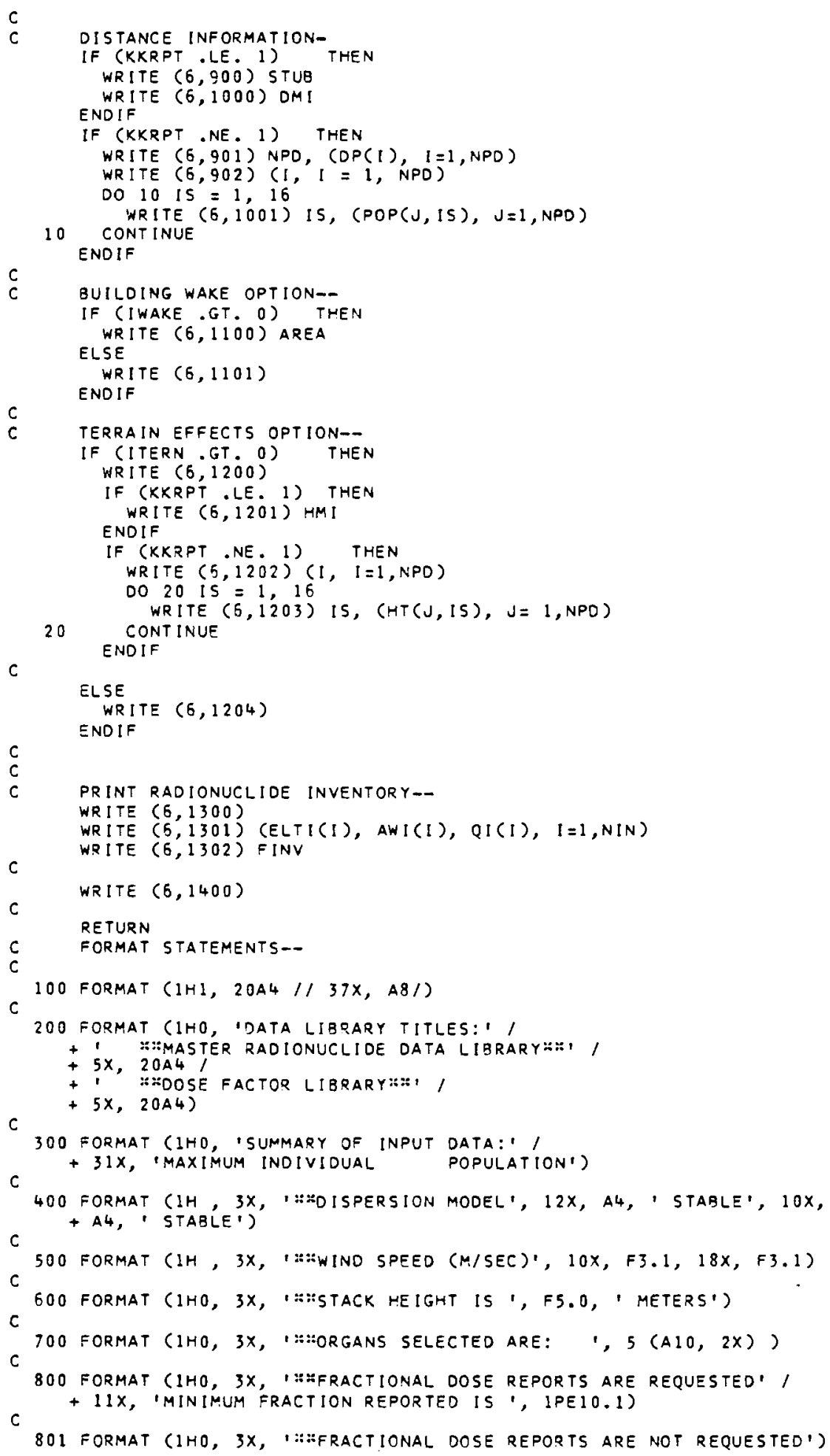

FIGURE $0.0-1$. ModuTe QAPAGE 


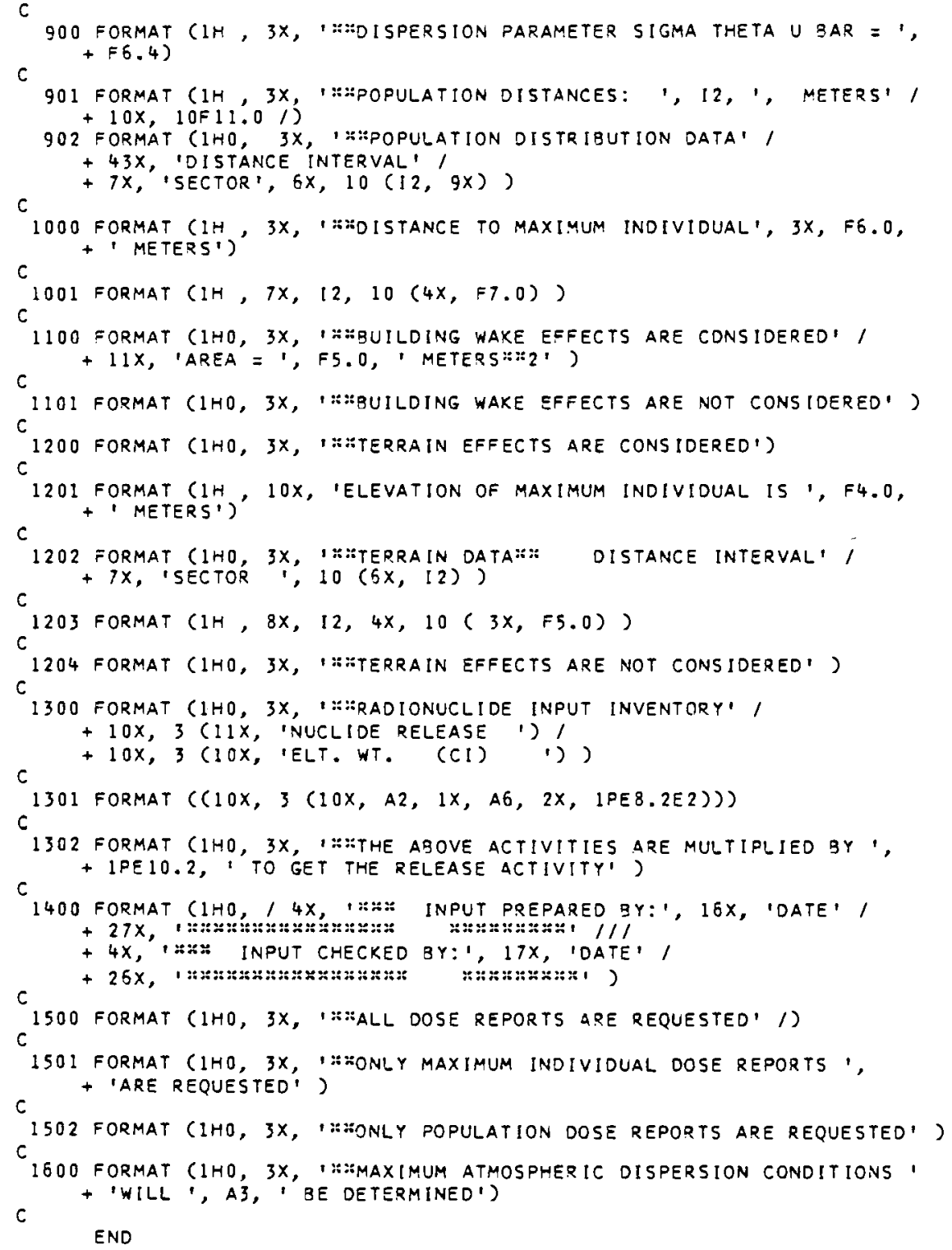

\section{FIGURE D.0-1. ModuTe QAPAGE}




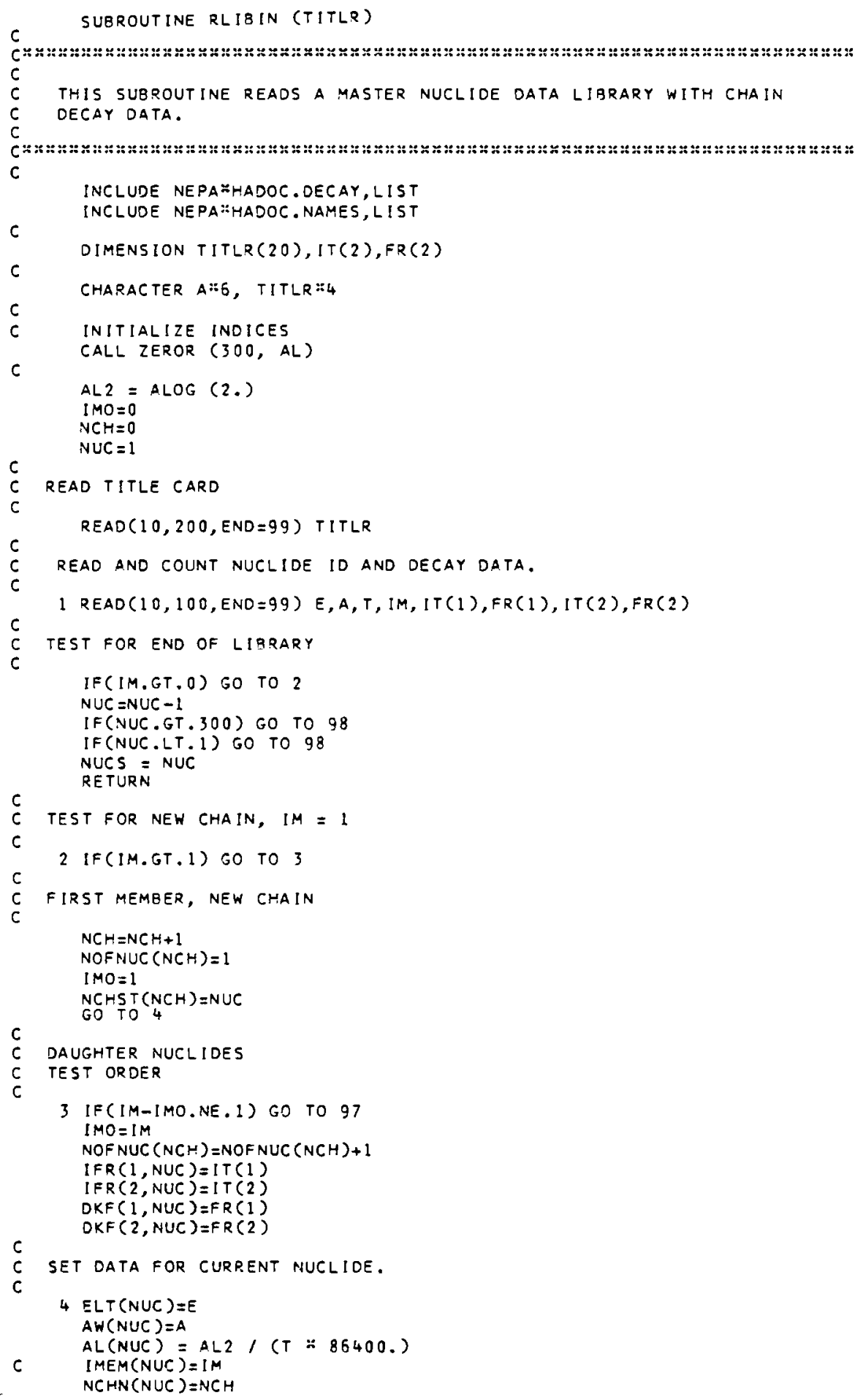

FIGURE D.0-1. ModuTe RLIBIN 


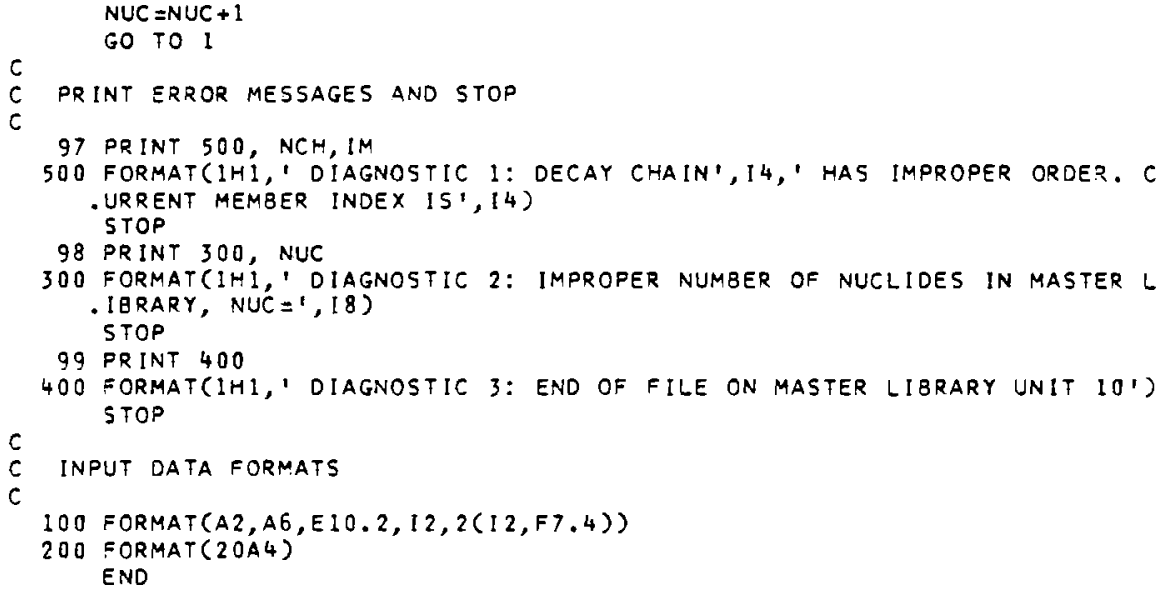

FIGURE $0.0-1$. Module RLIBIN 
FUNCTION SIGMAY (TT, STUB)

د:

$c$

C :

C CALLED BY-D DISPRS

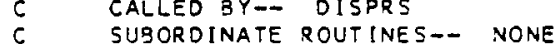

C INPUTS-- TT, STUB

C INPUT COMMONS - NONE

C OUTPUTS-- SIGMAY

C OUTPUT COMMONS-- NONE

C-D--

$c$

$A=13 .+230 . \approx 5 T U B$

ALPHA $=0.5 * A /$ (STUB $*$ STUB)

EXPO $=T T /$ ALPHA

$c$

c

$c$

SY2 = A : (TT - ALPHA $:(1 .-\operatorname{EXP(-EXPO)~)~}$

SIGMAY = SQRT (SYZ)

RETURN

END

FIGURE D.0-1. Module SIGMAY 
FUNCTION SIGMAZ (KS, TT)

\$\$START C

c

SIGMAZ CALCULATES SIGMA Z AT A GIVEN LOCATION.

"

c

CALLED BY-- DISPRS, POPEQ

SUBOROINATE ROUTINES-- NONE

INPUTS - KS, TT

INPUT COMMONS - NONE

OUTPUTS-- SIGMAZ

OUTPUT COMMONS-- NONE

C

IF (KS .GT. O) THEN

$\mathrm{C}$

EXPO $=8.8 E-4: T T * T T$

$5 Z 2=34 . *(1 .-\operatorname{EXP}(-\operatorname{EXPO}))+.025=\mathrm{TT}$

ELSE

EXPO $=2.54 E-4 * T T \because T T$

$5 Z 2=97 . \because(1-\operatorname{EXP}(-\operatorname{EXPO}))+.33 \approx T T$

ENDIF

SIGMAZ $=$ SQRT $(\$ Z 2)$

RETURN

END

FIGURE $0.0-1$. Module SIGMAZ 
MODULE TRNSIT

SUBROUT [NE TRNSIT (T)

A:

C TRNSIT CONTROLS radiological deCAY CALCULATIONS.

C

C CALLED BY-- POPDOS, MIDOSE

C SURORDINATE ROUTINES-- ACHAIN

C INPUTS- T

C INPUT COMMONS-- ACTVTY, DECAY, FLAGS

C OUTPUTS-- NONE

C OUTPUT COMMONS-- ACTVTY

c

INCLUDE NEPA:HADOOC.ACTVTY, LIST

INCLUDE NEPA:HADOC.DECAY, LIST

C

INCLUDE NEPA:HADOC.FLAGS, LIST

C

FOR EACH CHAIN--

DO 100 IC $=1, \mathrm{NCH}$

C IF DATA SUPPLIEO FOR ANY RADIONUCLIOES IN THIS CHAIN--

IF (NFLAGC (IC) .GT. O) THEN

$J=$ NOFNUC $(I C)$

IST $=$ INUC +1

$K=I S T+J-1$

$c$

CALL ACHAIN (J, T, DKF(I, IST), IFR(1,IST), AL(IST), Q(IST), $Q D(15 T), 0)$

C

$$
\begin{array}{ll}
\text { OO } 2001 N=I S T,{ }^{K} & \text { QD(IN) }=\text { QD(IN) } \because A L(I N) \\
200 \quad \text { CONTINUE } &
\end{array}
$$

C

ENOIF

$c$

C

INUC $=$ INUC + NOFNUC (IC)

100 CONTINUE

RETURN

ENO

FIGURE $0.0-1$. Module TRNSIT 


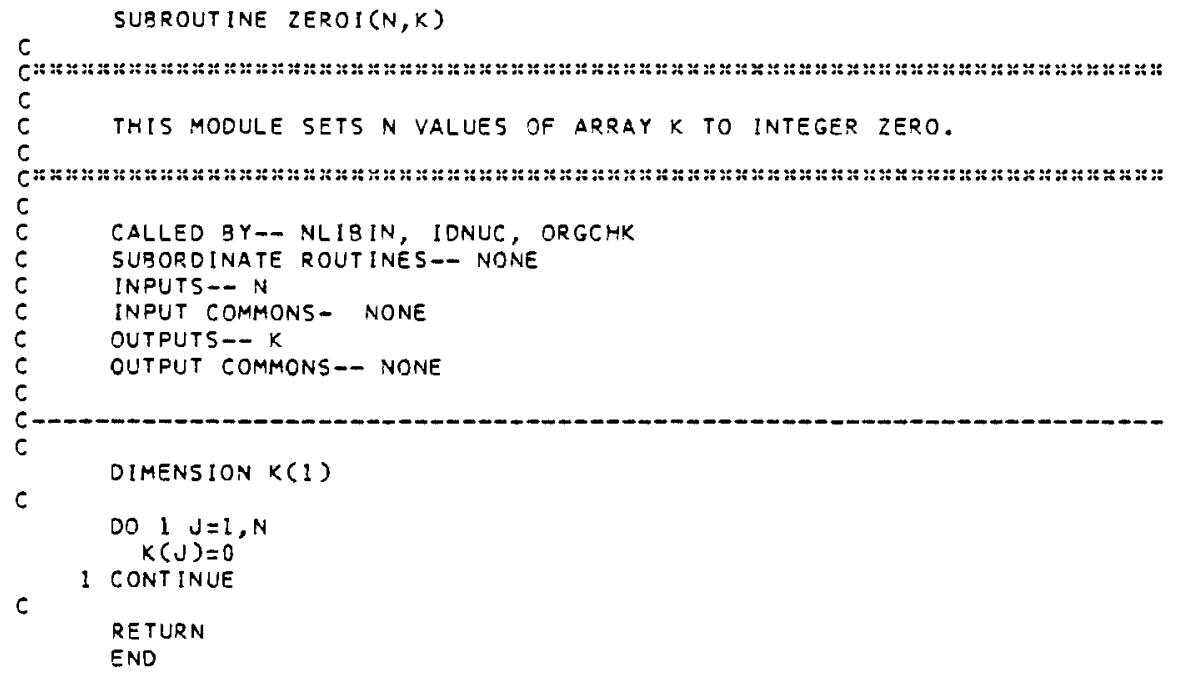

FIGURE D.0-1. Module ZEROI 


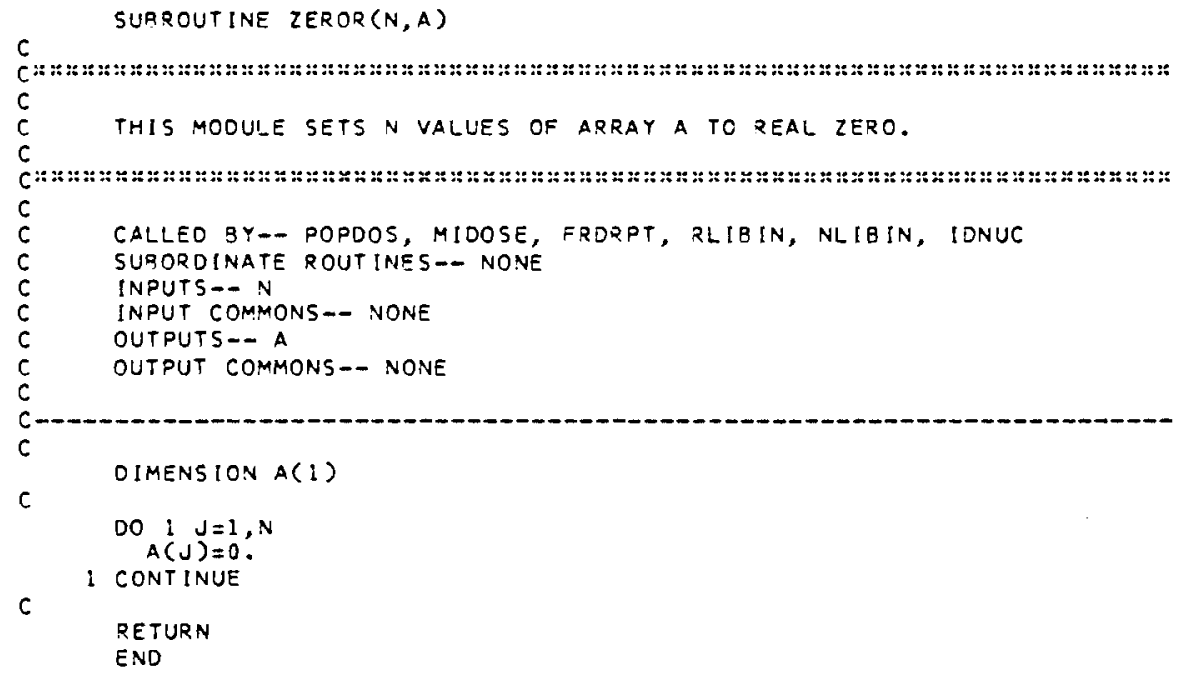

FIGURE D.0-1. Module ZEROR 


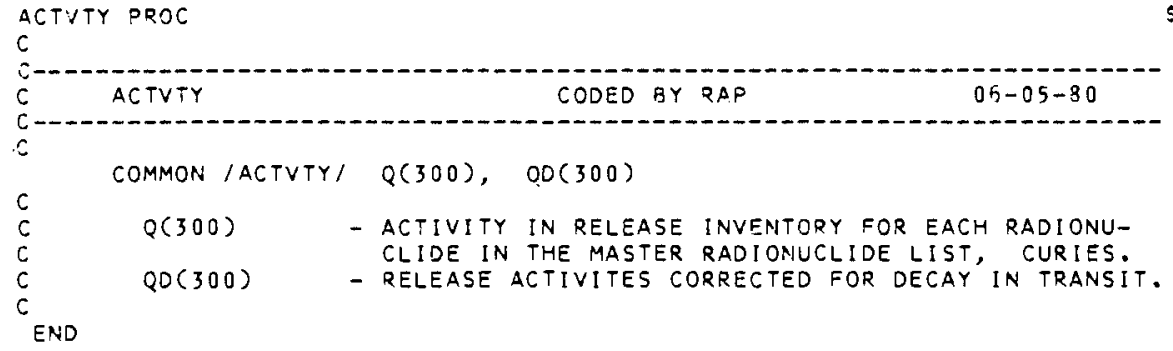

\section{FIGURE D. $0-1$. Common Blocks}




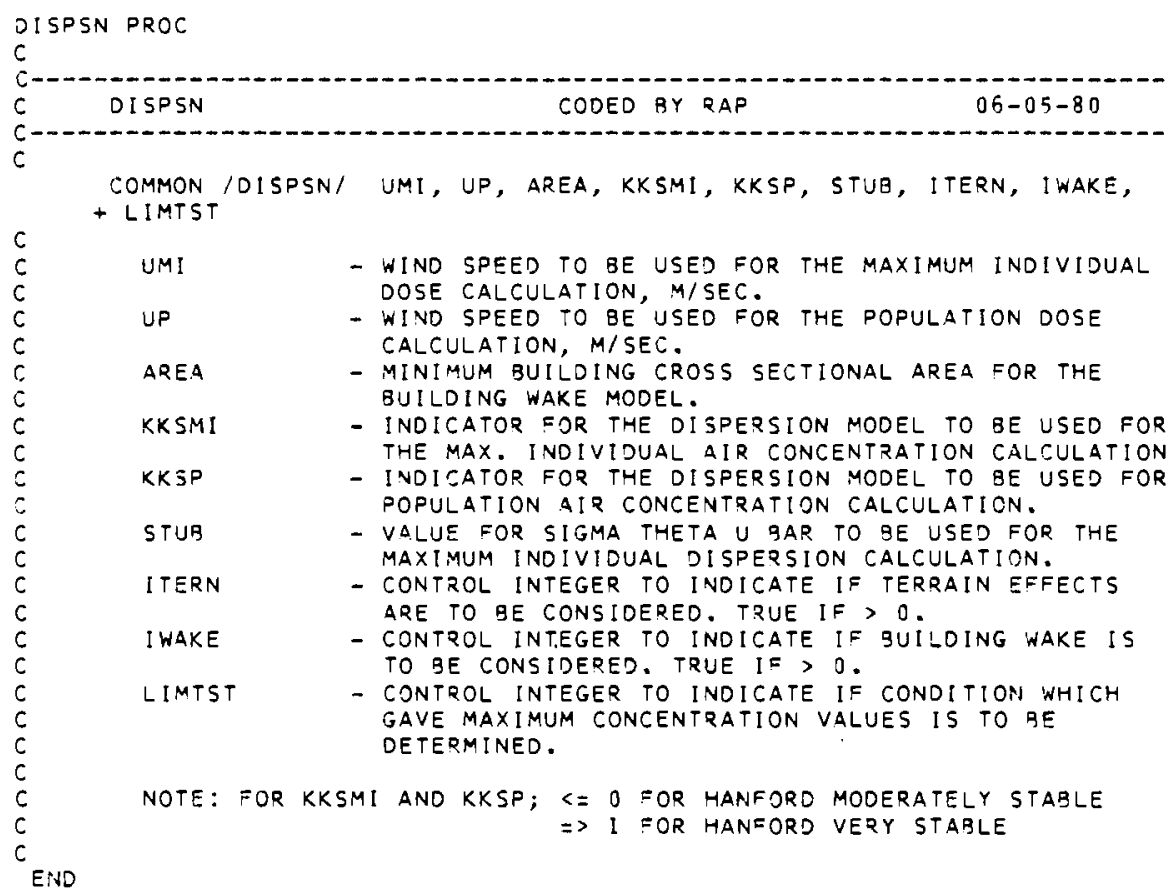

$C$
$C$

COMMON /DISPSN/ UMI, UP, AREA, KKSMI, KKSP, STUB, ITERN, IWAKE, + LIMTST

DOSE CALCULATION, M/SEC.

UP

AREA

KKSMI

KKSP

STUR

I TERN

IWAKE

LIMTST

NOTE: FOR KKSMI AND KKSP: $\angle=0$ FOR HANFORO MODERATELY STABLE $\Rightarrow I$ FOR HANFORD VERY STABLE

END

DISTNC PROC

$\mathrm{C}$
$\mathrm{C}$

COMMON IDISTNC/ NPD, DP(10), DMI

C NPD

DOSE CALCULATION. I $\angle=$ NPD $\Rightarrow 10$.

C DP(10) - DISTANCES FRON THE RELEASE POINT TO THE CENTER OF

EACH POPULATION RING, M. NPD VALUES MUST

GIVEN IN INICREASING ORDER.

END OF THE MAXI:AUM INDIVIDUAL.

DOSFAC PROC

$\mathrm{C}$

C DOSFAC CODED BY RAP

C CODED BY RAP

COMMON /OOSFAC/ EXDF(300), ODF $(2,10,300)$

EXDF(300) - EXTERNAL DOSE CONVERSION FACTORS FOR AIP SUMMERSION FOR EACH RADIONUCLIDE, PEM PER CI SEC/M::3.

OOF(2,10,300)- INHALATION DOSE CONVERSION FACTORS FOR TWO TIME

PERIODS, 10 ORGANS AND 300 RADIONUCLIDES. REM PER CI SEC, M::3.

END

FIGURE D.0-1. Common Blocks 


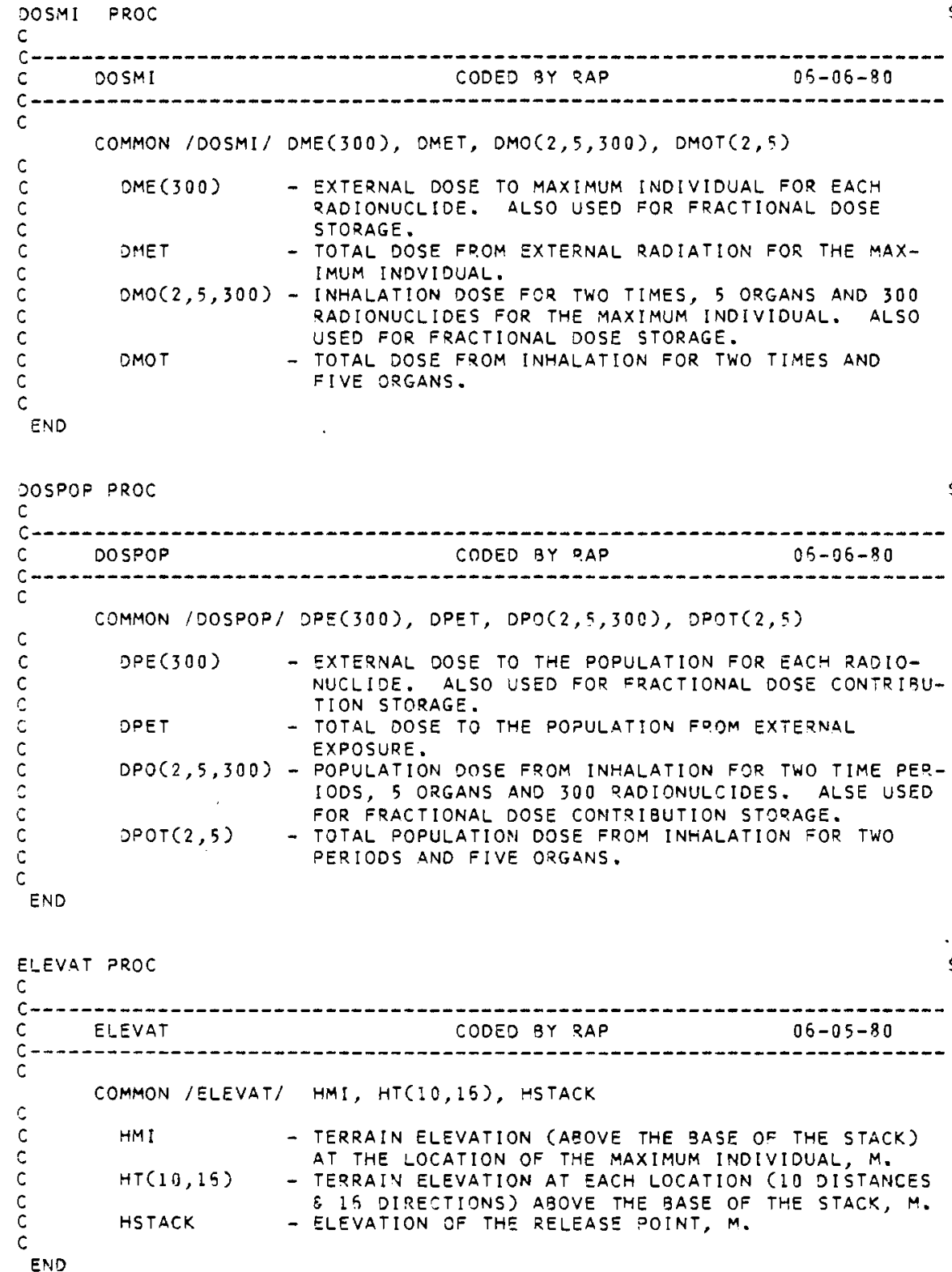

FIGURE $0.0-1$. Common Blocks 


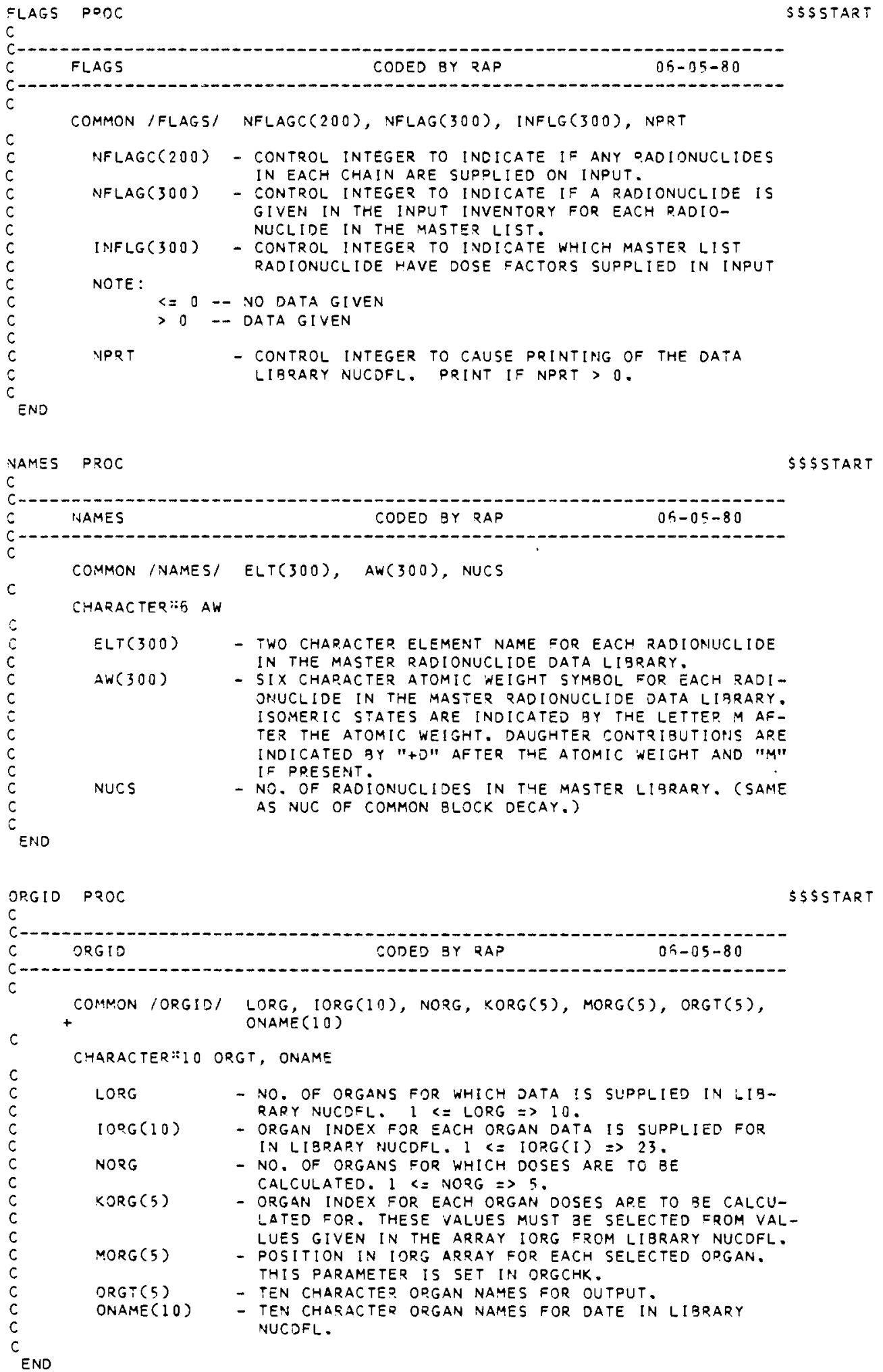

\section{FIGURE D.0-1. Common Blocks}




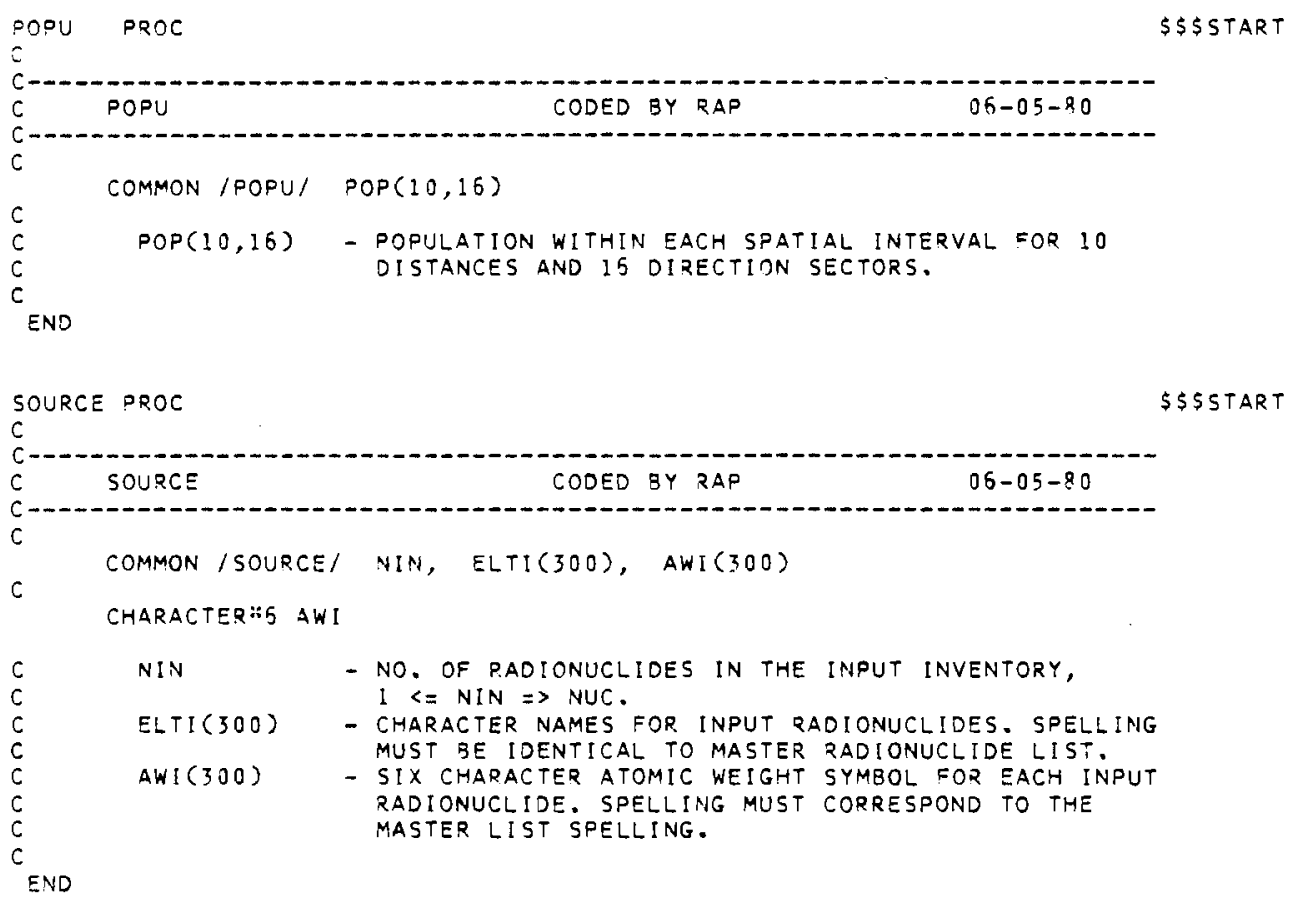

FIGURE D.0-1. Common Blocks 


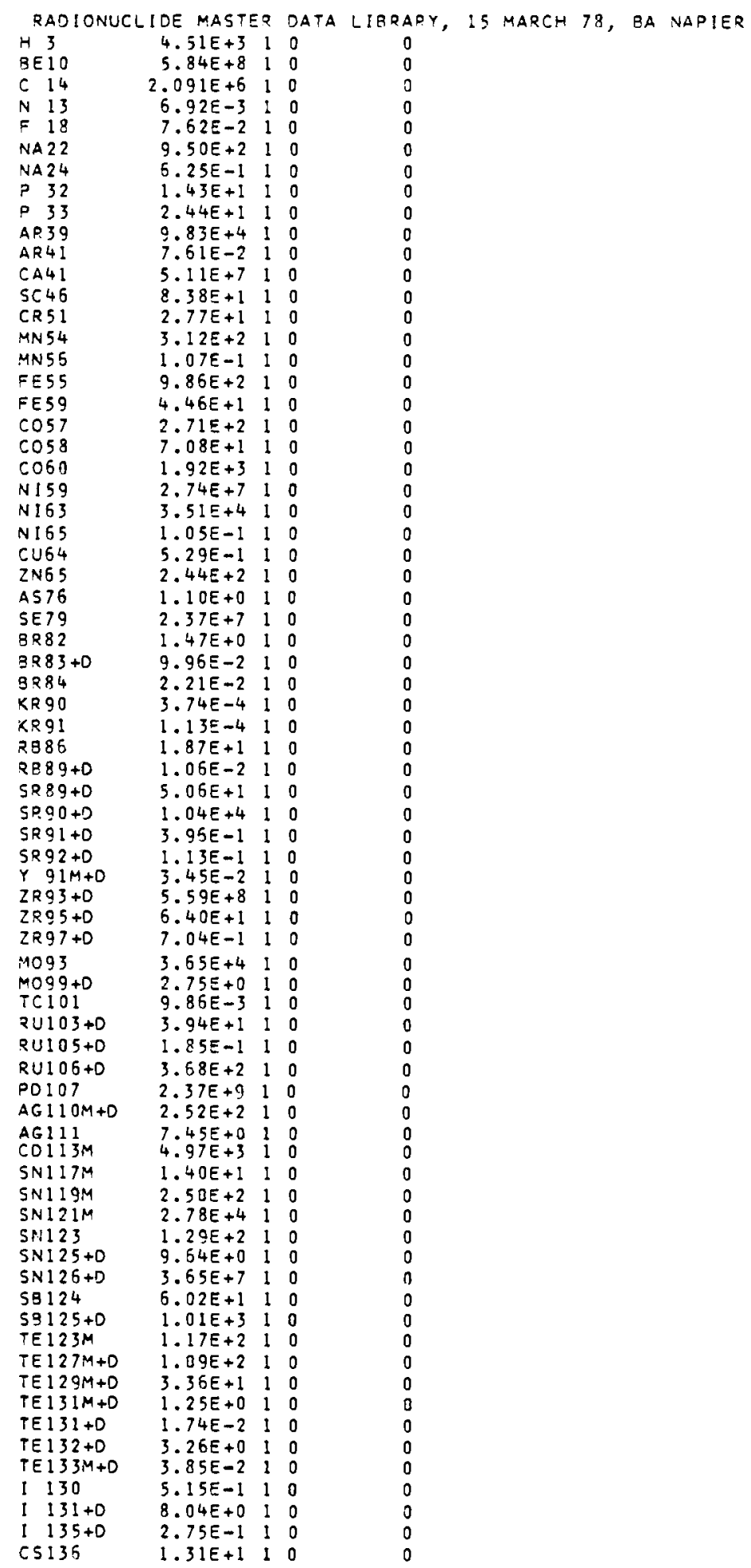

FIGURE D.0-2. Radionuclide Master Data Library-RMDLIB 


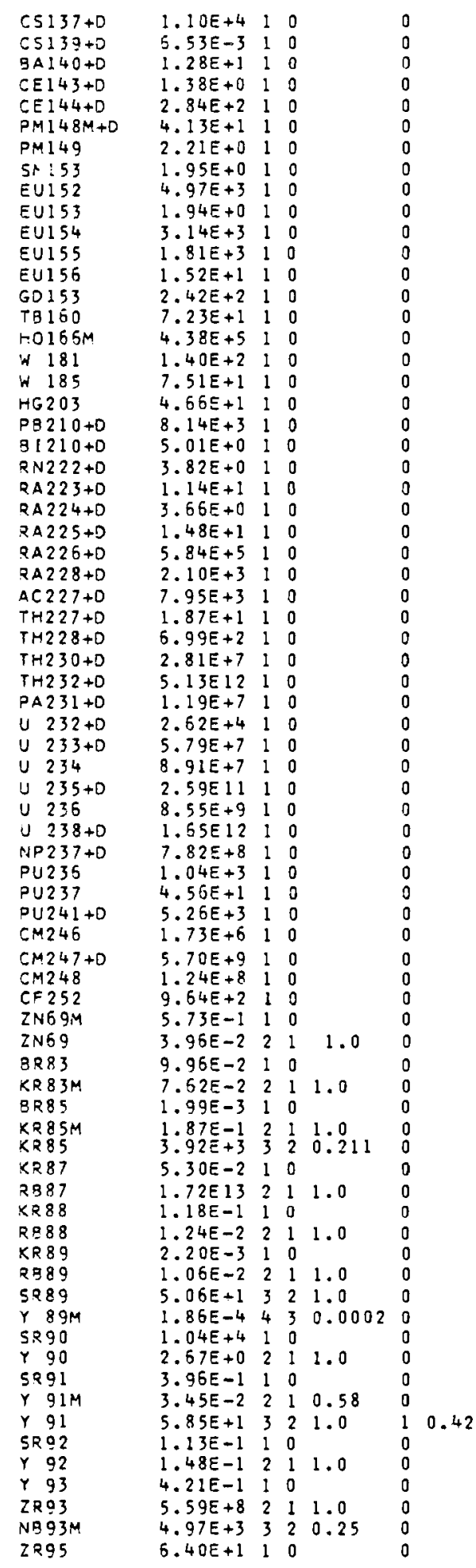

FIGURE D.0-2. Radionuclide Master Data Library-RMDLIB 


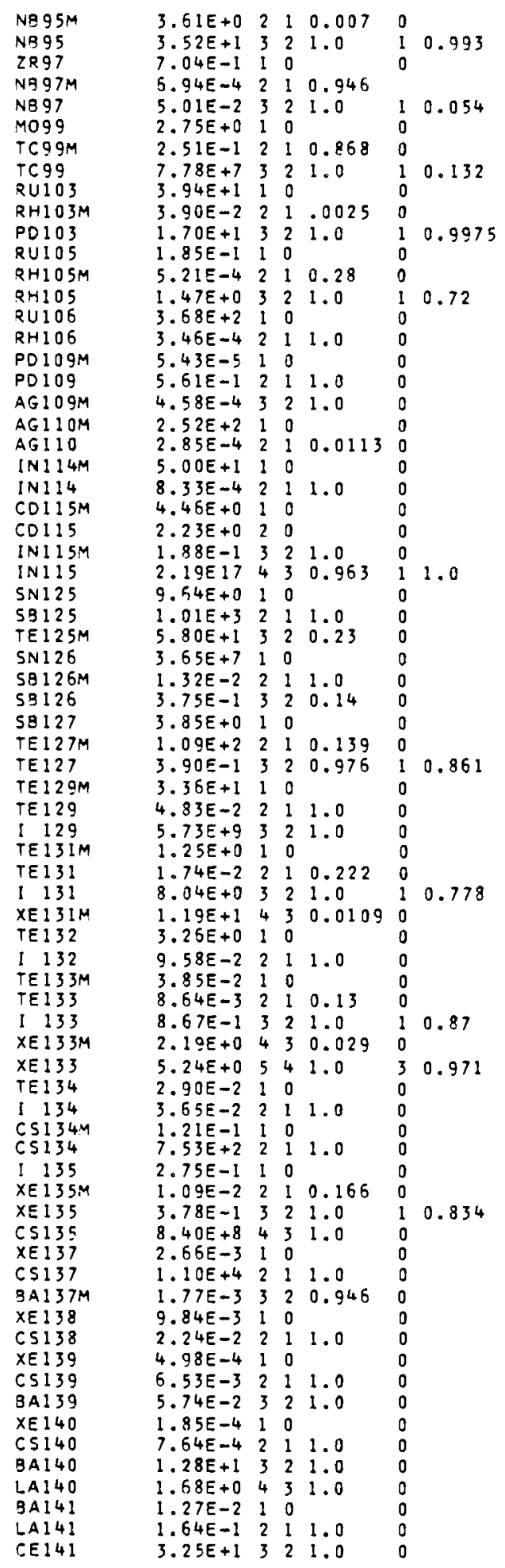

FIGURE D.0-2. Radionuclide Master Data Library-RMDLIB 


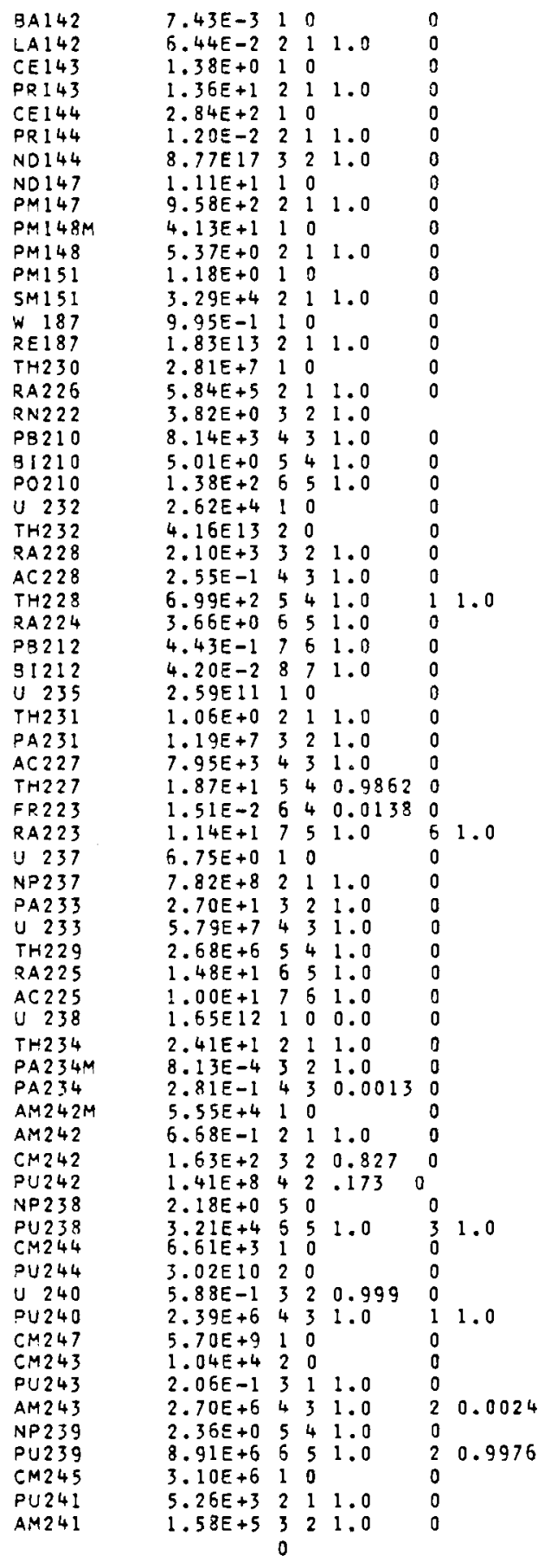

FIGURE D.0-2. Radionuclide Master Data Library-RMDLIB 
FILE 10 JATA LIBRARY

\begin{tabular}{|c|c|c|c|c|c|}
\hline $\begin{array}{l}100 \\
\text { CW:AS } \\
\text { TOTAL }\end{array}$ & $\begin{array}{l}7 \\
\text { ATA LIPSA } \\
\text { ROOYKIDNE }\end{array}$ & $\begin{array}{l}2 \\
\text { AUG }\end{array}$ & $\begin{array}{l}1 \\
\text { OSER }\end{array}$ & $\begin{array}{l}\text { E } \\
\text { RONE }\end{array}$ & LUNGS \\
\hline 1 & 50 & 30 & & & \\
\hline 3 & & $0.00+00$ & $0.00+00$ & $0.00+00$ & 6 \\
\hline 1 & $2.50-02$ & $2.60-02$ & $1.50-02$ & $1.70-02$ & $1.70-02$ \\
\hline 3 & $2.50-02$ & $2.50-02$ & $1.60-02$ & $1.70-02$ & $1.70-02$ \\
\hline 4 & $2.50-02$ & $2.50-02$ & $1.60-02$ & $1.70-02$ & $1.70-02$ \\
\hline$\varepsilon$ & $2.50-02$ & $2.60-02$ & $1.60-02$ & $1.70-02$ & $1.70-02$ \\
\hline 16 & $2.50-02$ & $2.60-02$ & $1.50-02$ & $1.70-02$ & $1.70-02$ \\
\hline 23 & $2.60-02$ & $2.50-02$ & $1.50-02$ & $1.70-02$ & $1.70-02$ \\
\hline RE 10 & & 0.0 & & & \\
\hline 1 & $4.80+00$ & $5.30+00$ & $1.90+100$ & $4.10+00$ & $4.10+00$ \\
\hline 3 & $2.50+01$ & 2. $80+01$ & $1.10+01$ & $1.90+01$ & $1.90+01$ \\
\hline 4 & $2.20+01$ & $3.70+01$ & $8.50+00$ & $2.40+01$ & $40+01$ \\
\hline 6 & $1.10+02$ & $2.50+02$ & $3.00+01$ & $1.70+02$ & $1.70+02$ \\
\hline 8 & $3.80+01$ & $3.80+01$ & $2.00+01$ & $2.50+01$ & $2.50+01$ \\
\hline 23 & $5.00+00$ & $5.00+00$ & $3.20+00$ & $3.30+00$ & $3.30+00$ \\
\hline C 14 & & $0.00+00$ & $0.00+00$ & $7.55-04$ & 7 \\
\hline 1 & $1.20-01$ & $1.20-01$ & $7.50-02$ & $7.88-02$ & $7.98-02$ \\
\hline 3 & $1.20-01$ & $1.20-01$ & $7.60-02$ & $7.88-02$ & -02 \\
\hline 4 & $1.20-01$ & $1.20-01$ & $7.60-02$ & $7.89-02$ & $7.88-02$ \\
\hline 6 & $5.99-01$ & $5.09-01$ & $3.30-01$ & $3.04-01$ & $3.94-01$ \\
\hline$\varepsilon$ & $1.20-01$ & $1.20-01$ & $7.20-02$ & $7.90-02$ & $7.90-02$ \\
\hline 16 & $1.20-01$ & $1.20-01$ & 7. $50-02$ & $7.88-02$ & -02 \\
\hline 23 & $3.30-01$ & $3.30-01$ & $2.10-01$ & $2.10-01$ & -01 \\
\hline$C A 41$ & & $0.00+00$ & $0.00+00$ & $0.00+00$ & 4 \\
\hline 1 & $1.81-01$ & $6.36-00$ & $6.00=02$ & 4. $21=00$ & $4.41+00$ \\
\hline$E$ & $1.53+00$ & $5.00+01$ & $5.40-01$ & $3.00+01$ & $10+01$ \\
\hline$\varepsilon$ & $6.58-01$ & $6.62-01$ & $3.50-01$ & $4.40-01$ & $4.40-01$ \\
\hline 23 & $3.50-02$ & $3.50-02$ & $2.20-02$ & $2.30-02$ & $2.30-02$ \\
\hline CR.51 & & 5. $.55=?$ & $7.17-3$ & $7.20-3$ & 5 \\
\hline 1 & $8.40-2$ & $8.40-2$ & $4.90-2$ & $5.50-2$ & $5.50-2$ \\
\hline 3 & 1. $90-2$ & $1.90-2$ & $1.10-2$ & $1.20-2$ & $1.20-2$ \\
\hline 8 & $1.40+0$ & $1.40+0$ & $8 .: 0-1$ & $9.03-1$ & $9.03-1$ \\
\hline 15 & $5.00-2$ & $5.00-2$ & $2.90-2$ & $3.30-2$ & $3.30-2$ \\
\hline $2 z$ & $1.20-1$ & $1.20-1$ & $7.70-2$ & $7.70-2$ & $7.70-2$ \\
\hline MN54 & & $1.09-01$ & $2.08-01$ & $2.09-01$ & 4 \\
\hline 1 & $1.42+00$ & $1.42+00$ & $0-01$ & $9.40-01$ & $\therefore .40-01$ \\
\hline 4 & $8.50+00$ & $8.50+00$ & $5.10+00$ & $5.50+00$ & $60+00$ \\
\hline 8 & $1.20+02$ & $1.57+02$ & $4.70+01$ & $1.10+02$ & $0+02$ \\
\hline 23 & $2.50+00$ & $2.70+00$ & $1.70+00$ & $1.80+00$ & $1.80+00$ \\
\hline FE 55 & & $2.09-O E$ & $2.29-06$ & $2.30-06$ & 5 \\
\hline 1 & $3.20-01$ & $7.30-01$ & $1.10-01$ & $4.80-01$ & $4.80-01$ \\
\hline 4 & $1.50+00$ & $2.90+00$ & $5.50-01$ & $1.90+00$ & +00 \\
\hline 6 & $1.50+00$ & $4.50+00$ & $5.30-01$ & $3.00+00$ & $1+00$ \\
\hline 8 & $6.20+00$ & $1.10+01$ & $2.30+00$ & $7.70+00$ & $70+00$ \\
\hline 23 & $2.10-01$ & $2.20-01$ & $1.30-01$ & $1.50-01$ & $1.50-01$ \\
\hline FE5 & & $2.88-01$ & $2.97-01$ & $3.11-01$ & 5 \\
\hline 1 & E. $00+00$ & $5.10+00$ & $3.30+00$ & $4.00+00$ & $0+00$ \\
\hline 4 & $1.61+01$ & $1.61+01$ & $8.70+00$ & $1.00+01$ & +01 \\
\hline 6 & $7.00+00$ & $7.10+00$ & $3.80+00$ & $4.60+00$ & $4.60+00$ \\
\hline 8 & $5.44+01$ & $6.45+01$ & $3.50+01$ & $4.24+01$ & $4.24+01$ \\
\hline 23 & $6.10+00$ & $6.14+00$ & & $4.00+00$ & $4.00+00$ \\
\hline $\cos 8$ & & $0.00+00$ & $0.00+00$ & $0.00+00$ & 4 \\
\hline 1 & $9.60-01$ & $9.60-01$ & $6.10-01$ & $5.30-01$ & -01 \\
\hline 4 & & & & $4.60-01$ & \\
\hline 8 & $6.50+0.1$ & $6.50+01$ & $3.30+01$ & $4.30+01$ & $4.30+01$ \\
\hline $\begin{array}{l}23 \\
\cos 60\end{array}$ & $.70+00$ & $\begin{array}{l}2.70+00 \\
6.06-01\end{array}$ & $\begin{array}{l}1.80+00 \\
6.25-01\end{array}$ & $\begin{array}{l}1.80+00 \\
6.34-01\end{array}$ & $\frac{1}{4} .8$ \\
\hline 1 & $2.70+00$ & $2.70+00$ & $1.71+00$ & $1.80+00$ & $80+00$ \\
\hline 4 & $2.00+00$ & $2.00+00$ & $1.30+00$ & 1. $30+00$ & \\
\hline 8 & $4.91+02$ & $1.00+03$ & $1.80+02$ & $6.81+02$ & 02 \\
\hline 23 & $7.70+00$ & $8.30+00$ & $4.90+00$ & $5.50+00$ & $50+00$ \\
\hline N15 & & $0.00+00$ & $0.00+00$ & $0.00+00$ & 5 \\
\hline 1 & $2.98-01$ & $9.40-01$ & $1.00-01$ & $6.21-01$ & 6.22 \\
\hline 4 & $7.70-01$ & $1.90-00$ & $2.70-01$ & $1.30+00$ & +00 \\
\hline 6 & $1.54+00$ & $5.67+00$ & $5.30-01$ & $3.72+00$ & $3.72+00$ \\
\hline 8 & $5.57+00$ & $1.30+01$ & $2.00+00$ & $9.20+00$ & 00 \\
\hline 23 & $1.30-01$ & $1.50-01$ & $8.40-02$ & $5.70=02$ & $9.70-02$ \\
\hline NIE 3 & & $0.00+00$ & $0.00+00$ & $0.00+00$ & 5 \\
\hline 1 & $8.10-31$ & $2.52+00$ & $2.80-01$ & $1.65+00$ & $1.65+00$ \\
\hline 4 & $2.10+00$ & $5.20+00$ & $7.40-01$ & $3.40+00$ & $x .40+00$ \\
\hline
\end{tabular}

FIGURE D.0-3. Dose Conversion Factor Data Library-NUCDFL 


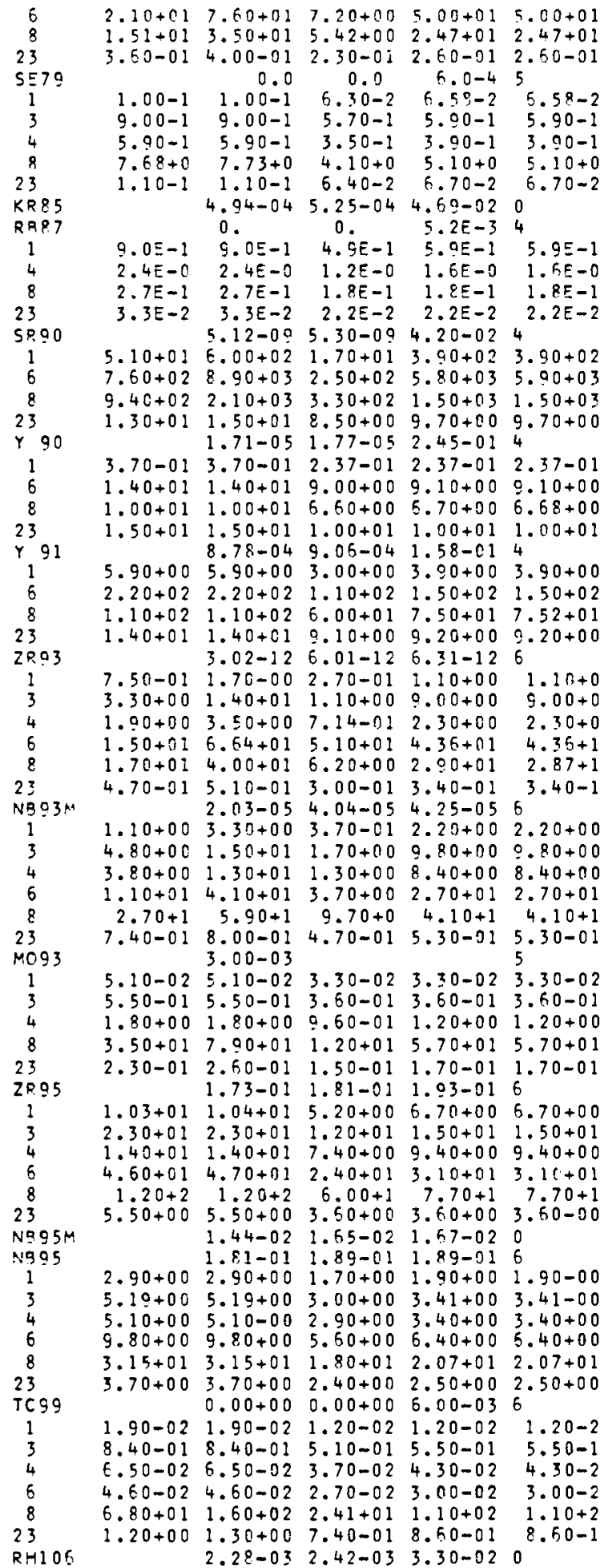

FIGURE $0.0-3$. Dose Conversion Factor Data Library-NUCDFL 


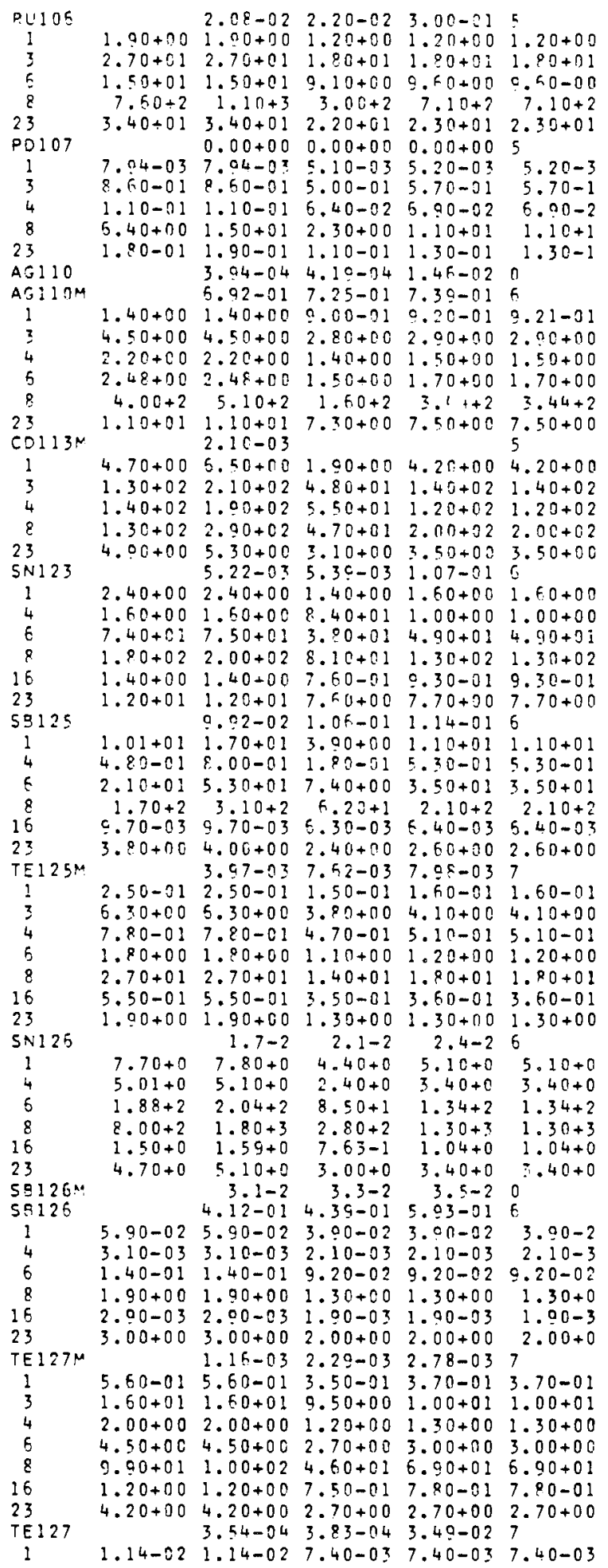

FIGURE D.0-3. Dose Conversion Factor Data Library-NUCDFL 


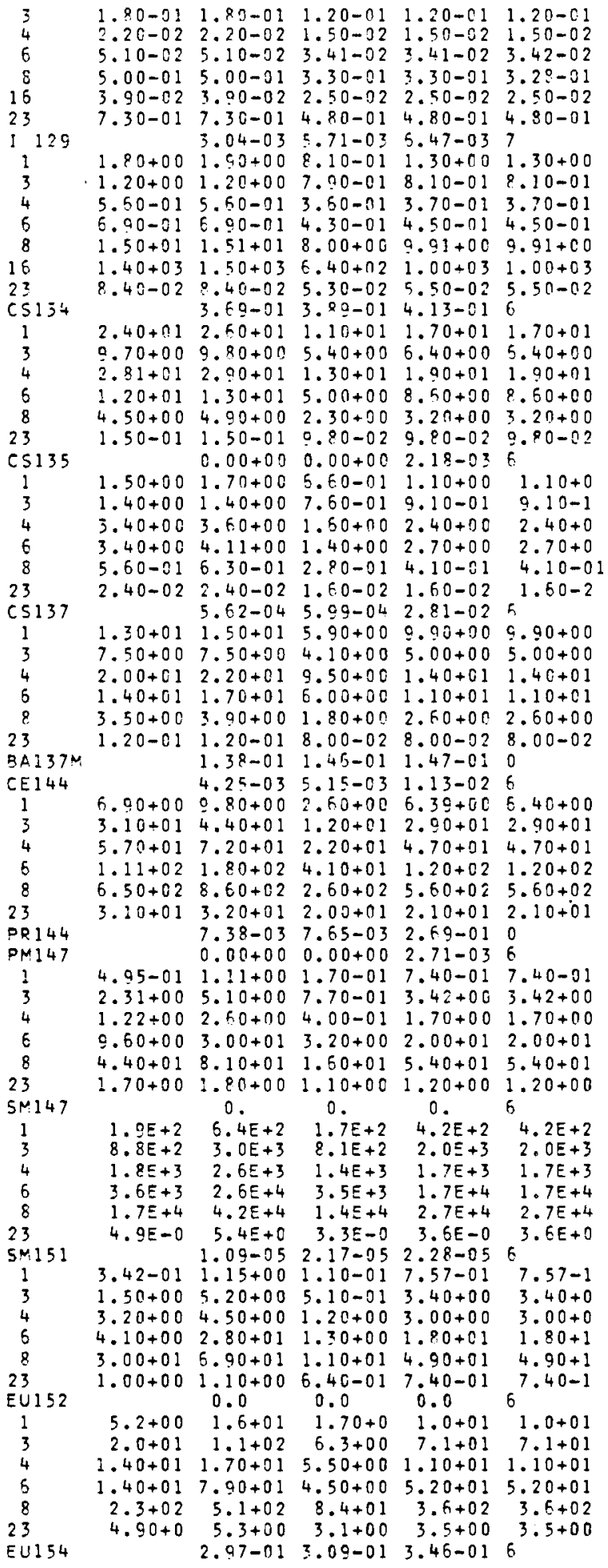

FIGURE D.0-3. Dose Conversion Factor Data Library-NUCDFL 


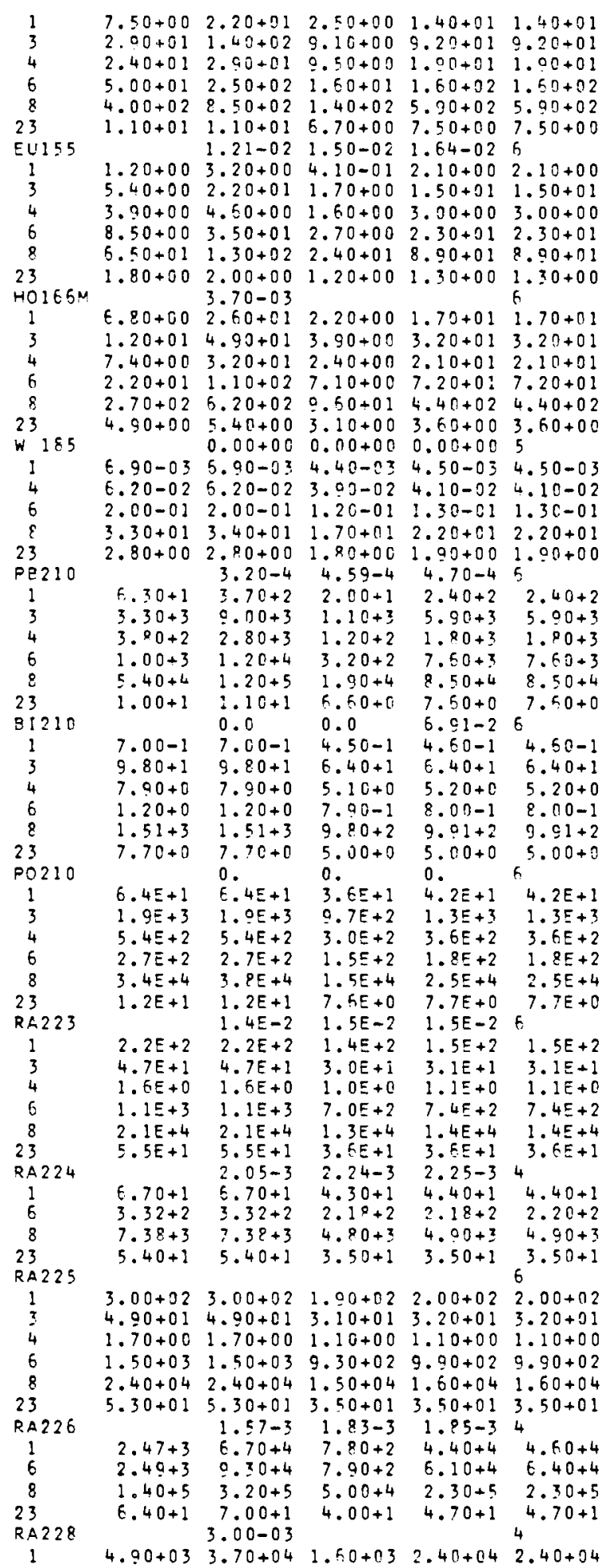

FIGURE D.0-3. Dose Conversion Factor Data Library-NUCDFL 


\begin{tabular}{|c|c|c|c|c|c|}
\hline & & & & & \\
\hline 2 & +05 & $3.50+05$ & $0+04$ & $j+c 5$ & $+0+05$ \\
\hline 3 & & $1.20+01$ & $5.90+00$ & $3+00$ & \\
\hline 2 & & $0.00+00$ & & & \\
\hline 1 & $.70+01$ & & $4.90+01$ & $5.10+01$ & $5.10+01$ \\
\hline 3 & & $1.70+02$ & $1.10+02$ & $1.10+02$ & $1.10+02$ \\
\hline 4 & & & & & \\
\hline 6 & & & & & +02 \\
\hline & & +04 & & $0+04$ & \\
\hline 3 & & & & $+0 \mathrm{i}$ & \\
\hline$c 22$ & & $00-4$ & $1-4$ & $1.89-4$ & \\
\hline & $1.91+3$ & & & $10+4$ & $1+4$ \\
\hline 3 & & $3.10+14$ & & +4 & \\
\hline 4 & & & & & \\
\hline 5 & & & & & \\
\hline 8 & $1+5$ & 0.00 & $1.40+5$ & $1+5$ & $1+5$ \\
\hline 3 & & & & & \\
\hline T1:227 & & & & & \\
\hline 1 & $1.1 E+2$ & $1.1 E$ & 5. 5 & $7.2 E+1$ & $7.2 E+1$ \\
\hline & & & & & \\
\hline 4 & & & & & \\
\hline 6 & & $3 . P E$ & & & \\
\hline 8 & & 2.7 & & & \\
\hline 23 & & 9.4 & & & \\
\hline T22 & & & & & 5 \\
\hline 1 & & 6.6 & & & $4 . ?$ \\
\hline 3 & & 1.80 & & & \\
\hline 4 & & 3.2 & & & \\
\hline 6 & & 1.9 & & & \\
\hline 8 & & 4.40 & 0.80 & & $0+5$ \\
\hline 23 & & 1.1 & 6.90 & & \\
\hline TH220 & & $5.1 \mathrm{c}$ & $5.98-3$ & $3-3$ & 6 \\
\hline 1 & & & & & \\
\hline 3 & & 2.3 & & & \\
\hline 4 & & 4.6 & & & \\
\hline & & & & & \\
\hline 8 & & 7.9 & & & \\
\hline 3 & & & & & \\
\hline & & & & & 6 \\
\hline 1 & & & & -4 & \\
\hline 3 & & & & & \\
\hline 4 & & & & & \\
\hline 6 & & 7.7 & & & \\
\hline$\varepsilon$ & & & & & \\
\hline 23 & & 1.3 & $7.30+0$ & & \\
\hline TH:23 & & & & & 6 \\
\hline 1 & & & & & \\
\hline 3 & & 1.9 & & & \\
\hline 4 & & & & & \\
\hline$\varepsilon$ & & 8.6 & & & \\
\hline 8 & & & & & \\
\hline 23 & $9.80+0$ & & & & $0+0$ \\
\hline PA2 & & & & & \\
\hline 1 & & & & & \\
\hline 3 & & 3.4 & & & \\
\hline 4 & & & & & \\
\hline 6 & & & & & \\
\hline$\varepsilon$ & & & & & \\
\hline & & & & & \\
\hline & & & & & \\
\hline 1 & & & & & \\
\hline 3 & & & & & \\
\hline & & 2.9 & & & \\
\hline 6 & & & & & \\
\hline$\varepsilon$ & & & & & \\
\hline 23 & & 2.9 & 1.9 & & 1. \\
\hline & & & & & \\
\hline & & & & & \\
\hline 3 & & 1.8 & & & \\
\hline 6 & & & & & \\
\hline & & $5.50+1$ & 8.6 & & \\
\hline & $0+01$ & 1.40 & & & \\
\hline & & & & & \\
\hline
\end{tabular}

FIGURE D.0-3. Dose Conversion Factor Data Library-NUCDFL 


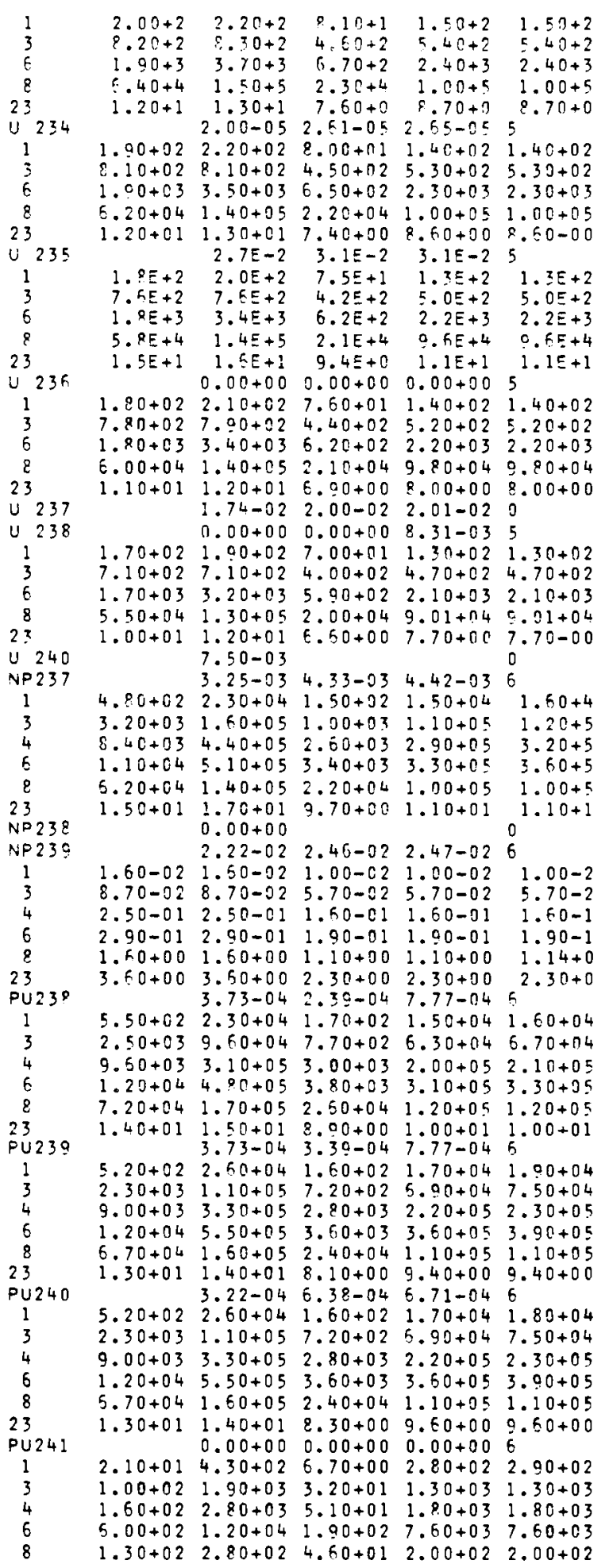

FIGURE D.0-3. Dose Conversion Factor Data Library-NUCDFL 


\begin{tabular}{|c|c|c|c|c|c|}
\hline $\begin{array}{l}23 \\
\operatorname{P} \cup 242\end{array}$ & $2.75-01$ & $\begin{array}{l}2.90-31 \\
4.04-94\end{array}$ & $\begin{array}{l}1.70-01 \\
8.03-04\end{array}$ & $\begin{array}{l}2.00-01 \\
44-04\end{array}$ & $2.00-01$ \\
\hline 1 & $5.00+02$ & $2.50+04$ & $1.50+02$ & $1 . \in 0+14$ & $1.80+04$ \\
\hline 3 & $2.20+03$ & $1.00+05$ & $5.00+02$ & $6.70+04$ & $7.20+04$ \\
\hline 4 & \&. $60+03$ & $3.20+0.5$ & $2.70+03$ & $2.10+05$ & $2.20+05$ \\
\hline 6 & $1.10+04$ & $5+10+05$ & $3.40+03$ & $3.30+05$ & $3.50+05$ \\
\hline$\varepsilon$ & $6.50+04$ & $1.50+05$ & $2.30+04$ & $1.10+05$ & $1.10+05$ \\
\hline $\begin{array}{l}23 \\
\text { PU243 }\end{array}$ & $1.30+01$ & $\begin{array}{l}1.40+01 \\
4.20-03\end{array}$ & $8.00+00$ & $9.20+00$ & $\frac{a}{E} \cdot 20+n 0$ \\
\hline 1 & $1.80-03$ & $1.80-03$ & $1.20-0 ?$ & $1.20-03$ & $1.20-03$ \\
\hline 3 & $8.40-03$ & $8.40-03$ & $5.50-03$ & $5.50-03$ & $5.50-03$ \\
\hline 4 & $2.20-02$ & $2.20-02$ & $1.40-02$ & $1.40-02$ & $1.40-02$ \\
\hline 5 & $4.50-02$ & $4.50-02$ & $3.00-02$ & $3.0-02$ & $3.0-02$ \\
\hline 8 & $2.20-01$ & $2.20-01$ & $1.40-01$ & $1.50-01$ & $1.50-01$ \\
\hline 23 & $2.20-91$ & $2.20-01$ & $1.50-01$ & $1.50-01$ & $1.50-01$ \\
\hline PU244 & & $0.00+00$ & & & 6 \\
\hline 1 & $5.70+02$ & $2.90+04$ & $1.80+02$ & $1.90+04$ & $2.00+04$ \\
\hline 3 & $2.60+03$ & $1.20+05$ & $7.90+02$ & $7.70+04$ & +04 \\
\hline 4 & $9.90+03$ & $3.70+05$ & $3.10+03$ & $2.40+05$ & $2.50+05$ \\
\hline 6 & $1.30+04$ & $6.00+05$ & $=.90+03$ & $3.90+05$ & $4.20+05$ \\
\hline 8 & $0+04$ & +05 & $0+04$ & $1.20+05$ & $1.20+05$ \\
\hline 23 & $1.90+01$ & $2.10+01$ & $1.20+01$ & $1.40+01$ & $1.40+01$ \\
\hline A? 241 & & $5.03-03$ & $7.23-03$ & $7.42-03$ & 5 \\
\hline 1 & $5.50+02$ & $2.20+04$ & $1.70+02$ & $1.40+04$ & $1.50+04$ \\
\hline 3 & $3.70+03$ & $1.50+05$ & 1. $20+03$ & $1.00+05$ & $1.10+05$ \\
\hline 4 & $\therefore .50+03$ & $3.50+0.5$ & $3.00+03$ & $2.30+05$ & $2.40+05$ \\
\hline 6 & 1.20 & & +03 & & +05 \\
\hline$\varepsilon$ & $7.20+04$ & $1.70+05$ & $2.50+04$ & $1.20+05$ & $1.20+05$ \\
\hline 23 & $1.40+01$ & 1.50 & $\therefore .00+00$ & $1.00+01$ & $1.00+01$ \\
\hline $\operatorname{AN} 2421{ }^{\circ}$ & & 04 & -03 & -03 & \\
\hline 1 & $5.00+02$ & $2.21+04$ & $1.80+02$ & $1.40+04$ & $0+04$ \\
\hline 3 & +03 & $1.50+05$ & $1.20+03$ & $1.00+05$ & +05 \\
\hline 4 & $9.60+03$ & $3.30+05$ & $3.00+03$ & $2.10+05$ & +05 \\
\hline 6 & $1.30+04$ & $5.60+05$ & $4.10+03$ & $3.60+05$ & $9+05$ \\
\hline 8 & $5.10+04$ & $1.20+05$ & $1.80+04$ & $8.30+04$ & $9+04$ \\
\hline 23 & $1.80+01$ & $2.00+01$ & $1.10+01$ & $1.30+01$ & $1.30+01$ \\
\hline$A M 242$ & & $.74-04$ & $1.34-03$ & $2,30-\pi 2$ & 6 \\
\hline 1 & $1.20+00$ & $1.10+00$ & $7.40-01$ & $7.40-01$ & $7.40-01$ \\
\hline$z$ & -00 & 7.50 & $4.90+00$ & $90+00$ & $0+0$ \\
\hline 4 & $1.00+01$ & $1.90+01$ & $1.20+01$ & $1.20+01$ & $1.20+01$ \\
\hline$E$ & $2.50+01$ & $2.60+0:$ & $1.70+01$ & $1.70+01$ & $1.70+01$ \\
\hline$\varepsilon$ & $2.40+02$ & $2.40+02$ & $1.50+02$ & $1.60+02$ & $1.60+02$ \\
\hline 23 & $1.60+00$ & $1.50+00$ & $1.00+00$ & $1.00+00$ & $1.00+00$ \\
\hline$A M 243$ & & $3.24-04$ & $4.55-04$ & $4.69-04$ & 6 \\
\hline 1 & $5.20+02$ & $.20+04$ & $1.50+02$ & $1.40+54$ & $1.50+04$ \\
\hline 3 & $3.60+C 3$ & $1.50+05$ & $1.10+03$ & $1.00+05$ & $1.10+05$ \\
\hline 4 & $0+03$ & +05 & +03 & $.20+0.5$ & $2.40+05$ \\
\hline 6 & $1.20+04$ & $5.50+05$ & $3.60+03$ & $3.60+05$ & $3.90+05$ \\
\hline 8 & $5.90+04$ & $1.60+05$ & $2.40+04$ & $1.10+05$ & $1.10+05$ \\
\hline 23 & $1.70+01$ & $1.80+01$ & $1.10+01$ & $1.20+0 !$ & $1.20+01$ \\
\hline$C M 242$ & & & $1.34-05$ & $35-05$ & 5 \\
\hline 1 & $3.70+02$ & $4.90+02$ & $1.50+02$ & $3.20+02$ & $3.20+02$ \\
\hline 3 & $1.70+03$ & $2.2 \mathrm{C}+03$ & $5.40+02$ & $1.40+03$ & $1.40+03$ \\
\hline 4 & & & & & \\
\hline 5 & $8.40+03$ & $1.10+04$ & $3.30+03$ & $7.30+03$ & $7.30+03$ \\
\hline 8 & 4.4 & 5.00 & $1.90+04$ & $3.30+04$ & $0+04$ \\
\hline 23 & $1.50+01$ & $.50+01$ & $9.50+00$ & $9.3+00$ & $0+0 c$ \\
\hline $\mathrm{CN}_{2} 243$ & & $.70-02$ & & & \\
\hline 1 & 5.8 & +04 & 1.80 & +04 & +04 \\
\hline 3 & & & 02 & & 04 \\
\hline 4 & $1.00+04$ & $2.40+05$ & $3.10+03$ & $1.60+05$ & $1.60+05$ \\
\hline$\varepsilon$ & & & 4.00 & & \\
\hline 8 & $7.50+04$ & $70+05$ & $2.70+04$ & $1.20+05$ & $20+05$ \\
\hline 23 & $1.50+01$ & $1.60+01$ & $9.50+00$ & $1.10+01$ & $1.10+01$ \\
\hline $\operatorname{cm} 244$ & & & $5.09-04$ & $6.40-04$ & \\
\hline 1 & $5.50+02$ & $.20+04$ & $1.70+02$ & $7.60+03$ & $7.80+03$ \\
\hline 3 & $2.5 \mathrm{C}+03$ & $5.30+04$ & $7.70+02$ & $3.50+04$ & $3.50+04$ \\
\hline 4 & $8.50+03$ & $1.60+05$ & $2.70+03$ & $1.10+05$ & $1.10+05$ \\
\hline 6 & $1.20+04$ & $80+05$ & $3.90+03$ & $1.80+05$ & $1.90+05$ \\
\hline 8 & $7.50+04$ & $1.70+05$ & $2.70+04$ & $1.20+05$ & 1. $20+05$ \\
\hline 23 & $1.50+01$ & & $.20+00$ & $1.10+01$ & $1.10+01$ \\
\hline & & & $-0=$ & $8-03$ & \\
\hline 1 & $40+0 ?$ & $30+04$ & $1.70+02$ & $1.50+04$ & $1,60+0$ \\
\hline
\end{tabular}

FIGURE D.0-3. Dose Conversion Factor Data Library-NUCDFL 


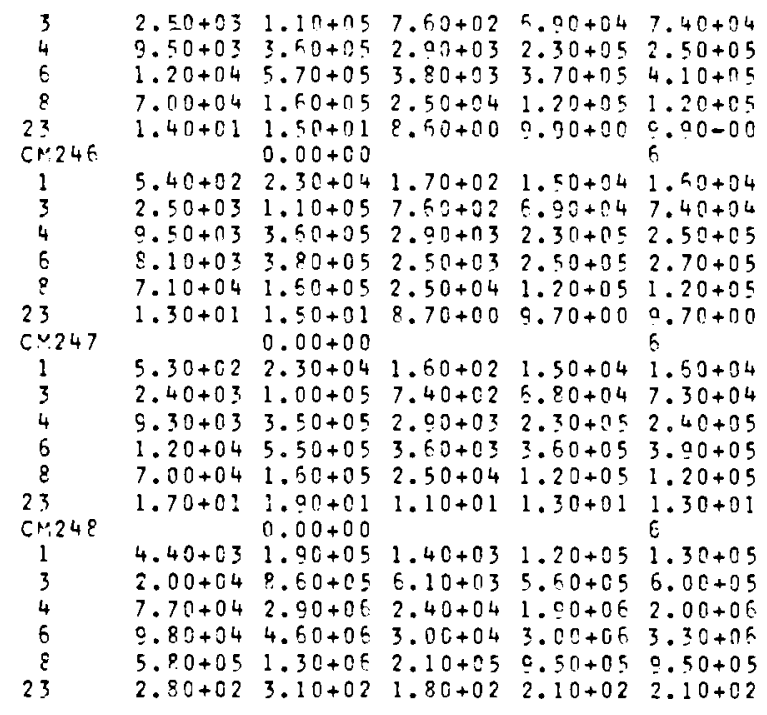

FIGURE D.0-3. Dose Conversion Factor Data Library-NUCDFL 


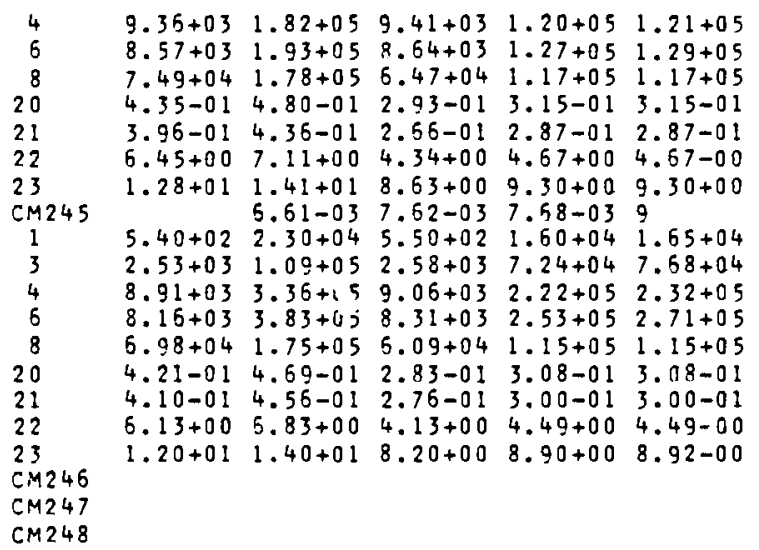

FIGURE D.0-3. Dose Conversion Factor Data Library-NUCDFL 



\section{APPENDIX E}

INPUT INSTRUCTIONS FOR HADOC 
APPENDIX E

INPUT INSTRUCTIONS FOR HADOC

This section describes preparation of input card images for HADOC. There are five main sets used to supply the necessary input information:

1) title or run,

2) NAMELIST parameters,

3) radionuclide release inventory,

4) population data and

5) terrain elevation data.

The control logic for input of these data sets in indicated in Figure E.0-1. Parameters and data supplied in each set are described in the following sections.

\section{E.1 TITLE OF RUN}

The first card of each case contains 80 characters of alphanumeric data used as a descriptive title for all output reports. The format is 20A4 and the characters are read into the array TITLEI.

\section{E.2 NAMELIST PARAMETERS}

The NAMELIST set titled INPUT is used to supply control parameters, dispersion parameters, and organ selection parameters as follows:

Parameter Description Control Parameters:

FRAC

Fractional contribution cutoff value. Any radionuclide contributing more than FRAC to the dose to an organ will be included in the fractional dose contribution tables.

IFRAC Control for printing fractional dose reports. Reports are printed if IFRAC $>0$.

IQP Control for printing of calculated dispersion parameters. Parameters are printed if $I Q P>0$. 


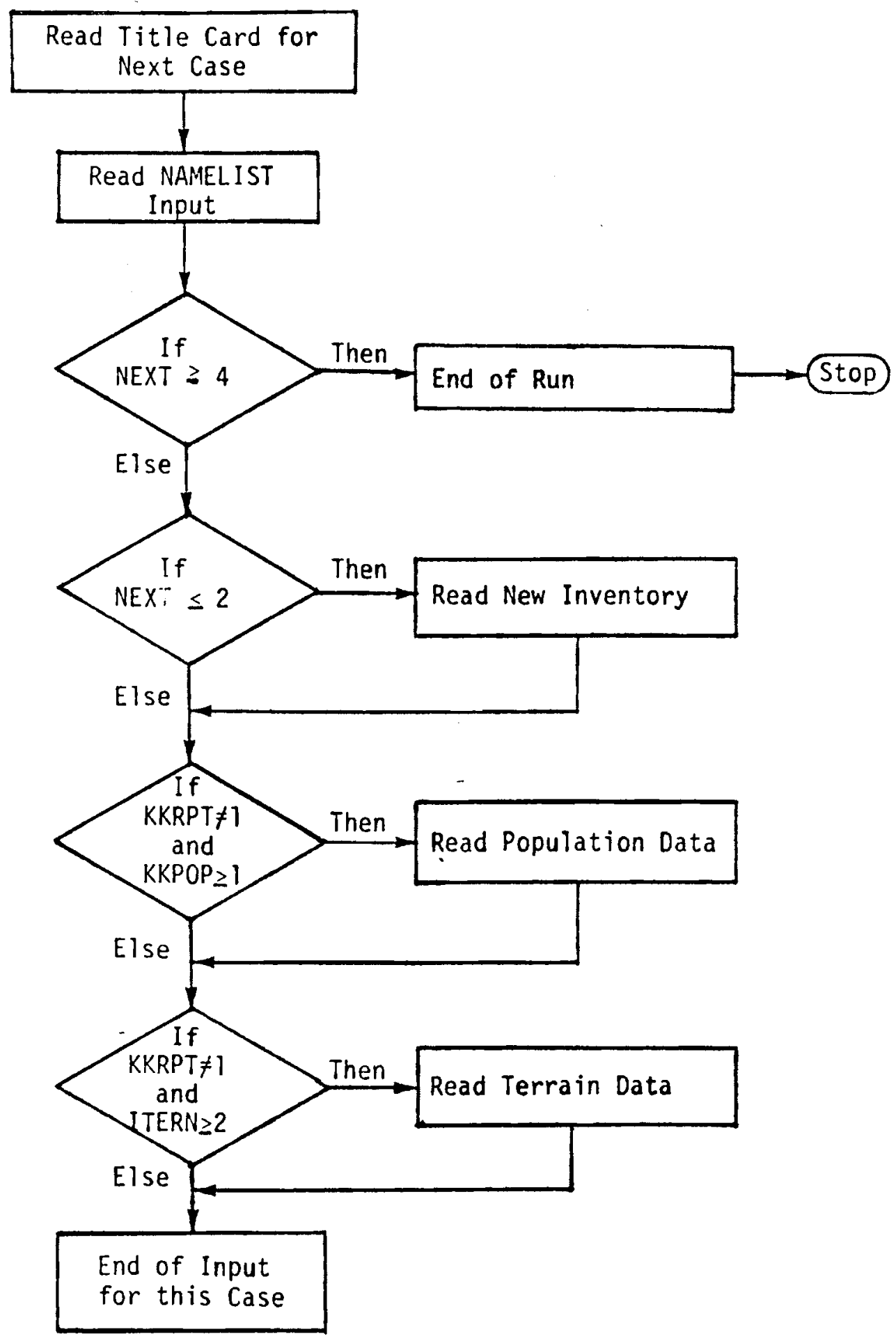

FIGURE E.0-1 HADOC Input Logic

$$
\text { E.2 }
$$


Parameter

ITERN

IWAKE

KKPOP

KKRPT

KKSMI

KKSP
Description

Control for reading terrain data and calculating terrain effects. ITERN causes data to be read only if KKRPT $\neq 1$ (i.e., only if population doses are requested).

ITERN $\leq 0$; no terrain effects

ITERN > 0 ; terrain effects considered

ITERN $\geq 2$; read terrain data for the population dose calculation.

Control for building wake effect considerations. If IWAKE $>0$ then building wake effects are to be considered and the parameter AREA should be specified.

Control of input of population data. Data may be read if KKPOP $>0$ (and if KKRPT $\neq 1$ ).

Controls selection of output reports; input of population and terrain data; and calculation of doses.

KKRPT

value

0 Read, calculate and print results for both the maximum individual and population doses.

$1 \quad$ Only calculate and print maximum individual doses. Population and terrain data are not read.

2 Only calculate and print population doses.

Population and terrain data may be read.

(See ITERN and KKPOP for input of data.)

Control for selection of Hanford dispersion models for the maximum individual dispersion calculation:

KKSMI $\leq 0$ for Hanford moderately stable, KKSMI > 0 for Hanford very stable.

Control for selection of Hanford dispersion models for the population dispersion calculation: 
KKSP $\leq 0$ for Hanford moderately stable, KKSP > 0 for Hanford very stable.

LIMTST Controls calculation of maximum atmospheric dispersion conditions. LIMTST $\leq 0$ causes use of specified Hanford model. LIMTST > 0 causes use of maximum conditions by testing Pasquill A-D stabilities.

NEXT Controls selection of input sets. NEXT = 1 allows input of all data sets (subject to other controls) and input of data libraries.

NEXT = 2 allows input of all data sets (subject to other controls) but libraries are not read when NEXT $>1$. NEXT $=3$ allows input of population and terrain sets. NEXT $=4$ indicates run is to be terminated.

NPRT Controls printing of library NUCDFL data; print if NPRT $>0$. Dispersion Parameters:

AREA

Minimum building cross-sectional area for the building wake effects model, $\mathrm{m}^{2}$. AREA is only used if IWAKE $>0$.

DMI Distance from the release point to the location of the maximum individual, $\mathrm{m}$.

DP(array) Distances from the release point to the center of each spatial interval for which population data is defined, $m$. NPD values are used. Up to 10 values may be specified.

HMI

Elevation of the maximum individual above the base of the release stack, m. HMI is used only if ITERN $>0$.

HSTACK Height of the release point above ground level, $\mathrm{m}$. NPD Number of distance locations to be used for the population dose calculations. 
STUB

Dispersion parameter ou for calculation of oy for the maximum individual caleulation. Recommended values are:

\begin{tabular}{clllll}
$\begin{array}{c}\text { Release } \\
\text { Time }\end{array}$ & \multicolumn{4}{c}{ Windspeed, $\mathrm{m} / \mathrm{sec}}$. \\
\cline { 5 - 6 } & & 1 & 2.5 & 5 & 10 \\
\cline { 5 - 6 } $10 \mathrm{~min}$. & 0.024 & 0.10 & 0.20 & 0.30 \\
$1 \mathrm{hr}$. & 0.04 & 0.15 & 0.25 & 0.35 \\
$2 \mathrm{hrs}$. & 0.08 & 0.25 & 0.35 & 0.45 \\
$4 \mathrm{hrs}$. & 0.10 & 0.40 & 0.50 & 0.60 \\
8 hrs. & 0.18 & 0.60 & 0.70 & 0.90
\end{tabular}

UMI Average wind speed to use in the maximum individual dispersion calculation, $\mathrm{m} / \mathrm{sec}$.

UP Average wind speed to use in the population dispersion calcuation, $\mathrm{m} / \mathrm{sec}$.

Organ Selection:

NORG Number of organs for which doses are requested. $1 \leq N O R G \leq 5$. KORG(array) Organ index values for selected organs (maximum of 5). These values must correspond to organ index values supplied in the library NUCDFL parameter array IORG. (See Table C.2-1).

A NAMELIST set is read for each case.

\section{E.3 RADIONUCLIDE RELEASE INVENTORY}

This card set is read when NEXT $\leq 2$. The first card gives the number of radionuclides in the release inventory and a modifying factor FINV (format I3, E10). The modifying factor is to be multiplied by each activity to give the actual release activity value used in the calculations. FINV is set to 1.0 if the given value is not greater than zero. The release inventory is supplied with one radionuclide per card. The cards contain the radionuclide name as represented in the master library RMDLIB and the total activity, curies, released during the accident. The format is $A 2, A 6,4 X, E 8.2$. 


\section{E.4 POPULATION DATA}

This set is read when KKRPT $\neq 1$ and KKPOP > 0 . The population distribtion near the release site is provided in this data set. One card is provided for each of sixteen compass directions with NPD values per card. Each value gives the number of people in the spatial interval. Data for the north sector is given first, then NNE, etc. The format is $10 \mathrm{~F} 8.0$.

\section{E.5 TERRAIN ELEVATION DATA}

This card set is read when KKRPT $\neq 1$ and ITERN $\geq 2$. Each data card contains information for one of sixteen compass directions. NPD values are given on each card; one for each distance. The values represent the maximum terrain elevation (above the base of the stack) at any point between the release point and the given distance. The values for a given sector are monatomic increasing (or constant). The format is 10F8.0.

\section{E.6 DEFAULT VALUES}

Several NAMELIST parameters have default values to be used if a value is not supplied on input cards. The default values are given in Table E.6-1.

TABLE E.6-1 NAMELIST Parameter Default Values

Parameter

Default Value

Control Parameters:

$\begin{array}{lc}\text { FRAC } & 0.0001 \\ \text { IFRAC } & 0 \\ \text { IQP } & 1 \\ \text { ITERN } & 0 \\ \text { IWAKE } & 0 \\ \text { KKPOP } & 1 \\ \text { KKRPT } & 0 \\ \text { KKSMI } & 0 \\ \text { KKSP } & 0 \\ \text { LIMTST } & 0 \\ \text { NEXT } & 1 \\ \text { NPRT } & 0\end{array}$


TABLE E.6-1 (contd)

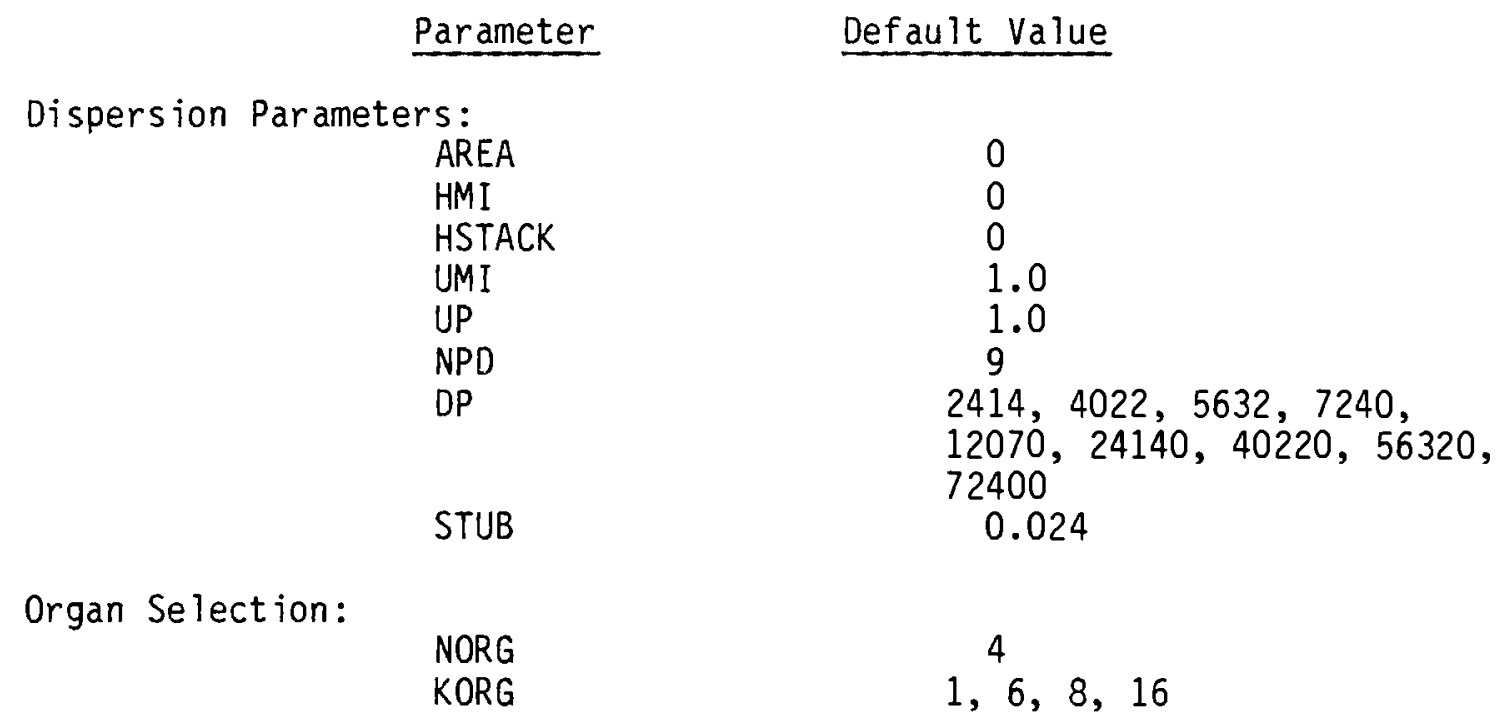


, 
APPENDIX $F$

SAMPLE PROBLEM 
APPENDIX F

SAMPLE PROBLEM

The sample problem presented here is designed to test the features of the code: the calculated results do not represent any real or hypothetical accidental release for the Hanford site. The sample problem is composed of three cases to be executed in one run. The first case tests all major options except the building wake model (IWAKE) and selection of maximum atmospheric stability conditions (LIMTST). Parameters for the first case are given in Table F.0-1. The radionuclide release inventory is presented in Table F.0-2. population data and terrain data are also supplied as indicated in the sample problem input listing of Figure F.0-1.

The second case is the same as case 1 except that the maximum dispersion calculation is selected (LIMTST=1) and the fractional contribution reports are not printed (IFRAC $=0$ ). The parameter NEXT is set to 3 to skip input of elease inventory since the case 1 inventory is to be retained. Also KKPOP is set to zero and ITERN to 1 to skip reading of population and terrain data respectively.

Case 3 is the same as case 1 except the release height is now ground level (HSTACK=0.0), fractional contribution reports are not printed (as for case 2) and building wake effects are selected (IWAKE=1). The building cross-section area (AREA) is set to $1000 \mathrm{~m}^{2}$.

The last two cards of the input listing with NEXT=4 cause normal termination of the run. The output listing for the sample problem is given in Figure F.0-2. 
TABLE F.0-1 Sample Problem Case 1 Input Parameters

Parameter Value

Description

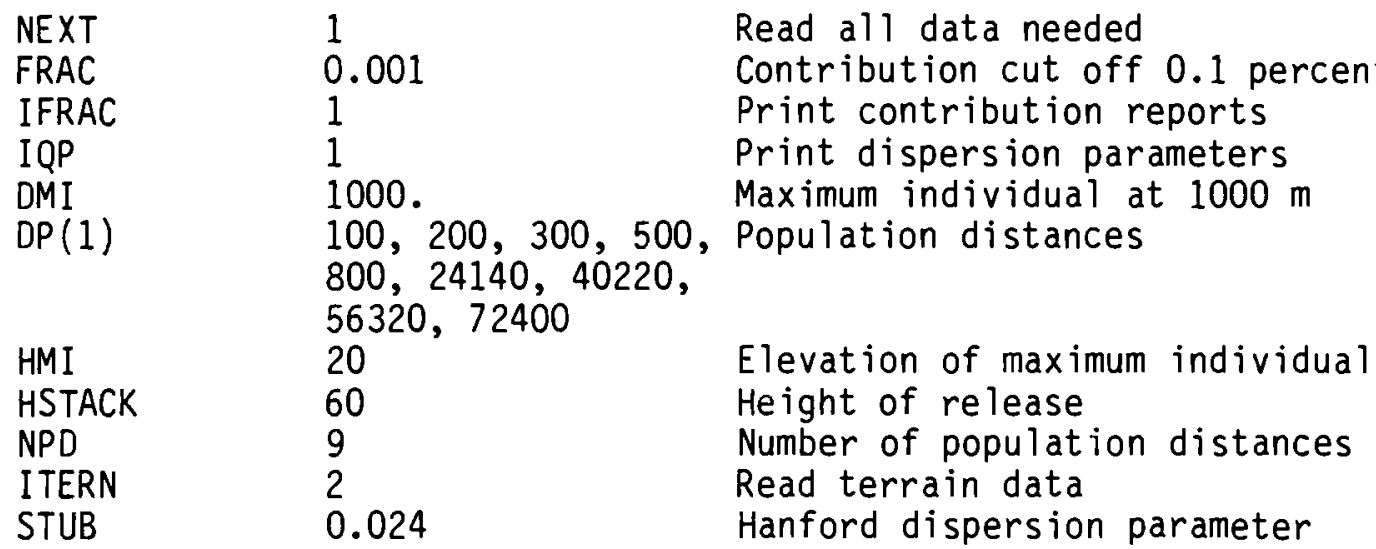

Default Values: (Not given on NAMELIST cards)

\begin{tabular}{|c|c|c|}
\hline $\begin{array}{l}\text { IWAKE } \\
\text { KKPOP } \\
\text { KKSMI } \\
\text { KKSP } \\
\text { LIMTST } \\
\text { NPRT } \\
\text { AREA } \\
\text { UMI } \\
\text { UP } \\
\text { NORG } \\
\text { KORG(1) }\end{array}$ & $\begin{array}{l}0 \\
1 \\
0 \\
0 \\
0 \\
0 \\
0.0 \\
1.0 \\
1.0 \\
4 \\
1,6,8,16\end{array}$ & $\begin{array}{l}\text { Do not consider building wake } \\
\text { Read population distribution data } \\
\text { Hanford moderately stable } \\
\text { Hanford moderately stable } \\
\text { No dispersion limit testing } \\
\text { Do not print NUCDFL data } \\
\text { Area of building (not needed) } \\
\text { Wind speed for maximum individual } \\
\text { Wind speed for populations } \\
\text { From organs } \\
\text { Selects total body, bone, lungs and } \\
\text { thyroid }\end{array}$ \\
\hline
\end{tabular}

TABLE F.0-2 Sample Problem Radionuclide Inventory

Radionuclide Released Activity, Curies

$\begin{array}{ll}\text { H3 } & 1.0 \times 10^{3} \\ \text { MN56 } & 1.0 \times 100 \\ \text { BR83 } & 1.0 \times 100 \\ \text { RU103 } & 1.0 \times 100 \\ \text { I131 } & 2.0 \times 101 \\ \text { CS137 } & 1.0 \times 102 \\ \text { BA127M } & 9.6 \times 101 \\ \text { PU239 } & 1.0 \times 100\end{array}$


HADOC SAMPLE PROBLEM, CASE 1. TEST OF ALL OPTIONS EXCEPT IWAKE AND LIMTST. SINPUT NEXT $=1, F R A C=.001$, IFRAC $=1, I Q P=1$, DMI $=1000$, DP $(1)=100,200,300,0$

STUB $=0.024$ SEND
STO

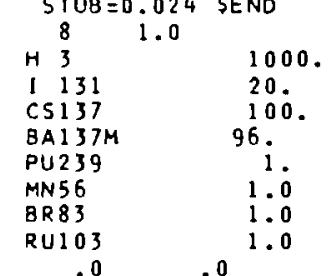

$\begin{array}{rrr}00 & .0 & .0 \\ .0 & .0 & .0 \\ .0 & .0 & .0 \\ .0 & .0 & .0 \\ .0 & .0 & .0 \\ .0 & .0 & .0 \\ .0 & .0 & .0 \\ .0 & .0 & .0 \\ .0 & .0 & .0 \\ .0 & .0 & .0 \\ .0 & .0 & .0 \\ .0 & .0 & .0 \\ .0 & .0 & .0 \\ .0 & .0 & .0 \\ .0 & .0 & .0 \\ .0 & .0 & .0\end{array}$

0. 0.00.

$\begin{array}{rrr}5 . & 5 . & 5 . \\ 10 . & 10 . & 10 .\end{array}$

$\begin{array}{lll}20 . & 20 . & 20 . \\ 40 . & 40 . & 40 .\end{array}$

$\begin{array}{ccc}50 . & 50 . & 50 . \\ 0 . & 0 . & 0 .\end{array}$

100. $100 . \quad 100$.

$\begin{array}{lll}0 . & 0 . & 0 .\end{array}$

$\begin{array}{lll}0 . & 0 . & 0 . \\ 0 . & 0 . & 0 .\end{array}$

o. $\quad 0.0$.

0. 0.

5. 5 .

0. 10.010.

20.

$\begin{array}{rrrrrr}.0 & .0 & 20 . & 1039 . & 461 . & 2696 . \\ .0 & .0 & 5 . & 733 . & 974 . & 15962 . \\ .0 & .0 & 273 . & 5890 . & 2366 . & 628 . \\ .0 & .0 & 257 . & 914 . & 2368 . & 903 . \\ .0 & .0 & 128 . & 384 . & 558 . & 855 . \\ .0 & .0 & 288 . & 1642 . & 140 . & 348 . \\ .0 & .0 & 3 . & 34522 . & 46456 . & 948 . \\ .0 & .0 & 1911 . & 1180 . & 309 . & 1935 . \\ .0 & .0 & 1029 . & 1644 . & 51 . & 555 . \\ .0 & .0 & 512 . & 9996 . & 788 . & 144 . \\ .0 & .0 & 545 . & 17054 . & 1047 . & 447 .\end{array}$

961. 2914. 14588. 5072 .

388.498 .4750 .78520$.

239.752 .01015 .560$.

$\begin{array}{rlll}225 . & 228 . & 394 . & 1058 .\end{array}$

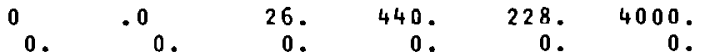

5.25

$\begin{array}{rrrr}0 . & 0 . & 0 . & 0 . \\ 5 . & 5 . & 5 . & 5 .\end{array}$

10. 10.

40.40.

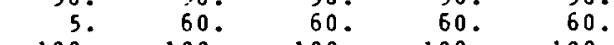

100.100

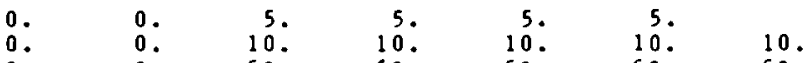

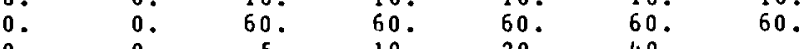

SINPUT NEXT $=3$, LIMTST $=1, K X P O P=0$, ITERN $=1$, IFRAC $=0$ SEN

HADOC SAMPLE PROALEM, CASE 3. SAME AS CASE I EXCEPT IFRAC OFF, IWAKE ON AND H=O SINPUT NEXT $=3$, LIMTST $=0$, HSTACK $=0$, AREA $=1000$, I WAKE $=1$ SEND

SINPUT NEXT $=4$ SENO

FIGURE F.0-1. HADOC Sample Problem Input 
HADOC SAMPLE PROBLFM, CASE 1. TEST UF ALL OPIIONS EYCEPT IWAKT. AND LIMTST.

\section{1}

EXECUTING NEPA:IIADNC(1). ABS CREATED ON JANUARY 16, 1981 AT $99: 31: 48$

DATA LIBRARY TIILES:

MASTER RADIONUCLIDE DATA LIBrary":

RADIONUCL IDE MASTER DATA LIARARY, 15 IAANUIARY BI, BA NAPIFO

\#UOSF FACTOR LIBPARY::

CWMS DATA LIIRRARY, AUG O5, 1930 (OLS)

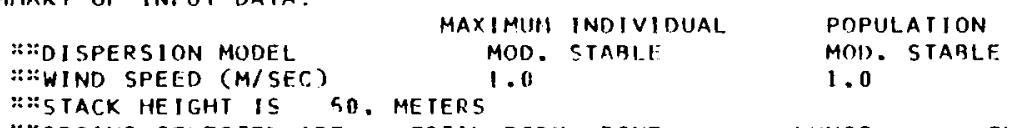

:":POPULATION DISTRIBUTION DATA
100.

INTEPVAL

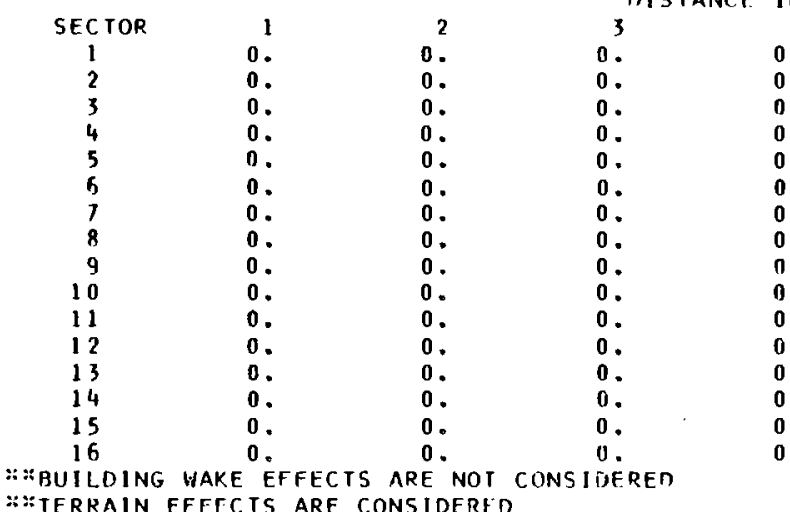

$\begin{array}{ll}\text { INTEPVAL } & 5 \\ 0 . & 0 . \\ 0 . & 0 . \\ 0 . & 0 . \\ 0 . & 0 . \\ 0 . & 0 . \\ 0 . & 0 . \\ 0 . & 0 . \\ 0 . & 0 . \\ 0 . & 0 . \\ 0 . & 0 . \\ 0 . & 0 . \\ 0 . & 0 . \\ 0 . & 0 . \\ 0 . & \end{array}$

40220.

56320.

72400

$\begin{array}{lr} & \\ 0 . & 6 \\ 0 . & 20 . \\ 0 . & 55 . \\ 0 . & 273 . \\ 0 . & 257 . \\ 0 . & 128 . \\ 0 . & 288 . \\ 0 . & 3 . \\ 0 . & 1911 . \\ 0 . & 1029 . \\ 0 . & 512 . \\ 0 . & 545 . \\ 0 . & 951 . \\ 0 . & 328 . \\ 0 . & 239 . \\ 0 . & 225 . \\ 0 . & 26 .\end{array}$

7
1039.
733.
5890.
914.
384.
1542.
34522.
1180.
1644.
9996.
17054.
2914.
498.
752.
228.
440.
9

$974 . \quad 15952$

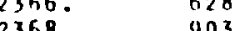

558.2855

348

46455.0948

309.1935.

447.

$14589 . \quad 5072$

$3750 . \quad 78520$

1015.0590

$394 . \quad 1058$
461.82695.

$51 . \quad 555$.

ELEVATION OF MAXIMUM INDIVIDUAL IS 20. METERS

FIGURE F.0-2. HADOC Sample Problem Output 


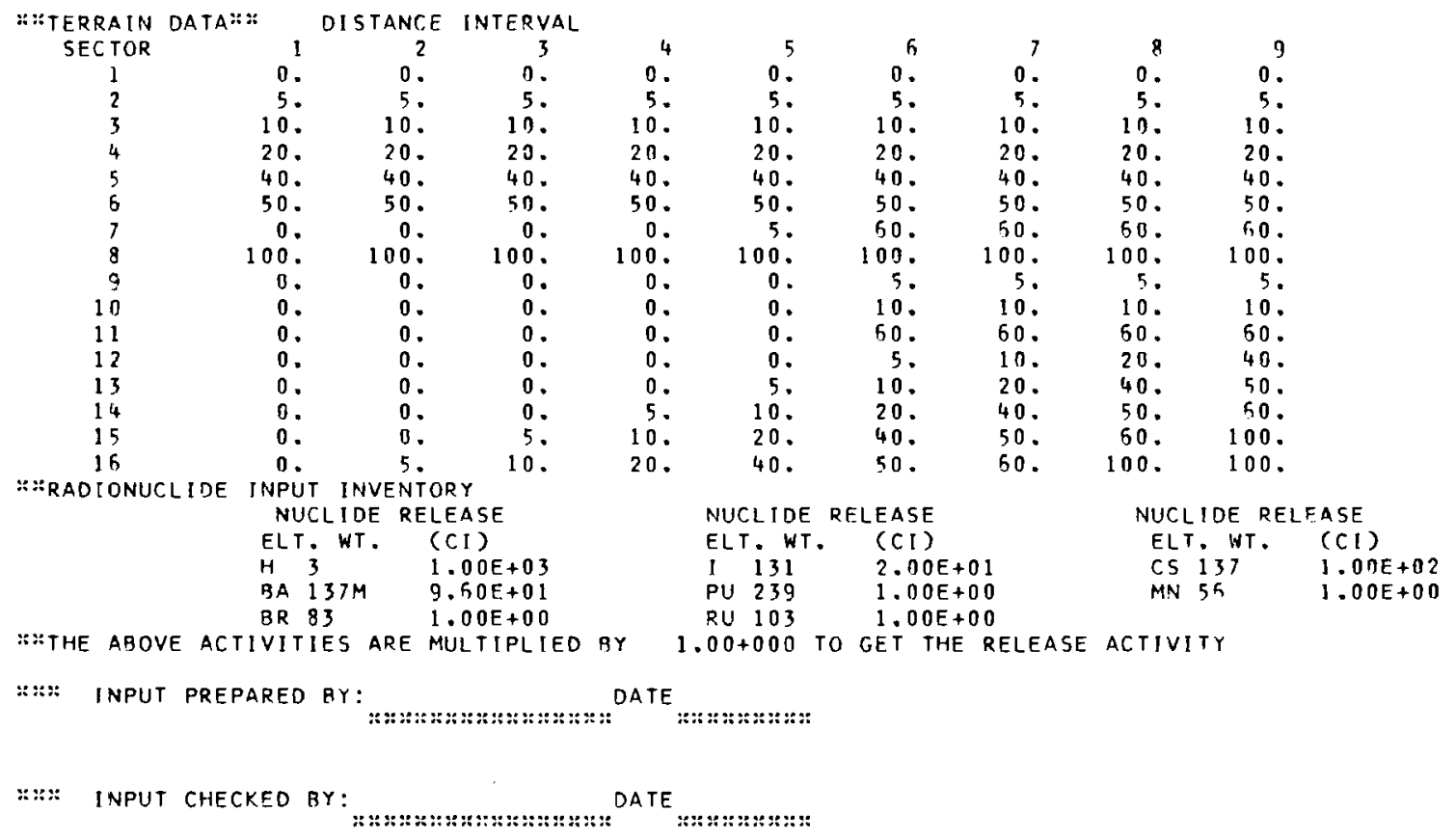

FIGURE F.0-2. HADOC Sample Problem Output 


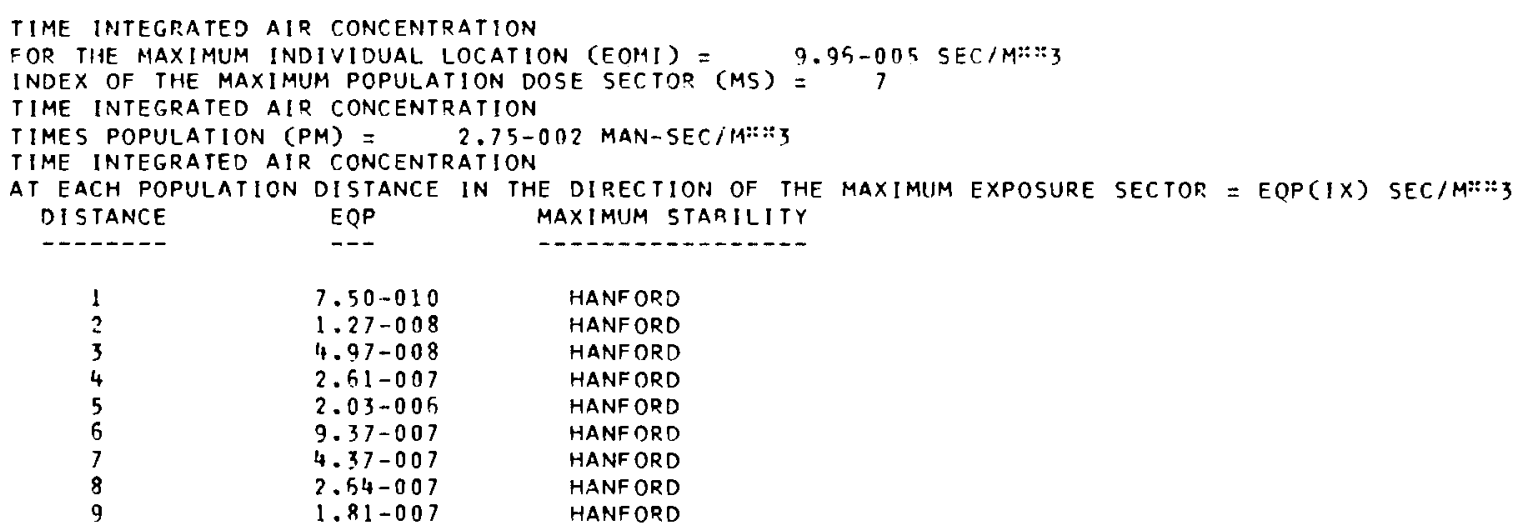

$\begin{array}{lll}1 & 7.50-010 & \text { HANFORD } \\ 2 & 1.27-008 & \text { HANFORD } \\ 3 & 4.97-008 & \text { HANFORD } \\ 4 & 2.61-007 & \text { HANFORD } \\ 5 & 2.03-006 & \text { HANFORD } \\ 6 & 9.37-007 & \text { HANFORD } \\ 7 & 4.37-007 & \text { HANFORD } \\ 8 & 2.54-007 & \text { HANFORD } \\ 9 & 1.81-007 & \text { HANFORD }\end{array}$

HADOC SAMPLE PROBLEM, CASE 1. TEST OF ALL. OPTIONS EXCEPT IWAKE AND LIMTST. 011681 MAXIMUM INDIVIDUAL DOSE COMMITMENTS (REM)

DOSE COMMITMENT PERIOD
1 YEAR

AIR SUGMERSION

TOTAL BODY

1. $3 E-03 \quad 1.3 E-03$

INHALATION

TOTAL BODY

BOPJE

LUNGS

THYROID

1. $8 E-01$

$5.5 E+01$

$6.7 E+00 \quad 1.5 E+01$

TAL. DOSES

TOTAL BODY

BOIJE

LUNGS

THYROID

$2.6 E-03$

2. $6 E-03$

FIGURE F.0-2. HADOC Sample Problem Output 


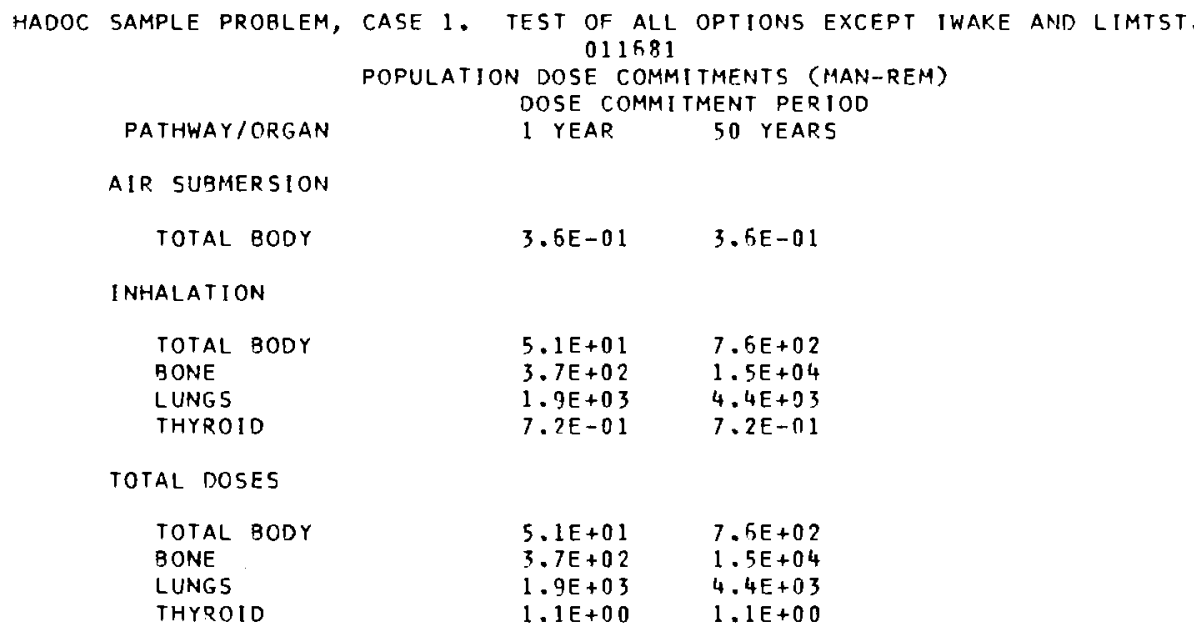

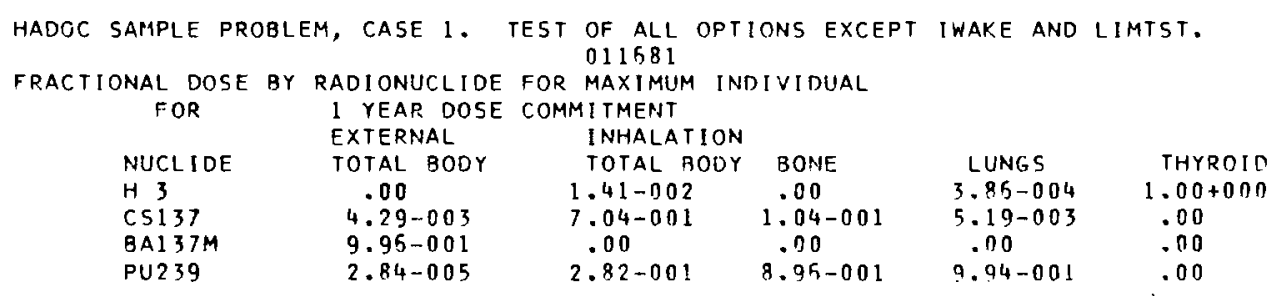

FIGURE F.0-2. HADOC Sample Problem Output 


\begin{tabular}{|c|c|c|c|c|c|c|c|c|}
\hline HADOC & SAMPLE & & CASE 1 . & TEST & $\begin{array}{l}\text { OF ALL OPT } \\
011681\end{array}$ & IONS EXCEPT & IWAKE AND & LIMTST. \\
\hline \multirow[t]{2}{*}{ FRACT I } & $\begin{array}{c}\text { IONAL DOSE } \\
\text { FOR }\end{array}$ & BY & $\begin{array}{l}\text { RADIONUCLIDE } \\
50 \text { YEAR DOSE } \\
\text { EXTERNAL }\end{array}$ & $\begin{array}{l}\text { FOR } \\
\text { COHM }\end{array}$ & $\begin{array}{l}\text { MAXIMUM IN } \\
\text { MI IMENT } \\
\text { INHALATION }\end{array}$ & DIVIDUAL & & \\
\hline & $\begin{array}{l}\text { NUCLIDE } \\
\text { H } 3 \\
\text { CS137 } \\
\text { BA137M } \\
\text { PU239 }\end{array}$ & & $\begin{array}{l}\text { TOTAL BODY } \\
.00 \\
4.29-003 \\
9.95-001 \\
2.84-005\end{array}$ & & $\begin{array}{l}\text { TOTAL BODY } \\
9.45-004 \\
5.45-002 \\
.00 \\
9.45-001\end{array}$ & $\begin{array}{l}\text { BONE } \\
.00 \\
3.08-003 \\
.00 \\
9.97-001\end{array}$ & $\begin{array}{l}\text { LUNG } \\
1.62-004 \\
2.43-003 \\
.00 \\
9.97-001\end{array}$ & $\begin{array}{l}\text { THYROID } \\
1.00+000 \\
.00 \\
.00 \\
.00\end{array}$ \\
\hline
\end{tabular}

HADOC SAMPLE PROBLEM, CASE 1. TEST OF ALL OPTIONS EXCEPT IWAKE AND LIMTST. 011681

FRACTIONAL DOSE BY RADIONUCLIDE FOR MAXIMUM INDIVIDUIAL

\begin{tabular}{lcccc}
\multicolumn{1}{c}{ FOR TOTAL } & 1 & YEAR DOSE COMMITMENT & \\
NUCLIDE & TOTAL BODY BONE & LUNGS & THYRO1D \\
H 3 & $1.40-002$ & .00 & $3.86-004$ & $5.55-001$ \\
CS137 & $6.99-001$ & $1.04-001$ & $5.19-003$ & $1.44-003$ \\
BA137M & $7.02-003$ & $9.73-004$ & $1.94-004$ & $3.34-001$ \\
PU239 & $2.80-001$ & $8.95-001$ & $9.94-001$ & $9.54-006$
\end{tabular}

HADOC SAMPLE PRORLEM, CASE 1. TEST OF ALL OPTIONS EXCEPT IWAKE ANO
O11681
FRACTIONAL DOSE BY RADIONUCLIDE FOR MAXIMUM INDIVIDUAL
FOR TOTAL 50 YEAR DOSE COMMITMENT
NUCLIDE
H 3

FIGURE F.0-2. HADOC Sample Problem Output 


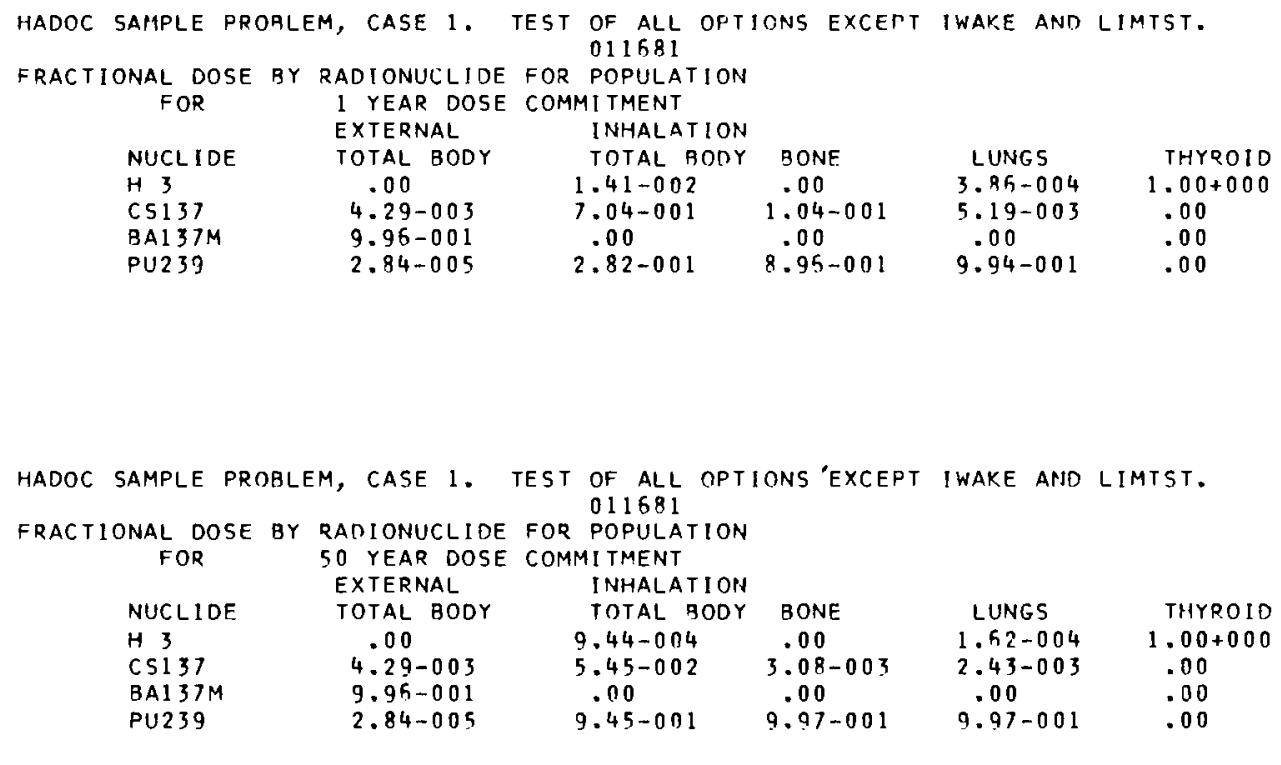

BONE

1.04-001

.00

8. $95-001$

HADOC SAMPLE PROBLEM, CASE 1. TEST OF ALL OPTIONS 'EXCEPT IWAKE AND LIMTST. 011681

FRACTIONAL DOSE BY RADIONUCLIOE FOR POPULATION

FOR 50 YEAR DOSE COMMI TMENT

NUCLIDE EXTERNAL INHALATION

H 3

CS137

.00

TOTAL BOOY

BA137M

4.29-003

$9.44-004$

$5.45-002$

$9.95-001$

.00

$2.84-005$

9.45-001

BONE

.00
$3.08-003$

00

9.00
$.97-001$

LUNGS

1. $62-004$

THYROIO

PU239

$8.84-0050$

$9.97-001$

.00

.00

9.97-001

.00
.00

HADOC SAMPLE PROBLEM, CASE 1. TEST OF ALL OPTIONS EXCEPT IWAKE AND LIMTST. 011681

FRACTIONAL DOSE BY RADIONUCLIDE FOR POPULATION FOR TOTAL 50 YEAR DOSE COMMITMENT NUCLI DE

H 3

CS137

BA137M

PU239

$\begin{array}{cc}\text { TOTAL BODY } & \text { BONE } \\ 9.44-004 & .00 \\ 5.45-002 & 3.08-003 \\ 4.74-004 & 2.37-005 \\ 9.44-001 & 9.97-001\end{array}$

\begin{abstract}
LUNGS
$1.62-004$

2.43-003

$8.14-005$
\end{abstract}

9.97-001

THYROID

$5.65-001$

$1.44-003$

$3.34-001$

$9.54-005$

FIGURE F.0-2. HADOC Sample Problem Output 
HADOC SAMPLE PROBLEM, CASE 2. SAME AS CASF 1 EXCEPT l.IMTST ON AND IFRAC OFF.

\section{1}

DATA LIBRARY TITLES

EXECUTING NEPA:HADOC(1).ABS CREATED ON JANIIAPY 1K, 1981 AT 09:31:48

::MASTER RADIONUCLIDE DATA LIARARY:::

RADIONUCLIDE MASTER DATA LITRARY, 15 JANUARY 81, RA NAPIFR

DOSE FACTOR LIBRARY::

CWHS DATA LIBRARY, AUG 06, 1980 (DLS)

SUMMARY OF INPUT DATA:

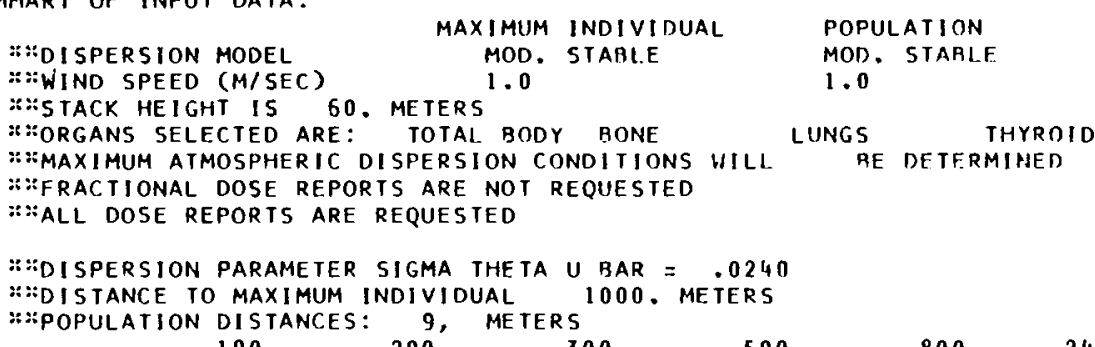

$\because \because$ POPULATION DISTRIBUTION DATA

40220.

$56320 . \quad 72400$

\begin{tabular}{|c|c|c|c|c|}
\hline 5 & 6 & 7 & 8 & \\
\hline 0 . & 20. & 1039. & 4 fil. & $269 r_{5}$. \\
\hline 0. & 5. & 733 & 974. & 15962 . \\
\hline 0 . & 273. & 5890. & 2365. & F28. \\
\hline 0. & $257^{\circ}$ & 914. & 2368. & 903. \\
\hline 0. & $2 R R$. & $\begin{array}{r}384 . \\
164+2\end{array}$ & 558. & $855^{\circ}$ \\
\hline 0. & 3. & 34522. & 46456. & 948. \\
\hline 0 . & 1911. & 1190 & 309 . & 1935. \\
\hline 0 , & 1029. & 1544. & 51. & 555. \\
\hline 0. & 512. & 9995. & $78 R$. & 144. \\
\hline 0 . & 545. & $\$ 7054$. & 1047. & 447. \\
\hline 0 . & 951. & 2914. & 14588. & 5072. \\
\hline 0. & $38 \%$. & 498. & 3750. & 78520. \\
\hline 0 . & 239. & 752. & 1015. & 560. \\
\hline 0 . & 225. & 228. & 394. & 1058. \\
\hline & 25. & 440. & 228. & 4000 \\
\hline
\end{tabular}

"BUILDING WAKE EFFECTS ARE Not CONSIDERED

$\begin{array}{ll} & \\ 0 . & 0 . \\ 0 . & 0 . \\ 0 . & 0 . \\ 0 . & 0 . \\ 0 . & 0 . \\ 0 . & 0 . \\ 0 . & 0 . \\ 0 . & 0 . \\ 0 . & 0 . \\ 0 . & 0 . \\ 0 . & 0 . \\ 0 . & 0 . \\ 0 . & 0 .\end{array}$

$\begin{array}{ll}\text { INERVAL } & \\ 0 . & 0 . \\ 0 . & 0 . \\ 0 . & 0 . \\ 0 . & 0 . \\ 0 . & 0 . \\ 0 . & 0 . \\ 0 . & 0 . \\ 0 . & 0 . \\ 0 . & 0 . \\ 0 . & 0 . \\ 0 . & 0 . \\ 0 . & 0 . \\ 0 . & \end{array}$

DIN EFFECTS ARE CONSIDERED

*: TERRAIN DATA:: SECTOR MAXIMUM INDIVIDUAL IS 20. METFRS

(n)




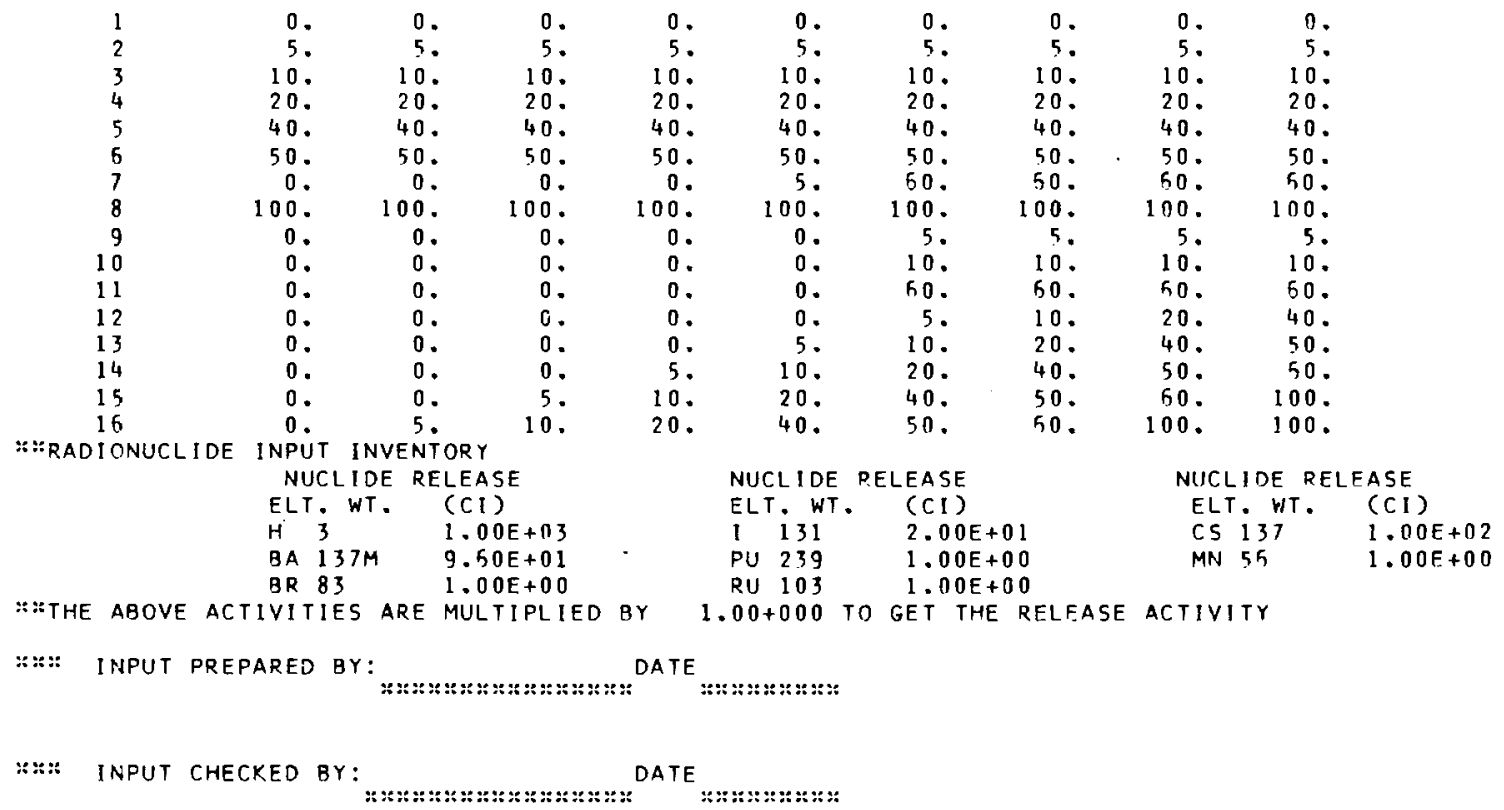

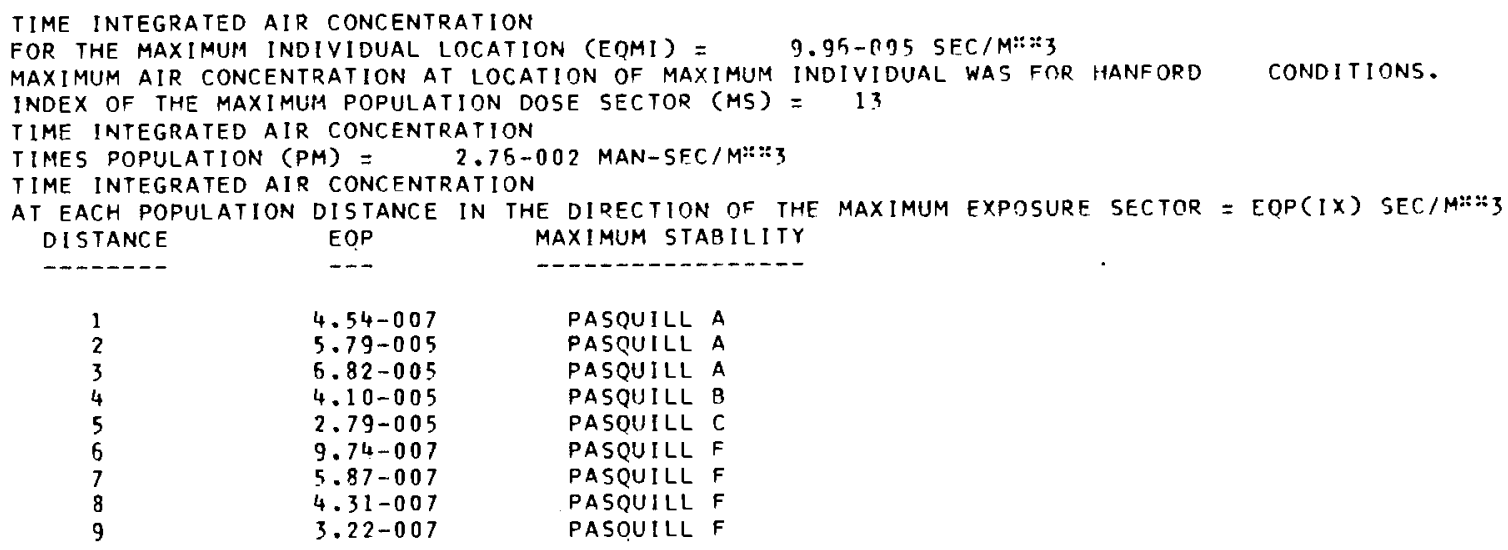

FIGURE F.0-2. HADOC Sample Problem Output 


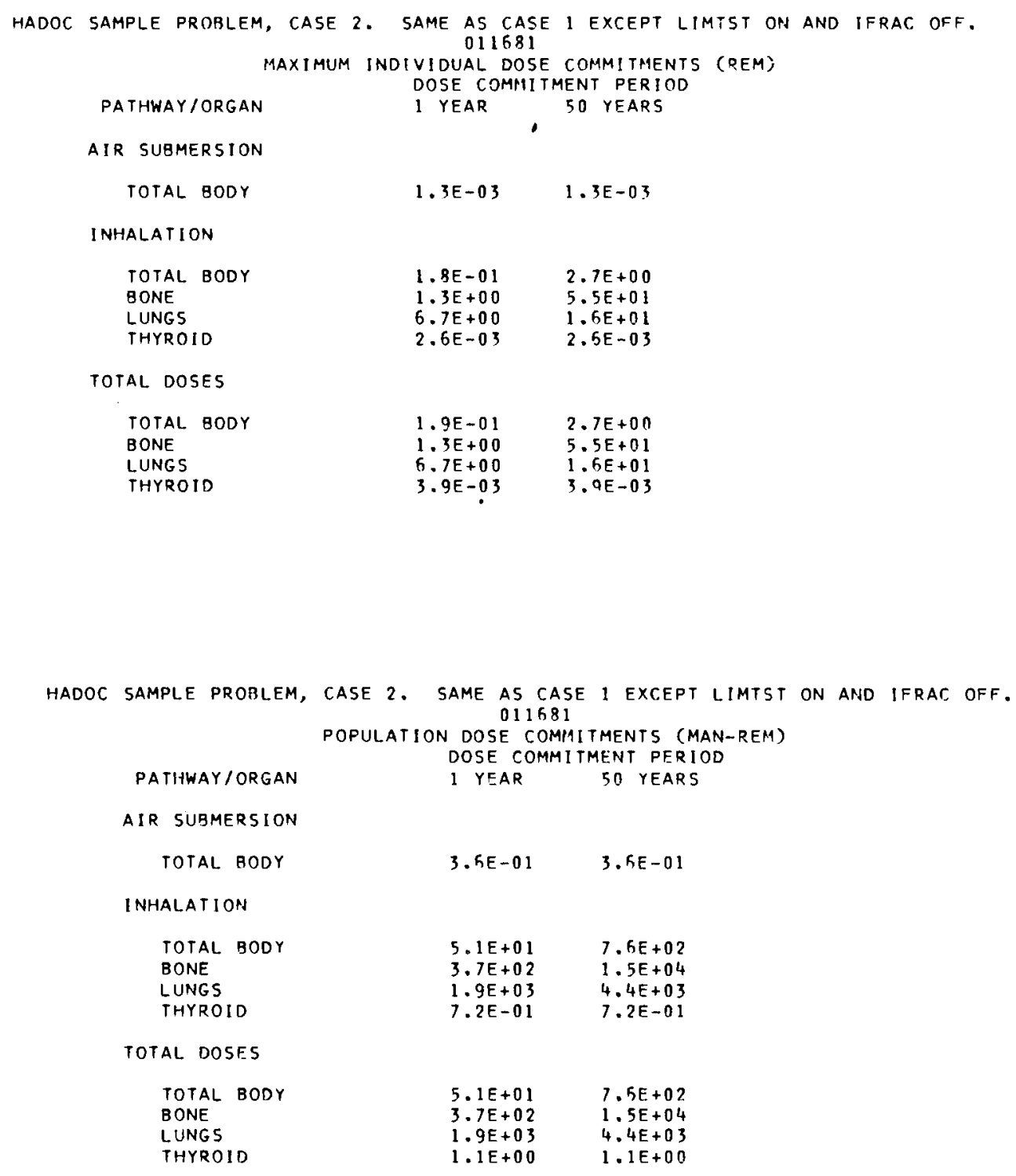

FIGURE F.0-2. HADOC Sample Problem Output 


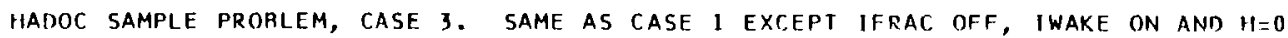

011681

EXFCUTING NEPA:HADOC(1).ABS CREATED ON JANUARY 16, 1981 AT 09:31:48 DATA LIBRARY TITLES:

*.. MASTER RADIONUCLIDE DATA LITRARY::

RADIONUCLIDE MASTER DATA LIBRARY, 15 JANUARY 81 , BA NAPIER

:"DOSE FACTOR LIBRARY:: 6
CWMS DATA LIBRARY, AUG 06, 1980 (DLS)

SUMMARY OF INPUT DATA:

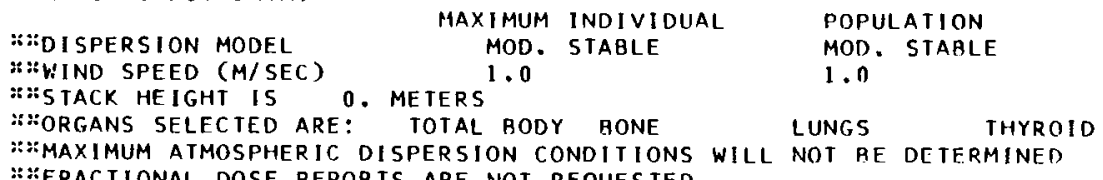

:FRACTIONAL DOSE REPORTS ARE NOT REQUESTED

$\because \because$ DISPERSION PARAMETER SIGMA THETA U BAR $=.0240$

:ODISTANCE TO MAXIMUM INDIVIDUAL UA $U$ OAR = METERS

:: :POPULATION DISTANCES: 9 , METERS

100, 200 , METERS 300 .

: :POPULATION DISTRIBUTION DATA

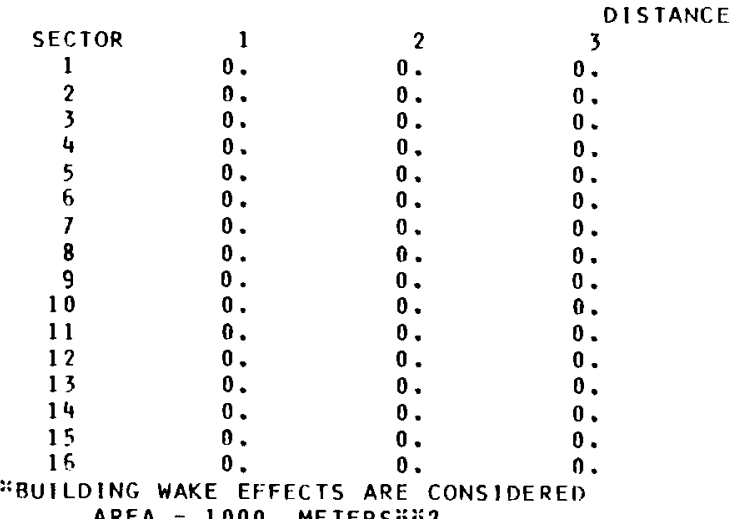

\begin{tabular}{|c|c|c|c|c|}
\hline 5 & h & 7 & 8 & 9 \\
\hline 0 . & 20. & 1039. & 461. & 2hgh. \\
\hline 0 . & 5. & 733. & 974. & 15952. \\
\hline 0. & 273. & 5890. & 2366. & 628 \\
\hline 0 . & 257. & 914. & 2368 . & 903. \\
\hline 0 . & 128. & 384. & 558. & 855. \\
\hline 0. & 288. & 1642. & 140 & 348. \\
\hline 0. & 3. & 34522 . & 45455. & 948. \\
\hline 0 . & 1911. & 1180 . & 309. & 1935. \\
\hline 0. & 1029. & 1644. & 51. & 555 \\
\hline 0. & 512 . & 9996. & 788. & 144. \\
\hline 0 . & 545. & 17054. & 1047. & 447. \\
\hline 0. & 951. & 2914. & 14588. & 5072 . \\
\hline 0 . & 388 . & 498. & 3750 . & 78520. \\
\hline n. & 239. & 752. & 1015. & 560 . \\
\hline 0 . & 225. & 228. & 394. & 1058 . \\
\hline 0. & 26. & 440. & 228. & 4000. \\
\hline
\end{tabular}

\section{FIGURE F.0-2. HADOC Sample Problem Output}




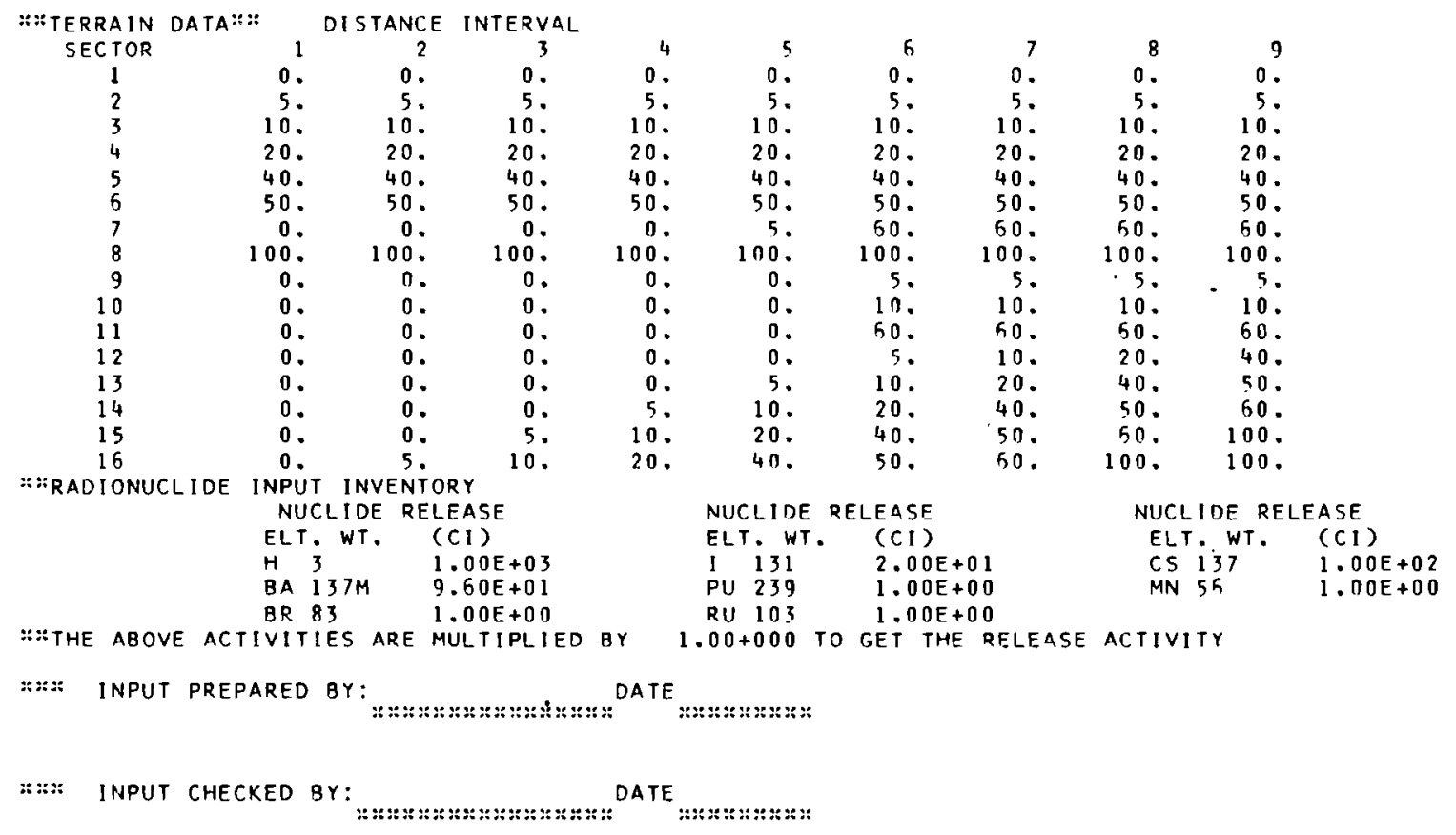

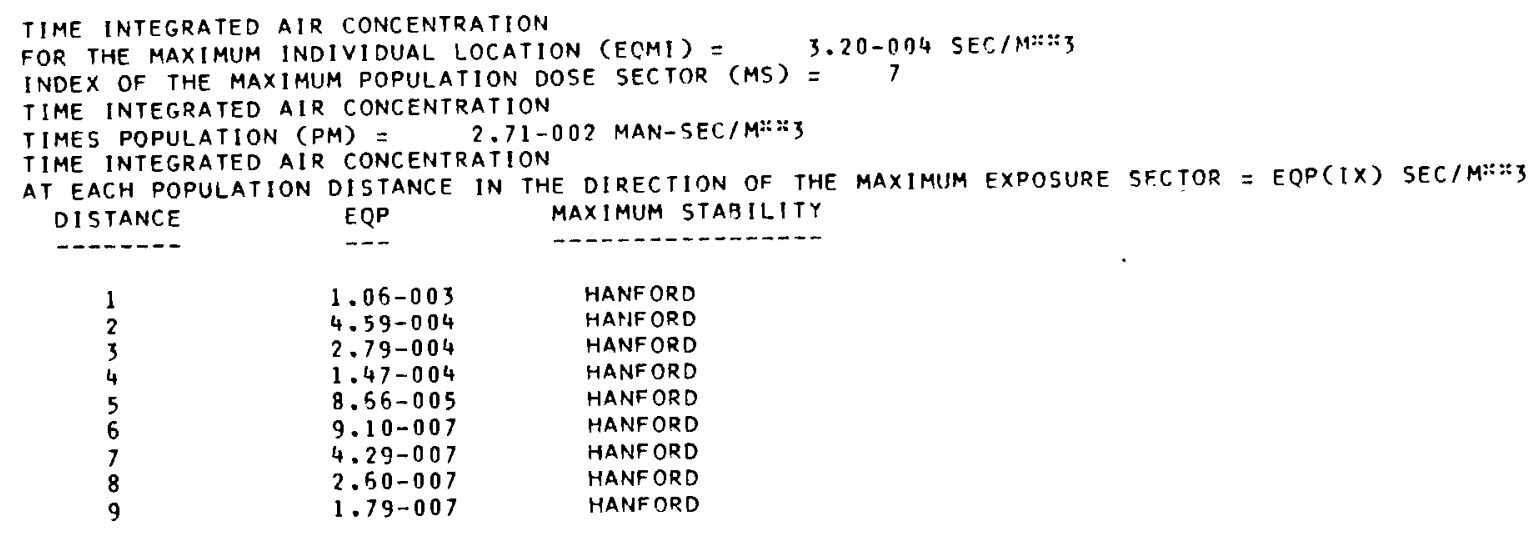

FIGURE F.0-2. HADOC Sample Problem Output 


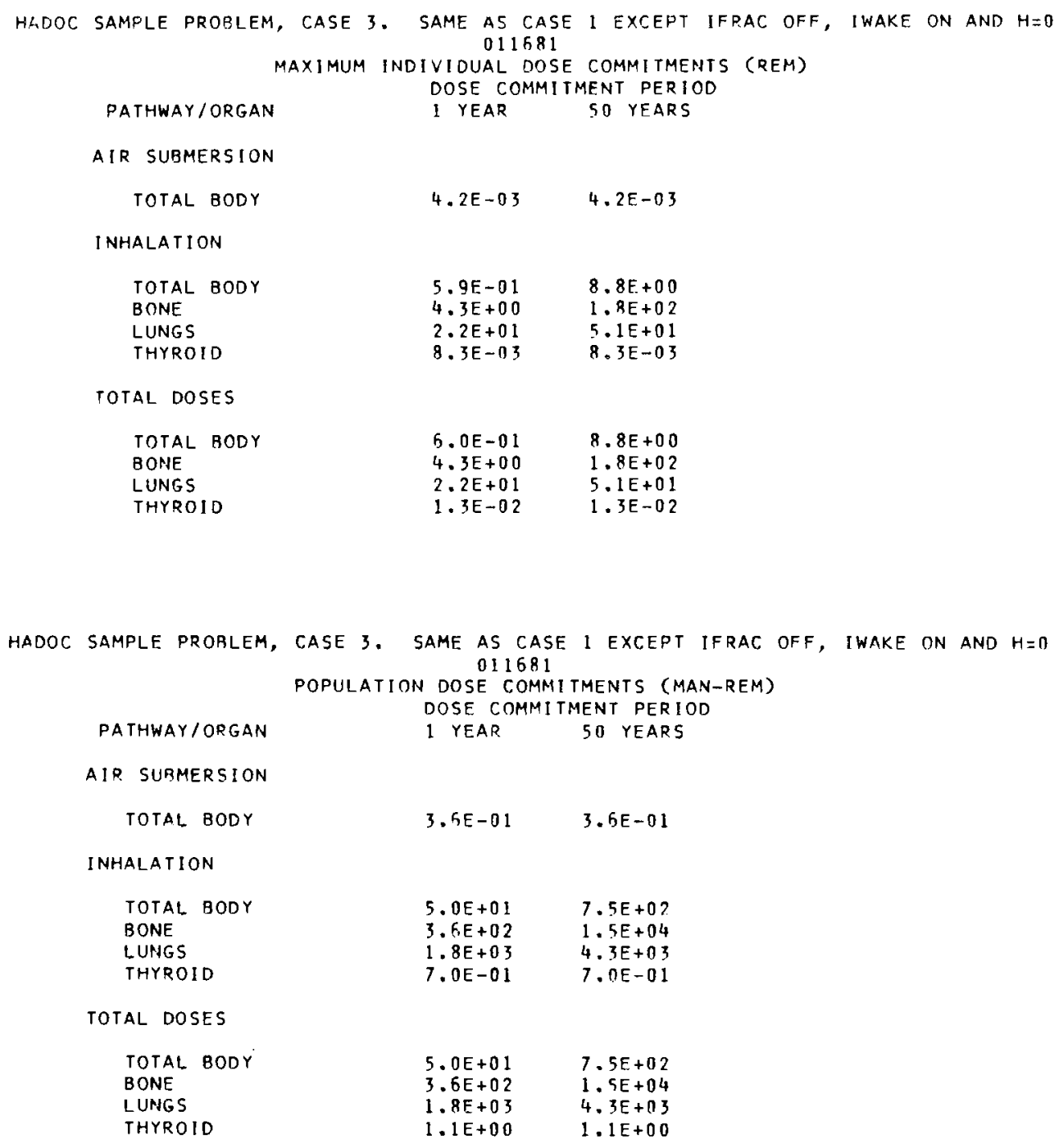

END OF INPUT FOR THIS RUN

FIGURE F.0-2. HADOC Sample Problem Output 
-

. 


\section{DISTRIBUTION}

OFFSITE

A. A. Churm DOE Chicago Patent Group 9800 South Cass Avenue

Argonne, IL 60439

27 DOE Technical Information Center

V. G. Trice

DOE Office of Nuclear Waste Management

Washington, D.C. 20545

J. W. Rowen

DOE Office of Nuclear Waste Management

Washington, D.C. 20545

E. F. Mastal

DOE Office of Nuclear Waste Management

Washington, D.C. 20545

R. Scott

DOE Office of Nuclear Waste Management

Washington, D.C. 20545

\section{ONSITE}

4 DOE Richland Operations Office

P. A. Craig

H. E. Ransom

J. J. Schreiber

M. W. Shupe
Hanford Engineering Development Laboratory

G. D. Carpenter

Rockwe 11 Hanford Operations

A. R. Hawkins

UNC Nuclear Industries

P. A. Carison

63 Pacific Northwest Laboratory

P. E. Bramson

J. B. Brown

G. R. Hoenes

W. E. Kennedy

W. D. McCormack

M. A. Mueller

B. A. Napier

R. A. Peloquin

J. V. Robinson

R. G. Schreckhise

J. K. Soldat

D. L. Strenge (40)

B. E. Vaughan (4)

E. C. Watson

Technical Information Library (5)

Publishing Coordination (2) 
